Escenarios actuales de aplicación de la psicología

\title{
Revista Digital Internacional de Psicología y Ciencia Social
}

Volumen 3 $\mid$ Número 2 | Julio-Diciembre 2017

\section{Current scenarios for the application of psychology}

\section{International Digital Journal of Psycholgy \& Social Science}


Escenarios actuales de aplicación de la psicología

\section{Revista Digital Internacional \\ de Psicología y Ciencia Social}

Volumen $3 \mid$ Número 2| Jufio-Diciembre 2017

\section{Current scenarios for the application of psychology}

\section{International Digital Journal of Psycholgy \& Social Science}

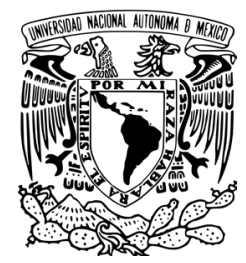

Universidad Nacional Autónoma de México

México, 2017 
Los editores gestionan las ideas que los científicos generan, por lo que son ellos, los que delinean el perfil de la ciencia de hoy 


\section{D.R. @ Universidad Nacional Autónoma de México}

Facultad de Estudios Superiores Iztacala

Av. de los Barrios No. 1, Los Reyes Iztacala

C.P. 54090, Tlalnepantla, Edo. de México

\section{Diseño Editorial}

Laboratorio de Evaluación y Educación Digital

UNAM, FES-Iztacala

Tel. (+52) - (55) -56231333 ext. \# 39707

\section{Publicación Periódica a Cargo}

Universidad Nacional Autónoma de México www.unam.mx

Facultad de Estudios Superiores Iztacala www.iztacala.unam.mx/

Corporativo Universitario Virtual de Educación a Distancia (CUVED) www.cuved.com.mx

El Colegio de Académicos de Psicología de la UNAM, FES-Iztacala (CAPSI)

Asociación de Profesionales e Investigadores en Ciencias de la Educación a Distancia (APICED) www.cuved.com.mx/apiced

Grupo de Investigación en Procesos Psicológicos y Sociales (GIPPS) www.gipps.org/

\section{Editor General de la Revista}

Arturo Silva Rodríguez

\section{CorRección de Estilo \\ Esther López González \\ Rubén Cortez Aguilar}

\section{Composición y Maquetación de La Revista \\ Oscar Giovanni Balderas Trejo}

Edición JULIO-DiciemBre, 2017

La edición en formato electrónico fue realizada en la Editorial LEED del Laboratorio de Evaluación y Educación Digital<smiles>[GeH3]</smiles>

Las imágenes de la cubierta, portada, portadillas, secciones y cubiertas de los artículos de la revista fueron cortesia de Freepik

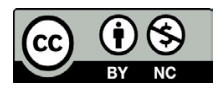

Copyright: @ 2017 Revista Digital Internacional de Psicología y Ciencia Social

Esta es una revista de acceso abierto distribuida bajo los términos de la licencia Creative Commons Reconocimiento-NoComercial 4.0 Internacional, por lo que su contenido gráfico y escrito se puede compartir, copiar y redistribuir total o parcialmente sin necesidad de permiso expreso de sus creadores con la única condición de que no se puede usar con fines directamente comerciales y los términos legales de cualquier trabajo derivado deben ser los mismos que se expresan en la presente declaración. La única condición es que se cite la fuente con referencia a la Revista Digital Internacional de Psicología y Ciencia Social y a sus creadores.

Revista Digital Internacional de Psicología y Ciencia Social, Año 3, Volumen 3, No. 2, julio-diciembre 2017, es una publicación semestral editada por la Universidad Nacional Autónoma de México, Ciudad Universitaria, Delegación Coyoacán, C.P. 04510, Ciudad de México, a través de la Facultad de Estudios Superiores Iztacala, Av. de los Barrios \#1, Colonia Los Reyes Iztacala, Tlalnepantla Estado. de México. C.P. 54090, Tel. (55) 5623-1333, Ext. \#39707, http://cuved.unam.mx/rdipycs/, rdipycs@gmail.com. Editor Responsable: Arturo Silva Rodríguez. Reserva de Derechos al Uso Exclusivo No. 042016-012514394300-203, ISSN: 2448-8119, ambos otorgados por el Instituto Nacional del Derecho de Autor. Responsable de la última actualización de este número, Laboratorio de Evaluación y Educación Digital de la Universidad Nacional Autónoma de México (UNAM), Facultad de Estudios Superiores Iztacala, Lic. José Manuel Sánchez Sordo, Av. de los Barrios \#1, Colonia Los Reyes Iztacala, Tlalnepantla Estado. de México. C.P. 54090, fecha de última modificación, 08 de Septiembre de 2017.

Las opiniones expresadas por los autores no necesariamente reflejan la postura del editor de la publicación. Se autoriza la reproducción total o parcial de los textos aquí publicados siempre y cuando se cite la fuente completa y la dirección electrónica de la publicación. 


\title{
Dirección Editorial
}

\author{
Arturo Silva Rodríguez \\ Editor General \\ Mirna Elizabeth Quezada \\ Editora Ejecutiva \\ J. Jesús Becerra Ramírez \\ Editor TÉcnico \\ Oscar Giovanni Balderas Trejo \\ Diseño Editorial
}

\section{Consejo Editorial}

\author{
Arturo Silva Rodríguez Adriana García Silva \\ Presidente Directora del Ấrea de las Ciencias Económico-Administrativas \\ Mirna Elizabeth Quezada
SeCretaria EJeCutiva \\ Luis Fernando García Silva \\ José Eduardo López Peralta \\ Claudia Lucy Saucedo Ramos \\ Directora del Área de la Ciencias Sociales \\ Miguel Ángel Tellez Jardínez \\ Director del Área de LAs Ingenierías \\ José Manuel Sánchez Sordo \\ Director del Área de las Humanidades y las Artes
}

Director del Área de las Ciencias Biológicas y de la Salud

Directora del Área de las Ciencias Físico_Matemáticas

\section{Editores Honorarios}

Juan Manuel Mancilla Díaz

Editor General

É́poca Revista de Psicología y Ciencia Social

Período 2000 a 2005

Jaime Montalvo Reyna

Editor General

Época Revista de Psicología y Ciencia Social

Período 2005 a 2009

\section{Rosario Espinosa Salcido}

Editora General

É́poca Revista de Psicología y Ciencia Social

Período 2009 a 2014

Rafael Palacios Abreu

Editor de Proyectos

É́poca Revista de Psicología y Ciencia Social

Período 2000 a 2014 
Universidad Nacional Autónoma de México

\section{Facultad de Ciencias Políticas y Sociales}

Ismene Ithai Bras Ruíz Relaciones Internacionales
Alma Adriana Becerril Ramírez Ciencias de la Comunicación

\section{Universidad Nacional Autónoma de México}

\section{Facultad de Estudios Superiores Acatlán}

José Eduardo López Peralta Matemáticas Aplicadas | Computación
Luis Daniel Vilchiz Alcántara

Matemáticas Aplicadas | Computación

\section{Universidad Nacional Autónoma de México}

\section{Facultad de Estudios Superiores Iztacala}

Laura Edna Aragón Borja

Evaluación Psicológica | Dislexia | Métodos Cuantitativos

María Leticia Bautista Díaz

Psicología de la Salud | Metodología de la Investigación

Enrique Berra Ruíz

Psicología de la Salud | Psicología Clínica

María de los Angeles Campos Huichán Psicología Cultural | Terapia Gestalt

Margarita Chávez Becerra Psicología Educativa | Métodos Cuantitativos

Norma Coffin Cabrera Psicológica Clínica | Psicología de la Salud

Ana Elena del Bosque Fuentes Entornos Virtuales de Aprendizaje | Psicología Educativa

María Guadalupe de los Milagros Damián Díaz Desarrollo Psicológico | Estimulación Temprana

David Javier Enríquez Negrete SUAyED Psicológica | Psicología Clínica y de la Salud

Estela Flores Ortiz Psicología Social | Desempeño Escolar
Gisel Gómez Escobar

Procesos Psicologógicos Básicos | Metodología

Esperanza Guarneros Reyes

SUAyED Psicología | Psicología del Desarrollo Infantil

Jorge Guerrero Barrios

Psicología Experimental | Psicología Educativa

Gilberto Hernández TzinTzun

Ciencias de la Salud | Sociología

Edilberta Joselina Ibáñez Reyes

Psicología Experimental

Omar Moreno Almazán

SUAyED Psicología | Psicología Clínica y de la Salud

Juan Manuel Montiel Génova

SUAyED Psicología | Terapia Familiar

Oscar Iván Negrete Rodríguez

SUAyED Psicología | Métodos Cuantitativos

Rafael Palacio Abreú

Psicología Educativa

Gilberto Pérez Campos

Psicología Cultural | Historia de la Psicología 
Mirna Elizabeth Quezada Gestión Organizacional | Educación Digital

Leticia Nayelli Ramírez Ramírez Psicología Educativa | Diseño curricular

Ma. Refugio Ríos Saldaña Psicología del Adolescente | Habilidades Sociales

David Ruíz Méndez

Psicología Experimental | Psicología Organizacional

Ricardo Sánchez Medina SUAyED Psicología | Psicología Clínica y de la Salud

José Manuel Sánchez Sordo Experto en Tecnologías de la Información | Psicología
Christian Sandoval Espinosa

SUAyED Psicología | Terapia Familiar

Claudia Lucy Saucedo Ramos

Psicología Cultural | Psicología Escolar

Aura Silva Aragón

SUAyED Psicología | Terapia Familiar

José de Jesús Vargas Flores

Editor de la Revista Electrónica de Psicología Iztacala

Cynthia Zaira Vega Valero

Psicología Organizacional | Psicología Clínica y de la Salud

Luis Zarzosa Escobedo

Psicología Experimental | Psicología Educativa

\section{Universidad Nacional Autónoma de México}

Facultad de Estudios Superiores Zaragoza

Luz María Flores Herrera Psicología Ambiental | Comportamiento Humano
Juan Jíménez Flores

Psicología de la Salud | Psicología Comunitaria

\section{Universidad Nacional Autónoma de México}

\section{Facultad de Psicología}

German Álvarez Díaz de León Historia de la Psicología | Criminología en México

Nestor Fernández Sánchez

Entornos Virtuales de Aprendizaje | Psicopedagogía
Javier Urbina Soria

Psicología Ambiental | Educación Ambiental

\section{Instituto Politécnico Nacional}

José Gonzalo Amador Salinas Psicología Educativa | Tecnología Educativa
Virginia González Rivera

Rendimiento Escolar | Metodología de la Investigación

\section{Universidad Autónoma de Aguascalientes}

Pedro Palacios Salas

Desarrollo Psicológico | Infancia 
Universidad Autónoma de Querétaro

Sonia Sujell Velez Baez Psicología Clínica | Psicoterapia

Universidad Autónoma del Estado de Hidalgo

Rebeca María Elena Guzmán Saldaña Psicología de la Salud | Trastornos Alimentarios

David Jiménez Rodríguez

Psicología de la Salud | Psicología Educativa

Universidad Autónoma del Estado de México

Reyna Amador Velázquez Psicología de la Salud | Adolescencia

Hugo Alberto Yam Chalé Psicología Aplicada | Criminología

Universidad de Guadalajara

Jorge Arauz Contreras

Psicología de la Salud | Gestión Educativa

Universidad de Sonora

Julio Alfonso Piña López

Psicología de la Salud | Gestión Educativa

Universidad JuÁRez Autónoma de Tabasco

Alba Cerino Soberanes

Psicología Educativa | Psicología del Desarrollo

Universidad JuÁREZ de Durango

Patricia Lorena Martínez Martínez Psicología Educativa | Psicología Clínica 


\section{Universidad Michoacana de San Nicolás de Hidalgo}

Fabiola González Betanzos Psicología de la Salud | Metodología Científica

Marisol Morales Rodríguez Psicología | Educación
Juan Torres Melgoza

Psicología | Educación

Alehtia Dánea Vargas Silva

Psicología | Educación

\section{Comité Editorial}

\section{Pontificia Universidad Católica Argentina}

Analía Verónica Losada

Abuso Sexual Infantil | Patologías Alimentarias

Universidad Católica de Nuestra Señora de la Asunción Paraguay

Norma Coppari González de Vera

Editora de la Revista Eureka

Universidad Federal Fluminense de Brasil

Marialia Etienne Arruguy

Psicología de la Salud | Metodología Científica

Fabiola Arellano Jiménez Terapia Familiar | Consultorio Particular

Silvia Alicia Cabrera Torres Psicología Educativa | Tecnología Educativa

Yu Hing Valeria Chuey Rosas Terapia Familiar | Consultorio Particular
María Fernanda Rodríguez Abello Terapia Familiar | Consultorio Particular

Alondra Belem Medina Luna

Terapia Familiar | Consultorio Particular

Sarai Yáñez Márquez

Evaluación | Capacitación Educativa Profesional 


\section{Evaluadores institucionales}

María Guadalupe Milagros Damián-Díaz Psicología del desarrollo | Educación especial UNAM | FES Iztacala | México

David Rodríguez-Medina Sexualidad UNAM | FES Iztacala | México

Emmanuel Arkad Pérez Psicoanálisis |Ética UNAM | FES Iztacala | México José Manuel Sánchez-Sordo Metodología de la investigación | Tecnología Educativa

UNAM | FES Iztacala | México

Liliana Moreyra Jimenez Psicológica educativa | Psicología de la salud UNAM | FES Iztacala | México

Carmen Susana González Montoya Terapía familiar UNAM | FES Iztacala | México

Leticia Nayeli Ramírez-Ramírez Psicología educativa | Metodología de la investigación UNAM | FES Iztacala | México

Gabriela Leticia Sánchez Martínez Neuropsicología clínica UNAM | FES Iztacala | México

\section{Evaluadores externos a la institución}

Analía Verónica Losada

Terapia familiar | Metodología de la investigación Pontificia Universidad Católica Argentina | Argentina

María Leticia Bautista-Díaz

Psicología de la salud | Trastornos alimenticios

Universidad Autónoma del Estado de Hidalgo | México

Adriana Irene Hernández Gómez

Psicoanálisis I Psicología Social

UNAM | FCPyS | México

Marcelo Della Mora

Psicología clínica | Psicología forense

Centro de Estudios de Ejecución Pena| Universidad de Buenos Aíres

Antonio Rohman Montufar Melo

Psicología organizacional

UNITEC | México

Oscar Giovanni Balderas Trejo

Metodología de la investigación | Tecnología Educativa Independiente| México 


\section{VOLUMEN 3 | NÚMERO 2 | JULIO-DiCIEMBRE 2017 ESCENARIOS ACTUALES DE APLICACIÓN DE LA PSICOLOGÍA}

Presentación del Número, 111

REVISIÓN DE LA LITERATURA

Modelo ecológico aplicado al campo de la salud sexual, 120

El quehacer del profesional de la psicología de la salud: Definiciones y objetivos, 137

ARTículos EMpíricos

Percepción de los estudiantes de licenciatura respecto a los conocimientos éticos adquiridos en la carrera de Psicología, 158

Humor, violencia y ámbito universitario, 180

Efectos del Taller de Estrategias de Aprendizaje en el desempeño de alumnos de Psicología, 197

Apoyo psicológico a la familia: efecto en la estructura familiar de pacientes con hemofilia, 213

INNOVACIÓN Y DESARROLLO TECNOLÓGICO

La evaluación psicofisiológica con imagen térmica infrarroja en los procesos psicológicos, 228 


\section{(4)}

El lado oscura de la divulgación científica Revista Digital Internacional de Psicología y Ciencia Social

Volumen $3 \mid$ Número $1 \mid$ Enero-Junio 2017

International Digital Journa of Psycholgy \& Social Science

Volumen 3 | Número 2 | Enero-Junio 2017 
http://dx.doi.org/10.22402/j.rdipycs.unam.3.2.2017.169.111-117

\section{Presentación del NúMERo}

\section{| VOLUMEN 3 | NÚMERo 2 | JULIO-DiCIEMBRe 2017 |}

\section{TABLA DE CONTENIDO}

INTRODUCCIÓN

ESQUEMA EDITORIAL

ANÁLISIS DE LOS DICTÁMENTES DE LOS REVISORES

Panorama general, 113

Perfil de Evaluación entre pares, 113

Calificación Promedio de los Artículos, 114

Índice de Concordancia, 115

Correlograma, 115

Desacuerdo entre revisores, 115

Material Científico Publicado, 116 


\section{INTRODUCCIÓN}

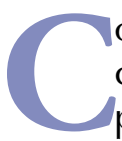
omo equipo editorial de la Revista Digital Internacional de Psicología y Ciencia Social (RDIPyCS), presentamos el segundo número del año 2017 el cual conforma el tercer volumen publicado totalmente a través de medios digitales, con lo cual se busca mantener año con año el espíritu de difusión del conocimiento científico atendiendo fielmente las políticas de transparencia e inclusión que rigen esta publicación digital semestral. Este número implica el esfuerzo de autores y revisores por producir conocimiento científico bajo las políticas de calidad establecidas por la revista. De igual manera, el equipo editorial reitera con esta publicación su compromiso con la comunidad científica por ofrecer un espacio colaborativo y transparente de diseminación del conocimiento fruto de las investigaciones aquí presentadas.

Dicha diseminación del conocimiento científico sólo es posible al ofrecer distintos formatos de publicación que garanticen el alcance a un gran número de lectores interesados en las temáticas desarrolladas, como lo es el tradicional artículo en formato PDF que responde a la a estructura clásica de información para la presentación de textos científicos, el cual incluye los metadatos necesarios para su posterior búsqueda y recuperación a través de la red. Además, se incluye el formato ePub que cumple el cometido de portabilidad y accesibilidad a la información a través de distintas herramientas de lectura. De igual manera, se ofrece el formato MP3 el cual representa el esfuerzo del equipo editorial por garantizar la difusión de la información de manera inclusiva.

Por último pero no menos importante, se reitera a la comunidad científica y al público en general el compromiso con un proceso editorial transparente, lo cual en congruencia con nuestra política editorial es alcanzable a través de la revisión abierta por pares, la cual es aceptada por los autores y revisores que participan número con número en la difusión abierta de la experiencia editorial.

\section{ESQUEMA EDITORIAL}

La Revista Digital Internacional de Psicología y Ciencia Social garantiza la transparencia de sus decisiones editoriales a través del siguiente esquema editorial que compone cada artículo científico publicado en formato PDF:
- Portada. Está constituida por título del artículo y resumen en español e inglés y palabras clave. De igual manera se incluye la bitácora del artículo la cual expone los tiempos editoriales (cuándo se recibió, cuándo fue aceptado para su publicación y la fecha en que fue publicado), así como el Digital Object Identifier (DOI) que permite dar seguimiento al trabajo del autor y búsqueda posterior de su producción científica a través de la red.

- Autoría y derechos de propiedad intelectual. Esta sección está integrada por las imágenes iconográficas de los dos primeros autores/as del artículo, los extractos curriculares de ambos autores, la contribución de cada uno de los autores/as en la elaboración del manuscrito, los agradecimientos y los datos de afiliación de las autores/as. De igual manera se presentan los términos de licencia bajo Creative Commons.

- Índice. Es una serie de vínculos que permiten al lector navegar de forma libre por el cuerpo del artículo, desarrollando así una lectura dinámica del material científico publicado.

- Cuerpo. Consiste en el artículo científico propiamente dicho. Los apartados en que se desarrolle el material científico dependerán del tipo de estudio que se desarrolle (teórico, empírico y de innovación tecnológica para el presente número).

- Meta-análisis del artículo. Está constituido por dos secciones, una cuantitativa y otra cualitativa, la primera está constituida por procedimientos meta-analíticos en donde se presentan cuantitativamente las opiniones que emitieron los revisores sobre el artículo. Esta sección del artículo tiene tres partes: la primera es el perfil en donde se presentan las opiniones que emitieron los revisores en cuanto a la calidad de la introducción, la metodología, los resultados y todos los apartados del artículo. La segunda parte presenta la figura de concordancia que existió entre las opiniones de los revisores, construida utilizando el método de Bland y Altman (1986). Finalmente, la tercera muestra el nivel de acuerdo que se dio entre los revisores al calificar todos los apartados del material científico. Por otra parte, se presenta la dimensión cualitativa de la revisión abierta por pares, la cual expone los comentarios de los revisores a cada una de las secciones desarrolladas por los autores.

- Historia del proceso editorial. En esta sección se presenta un enlace al seguimiento del proceso editorial de cada artículo, en el cual se comparte el manuscrito en las diferentes fases de revisión por el equipo editorial y por los dictaminadores. 


\section{ANÁLISIS DE LOS DICTÁMENTES DE LOS REVISORES}

\section{Panorama general}

A continuación se presenta el análisis global de los dictámenes que los revisores hicieron de todos los artículos publicados en este número bajo el esquema de la revisión abierta por pares. El objetivo del presente análisis es mostrar al lector la opinión que los revisores se formaron de los materiales científicos publicados en el presente número, y que a través de la opinión de los revisores, el lector genere su propio punto de vista sobre la calidad, relevancia e impacto de los trabajos publicados. Con esta acción se pretende generar una opinión pública y transparente sobre las decisiones editoriales realizadas, lo cual se alinea con la filosofía de la revista de difundir conocimiento científico de calidad.

En este apartado de la revista se presenta el meta-análisis de manera similar al esquema editorial de cada artículo, la diferencia radica en que aquí se muestra el resultado de la opinión que emitieron los revisores/as en su conjunto de los artículos publicados. Las secciones que se analizan a continuación son: el perfil de evaluación entre pares, la calificación promedio otorgada a cada uno de los artículos, el índice de concordancia entre revisores, el correlograma y el índice de desacuerdo entre revisores/as.

En el presente análisis se habla de la opinión de los revisores/as considerando cada uno como una unidad de análisis, es decir, el conjunto de dictámenes de cada artículo se tomó a manera de una unidad replicativa, ya que cada dictamen fue hecho por diferentes revisores/as. $\mathrm{Si}$ bien como lo señalan Glass, Wilson, y Gottman (1975); Yin (1984); Menard (1991) y Silva Rodríguez (2004), los análisis que se basan en unidades replicativas son más propensos a verse afectados por fuentes de invalidez, debido a la alteración de la naturaleza de los individuos (en nuestro caso diferentes revisores/as) que componen la unidad de observación, puesto que es probable confundir el efecto de los juicios de los revisores/ as con cambios abruptos en la composición de dicha unidad. Sin embargo, la unidad replicativa está menos sujeta a efectos de información y reactividad, puesto que si fueran los mismos revisores/es de todos los artículos que se publican en un determinado número de la revista acarrearían su sesgo en todos los artículos evaluados. En este caso se analizan la opinión de 14 revisores correspondiente a 7 artículos que componen el número 2 del volumen 3 año 2017.

\section{Perfil de Evaluación entre pares}

El perfil de evaluación entre pares evalúa la opinión de los revisores sobre cada una de las partes más amplias que constituyen el reporte de la literatura científica como son la introducción, el método, los resultados y todos los apartados del artículo.

\section{Introducción}

En la figura 1 se muestra la opinión que emitieron los revisores respecto a la introducción de todos los artículos. Como se puede observar, los revisores opinaron que el planteamiento del problema de los artículos así como el marco teórico eran muy satisfactorios puntuando 3.07 y 3.06 respectivamente de una calificación máxima de 4 . Por otro lado, la calificación más baja obtenida dentro de esta sección fue la definición de variables por lo que le asignaron la calificación de 2.17 de una calificación máxima de 4 posicionándose en un nivel satisfactorio. Finalmente, al observar a lo largo de todo el patrón de opinión, los revisores consideraron que los artículos en cuanto a introducción eran satisfactorios en general, ya que el desarrollo, la pertinencia de las referencias y los objetivos e hipótesis fueron calificados dentro de esta categoría.

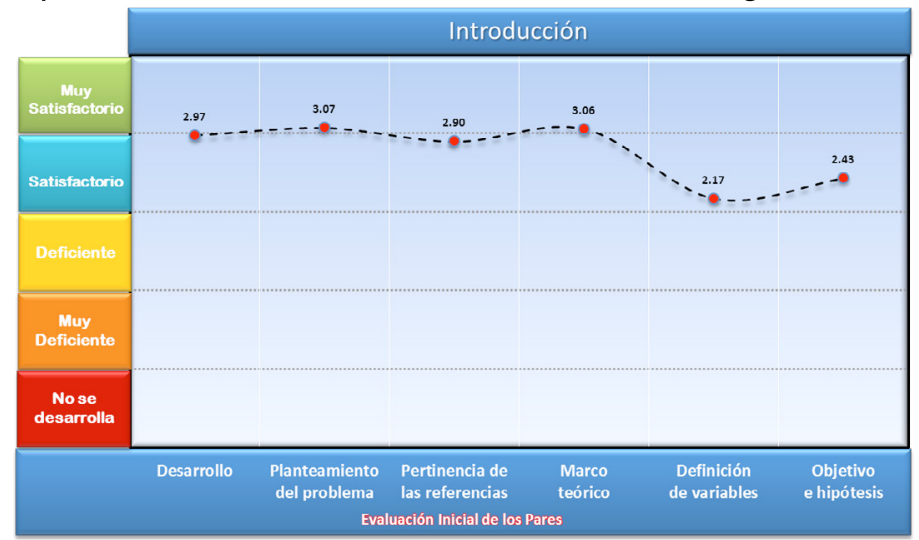

Figura 1.

Perfil de la opinión de los revisores sobre cada uno de los componentes de la introducción de los artículos.

\section{Método}

Según los revisores, los artículos que componen a este número muestran un nivel deficiente en general como se observa en la figura 2. Para los revisores la población y muestra, la recolección de datos y el abordaje de cuestiones éticas en cada artículo no se desarrolló de manera adecuada presentando puntuaciones entre 1 y 1.99 de una calificación máxima de 4. La opinión más favorable fue para los aspectos relacionados con la forma en la que se desarrollaron los estudios presentando una puntuación de 2.08 . 


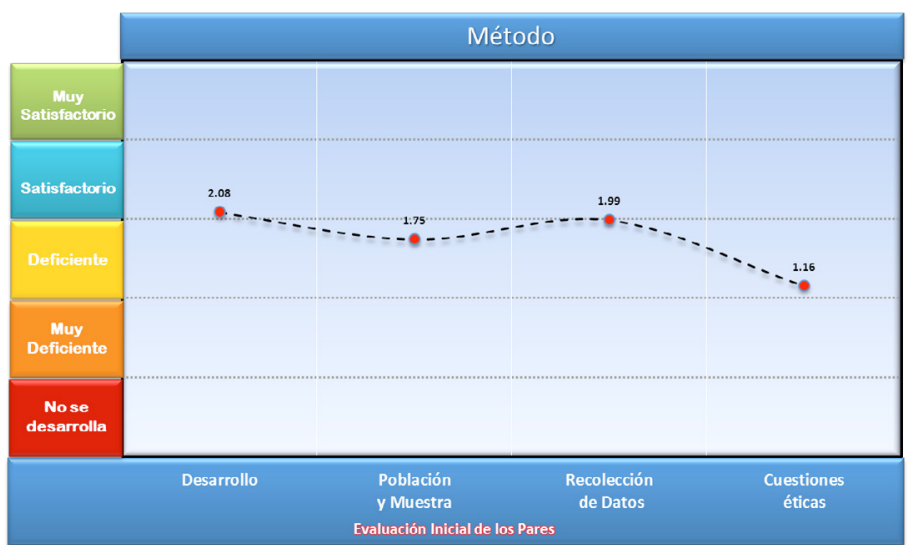

Figura 2.

Perfil de la opinión de los revisores sobre cada uno de los componentes del método de los artículos.

\section{Resultados}

En cuanto a la presentación de resultados (véase figura 3) los revisores consideraron que la forma en que se presentó este apartado en general fue satisfactoria con calificaciones de 2.26 para el desarrollo de esta sección y de 2.63 para la presentación de datos, la cual es la calificación más alta recibida en la sección de resultados. Por otra parte, los revisores consideraron que los análisis de datos expuestos en los resultados se realizaron de manera deficiente, ya que como se puede apreciar en la gráfica, presenta una puntuación de 1.62 la cual resulta la más baja para esta sección.

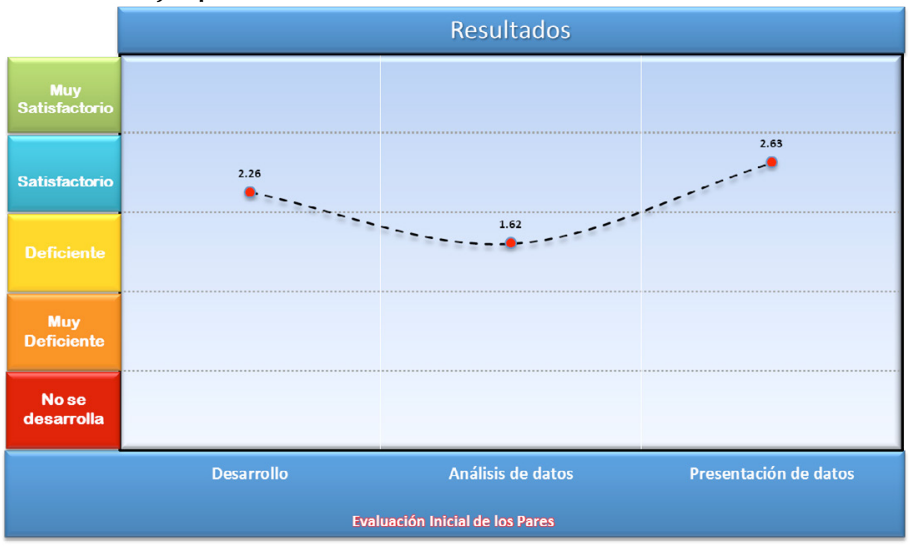

Figura 3.

Perfil de la opinión de los revisores sobre cada uno de los componentes de los resultados de los artículos.

\section{Todos los apartados}

En la figura 4 se muestra la opinión emitida sobre todos los apartados de cada artículo. Como se puede observar, los revisores otorgaron puntajes que varían de satisfactorio a muy satisfactorio, siendo las calificaciones más altas las referentes al título y a la apreciación global de los artículos con 3.15 y 3.02 respectivamente de una ca- lificación máxima de 4. El resto de los apartados se posicionó en la categoría de satisfactorio con puntuaciones que varían de 2.18 a 2.91. Sin embargo, se presenta el apartado de discusión en la categoría de deficiente con una puntuación de 1.90 de 4, con lo cual los revisores opinan que dicho apartado no se desarrolló de la mejor manera en los artículos dictaminados.

Por último, la calificación promedio otorgada a los artículos de este número fue de 2.99 de una puntuación máxima de 4, con lo cual se puede decir que los revisores opinaron que su calidad fue satisfactoria.

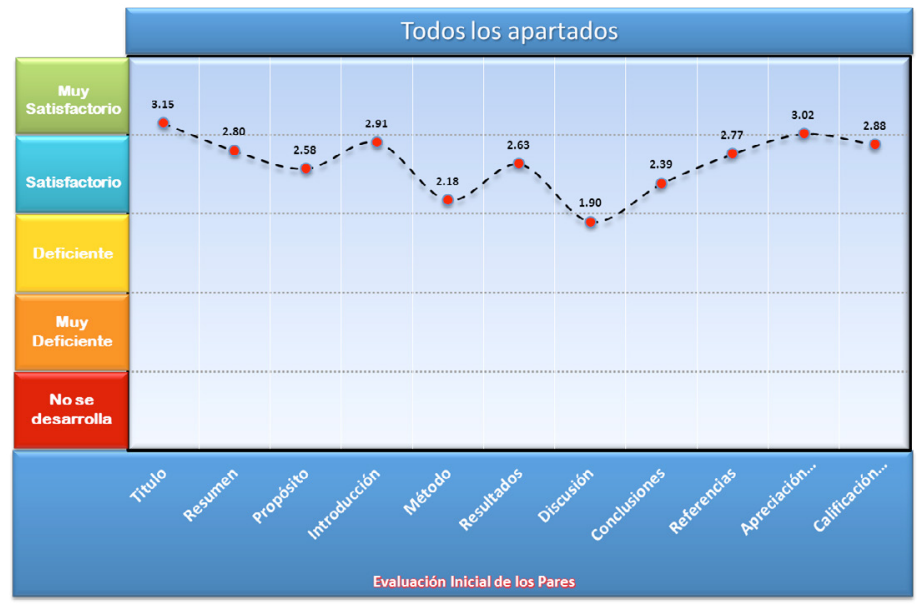

Figura 4.

Perfil de la opinión de los revisores en todos los apartados de los artículos.

\section{Calificación Promedio de los Artículos}

En la figura 5 se presenta la calificación promedio otorgada por los evaluadores al artículo que revisaron. En dicha figura puede observarse que la calificación otorgada a los artículos varió en una escala del 0 al 100 entre 76.72 y 61.78, que corresponde al artículo escrito por los autores Sánchez y Rosales, y al escrito por Coffin, Hernández y Jiménez respectivamente. Como se puede observar, el resto de calificaciones se posicionan alrededor del $70 \%$.

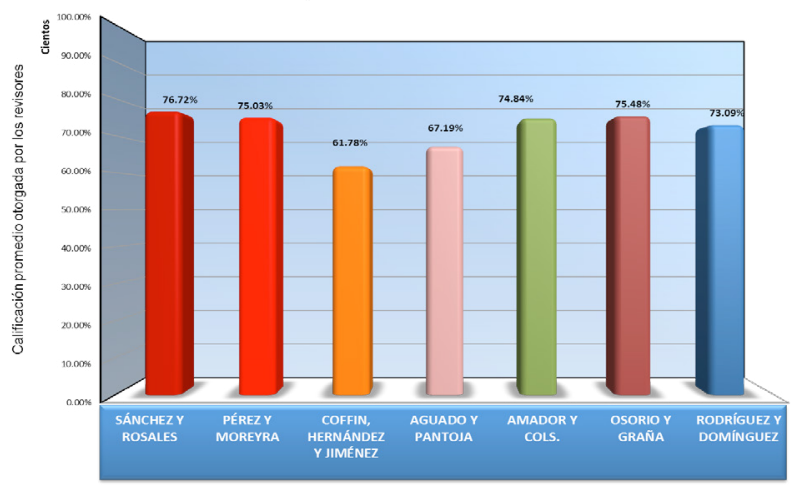

Figura 5.

Calificación promedio otorgada por los revisores los artículos. 


\section{Índice de Concordancia}

Este índice indica el acercamiento que hubo en los juicios de los revisores; es decir, la magnitud en que éstos reportan resultados iguales; mide por lo tanto la variabilidad entre sus opiniones o juicios con respecto a los dictámenes que emitieron del artículo. Para construir la figura 6 , se tomó la calificación promedio de los juicios que los revisores asignaron a las nueve partes del artículo, como fueron título, resumen, propósito, introducción, método, resultados, discusión, conclusiones y referencias.

En dicha figura se observa que la concordancia entre los revisores fue grande, ya que la diferencia entre la mayoría no superó los límites de las desviaciones estándar de las diferencias; solamente en el apartado de método la diferencia entre las opiniones superó el límite superior de .90.

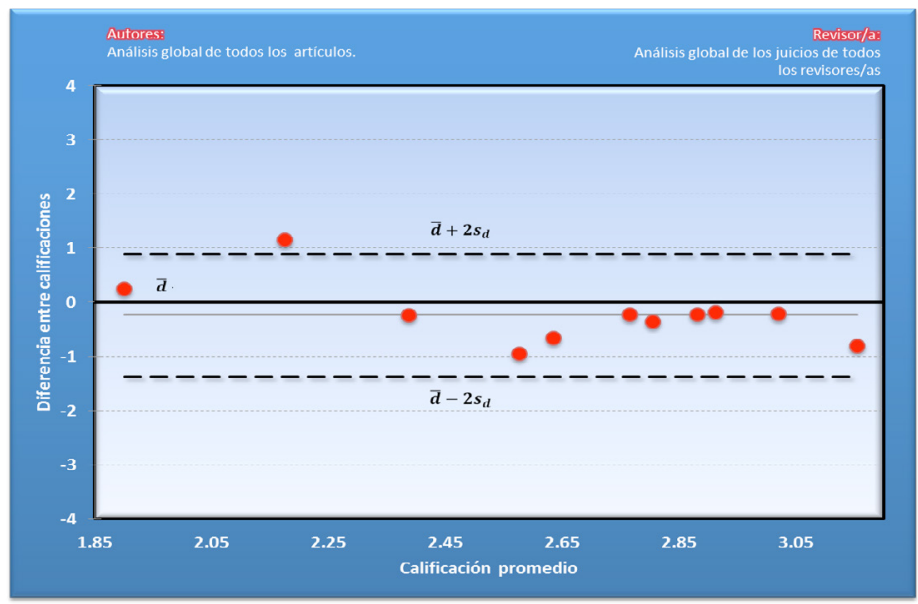

Figura 6.

Indice de concordancia en los juicios de los revisores.

\section{Correlograma}

En la figura 7 se muestra el correlograma de los juicios que emitieron los revisores, es una figura construida a partir de calcular los índices de correlación entre las opiniones emitidas. Los juicios de los revisores que se correlacionaron en el mismo sentido y con una magnitud moderada fueron los que revisaron el artículo de Pérez y Moreyra con un índice de 0.67, así como el de Osorio Graña con un índice de correlación de .54.

Por otra parte, las opiniones de los revisores que no se correlacionaron fueron los que dictaminaron el artículo de Sánchez y Rosales con 0.02, el artículo de Coffin, Hernández y Jiménez con 0.09, igualmente los que revisaron el artículo de Amador y cols. con un puntaje de 0.06. Por último, se presentaron índices de correlación débiles negativos para los artículos de Aguado y Pantoja con -0.16 y para Rodríguez y Jiménez con -0.36 .

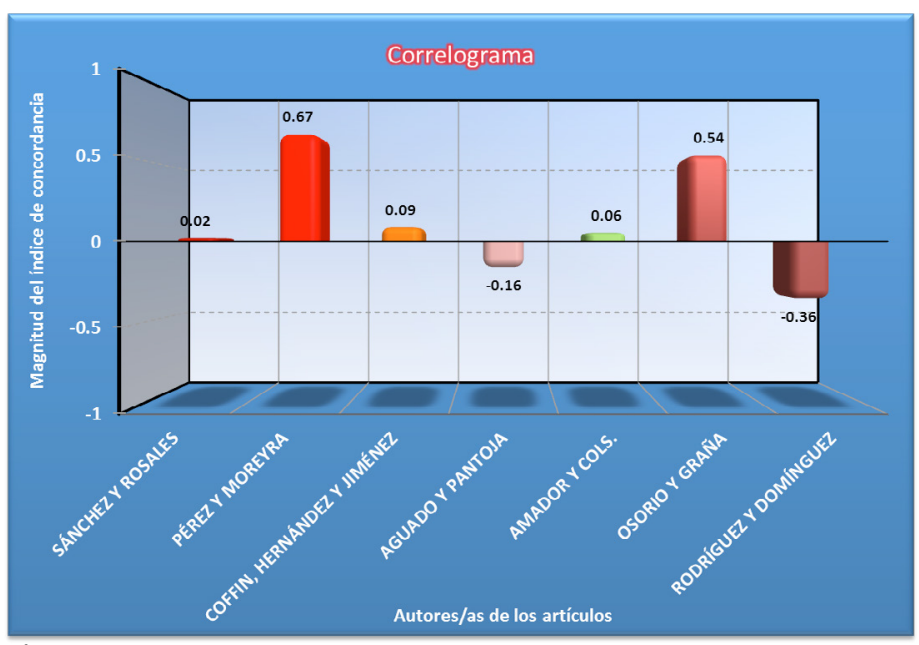

Figura 7.

Correlación entre los juicios de revisores.

\section{Desacuerdo entre revisores}

Finalmente, la figura 8 muestra el desacuerdo entre los revisores, independientemente de su sentido, puesto que sólo evalúa la magnitud de la diferencia de opinión.

Los revisores que menos desacuerdos tuvieron fueron los que dictaminaron el artículo de Sánchez y Rosales así como el artículo de Rodríguez y Domínguez con una diferencia menor a un punto porcentual en cada uno. Por otro lado, los desacuerdos más grandes en la opinión de los revisores se encontraron en los que dictaminaron el artículo de Amador y cols. con una diferencia 26.49 puntos porcentuales, uno le otorgó la calificación de 61.60 mientras que el otro le designó un valor de 88.09.

También se observó una variabilidad muy grande en las opiniones de quienes dictaminaron el artículo de Osorio y Graña, en donde la diferencia de la calificación entre ellos fue de 25.33 puntos porcentuales, uno le asignó un valor de 62.82 y el otro de 88.15. De igual manera, se observa una diferencia de opinión considerable entre los revisores del artículo de Coffin, Hernández y Jiménez, la cual alcanzo la magnitud de 23.04 puntos porcentuales, uno le asignó 50.25 puntos y el otro 73.30 .

Estas discrepancias en la apreciación de la calidad de los artículos son valoraciones que los revisores perciben subjetivamente, lo relevante de todo esto es encontrar el punto en donde las diversas subjetividades, principalmente de los revisores, coincidan para así tener una revista que facilite la comunicación científica, no obstante que sea una realidad artificial producto de los múltiples significados y sentidos que los revisores le asignen al material científico revisado. 


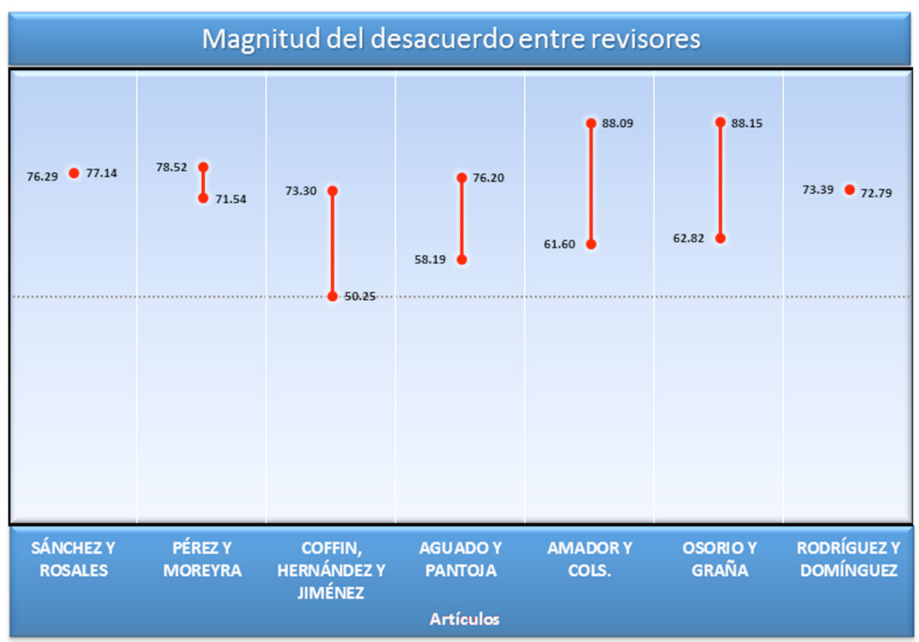

Figura 8.

Desacuerdo entre revisores.

\section{Material Científico Publicado}

El número presentado en esta ocasión recopila artículos teóricos, empíricos así como de innovación y desarrollo tecnológico. El primer artículo presentado es el de Sánchez y Rosales, el cual expone una revisión teórica del modelo ecológico aplicado al ámbito de la salud sexual, dentro del cual se contempla el contexto de desenvolvimiento del individuo y no sólo el trabajo terapéutico en aislado para el cambio conductual. Los autores expresan su interés en generar un panorama amplio de acción en el cual se distingan las variables contextuales que intervienen en la adquisición de conductas sexuales protegidas, contemplando la interacción del individuo con su contexto social, atendiendo a diferencias culturales que propicien un comportamiento preventivo. Los autores destacan el trabajo bajo este modelo reconociendo la dificultad de incidir en todas las variables que lo componen, sin embargo enfatizan en la necesidad de reconocimiento de dichas variables para sustentar un trabajo congruente.

El siguiente artículo que compone este número es el realizado por las autoras Pérez y Moreyra, en el cual se presenta una revisión teórica del quehacer del profesional en el campo de la psicología de la salud. Las autoras plantean la necesidad de distinguir los elementos que definen y constituyen este campo de aplicación a fin de esclarecer la confusión que se genera con otros campos de acción de la psicología. A lo largo del manuscrito se revisa el objeto de estudio de la psicología de la salud, sus objetivos de intervención entre los que se destacan la promoción de la salud y la prevención de la enfermedad; de igual manera se revisa modelo de intervención psicológica en el campo de la psicología de la salud, desde el diagnóstico hasta el seguimiento de la intervención, así como el campo de acción del psicólogo de la salud.

El artículo concluye con una clara distinción entre psicología clínica, medicina conductual y psicología comunitaria. Los esfuerzos de las autoras por delimitar con precisión el quehacer del psicólogo en este campo de acción concluyen con la discusión dirigida a la importancia de una formación sólida que aporte congruencia al ejercicio del psicólogo de la salud.

Para iniciar con los artículos de corte empírico presentados en este número, se presenta el trabajo de las autoras Coffin, Hernández y Jiménez, el cual expone de manera sistemática la percepción de los estudiantes sobre los conocimientos éticos adquiridos en su formación profesional. El tema es por sí mismo relevante para la comunidad científica, ya que se busca con este tipo de estudios generar acciones encaminadas a una sólida formación ética de los futuros psicólogos. El estudio empírico inicia con una evaluación a través de un Autoinforme proporcionado a alumnos que se encontraban cursando la carrera de psicología en distintos semestres, en el cual se indagaba sobre la opinión referente a ética profesional y dilema ético, así como la percepción que se tenía sobre la preparación para tratar con pacientes con los conocimientos sobre ética que se poseían.

Los resultados del estudio muestran opiniones interesantes sobre la preparación que han tenido los estudiantes para llevar a cabo su práctica profesional, así como una inquietud por recibir mayor preparación en contenidos de carácter ético a lo largo de su formación. Los resultados llevan a las autoras a concluir en la necesidad de crear una cultura ética en todos los actores que se desenvuelven en el ámbito educativo, y no sólo en la comunidad estudiantil, a fin de generar conciencia sobre la responsabilidad del ejercicio profesional.

Continuando con los trabajos empíricos presentados, se incluye el artículo titulado Humor, violencia y ámbito universitario desarrollado desde una perspectiva psicoanalítica por las autoras Aguado y Pantoja, las cuales exponen la relevancia que tiene el estudiar la violencia dentro de los centros universitarios desde el enfoque del humor y la risa para la resignificación del fenómeno. El humor como lo abordan las autoras, está entendido como la superación de la adversidad y el sufrimiento a través del enfrentamiento de la situación desde el lenguaje y el psicodrama.

En el artículo se exponen los resultados de la aplicación de un taller dirigido a alumnos basado en lo anteriormente mencionado, cuyo objetivo se centraba en generar un cambio subjetivo sobre la violencia presente en las instituciones educativas. Las autoras discuten los resultados de la intervención haciendo énfasis 
en la importancia que tiene el identificar las distintas expresiones de violencia y su superación a través del intercambio de experiencias que permitan solucionar la situación de manera personal y subjetiva.

Otro de los artículos empíricos que se incluyen en este número es el presentado por Amador, González, Reyes, González, Balderrama y Prado, el cual expone los resultados de la aplicación de un taller de estrategias de aprendizaje implementado en alumnos de reciente ingreso de la carrera de psicología del Instituto Politécnico Nacional. El estudio tuvo como objetivo analizar el efecto en el conocimiento, uso y aplicación de las estrategias de aprendizaje instruidas a través del taller implementado para mejorar el rendimiento del alumnado participante.

Los autores emplearon un método de test - retest en el cual pudieron analizar el efecto del taller a través del tiempo. Se encontraron diferencias significativas en el uso y aplicación de las estrategias de aprendizaje instruidas, así como en el rendimiento académico por medio de las calificaciones antes y después del taller, con lo cual se concluyó la efectividad de la intervención. Se discute la importancia de proporcionar espacios de capacitación derivadas de un adecuado diagnóstico y acordes a los objetivos institucionales, en miras de proporcionar a los alumnos las herramientas necesarias para su autorregulación en el proceso de aprendizaje.

Para concluir la sección de artículos empíricos, se presenta el trabajo desarrollado por Osorio y Graña en el cual se expone la importancia de contemplar al grupo primario de pacientes diagnosticados con hemofilia en el trabajo terapéutico del psicólogo. Para esto se analizó la estructura familiar de una muestra de padres que tienen un hijo con hemofilia, de igual manera se analizó la estructura familiar de las personas que asisten a terapia psicológica y que son apoyados por un programa de acompañamiento a los miembros de familias con pacientes con hemofilia, el cual tiene el objetivo de crear una red de soporte social, familiar e institucional que colabore en la aceptación del diagnóstico y en el restablecimiento de la homeostasis familiar.

Los resultados encontrados a través de esta investigación llevan a las autoras a concluir que el análisis de la estructura familiar de las personas involucradas en un proceso de salud enfermedad, brinda a los psicoterapeutas las herramientas necesarias para programar actividades de apoyo que permitan superar y/o adaptarse a las condiciones que la enfermedad trae consigo. Los resultados permiten proyectar programas que difundan la importancia de incluir el seno familiar en procesos de apoyo psicológico, y de esta manera tener un mayor impacto en el bienestar del enfermo así como en el de su familia.
Para cerrar este número se presenta la contribución de los autores Rodríguez y Domínguez, la cual es una interesante propuesta de innovación tecnológica que expone la importancia de utilizar instrumentos de medición no invasivos ni obstrusivos para el monitoreo clínico y registro psicofisiológico de los participantes, como lo es la imagen térmica infrarroja, la cual permite detectar cambios de temperatura asociados a procesos cognitivos, afectivos y/o conductuales. El artículo muestra los usos, la naturaleza, el funcionamiento y utilidad de la evaluación psicofisiológica basada en la imagen térmica infrarroja. A lo largo del manuscrito, los autores enmarcan los múltiples usos de la evaluación psicofisiológica fundamentada en los cambios térmicos que registra un organismo relacionados con procesos afectivos y cognitivos, lo cual da lugar a que se desarrollen herramientas de medición que permitan valorar los cambios psicofisiológicos que subyacen a procesos psicológicos.

La implementación de la herramienta de evaluación aquí presentada, abre un abanico de posibilidades de investigación para la psicología en México: en el campo de la psicología clínica y de la salud para el estudio de trastornos afectivos y/o de regulación emocional; en el campo de la psicología social experimental al evaluar las interacciones socio-afectivas; en el campo de psicología educativa al estudiar los procesos cognitivos de aprendizaje; y en la psicología fisiológica al estudiar sobre la influencia de fármacos en condiciones experimentales. Se concluye el manuscrito presentando las bondades y limitaciones de la imagen térmica infrarroja, lo cual promueve un análisis crítico de sus posibles usos en la investigación experimental.

Es así que finalizamos el presente número. El equipo de edición de la Revista Digital Internacional de Psicología y Ciencia Social agradece como siempre su atención. Esperamos disfrute ampliamente la difusión de la ciencia en formato digital, libre y gratuito. 


\section{Referencias}

Bland, J. M., \& Altman, D. G. (1986). Statistical methods for assessing agreement between two methods of clinical measurement. Lancet, 327(8), 307-310.

https://wwwusers.york.ac.uk/ mb55/meas/ba.pdf

Glass, G. V., Wilson, F., \& Gottman, G. (1975). Design and analysis of time-series experiments. Boulder: Colorado Associated Press.
Menard, S. (1991). Longitudinal research. London: SAGE University paper.

Silva Rodríguez, A. (2004). Diseño de investigación con N=1 o series de tiempo. In A. Silva Rodríguez (Ed.), Métodos cuantitativos en psicología. Un enfoque metodológico (pp. 45-70). México: Trillas.

Yin, R. K. (1984). Case study research: design and methods. Thousand Oaks: Sage Publications, Inc.

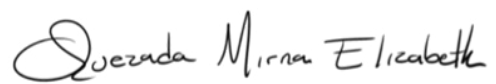

Mtra. Mirna Elizabeth Quezada Editora ejecutiva 


\section{Sección}

\section{Revisión de la Literatura}


http://dx.doi.org/10.22402/j.rdipycs.unam.3.2.2017.80.119-135

\title{
MOdELO ECOLÓGICO APLICADO AL CAMPO DE LA SALUD SEXUAL
}

\author{
Ricardo Sánchez-Medina y Consuelo Rubi Rosales-Piña \\ FES Iztacala, UNAM \\ México
}

\begin{abstract}
RESUMEN
La psicología de la salud ha cobrado relevancia en los últimos años contribuyendo en la explicación y predicción del comportamiento de riesgo en el proceso de salud-enfermedad. Algunos modelos parten de la premisa de que cambios en variables de tipo cognitivo generarán cambios en el comportamiento; sin embargo, la evidencia empírica muestra que las personas pueden creer que llevar a cabo cierto tipo de comportamientos son perjudiciales para su salud, pero no hacen nada por cambiar esos hábitos. Una explicación de por qué no se generan cambios a partir de la intervención en variables cognitivas, es porque se deja de lado el contexto en el cual se encuentran las personas, como la familia y la escuela, entre otros; de esta manera, considerar que un individuo está inmerso en diversos ambientes dará un panorama diferente para explicar el por qué una persona se enferma o está saludable. Una aproximación que permite entender el proceso de salud-enfermedad desde esta perspectiva es el modelo ecológico, por lo cual el objetivo del presente trabajo es ejemplificar la utilización de dicho modelo mediante una revisión teórica en el ámbito de la salud sexual.
\end{abstract}

\section{Palabras Clave:}

salud sexual, comportamiento de riesgo, modelo ecológico

\section{ECOLOGICAL MODEL APPLIED TO THE FIELD OF SEXUAL HEALTH}

\begin{abstract}
In the health-disease process, health psychology has become relevant in explaining and predicting risk behavior. Some models start from the premise that changes in variables of cognitive type generate changes in behavior; However, empirical evidence shows that people may believe that carrying out certain behaviors are detrimental to their health, but they do nothing to change those habits. An explanation of why they do not generate changes from the intervention in cognitive variables, is because they leave aside the context in which they are, such as: family, school, among others; In this way consider that an individual is immersed in different environments will give a different view to explain why a person gets sick or not. An approach that allows to understand the health-disease process from this perspective is the Ecological Model, so the objective of the present work is to exemplify the use of this model through a theoretical revision in the field of sexual health.
\end{abstract}

\section{Keywords:}

sexual health, risk behavior, ecological model. 


\title{
Modelo eCOLÓGICO APLICAdO AL CAMPO DE LA SALUD SEXUAL
}

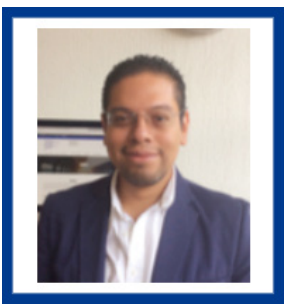

Ricardo Sánchez-Medina

FES Iztacala, UNAM

Correo: ricardo.sanchez@ired.unam.mx

Doctor en Psicología en la UNAM en el campo de Psicología y Salud, Maestro en Psicología con Residencia en Terapia Familiar en la FESI-UNAM, en 2008. Está acreditado como Tutor en Educación E-learnig por parte de la FESI-UNAM; cuenta con una Especialidad en entornos virtuales de aprendizaje por la OEI. Ver más...

\author{
Ricardo Sánchez-Medina y Consuelo Rubi Rosales-Piña \\ FES Iztacala, UNAM \\ México
}

\section{CONTRIBUCIÓN DE lOS AUtORES}

Se atribuye a los autores la responsabilidad única de concebir y desarrollar los puntos de vista en cada una de las secciones que se presentan en este trabajo.

\section{AgRADECIMIENTOS}

Investigación realizada gracias al Programa UNAM-DGAPA-PAPIIT IA304317

Grupo de Investigación en Procesos Psicológicos y Sociales (GIPPS), Facultad de Estudios Superiores Iztacala,

Universidad Nacional Autónoma de México.

\section{Datos de Filiación de los Autores}

Sistema de Univeridad Abierta y Educación a Distancia, Facultad de Estudios Superiores Iztacala, UNAM.

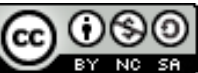

Copyright: (C) 2017 Sánchez-Medina R., Rosales-Piña, R.

Este es un artículo de acceso abierto distribuido bajo los términos de la licencia Creative Commons Reconocimiento-NoComercial -Compartirlgual 4.0 Internacional, por lo que su contenido gráfico y escrito se puede compartir, copiar y redistribuir total o parcialmente sin necesidad de permiso expreso de sus autoras con la única condición de que no se puede usar con fines directamente comerciales y los términos legales de cualquier trabajo derivado deben ser los mismos que se expresan en la presente declaración. La única condición es que se cite la fuente con referencia a la Revista Digital Internacional de Psicología y Ciencia Social y a sus autoras. 


\section{TABLA DE CONTENIDO}

INTRODUCCIÓN

MODELO ECOLÓGICO Y SALUD SEXUAL

EVALUACIÓN DEL COMPORTAMIENTO SEXUAL DESDE EL MODELO ECOLÓGICO

INTERVENCIÓN PARA PROMOVER LA SALUD SEXUAL DESDE EL MODELO ECO-

LOGICO 


\section{INTRODUCCIÓN}

$\mathrm{E}$ n las últimas décadas los especialistas en el campo de la psicología de la salud, han incursionado en el estudio de las relaciones entre el funcionamiento psicológico, la preservación de la salud y el desarrollo de diferentes enfermedades, para lo cual se han utilizado y/o creado modelos que pretenden explicar, predecir y/o modificar el comportamiento de riesgo o de prevención.

Algunos de dichos modelos son: Modelo de Creencias de Salud de Rosentock, Strecher y Becker (1994); Modelo de Autoeficacia de Bandura (1999); Modelo de Reducción de Riesgo de Catania, Kegeles y Coates (1990); Modelo basado en la Teoría de Acción Razonada de Ajzen y Fishbein (1980); Modelo basado en la Teoría de la Conducta Planeada de Ajzen (1985); Modelo de Información-Motivación-Habilidades Conductuales de Fisher y Fisher (1992), y Modelo Integral de Fishbein (2000).

Desde estos modelos se ha encontrado una relación entre variables de tipo cognitivo y el comportamiento preventivo, es decir, se ha observado que las personas que piensan en alimentarse adecuadamente pueden prevenir la diabetes, es más probable que lo hagan, en comparación a las que no lo conciben así; sin embargo, también se han encontrado algunas inconsistencias; Ribes (1990) menciona que suponer cambios de tipo cognitivo para producir cambios en el comportamiento no necesariamente da ese efecto; por ejemplo, en el ámbito de la prevención de salud sexual se ha encontrado que los adolescentes en general poseen creencias favorables hacia el uso del condón sin ser equivalente a que lo usen en todas sus relaciones sexuales (Enríquez y Sánchez, 2015).

En este sentido, DiClemente, Salazar y Crosby (2007) sugieren que para lograr una mejor comprensión de los problemas que afectan la salud se deben tener en cuenta las distintas esferas sociales en las cuales la persona se encuentra inmersa, dado que los modelos antes mencionados sólo se centran en el individuo, dejando de lado otros entornos que pueden estar participando, como la familia, la escuela y el trabajo, entre otros, y que pueden ser determinantes en el comportamiento preventivo o de riesgo. Considerar estos contextos ofrece un panorama diferente que permite entender la compleja red de elementos que afectan a las personas, y en función de ello generar e implementar intervenciones que disminuyan el comportamiento riesgoso.
Con base en lo anterior, se aborda el Modelo Ecológico de Bronfenbrenner (1987); desde esta perspectiva se concibe al ambiente ecológico como un conjunto de estructuras seriadas y ordenadas en diferentes niveles microsistema (micro), mesosistema (meso), exosistema (exo) y macrosistema (macro); se parte de la premisa de que para analizar al individuo es indispensable estudiarlo en relación con los diferentes contextos en que se encuentra inmerso; esto es importante debido a que el comportamiento para prevenir la enfermedad o promover la salud se establece en múltiples ambientes, recibiendo influencia directa o indirecta de distintos lugares y personas que establecen determinados tipos de conductas; el modelo es considerado explicativo, aunque actualmente se utiliza para la intervención.

Al retomar este modelo, Enríquez, Sánchez y Robles (2011) mencionan que en el nivel micro se contemplan las variables de tipo psicosocial que se evalúan en los diferentes modelos de salud — como conocimientos, actitudes, intenciones y autoeficacia, por mencionar algunas-. El nivel meso comprende los ambientes que están directamente relacionados con las personas, como la familia (estructura familiar, el apoyo y supervisión familiar), la escuela (relación con maestros y compañeros) y los grupos recreativos (grupos de baile, deportivos, espirituales, etcétera). El nivel exo se refiere a los sistemas que no están directamente relacionados con la persona, pero que lo afectan de manera indirecta, es decir, la situación laboral, características de la localidad, nivel de escolaridad de los padres, etcétera. El nivel macro lo configuran los factores socioeconómicos, ideológicos y culturales en los que se desenvuelve la persona; entre estos se pueden mencionar los estereotipos de género, la influencia de los medios de comunicación, usos y costumbres, de tal modo que el modelo funciona como guía para identificar las condiciones particulares en que actúa un sujeto, así como los factores que determinan sus comportamientos, relaciones, decisiones e interconexiones de todo tipo.

Las investigaciones que retoman el Modelo Ecológico explican el comportamiento de las personas y sus interacciones en los diferentes ambientes y cómo esto hace más probable la adquisición de una enfermedad o la prevención de la misma. Ejemplo de ello es la investigación de Abrams, Theberge y Karan (2005), donde analizaron el punto de vista psiquiátrico contrastándolo con la perspectiva ecológica; estos autores hacen una crítica a los sistemas de clasificación para diagnosticar la depresión en adolescentes, enfatizando que dichos criterios la mayoría de las veces no se cumplen, además de que asignan una etiqueta negativa a las personas; la relevancia principal de este trabajo es que considera 
que en un primer momento es fundamental hacer una evaluación general de todas las variables en que se encuentra inmerso el adolescente para conocer en qué medida cada uno de éstas se vincula con la depresión, sin centrarse en criterios diagnósticos.

En cuanto al tema de adicciones a sustancias en adolescentes, se han estudiado los factores que se vinculan con el consumo de drogas; algunos de estos son: altos índices de depresión, percepción de problemas familiares, exposición a situaciones de violencia con la familia o con la escuela, y de manera general en la comunidad donde viven (Hilarski, 2006). En esta misma línea, para las personas que están en tratamiento por abuso de sustancias los factores que se han encontrado para que las personas se mantengan en dicho programa, está relacionado con el soporte social que reciben tanto de la institución como de su familia; destacando que los jóvenes que reciben apoyo familiar son quienes mejores resultados tienen en la intervención (Jones, Heflinger y Saunders, 2007).

Asimismo se ha estudiado el contexto del adolescente en relación con el control diabético, resaltando que para establecer una mejor regulación en la alimentación y en el monitoreo de la glucosa es indispensable el apoyo de la familia, porque se ha encontrado que los jóvenes que tienen una buena comunicación con los padres y se sienten apoyados por éstos tienen mayor control de la diabetes (Liles y Juhnke, 2008).

En la investigación realizada por Wells y Olson (2006) se identificaron los componentes que se relacionan con el sobrepeso y la obesidad; estos autores encontraron que los hábitos de alimentación, de actividad física y el tiempo dedicado a ver televisión se asocian con aspectos asociados con la tecnología del hogar y del lugar de trabajo, esto es, el diseño de las construcciones, del vecindario, los sistemas de transporte, así como el empleo de la madre que le limita el tiempo disponible para cocinar algo saludable, causando la compra de comida rápida rica en carbohidratos.

En la investigación de Sánchez y Robles (2014) se encontró que los jóvenes que se comunicaban con mayor frecuencia con sus padres acerca de aspectos relacionados con comprar condones y prevenir infecciones de transmisión sexual eran los que retardaron la edad del inicio de relaciones sexuales y quienes reportaron utilizar condón con mayor frecuencia.

Desde la perspectiva del modelo ecológico se retoman las principales variables que los diferentes modelos de salud de corte individual mencionan, lo que significa que desde este enfoque se intenta ampliar el foco de análisis centrándose en los diferentes contextos en que se encuentra inmersa la persona; para tener una mejor com- prensión de este modelo, el objetivo del presente trabajo es ejemplificar la utilización del Modelo Ecológico mediante un revisión teórica en el ámbito de la salud sexual.

\section{Modelo Ecológico y SAlud SEXuAl}

El Modelo Ecológico de Bronfenbrenner ha sido utilizado como marco de referencia para evaluar el comportamiento sexual, siendo una herramienta que permite reconocer el contexto en que el joven se encuentra inmerso. Desde esta visión, se concibe al ambiente ecológico como un conjunto de estructuras interconectadas en un mismo fenómeno desde sus cuatro diferentes niveles.

El nivel micro se refiere al contexto más inmediato de la persona; corresponde al patrón de actividades, roles, relaciones interpersonales que la persona experimenta en un entorno determinado en el que participa. Dadas las características de los elementos que define este nivel, algunas variables que se pueden ubicar respecto al comportamiento sexual de riesgo han sido los siguientes.

1) Conocimientos que se tienen respecto a la prevención y transmisión del VIH/SIDA, en donde se ha encontrado que niveles altos de información son necesarios, pero no suficientes, para que una persona se comporte de manera preventiva (Enríquez et al., 2011).

2) Actitudes e intenciones para usar el condón; entre más favorables sean, es más probable la ocurrencia de una conducta sexual saludable (González, 2009).

3) Autoeficacia de negociar y usar el condón en sus relaciones sexuales; a mayor autoeficacia mayor probabilidad de usar condón en sus relaciones sexuales (Vargas y Barrera, 2002).

4) Creencias sobre el uso del condón; creencias favorables coadyuvan a que las personas lo utilicen (Enríquez y Sánchez, 2015).

5) Autoestima; se ha encontrado que una autoestima más alta se asocia con el uso del condón en relaciones sexuales (Van Horne, Wiemann y Berenson, 2009).

6) Comunicación con la pareja sobre temas sexuales; se ha observado que a mejor comunicación sobre el uso del condón, mayor es su uso (Auerbach y Coates, 2000).

El nivel meso comprende las interrelaciones de dos o más entornos en los que la persona participa activamente, como la familia, el grupo de pares y la comunidad donde vive. Respecto a la familia, se considera que cuando ésta se involucra en las actividades que realizan los hijos y cuando existe una mejor comunicación entre padres e hijos, éstos tienden a tener comportamientos sexuales de prevención (Henrich, Brookmeyer, Shrier y Shahar, 2006; Okafor y Holder, 2005). Algunas variables familiares, son las siguientes. 
1) Estructura familiar; se refiere a con quién vive la persona; se ha reportado que cuando los adolescentes viven con ambos padres es más probable que tengan comportamientos sexuales preventivos (Kim, 2007).

2) Apoyo familiar; indica el tipo de respaldo y solidaridad recibido por parte de la familia, sobre todo de los padres en términos emocionales, financieros y de información; al respecto se ha encontrado que a mayor apoyo de los padres los hijos retardan la edad de iniciación sexual o incrementan el uso del condón (Van Horne et al., 2009).

3) Monitoreo y supervisión parental, es decir, cuánta participación existe del padre o la madre en el cuidado de los hijos; se ha asociado que cuando hay mayor monitoreo parental, los hijos retardan la edad de la actividad sexual (Voisin, DiClemente, Salazar, Crosby y Yarber, 2006).

4) Comunicación entre padres e hijos sobre temas sexuales; por ejemplo, el uso de condón, embarazos y relaciones sexuales, entre otros; los hallazgos han sido que a mayor comunicación más conductas sexuales protectoras (Chapman y Werner-Wilson, 2008).

5) Norma social; son reglas que se espera sigan las personas y que pueden ejercer presión social para realizar determinado tipo de conductas, como tener relaciones sexuales protegidas o no (Ayoola, Nettleman y Brewer, 2007).

6) Contextos de interacción, como la escuela, el trabajo y la comunidad donde viven; éstos son significativos en la medida en que repercuten en el comportamiento sexual si en la comunidad en donde vive hay mayor incidencia de VIH/SIDA o de embarazos no deseados (Brendgen, Wanner y Vitaro, 2007; Padilla, Guilamo-Ramos y Bouris, 2010).

El nivel exo se refiere a los sistemas que no están directamente relacionados con la persona, pero que lo afectan de manera indirecta; en el caso de los adolescentes se enlistan los siguientes.

1) Situación laboral de los padres; influye en el monitoreo y la supervisión parental, ya que cuando se tiene una gran cantidad de horas laborando es menos probable que se tenga tiempo para supervisar lo que hacen los hijos (DiClemente et al., 2007).

2) Nivel de escolaridad de los padres; bajos niveles de escolaridad se han asociado con el comportamiento sexual de riesgo en los hijos (Vélez-Pastrana, González-Rodríguez y Borges-Hernández, 2005).

El nivel macro lo configuran los factores socioeconómicos, ideológicos y culturales en los que se desenvuelve la persona, que afecta de manera transversal a los sistemas de menor orden; la evidencia empírica considera en este nivel el estatus socioeconómico (Corcoran y Franklin, 2002) y la raza (Knowlton, Buchanan, Wissow, Pilowsky y Latkin, 2008). La crítica fundamental es que evaluar un nivel macro sólo con ingresos y raza no es representativo de la cultura, por lo que se propone incluir en este nivel dos aspectos.

1) Premisas socioculturales; entendidas como las que norman, rigen y gobiernan los sentimientos, las ideas y el comportamiento (Díaz-Guerrero, 1994); partiendo de estas premisas, la cultura entreteje las creencias relacionadas con el papel que hombres y mujeres juegan en la sociedad, dando lugar a los estereotipos de género (Rocha-Sánchez y Díaz-Loving, 2005); en particular, cuál es el comportamiento sexual que socialmente se permite a un hombre o a una mujer.

2) Influencia de los medios de comunicación; asociados con el comportamiento de los adolescentes, particularmente en lo referente a la información que reciben de la televisión, radio e internet acerca de la sexualidad (Voisin et al., 2006).

Con base en este modelo, se plantea que para que una persona tenga comportamientos preventivos es necesario analizar no sólo lo que ocurre en cada uno de estos niveles, sino la interacción entre niveles; por ejemplo, para que una persona use condón en sus relaciones sexuales se tiene que indagar acerca de cuál ha sido su patrón de comportamiento sexual, la información que tiene sobre prevención del VIH/SIDA, lo que percibe en torno a contagiarse de $\mathrm{VIH}$, los contextos en que tiene relaciones sexuales, si son bajo la influencia de alcohol, drogas, el tipo de pareja (ocasional/estable), la comunicación con la pareja, el papel de la familia y los amigos en el comportamiento sexual, así como la influencia cultural, por mencionar algunos. A continuación se presentan algunas investigaciones realizadas para explicar, predecir y modificar el comportamiento sexual desde el Modelo Ecológico.

\section{EVALUACIÓN DEL COMPORTAMIENTO SEXUAL DES- de el Modelo Ecológico}

En cuanto al tema de la iniciación romántica y sexual temprana, Vargas y Barrera (2002) identificaron las variables que se asocian para que un adolescente inicie su vida sexual activa, encontrando variables individuales - como la autoestima, la autoeficacia y la autonomía emocional_- familiares — como la calidad en la relación familiar y el apoyo parental- y sociales — como la influencia del grupo de pares y de la televisión-; estos autores mencionan que si se pretende comprender por qué los adolescentes inician su vida sexual a edades tempra- 
nas, se deben de analizar sobre todo estos contextos para tener una comprensión más amplia que permita ayudar a los jóvenes a tomar la decisión de cuándo iniciar su vida sexual con un comportamiento preventivo.

En este mismo sentido, también se han evaluado los factores contextuales que lleva a las personas a tener relaciones sexuales de riesgo, por ejemplo, Padilla et al. (2010) analizan el contexto político y social de República Dominicana en relación con el turismo y la incidencia de VIH/SIDA, encontrando que los hombres que viven del turismo, en su mayoría, han tenido intercambios sexuales con hombres o con mujeres, poniéndolos en una situación de riesgo debido a que es más alto el predominio de VIH entre trabajadores sexuales y sus clientes, por la influencia del consumo de alcohol y de drogas en las zonas turísticas y porque los hombres reportaron que aunque usan el condón en sus relaciones sexuales, cuando sus clientes son frecuentes dejan de usarlo por la confianza que sienten hacia ellos.

Específicamente, Van Horne et al. (2009) encontraron algunas asociaciones con el no uso del condón en mujeres adolescentes, entre las que destacan: estar embarazada, que la pareja no quiera usar condón, recibir violencia por parte de la pareja, la asistencia a la iglesia y el reducido monitoreo parental.

Respecto del embarazo, Ayoola et al. (2007) han encontrado algunas razones de por qué las mujeres tienen embarazos no deseados; estos investigadores las dividen en tres bloques; 1 ) razones individuales: poca percepción de riesgo de embarazarse, carencia de conocimientos, actitudes negativas y creencias negativas hacia el uso del condón; 2) razones interpersonales: pareja, familia o amigos que no están de acuerdo con el uso de métodos anticonceptivos, y 3) razones sociales: limitaciones en el acceso a los condones, inconveniencia y costo; en este sentido, los autores plantean que para el diseño de programas de intervención no sólo basta con cambiar percepciones y dar información acerca del tema, sino que se debe dotar de las herramientas necesarias que les permita llevar a cabo una conducta sexual protegida dentro del contexto y de las personas con que se relaciona; tal y como lo demuestra el estudio de Corcoran y Franklin (2002) en donde los programas que incluyen el trabajo con mujeres adolescentes y algún integrante de su familia se sienten más apoyadas y permanecen más tiempo en las sesiones de intervención.

En un nivel más amplio se considera necesario evaluar el impacto que juegan el género, la pobreza, el desempleo y la carencia al acceso al cuidado médico (El-Bassel, Caldeira y Ruglass, 2009).
En relación con el estigma en la sociedad respecto al VIH, se ha analizado a partir de cinco factores (Okafor y Holder, 2005): 1) percepción del estigma, autoestima de la persona que vive con VIH, conocimientos, creencias, actitudes y conductas relacionadas hacia las personas que son portadores del virus; 2) relación que tiene la persona con VIH en su escuela, trabajo, iglesia y otros contextos significativos, así como el uso de drogas por parte de la pareja y amigos; 3) cuidado y soporte de la familia; 4) intereses, características, valores y normas dentro de la comunidad en donde vive, y 5) leyes, políticas y estrategias utilizadas para proteger a la población que vive con VIH, concluyendo que cada uno de estos contextos, asociados con la estigmatización y la discriminación, deben ser tomados en cuenta para el trabajo que se realice con este tipo de población.

También se ha evaluado a personas que viven con $\mathrm{VIH}$. En un estudio realizado por Knowlton et al. (2008) se identificaron las situaciones de vida de niños afectados por sus padres que viven con $\mathrm{VIH}$, señalando que la falta de redes sociales por parte de los padres con $\mathrm{VIH}$ se relaciona con un mal comportamiento del hijo, o incluso asumen el papel de cuidadores de los padres; los autores concluyen diciendo que es necesario dotar a estas familias de recursos y de redes sociales que les ayuden a salir adelante y que, a pesar de ser portadores o haber desarrollado el SIDA, sean los padres los encargados de favorecer el desarrollo de sus hijos y no a la inversa.

En este sentido, también se ha evaluado el papel que juega la familia no sólo en el desarrollo adecuado de los hijos, sino se ha considerado su influencia dentro del comportamiento sexual. Por ejemplo, Corcoran (2001) encontró una relación entre el funcionamiento familiar, la estructura familiar, la raza y el estatus socioeconómico en el comportamiento sexual de los adolescentes, encontrando que los principales problemas que suelen presentar son en las áreas de comunicación, resolución de problemas, roles y control de los padres hacia los hijos; esta investigación aporta la relevancia del entrenamiento conductual enfocado en el desarrollo de habilidades para la comunicación y de resolución de problemas dentro de la familia, con el objetivo de favorecer comportamientos sexuales preventivos.

Otras variables familiares que se han asociado al comportamiento sexual de los adolescentes están relacionados con la actitud de los padres respecto al sexo (Chapman y Werner-Wilson, 2008), sobre el apoyo recibido por parte de los padres (Henrich et al., 2006) y acerca de los estilos parentales y la disciplina (Vélez-Pastrana et al., 2005). 
Como se puede ver en la revisión previa, gran parte de las variables que se consideran en el Modelo Ecológico parten de los modelos de salud de corte individual; esto sugiere que no se trata de anular las propuestas ya existentes que se han elaborado, sino más bien de incluir las variables que se encuentran en un nivel individual y ampliar el foco de análisis considerando los contextos que pueden afectar o ayudar al desarrollo óptimo de la persona.

Las investigaciones que toman en cuenta el nivel macro generalmente evalúan en este nivel atributos como la raza y las diferencias de género, centrando el análisis sólo en establecer diferencias entre razas o entre hombres y mujeres; asimismo, el estatus socioeconómico es evaluado a partir de los ingresos económicos anuales. Finalmente, las investigaciones que mencionan aspectos culturales y de valores no especifican de qué manera se pueden evaluar (El-Bassel et al., 2009; Knowlton et al., 2008; Okafor y Holder, 2005).

\section{INTERVENCIÓN PARA PROMOVER LA SALUD SE- XUAl desde el Modelo Ecológico}

Desde este modelo las variables que se utilizan para generar cambios son muy similares a las que parten de otros modelos de salud, ubicándolas en un nivel individual (micro); se consideran aspectos como la autoestima y el desarrollo de habilidades (Banyard y Williams, 2007), empoderamiento (Cornish y Campbell, 2009; Trickett, 2009), información, actitudes y autoeficacia (DiClemente et al., 2007; Schaalma, Abraham, Gillmore y Kok, 2004) y toma de decisiones y resolución de problemas (ShoveIler, Johnson, Savoy y Pietersma, 2006; Trickett, 2009).

La diferencia fundamental estriba en que en este nivel no sólo se considera el entrenamiento en habilidades a partir de una simulación, sino más bien se incluye a la pareja en la intervención o se invita a la pareja que participe en alguna sesión (DiClemente et al., 2007; Pinto y McKay, 2006).

En el nivel meso a nivel familiar, las variables en que se interviene son monitoreo y supervisión parental (Banyard y Williams, 2007; DiClemente et al., 2007), y comunicación entre padres e hijos sobre sexualidad (Hutchinson, 2002; Pinto y McKay, 2006). Las investigaciones basadas en este nivel están en tres vertientes: 1) aquellas en las que sólo se interviene con los hijos; 2) en las que sólo se interviene con los padres, y 3) ambos; la postura es que se pueda trabajar tanto con padres e hijos para tener una mejor comprensión de lo que sucede en el terreno sexual, y así poder conocer qué lleva a los adolescentes a tener una conducta sexual segura (Bárcena, Robles y Díaz-Loving, 2013).
Respecto al nivel macro, se realiza el análisis en términos de la disponibilidad de los servicios de salud (Banyard y Williams, 2007; Shoveller et al., 2006), sobre las estrategias de gobierno en relación con la prevención (Berkman, Garcia, Munoz-Laboy, Paiva y Parker, 2005; Schaalma et al., 2004), disponibilidad y acceso de condones (DiClemente et al., 2007; Trickett, 2009), redes sociales y soporte social (Mooney y Sarangi, 2005; NIMH Multisite HIV/STD Prevention Trial for African American Couples Group, 2008), e influencia del grupo de pares (Pedraza, 2009; Pinto y McKay, 2006). Cabe mencionar que, dentro de estas investigaciones, la intervención que muestra evidencia empírica sólo es el soporte social, a través de la influencia del grupo de pares, demostrando que cuando se trabaja con algún líder del grupo es más probable que el resto de compañeros sigan sus pasos; a nivel institucional sólo se menciona que se deben crear campañas para prevenir la infección por $\mathrm{VIH}$; sin embargo, no reportan acciones concretas a seguir o de qué forma poder hacerlo; es por ello que dentro de este nivel se debe tener cuidado al momento de diseñar un programa de intervención que pretenda impactar en este nivel, por las múltiples condiciones que a nivel institucional no son tan fáciles de atender.

En este mismo sentido es importante hacer notar que, dentro de las intervenciones, se trata de hacer un análisis desde una visión ecológica en donde —en la medida de lo posible- se incluyan al menos dos contextos para generar una intervención; el más común es combinar algunas variables del nivel individual con variables del nivel relacional o familiar centrados sobre todo en habilidades de comunicación y negociación. Respecto al nivel comunitario y social, a pesar de que se tienen contempladas variables que van desde el grupo de amigos hasta considerar la influencia de gobierno, en general las intervenciones trabajan sobre la modificación de la norma entre pares o buscan recursos para lograr un comportamiento sexual preventivo; por ejemplo, buscar la disponibilidad de condones.

En cuanto a los efectos de las intervenciones diseñadas a partir de este enfoque, es necesario considerar que su efectividad en una población no necesariamente lo será en otra, por muy similares que éstas sean, por lo que se deben considerar el contexto cultural y el social en los que se encuentra el grupo al que se aplicará la intervención (Cornish y Campbell, 2009; Trickett, 2009).

En cuanto a la efectividad de las intervenciones, se ha encontrado que cuando se trabaja con profesores y alumnos no siempre existe una buena interacción entre éstos, lo que dificulta el proceso del programa; asimismo, el personal escolar no reconoce la severidad del 
problema, dado que existe poca motivación para llevarlos a cabo; a pesar de ello, dentro del contexto escolar los adolescentes tienden a incrementar el nivel de conocimientos, mejorar sus actitudes y a desarrollar habilidades para tener un comportamiento sexual seguro (Visser y Schoeman, 2004). Es necesario sensibilizar a los directivos y profesores acerca de la importancia de generar programas de intervención con los estudiantes, dado que se ha demostrado que sólo es una creencia suponer que si se habla de sexualidad con los jóvenes se está promoviendo una vida sexual activa; por el contrario, se ha demostrado que los adolescentes retardan su edad en el comienzo de su actividad sexual, y cuando tienen su primer encuentro es más probable que se use condón (Nagamatsu, Saito y Sato, 2008).

De igual forma, cuando se trabaja en las sesiones en conjunto con la pareja, se obtienen mejores resultados en las habilidades para usar condón en las relaciones sexuales (NIMH Multisite HIV/STD Prevention Trial for African American Couples Group, 2008), aunque no necesariamente implica que usen el condón; es por ello que se debe complementar con el cambio en el sistema de creencias respecto al uso del condón y la importancia de utilizarlo.

También se ha intentado intervenir en cuanto a qué hacen los padres y cómo su influencia repercute en la salud sexual de sus hijos; esto debido a que es en la familia en donde se transmiten valores, emociones, afectos, creencias, usos y tradiciones (Padilla y Díaz-Loving, 2013), aunado a que es el sistema primario - por el cual atraviesa toda persona y representa la influencia más temprana y duradera en el proceso de socializaciónen donde hombres y mujeres definen qué se debe hacer y cómo se debe hacer, qué está permitido y qué no (Rocha-Sánchez y Díaz-Loving, 2005). Cuando se trabaja con padres se mejora la comunicación con sus hijos y se promueve mayor supervisión y monitoreo (Pinto y McKay, 2006); esto es importante porque cuando se promueven estos comportamientos en los padres, es más probable que los hijos tengan una conducta sexual segura o que retarden la edad en que se inician sexualmente (Baptiste, Tolou-Shams, Miller, Mcbride y Paikoff, 2007; Guilamo-Ramos et al., 2006; Henrich et al., 2006).

A partir del Modelo Ecológico, se sugiere que se debe invitar a las sesiones a las personas significativas que contribuyan a que las personas tengan una conducta sexual segura; sin embargo, no siempre es posible hacerlo por cuestiones de disponibilidad de todos los involucrados. A pesar de ello, se intenta conocer a través de los usuarios qué hacen y qué piensan las personas significativas para ellos, y se desarrollan estrategias que les permitan hablar o interactuar de manera diferente; esto es a través de ofrecer los recursos para que las personas puedan tener conductas saludables en los contextos en que se encuentran (Trickett, 2009).

De este modo, se pretende que las personas encuentren redes de apoyo, que se empoderen de las acciones que realizan y que sean capaces de afrontar situaciones sexuales en las que no hay preservativos, o de buscar los medios para evitar el riesgo de infección sexual (Banyard y Williams, 2007; Mooney y Sarangi, 2005). Asimismo se pretende que las personas rastreen dentro de su comunidad cómo tener acceso a condones; que no sólo implique comprarlos, sino conseguirlos de manera gratuita en algún Centro de Salud (Cornish y Campbell, 2009); este tipo de estrategias ayuda a describir y entender qué sucede en su entorno y así analizar qué tan fácil o difícil es tener acceso a un condón, lo cual en muchas ocasiones es prácticamente imposible, sobretodo en personas muy jóvenes a quienes se les llega a negar el servicio.

Las intervenciones enfocadas en la prevención del $\mathrm{VIH} / \mathrm{SIDA}$ desde una perspectiva ecológica son pocas; la compilación que se presentó con antelación incluye algunos estudios de corte empírico, pero en general son propuestas teóricas que delimitan qué aspectos se deben contemplar en los programas de intervención; sin embargo, no reportan resultados que demuestren su efectividad.

A pesar de que retoman la idea central del Modelo Ecológico, en la cual se debe estudiar al individuo desde diferentes niveles, no mencionan propiamente el nivel micro, meso, exo y macro; más bien las variables que consideran las dividen en cuatro grupos: nivel individual, nivel relacional, nivel familiar y nivel comunitario o social.

\section{CONCLUSIONES}

En la revisión de las investigaciones presentadas se aprecia que las variables que se consideran en el Modelo Ecológico para la evaluación e intervención parten de los modelos de salud de corte individual, por lo que desde este modelo se deben incluir variables de otros modelos que han demostrado ser efectivos, pero con la condición de tomarlos dentro de un contexto social (Schaalma et al., 2004). Esto debido a que los problemas no son inherentes a las personas, sino que se presentan en un contexto social, esto es, en ocasiones el medio dificulta que las personas realicen conductas sexuales protegidas (Cornish y Campbell, 2009).

A pesar de incluir variables de otros modelos, no se debe olvidar que incrementar el grado de información y cambiar el sistema de creencias es necesario, pero no suficiente, por lo que se debe incidir en el desarrollo de habilidades conductuales considerando el contexto en 
que ocurren para su evaluación e intervención, e incluso considerar técnicas tanto cuantitativas como cualitativas (Shoveller et al., 2006).

Para tener éxito en las intervenciones se deben crear contextos sociales y políticos para promover la salud sexual (Berkman et al., 2005), pero reconociendo que no tan fácil se pueden cambiar las normas sociales y políticas; pese a ello, se debe hacer lo posible por integrar contextos más amplios (Schensul y Trickett, 2009), siempre enfatizando la interacción de los contextos significativos vinculados al comportamiento. Considerando lo anterior, los programas de intervención deben incluir a más de dos personas relacionadas con la conducta; por ejemplo, la pareja (Schensul y Trickett, 2009) o los padres (Guilamo-Ramos et al., 2006) para propiciar cambios no sólo en el individuo sino en la interacción que establece con ellos.

Como se ha evidenciado, la inclusión de variables a nivel relacional en los diferentes contextos es uno de los grandes aportes del Modelo Ecológico, pero hasta el momento la mayor evidencia es teórica, sobre todo en el ámbito de la evaluación, por lo que es necesario generar líneas de investigación que permitan someter estas propuestas a prueba empírica.

En un primer momento, para identificar cuáles son las variables que se deben evaluar y cómo evaluarlas, y segundo, para conocer qué estrategias se deben emplear en función de los diferentes contextos e individuos involucrados en los programas de intervención que permitan evidenciar cómo se generan los cambios en el comportamiento.

Por ejemplo, habilidades que permitan a los participantes buscar en su comunidad los recursos sociales (Labbok, 2008), reconociendo las diferencias culturales, con el objetivo de proporcionar herramientas para enfrentar a su medio, y que éste no obstaculice el comportamiento preventivo (Stephenson, 2009).

Una de las ventajas de esta revisión es que ofrece un panorama amplio de las variables que componen al modelo, y si bien es dificil intervenir en todas las variables, es necesario contar con información acerca de la totalidad de las variables que definen al modelo para tener un sustento conceptual congruente con la teoría con la cual se esté trabajando (Robles y Diaz-Loving, 2011).

Si bien durante la revisión teórica presentada se aborda el Modelo Ecológico con la conducta sexual, se busca que se puedan atender otras problemáticas para contribuir a la promoción de la salud y la prevención de la enfermedad.

\section{RefERENCIAS}

Abrams, K., Theberge, S. K., y Karan, O. C. (2005). Children and Adolescents Who Are Depressed: An Ecological Approach. Professional School Counseling, 8(3), 284.

Ajzen, I. (1985). Recuperado de intentions to actions: a theory of planned behavior. En J. Kuhl y J. Beckman (eds.), Action control form cognition to behavior (pp. 11-39). Nueva York: Springer-Verlag.

Ajzen, I., y Fishbein, M. (1980). Understanding attitudes and predicting social behavior. Nueva York: Prentice-Hall.

Auerbach, J., y Coates, T. (2000). HIV prevention research: accomplishments and challenges for the third decade of AIDS. The American Journal of Public Health, 90(7), 10291032.

Ayoola, A. B., Nettleman, M., y Brewer, J. (2007). Reasons for Unprotected Intercourse in Adult Women. Journal of Women's Health, 16(3), 302-310.

Bandura, A. (1999). Autoeficacia: cómo afrontamos los cambios de la sociedad actual. España: Desclée de Broker.

Banyard, V. L., y Williams, L. M. (2007). Adolescent survivors of sexual abuse: developmental outcomes. Prevention Researcher, 14(2), 6-10.

Baptiste, D., Tolou-Shams, M., Miller, S., Mcbride, C., y Paikoff, R. (2007). Determinants of parental monitoring and preadolescents sexual risk situations among African American families living in urban public housing. Journal of Child and Family Studies(16), 261-274.

Bárcena, S., Robles, S., y Díaz-Loving, R. (2013). El Papel de los padres en la salud sexual de sus hijos. Acta de Investigación Psicológica, 3(1), 956-968.

Berkman, A., Garcia, J., Munoz-Laboy, M., Paiva, V., y Parker, R. (2005). A Critical Analysis of the Brazilian Response to HIV/ AIDS: Lessons Learned for Controlling and Mitigating the Epidemic in Developing Countries. American Journal of Public Health, 95(7), 1162-1172.

Brendgen, M., Wanner, B., y Vitaro, F. (2007). Peer and teacher effects on the early onset of sexual intercourse. American Journal of Public Health, 97(11), 2070-2075.

Bronfenbrenner, U. (1987). La ecología del desarrollo humano. Experimentos en entornos naturales y diseñados. Barcelona: Paidós.

Catania, J., Kegeles, S., y Coates, T. (1990). Towards an understanding of risk behavior: an AIDS risk reduction model (ARRM). Health Education, 17, 53-72.

Chapman, E. N., y Werner-Wilson, R. J. (2008). Does positive youth development predict adolescent attitudes about sexuality? Adolescence, 43(171), 505-523.

Corcoran, J., y Franklin, C. (2002). Multi-systemic risk factors predicting depression, self-esteem, and stress in low SES and culturally diverse adolescents. Journal of Human Behavior in the Social Environment, 5(2), 61-76.

Corcoran, J. (2001). Multi-Systemic Influences on the Family Functioning of Teens Attending Pregnancy Prevention Programs. Child \& Adolescent Social Work Journal, 18(1), 37-49.

Cornish, F., y Campbell, C. (2009). The social conditions for successful peer education: A comparison of two HIV 
prevention programmes run by sex workers in India and South Africa. American Journal of Community Psychology, 44(1-2), 123-135.

Díaz-Guerrero, R. (1994). Premisas socioculturales, actitudes e investigación transcultural. En Psicología del mexicano (pp. 116-128). México: Trillas.

DiClemente, R., Salazar, L., y Crosby, R. (2007). A review of STD/ HIV preventive interventions for adolescents: Sustaining effects using an ecological approach. Journal of Pediatric Psychology, nil(nil), 1-19.

El-Bassel, N., Caldeira, N. A., y Ruglass, L. M. (2009). Addressing the Unique Needs of African American Women in HIV Prevention. [Feature]. American Journal of Public Health, 99(6), 996-1001.

Enríquez, D. y Sánchez, R. (2015). Patrón de comportamiento sexual en estudiantes universitarios: diferencias de género en el comportamiento sexual. En G. García y O. Cruz. Los retos de la Psicología en la sociedad contemporánea. México: Colección Montebello, UNICACH. 159-166.

Enríquez, J., Sánchez, A. y Robles, J. (2011). Teorías y modelos psicológicos sobre el estudio de la salud sexual. México: UNAM.

Fishbein, M. (2000). The role of theory in HIV prevention. AIDS Care, 12(3), 273-278.

Fisher, J., y Fisher, W. (1992). Changing AIDS-risk behavior. Psychological Bulletin, 3(3), 455-474.

González, J. (2009). Conocimientos, actitudes y prácticas sobre la sexualidad en una población adolescente escolar. Revista de Salud Pública, 11(1), 14-26.

Guilamo-Ramos, V., Dittus, P., Jaccard, J., Golberd, V., Casillas, E., y Bouris, A. (2006). The content and process of motheradolescent communication about sex in latino families. Social Work Research, 30(3), 169-181.

Henrich, C. C., Brookmeyer, K. A., Shrier, L. A., y Shahar, G. (2006). Supportive Relationships and Sexual Risk Behavior in Adolescence: An Ecological-Transactional Approach. Journal of Pediatric Psychology, 31(3), 286-297.

Hilarski, C. (2006). Exploring Predictive Factors for Substance Use in African American and Hispanic Youth Using an Ecological Approach. Journal of Social Service Research, 32(1), 65-86.

Hutchinson, K. (2002). The influence of sexual risk communication between parents and daughters on sexual risk behaviors. Family Relations, 51(3), 238-247.

Jones, D., Heflinger, C., y Saunders, R. (2007). The ecology of adolescent substance abuse service utilization. American Journal of Community Psychology, 40, 345-358.

Kim, S. (2007). Gender matters: Towards an ecological model of HIV/AIDS education. Estados Unidos: Stanford University.

Knowlton, A., Buchanan, A., Wissow, L., Pilowsky, D. J., y Latkin, C. (2008). Externalizing Behaviors among Children of HIV Seropositive Former and Current Drug Users: Parent Support Network Factors as Social Ecological Risks. [Feature]. Journal of Urban Health, 85(1), 62-76.

Labbok, M. (2008). Transdisciplinary breastfeeding support: creating program and policy synergy across the reproductive continuum. International Breastfeeding Journal, 3(16), 1-8.
Liles, R. G., y Juhnke, G. A. (2008). Adolescent Diabetic Control: Using the Process-Person-Context-Time Model. Journal of Counseling \& Development, 86(1), 75-84.

Mooney, A., y Sarangi, S. (2005). An ecological framing of HIV preventive intervention: a case study of non-government organizational work in the developing world. Health: An Interdisciplinary Journal for the Social Study of Health, Illness and Medicine, 9(3), 275-296.

Nagamatsu, M., Saito, H., y Sato, T. (2008). Factors associated with gender differences in parent-adolescent relationships that delay first intercourse in Japan. The Journal of School Health, 78(11), 601-607.

NIMH Multisite HIV/STD Prevention Trial for African American Couples Group (2008). Eban HIV/STD Risk Reduction Intervention: Conceptual Basis and Procedures. Journal of Acquired Immune Deficiency Syndromes 49(1), 15254135.

Okafor, C. B., y Holder, B. (2005). HIV/AIDS Related Stigma in SubSaharan Africa: Context and Consequences. [Feature]. Journal of Development Alternatives and Area Studies, 24(3/4), 131-152.

Padilla, N., y Díaz-Loving, R. (2013). Premisas familiares y socioculturales del emparejamiento. Enseñanza e Investigación en Psicología, 18(2), 249-262.

Padilla, M. B., Guilamo-Ramos, V., y Bouris, A. (2010). HIV/AIDS and Tourism in the Caribbean: An Ecological Systems Perspective. [Feature]. American Journal of Public Health, 100(1), 70-77.

Pedraza, A. (2009). A Quasi-Experimental Evaluation of a Community-Based HIV Prevention Intervention for Mexican American Female Adolescents: The Shero's Program. AIDS Education and Prevention, 21(1), 109-123.

Pinto, R. M., y McKay, M. M. (2006). A mixed-method analysis of African-American women's attendance at an HIV prevention intervention. Journal of Community Psychology, 34(5), 601-616.

Ribes, E. (1990). Psicología y salud: un análisis conceptual. España: Martínez Roca.

Robles, S. y Díaz-Loving, R. (2011). Validación de la Encuesta Estudiantil sobre Salud Sexual (EESS). México: Facultad de Estudios Superiores Iztacala.

Rocha-Sánchez, T., y Díaz-Loving, R. (2005). Cultura de género: la brecha ideológica entre hombres y mujeres. Anales de Psicología, 21(1), 42-49.

Rosentock, I., Strecher, V., y Becker, M. (1994). The Health Belief Model and HIV Risk Behaviour Change. En R. DiClemente y J. Peterson (eds.), Preventign AIDS: theories and methods of behavioral interventions (pp. 5-24). Nueva York: Plenum Press.

Sánchez, R.y Robles, S. (2014). Apoyo, supervisión y comunicación con padres y su relación con el comportamiento sexual de jóvenes en conflicto con la ley. Acta de Investigación Psicológica, 4 (1), 1398-1411.

Schaalma, H., Abraham, C., Gillmore, M., y Kok, G. (2004). Sex education as health promotion: What does it take? Archives of Sexual Behavior, 33(3), 259-269.

Schensul, J., y Trickett, E. (2009). Introduction to multi-level community based culturally situated interventions. Am J Community Psychol, 43, 232-240. 
Shoveller, J., Johnson, J., Savoy, D., y Pietersma, W. A. W. (2006). Preventing sexually transmitted infections among adolescents: an assessment of ecological approaches and study methods. Sex Education: Sexuality, Society and Learning, 6(2), 163-183.

Stephenson, R. (2009). Community influences on young people's sexual behavior in 3 African countries. The American Journal of Public Health, 99(1), 102-109.

Trickett, E. (2009). Multilevel community-based culturally situated interventions and community impact: An ecological perspective. Am J Community Psychol, 43(257266).

Van Horne, B. S., Wiemann, C. M., y Berenson, A. B. (2009). Multilevel Predictors of Inconsistent Condom Use Among Adolescent Mothers. [Feature]. American Journal of Public Health, 99(S2), 417-424.

Vargas, E., y Barrera, F. (2002). Adolescencia, relaciones romanticas y actividad sexual: Una revisión. Revista Colombiana de Psicología (11), 115-134.
Vélez-Pastrana, M., González-Rodríguez, R., y BorgesHernández, A. (2005). Family functioning and early onset of sexual intercourse in latino adolescents. Adolescence, 40(160), 777-791.

Visser, M. J., y Schoeman, J. B. (2004). Implementing a community intervention to reduce young people's risks for getting HIV: Unraveling the complexities. Journal of Community Psychology, 32(2), 145-165.

Voisin, D. R., DiClemente, R. J., Salazar, L. F., Crosby, R. A., y Yarber, W. (2006). Ecological Factors Associated with STD Risk Behaviors among Detained Female Adolescents. Social Work, 51(1), 71-79.

Wells, N., y Olson, C. (2006). The ecology of obesity: Perspectives from life course, design, and economics. Journal of Hunger \& Environmental Nutrition, 1(3), 99-129. 


\section{Meta-Análisis del Artículo}




\section{Dimensión Cuantitativa}

\section{Perfil de Evaluación entre pares}
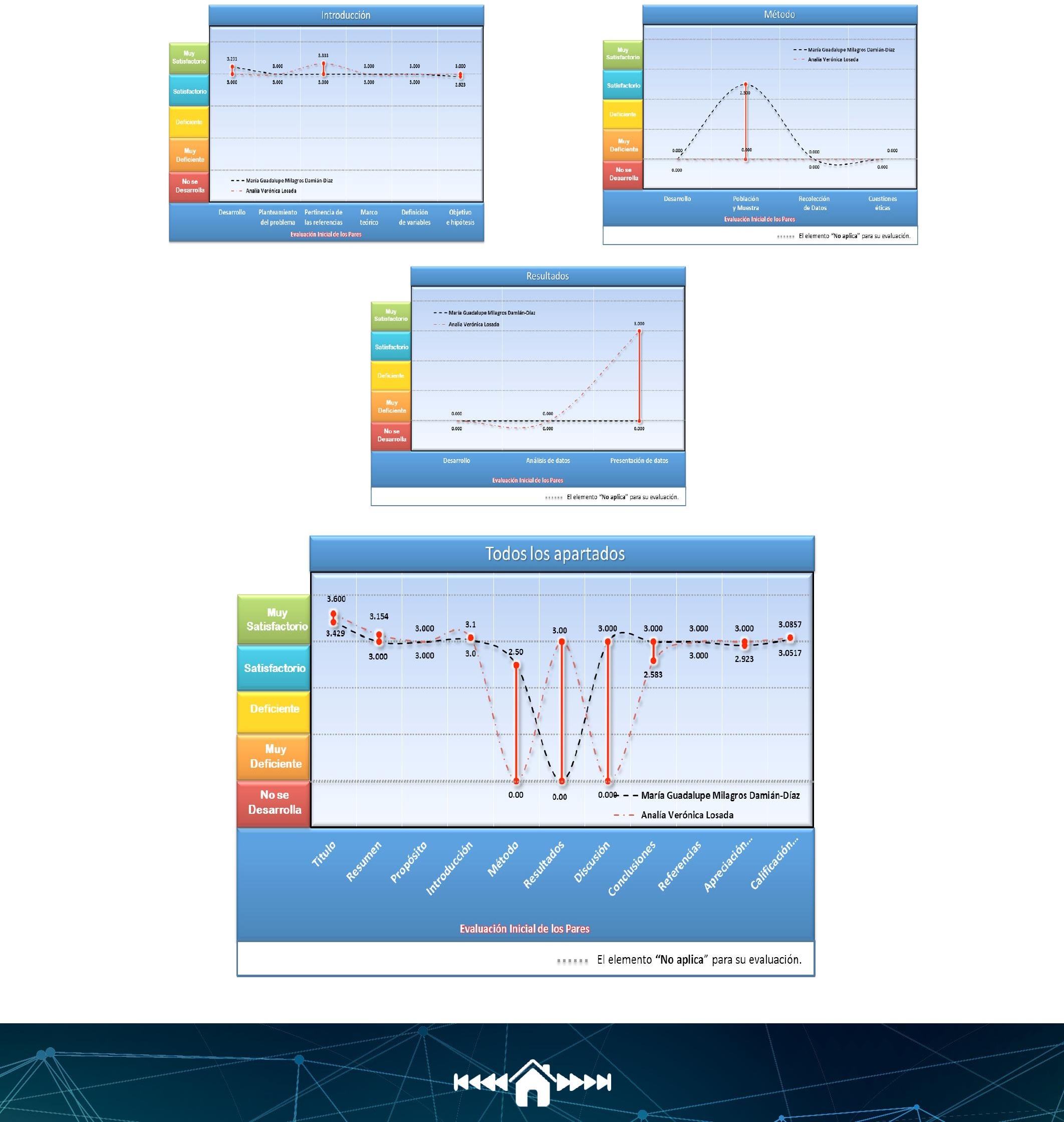


\section{Índice de Concordancia}

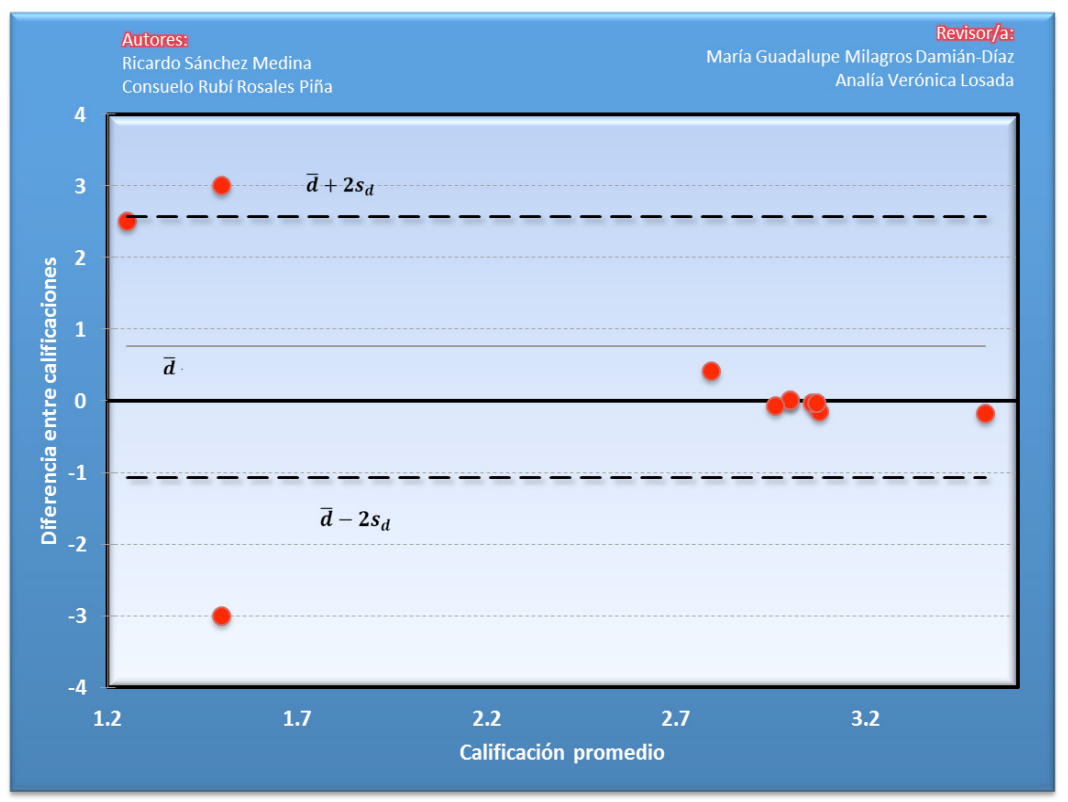

Índice de Acuerdo
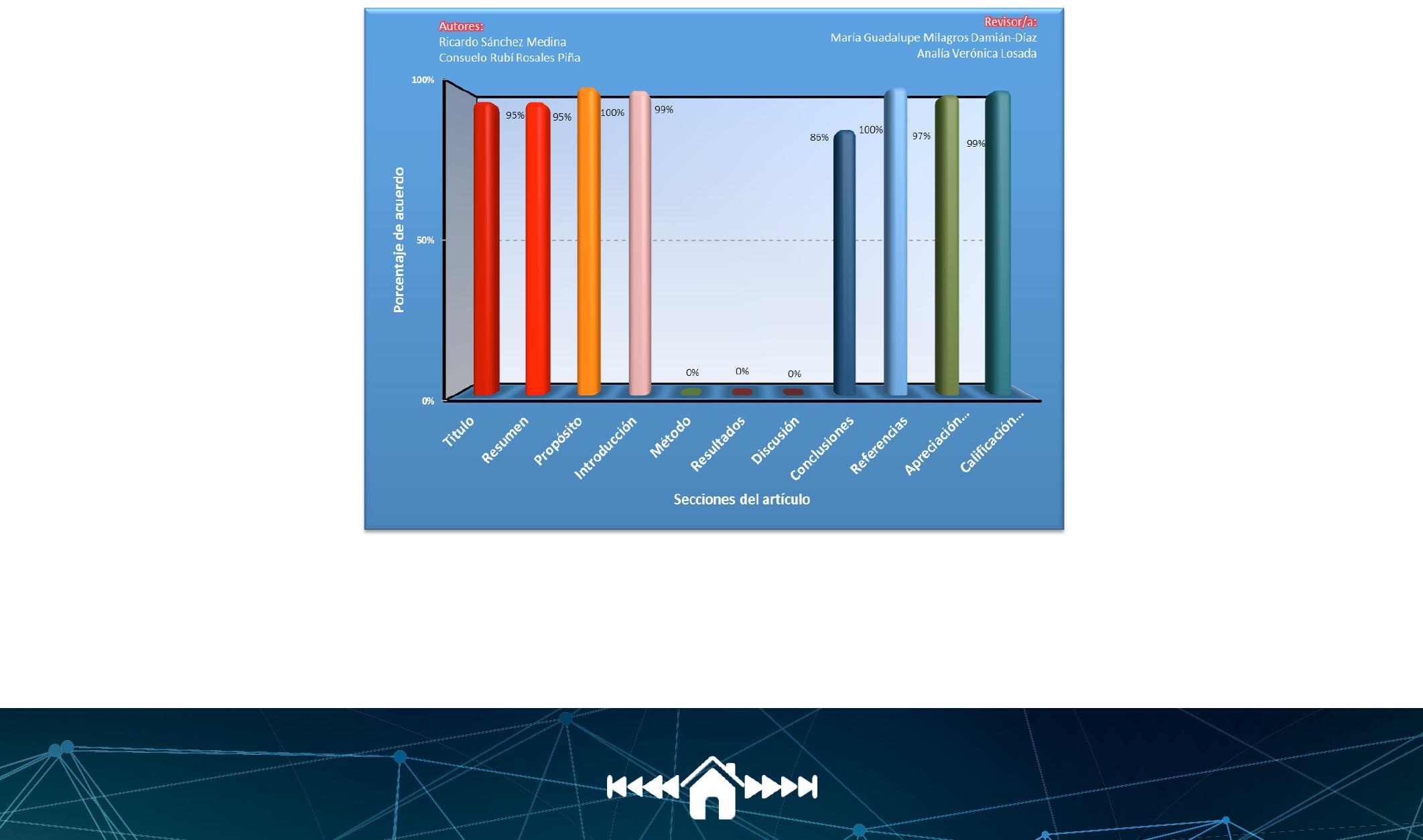
Dimensión Cualitativa

\begin{tabular}{|c|c|}
\hline Revisor 1 & Revisor 2 \\
\hline María Guadalupe Milagros Damián-Díaz & Analía Verónica Losada \\
\hline \multicolumn{2}{|c|}{ Título/Autoría } \\
\hline Es comprensible y corto el titulo. & No tengo. \\
\hline \multicolumn{2}{|c|}{ Resumen } \\
\hline Es concreto y correcto. & No poseo. \\
\hline \multicolumn{2}{|c|}{ Próposito del Estudio } \\
\hline Es breve pero consiso. & El propósito es claro. \\
\hline \multicolumn{2}{|c|}{ Introducción } \\
\hline $\begin{array}{l}\text { No mencionan muchos objetivos a realizar, más bien } \\
\text { justifica lo importante del modelo a trabajar, se hace } \\
\text { una extensa indagación de formas y variables de dife- } \\
\text { rentes y cada modelo, y se describen lo vulnerable y } \\
\text { fortaleces que puede pudiesen tener. }\end{array}$ & $\begin{array}{l}\text { Debe eliminar la primera persona por ejemplo cuando } \\
\text { cita "vemos", y pasar al estilo impersonal. También elimi- } \\
\text { nar los paréntesis para aclaraciones y solo usarlos para au- } \\
\text { tores y años. }\end{array}$ \\
\hline \multicolumn{2}{|c|}{ Método } \\
\hline $\begin{array}{l}\text { Es un análisis descriptivo de una propuesta de un modelo } \\
\text { ecológico. }\end{array}$ & No aplica. \\
\hline \multicolumn{2}{|c|}{ Resultados } \\
\hline $\begin{array}{l}\text { La implementación del estudio aún no se realiza, sola- } \\
\text { mente se describen pros y contras de diferentes modelos } \\
\text { de intervención, son justificaciones importantes para to- } \\
\text { mar en cuenta en su configuración e implementación. }\end{array}$ & No aplica. \\
\hline \multicolumn{2}{|c|}{ Discusión } \\
\hline $\begin{array}{l}\text { A hacer una revisión de modelos se discuten los resul- } \\
\text { tados propios de cada modelo y los resultados de los } \\
\text { estudios que realizaron. }\end{array}$ & No aplica. \\
\hline \multicolumn{2}{|c|}{ Conclusiones } \\
\hline $\begin{array}{l}\text { Presentan conclusiones de estudios de los modelos } \\
\text { tratados no conclusiones de estudios empíricos con el } \\
\text { modelo propuesto por los autores. }\end{array}$ & No tiene futuras líneas de investigacion. \\
\hline \multicolumn{2}{|c|}{ Referencias } \\
\hline $\begin{array}{l}\text { La busqueda es satisfactoria y justificable para el objeti- } \\
\text { vo planteado por los autores. }\end{array}$ & Son correctas. \\
\hline
\end{tabular}




\title{
El QUEHACER DEL PROFESIONAL DE LA PSICOLOGÍA DE LA SALUD: DEFINICIONES Y OBJETIVOS
}

\author{
Laura Edith Pérez-Laborde y Liliana Moreyra-Jiménez \\ FES Iztacala, UNAM \\ México
}

\section{RESUMEN}

La psicología de la salud es un campo de aplicación que surgió como respuesta ante la necesidad de comprender los factores psicológicos involucrados en el proceso de salud-enfermedad con el objetivo de generar acciones efectivas de promoción de la salud y prevención de la enfermedad. Se han hecho múltiples propuestas para definirla, creado o adaptado diversos modelos teóricos y herramientas para responder a sus objetivos. Sin embargo, en la práctica se suele confundir con otras áreas de la psicología. El presente trabajo pretende clarificar el quehacer del profesional de la psicología de la salud respecto a los elementos fundamentales que la definen y constituyen, se revisan sus objetivos, los niveles de intervención preventiva, los campos de acción y las diferencias entre psicología de la salud y otras áreas. Todo ello con la intención de facilitar su comprensión a quienes se interesen en el estudio de esta área de aplicación.

\section{Palabras Clave:}

Psicología de la salud, promoción de la salud, prevención de la enfermedad, modelos en psicología de la salud, competencias en psicología de la salud.

\section{THE WORK OF THE HEALTH PSYCHOLOGY PROFESSIONAL: DEFINITIONS AND OBJECTIVES}

\begin{abstract}
Health psychology is a field of application that emerged as a response to the need to understand the psychological factors involved in the disease health process in order to generate effective actions for health promotion and disease prevention. There have been multiple proposals to define it and created or adapted various theoretical models and tools to respond to its objectives. However, in practice it is often confused with other areas of psychology. This paper aims to clarify the work of the health psychology professional with respect to the fundamental elements that define and constitute it, review its objectives, the levels of preventive intervention, the fields of action and the differences between health psychology and other areas. All this with the intention of facilitating their understanding to those who are interested in the study in this area of application.
\end{abstract}

Keywords:

Health psychology, health promotion, disease prevention, models in health psychology, competencies in health psychology.

Bitácora del Artículo:

| Recibido: 1 de Agosto de 2017 | Aceptado: 1 Septiembre de 2017 | Publicado en línea: Julio-Diciembre de 2017 | 


\title{
Autoría y Derechos de Propiedad Intelectual
}

\section{EL QUEHACER DEL PROFESIONAL DE LA PSICOLOGÍA DE LA SALUD: DEFINICIONES Y OBJETIVOS}

\author{
Laura Edith Pérez-Laborde y Liliana Moreyra-Jiménez \\ FES Iztacala, UNAM \\ México
}

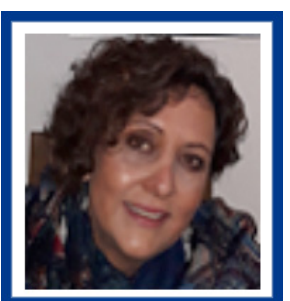

Laura Edith Pérez-Laborde

FES Iztacala, UNAM

Correo: edith.perez@ired.unam.mx

Licenciada y maestra en Psicología por la UNAM con residencia en terapia familiar sistémica. Profesora de asignatura en la licenciatura en Psicología a Distancia (SUAYED) en el área de Psicología de la Salud, jefa de Claustro en Procesos en Psicología de la Salud, docente y supervisora en la maestría en Psicología, Ver más...

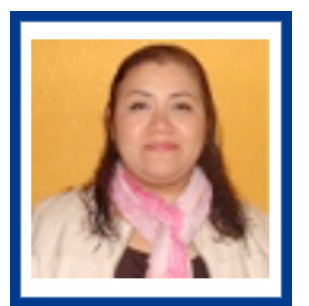

Liliana Moreyra-Jiménez FES Iztacala, UNAM

Correo: liliana.moreyra@ired.unam.mx

Profesora de la licenciatura en Psicología a Distancia en la Facultad de Estudios Superiores Iztacala (SUAyED-UNAM) de las áreas en Psicología de la Salud y Psicología Clínica. Licenciada en Psicología por la Facultad de Psicología de la UNAM.

Ver más...

\section{CONTRIBUCIÓN DE LAS AUTORAS}

Laura Edith Pérez-Laborde coordinó la integración del documento, construyó el esquema y participó en la redacción del artículo, I Liliana Moreyra-Jiménez participó en la redacción del artículo

\section{AGRADECIMIENTOS}

[Agradecimiento por parte de los autores a intituciones, personas, etc. participantes en el estudio.]

\section{DATOS de FiLIACIÓN DE LAS Autoras}

Sistema de Univeridad Abierta y Educación a Distancia, Facultad de Estudios Superiores Iztacala, UNAM.

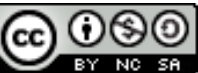

Copyright: @ 2017 Pérez-Laborde, L. E. \& Moreyra-Jiménez, L.

Este es un artículo de acceso abierto distribuido bajo los términos de la licencia Creative Commons Reconocimiento-NoComercial-Compartirlgual 4.0 Internacional, por lo que su contenido gráfico y escrito se puede compartir, copiar y redistribuir total o parcialmente sin necesidad de permiso expreso de sus autoras con la única condición de que no se puede usar con fines directamente comerciales y los términos legales de cualquier trabajo derivado deben ser los mismos que se expresan en la presente declaración. La única condición es que se cite la fuente con referencia a la Revista Digital Internacional de Psicología y Ciencia Social y a sus autoras. 


\section{TABLA DE CONTENIDO}

INTRODUCCIÓN

MÉTODO

Diseño., 6

Participantes., 6

Instrumento., 7

Procedimiento., 7

Resultados, 7

CONCLUSIONES

Discusión

REFERENCIAS

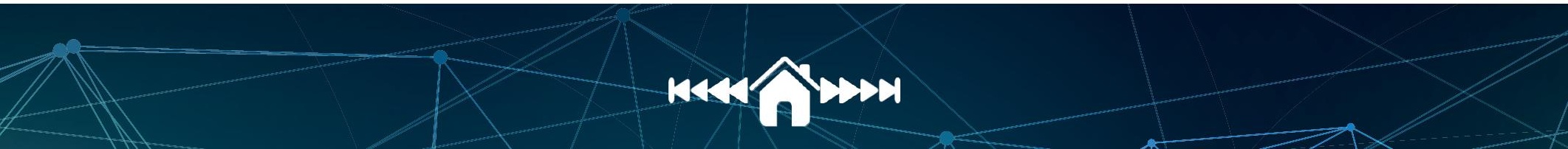




\section{INTRODUCCIÓN}

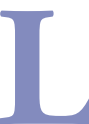

a salud había sido entendida, durante muchos siglos, como la ausencia de enfermedad, pero en 1974 la Organización Mundial de la Salud (OMS) declaró que esta forma de concebirla limitaba la comprensión acerca de su complejidad y su abordaje, de modo que la definió desde entonces como "el completo bienestar físico, mental y social y no simplemente como la ausencia de dolencias o enfermedades" (Oblitas, 2008: 222). Esta nueva concepción de la salud impulsó no sólo un cambio conceptual, sino que abrió la perspectiva respecto a los retos profesionales que implicaba.

La salud había sido entendida, durante muchos siglos, como la ausencia de enfermedad, pero en 1974 la Organización Mundial de la Salud (OMS) declaró que esta forma de concebirla limitaba la comprensión acerca de su complejidad y su abordaje, de modo que la definió desde entonces como "el completo bienestar físico, mental y social y no simplemente como la ausencia de dolencias o enfermedades" (Oblitas, 2008: 222). Esta nueva concepción de la salud impulsó no sólo un cambio conceptual, sino que abrió la perspectiva respecto a los retos profesionales que implicaba.

La psicología de la salud es un campo de conocimiento de la Psicología que comenzó su desarrollo en la década de los setenta como respuesta ante la necesidad de abordar el proceso de salud-enfermedad de los seres humanos desde una nueva visión integradora respecto a los elementos biológicos, psicológicos y sociales que intervienen en ella, colaborando con otras disciplinas científicas en su esfuerzo por mejorar la calidad de vida y disminuir la exposición ante diversos riesgos para la salud, específicamente los que provienen de factores psicológicos, emocionales, cognitivos, conductuales y relacionales del propio individuo (Oblitas, 2008).

Este campo ha avanzado notablemente respecto a la construcción de sus propios modelos, la comprensión de los aspectos involucrados en el comportamiento saludable y no saludable, así como las estrategias de intervención que la diferencian de otras áreas de la Psicología; sin embargo, en la práctica aún falta camino por recorrer respecto a la comprensión de lo que se aporta en el campo profesional.

Piña, Sánchez, García, Ybarra y García (2013) señalan tres aspectos que aún representan un reto para el profesional de la Psicología. El primero, fundamental, es el hecho de que la psicología de la salud no está siendo considerada en los marcos normativos en materia de atención a la salud, ya que se considera un asunto de competencia médica casi exclusivamente; el segundo es que los esfuerzos para intervenir de manera interdisciplinaria se consolidan desde las instituciones de salud, colocando a la medicina como el eje de las acciones en las que la prevención tiene poco o nulo lugar. El tercer aspecto es que la formación académica del profesional que interviene desde la psicología de la salud, salvo algunas excepciones, aún es deficiente y no proporciona los conocimientos teórico-metodológicos suficientes ni entrena las competencias necesarias para hacer intervenciones congruentes con los objetivos y herramientas de esta área.

En una revisión de planes de estudio de la licenciatura en Psicología en México (Universidad Autónoma Metropolitana, Universidad Iberoamericana, Universidad del Valle de México y Universidad Autónoma de Puebla, por mencionar algunos) se observa que no todos los programas contemplan el área de psicología de la salud, y en algunos casos, como en los programas presenciales de las diferentes facultades de la Universidad Nacional Autónoma de México (UNAM), se considera como área clínica y de la salud; sólo la licenciatura a distancia contiene en su plan de estudios el área de psicología de la salud como un campo de profundización (UNAM, 2012). La Universidad de Sonora, en cambio, ofrece una licenciatura en Psicología de la Salud, y la Universidad de Guadalajara tiene un programa de maestría en esta área. En Cuba se incluye como una asignatura en la carrera de medicina.

Lo anterior resulta relevante porque la mayoría de los psicólogos insertos en instituciones donde cumplen funciones propias de la psicología de las salud no tienen formación académica en esta área, o su formación no les dota de suficientes competencias específicas (Piña et al., 2013).

También se ha observado que quienes se encuentran trabajando en este campo no se definen a sí mismos como psicólogos de la salud ni identifican sus intervenciones como acciones propias de este campo. En otros casos se percibe una gran confusión respecto a qué acciones se pueden realizar para responder a los objetivos de la psicología de la salud y con qué estrategias, de modo que, aún teniendo la intención de efectuar una intervención en esta área, se hace en realidad desde otro dominio de la Psicología (Piña et al., 2013).

Además, las instituciones de salud en México contratan profesionales de la Psicología con formación clínica, en tanto la Norma Oficial Mexicana (2015) ${ }^{1}$ así lo establece

1 La Secretaría de Salud (2015) crea la Norma Oficial Mexicana NOM-025-SSA2-2014, para la prestación de servicios de salud en unidades de atención integral hospitalaria médico-psiquiátrica que define la atención psicológica como: 4.1.4 Atención Psi- 
al describir la atención psicológica, aunque en el perfil se incluyen acciones propias de la psicología de la salud.

Entonces si una intervención tiene un efecto positivo en la persona o grupo con el que se trabaja podría no ser importante mezclar la psicología clínica con la psicología comunitaria y la medicina conductual; sin embargo, no puede considerarse que eso resulte productivo en lo que respecta al desarrollo teórico metodológico de esta área y a la comprensión de sus objetivos y estrategias particulares; mucho menos para clarificar el perfil profesional que, en términos de competencias, debería tener (Arco \& Fernández, 2002; Piña et al., 2013).

Bajo esta perspectiva se pretende clarificar los elementos que delimitan el quehacer específico del profesional de la psicología de la salud en los diversos contextos donde se inserta y el enfoque de las intervenciones que realiza que la definen como tal.

\section{Objeto de estudio de la psicología de la}

\section{SALUD}

A lo largo de los últimos años se han escrito diversas definiciones de psicología de la salud, cada una de ellas enfatizando aspectos distintos; se muestran aquí las que se consideran más representativas de la forma como se entiende actualmente el objeto de estudio de esta área.

La psicología de la salud es el campo de especialización de la psicología que centra su interés en el ámbito de los problemas de salud, especialmente físicos y orgánicos, con la principal función de prevenir la ocurrencia de los mismos o de tratar o de rehabilitar éstos en caso de que tengan lugar, utilizando para ello metodología, los principios y conocimientos de la actual psicología científica sobre la base de que la conducta constituye, junto con las causas biológicas y sociales, los principales determinantes tanto de la salud como de la mayor parte de las enfermedades y problemas humanos de la salud existentes en la actualidad (Carrobles, 1993, apud Gómez, 2007: 163).

La suma de contribuciones profesionales, científicas y educativas específicas de la psicología como disciplina, para la promoción y mantenimiento de la salud, la prevención y tratamiento de la enfermedad, la identificación de los correlatos etiológicos y diagnósticos de la salud, la enfer-

cológica: Es la atención especializada brindada por un psicólogo clínico que trata diferentes trastornos mentales y del comportamiento y problemáticas de salud mental utilizando psicoterapia y otros recursos terapéuticos dependiendo de la severidad de la patología. La atención psicológica difiere de acuerdo al tipo de unidad de atención de salud mental, si es de primer nivel donde se hacen detecciones de casos, psicoeducación y actividades preventivas; las unidades de segundo nivel atienden casos de forma ambulatoria, el tercer nivel atiende a personas que están en hospitalización o en alguna unidad comunitaria de rehabilitación psicosocial. medad y la disfunción asociada, además del mejoramiento del sistema sanitario y la formulación de una política de la salud (Matarazzo, 1980, apud Labiano, 2010: 15).

Un conjunto de contribuciones científicas y profesionales (investigación, evaluación, intervención, formación y gestión) de la psicología relativas a la promoción y acrecentamiento de la salud y a la prevención, tratamiento y rehabilitación de la enfermedad, así como análisis y mejora del sistema sanitario y de las políticas de salud, y consistentes en la investigación de la importancia de los aspectos comportamentales en la preservación de la salud (y generación, mantenimiento o eliminación de la enfermedad) y la elaboración y aplicación de programas destinados al control o modificación de los mismos (Godoy, 1999, apud Gómez, 2007: 165).

Las autoras coinciden con la definición de Gómez (2007) ya que sintetiza todos los elementos implicados en el campo de la Psicología de la Salud y señala las acciones profesionales con que se puede intervenir. Es así que esta área surgió como una necesidad de abordaje de algunos aspectos de la salud y de los procesos de enfermedad de las personas, aporta también elementos para mejorar el sistema sanitario que no estaban considerados por el modelo biomédico, ya que éste ha dirigido su atención hacia procesos biofísicos de la enfermedad y ha ignorado los aspectos psicológicos y sociales que inciden en ella, para dar prioridad a la visión curativa sobre la preventiva y enfocar sus intervenciones en la prolongación de los años de vida y no en la calidad de la misma.

En la década de los setenta surgió el modelo biopsicosocial como alternativa al biomédico e introdujo una mirada ampliada respecto a las necesidades y retos individuales, institucionales y sociales relativos a la salud. Desde el campo de la Psicología de la Salud, que adopta la visión del modelo biopsicosocial, se ofrecen nuevas explicaciones y alternativas de intervención ante el aumento de enfermedades crónico-degenerativas así como una comprensión más amplia de la responsabilidad de cada persona en el desarrollo de las enfermedades que padece y el modo en que las afronta (Grau \& Hernández, 2005).

El modelo biomédico se sustenta en la idea de que se tiene salud cuando no se padece ninguna enfermedad; el modelo biopsicosocial plantea que tanto la salud como la enfermedad son procesos influenciados por aspectos biológicos, psicológicos y sociales, lo que propone que la salud se encuentra en estrecha relación con el bienestar experimentado por un individuo en la esfera biológica, psicológica y social, y más recientemente con la calidad de vida; ambos conceptos aluden a aspectos subjetivos que provienen del propio individuo, asumiendo que están vinculados directamente con su estado de salud física (Juárez, 2011). 
Desde este nuevo enfoque se cuestiona el papel pasivo y receptor de la persona enferma, tanto en lo que concierne a su padecimiento como en su tratamiento. Incluso podría afirmarse que estas formas de comprender la salud y la pérdida de ésta visualizan al individuo integralmente, en interacción, de forma sistémica, con todas las esferas que le rodean y conforman. El modelo biopsicosocial sustenta esta visión, contemplando que existen múltiples factores que inciden en el estado de salud, en su deterioro y su recuperación, de modo que no debe esperarse a que una persona enferme para atenderlo porque se pueden generar acciones de prevención, si se comprenden y abordan las variables involucradas que, de manera amplia y de acuerdo con Labiano (2010) son las siguientes.

1. Situacionales: factores que incrementan, disminuyen o eliminan conductas saludables, como son las redes de apoyo, el acceso a la información, los factores económicos y los modelos sociales de comportamiento relacionado con la salud, tanto del entorno inmediato como los promovidos culturalmente.

2. Personales: factores que influyen en la aceptación y sostenimiento de patrones saludables a partir de las creencias, la motivación y las expectativas.

3. Consecuencias anticipadas: se refieren a la percepción subjetiva de la persona acerca de los costos o beneficios que conlleva la adopción de conductas saludables y la evaluación que hace a partir de dicha percepción.

\section{Objetivos de intervención en psicología de}

\section{LA SALUD}

Así, se plantea que el objeto de estudio de la psicología de la salud es la comprensión de los factores psicológicos involucrados en el proceso de salud-enfermedad de un individuo o una comunidad y el objetivo principal en cualquier intervención será la prevención. Entendida en su más amplio significado, la prevención, aplicada a este campo del conocimiento, estará dirigida a optimizar las posibilidades de las personas para desarrollar un adecuado estado de salud y para afrontar la enfermedad del mejor modo que sea posible, así como la adherencia al tratamiento prescrito desde otras áreas de atención a la salud (medicina, nutrición y rehabilitación, entre otras), además de mejorar la calidad de vida.

La división 38 de la American Psychological Association (APA) plantea que, además, la psicología de la salud tiene como objetivos aquellos relacionados con comprender y evaluar el estado de bienestar físico y los diferentes factores biológicos, psicológicos y sociales involucrados en el pro- ceso de salud-enfermedad, así como entender los métodos de investigación psicológica aplicados a la prevención y la intervención ante la enfermedad (Gómez, 2007).

Sin embargo, la prevención puede ser abordada desde dos perspectivas distintas, ambas con el objetivo de mejorar la calidad de vida de las personas; Oblitas (2008) las describe de la siguiente manera.

a) Promoción de la salud: Impulsar estilos de vida saludables con la intención de desarrollar un estado integral de bienestar físico y psicológico en el individuo y así mejorar su calidad de vida. De algún modo la promoción de la salud busca optimizar las posibilidades de una persona o grupo para lograr un desarrollo pleno y la mejor calidad de vida que puede tener de acuerdo con sus condiciones particulares. Como tal, es una estrategia establecida en Ottawa, en 1986, donde se la define como: "el proceso que proporciona a los individuos y las comunidades los medios necesarios para ejercer un mayor control sobre su propia salud y así poder mejorarla" (Vignolo, Vacarezza, Álvarez \& Sosa, 2011: 13). Es decir, es una estrategia basada en la idea de que las personas pueden desarrollar comportamientos que optimizan su salud si se proporcionan herramientas que le permitan tener control y dirección. Al promover la salud, se hace énfasis en la comprensión sobre los aspectos que la influyen positivamente y que generan bienestar.

b) Prevención de la enfermedad: Esta estrategia había sido la más usada dada la influencia del modelo biomédico en la atención del proceso salud enfermedad. Las acciones que plantea se basan en la intervención directa sobre los factores de riesgo asociados con el desarrollo de una enfermedad, intentando minimizar o eliminar su influencia, así que la intención es modificar hábitos no saludables y eliminar comportamientos de riesgo asociados a múltiples patologías crónicas, agudas, infecciosas y accidentes que pueden evitarse o retrasarse si se adoptan las medidas pertinentes.

De manera que la prevención, desde sus dos perspectivas, es el objetivo principal de la psicología de la salud, pero se plantean otros dos, implícitamente. El primero - dirigido al individuo o la comunidad — se refiere a la evaluación y tratamiento de los aspectos psicológicos (conducta, emociones y pensamientos) relacionados con enfermedades específicas como diabetes, intestino irritable, cáncer, SIDA, hipertensión, dependencia a sustancias y epidemias, entre otras. El segundo, que coloca su enfoque en el funcionamiento institucional y político, planteando la evaluación y mejora del sistema sanitario mediante propuestas dirigidas a optimizar la atención sanitaria en lo que se refiere a la práctica profesional y los programas 
preventivos dirigidos a la población, así como las políticas públicas relacionadas con dichos programas.

Este objetivo resulta muy relevante puesto que los programas preventivos y las políticas públicas que los sustentan deben estar basados en información científica que guíe las acciones a partir de la comprensión de las variables en las que se debe intervenir, los modelos teóricos y estrategias que podrían ser más efectivos; de otro modo, se realizan acciones que terminan siendo inútiles $y$, desde luego, no preventivas. Al respecto, Arco y Fernández (2002) señalan que las fallas en la efectividad de los programas diseñados para la prevención se vinculan sobre todo con la falta de sustento teórico, el hecho de no considerar la necesidad de la colaboración interdisciplinaria, la dificultad para definir los grupos de riesgo y la ineficacia de la evaluación de resultados, por no decir inexistencia. Las políticas públicas no contemplan la necesidad de incorporar al profesional de la psicología de la salud en el diseño de estrategias y, en muchos casos, tampoco en las acciones, ya que la práctica está regulada por el Sistema de Salud y la prioridades que desde ahí se establecen.

Tanto la promoción de la salud como la prevención de la enfermedad deben ser entendidas como formas de enfocar una intervención que, al mismo tiempo, guían las estrategias para efectuarlas. Resulta de suma relevancia distinguirlas claramente porque el diseño de las intervenciones debe ser congruente con ellas; ambas responden al objetivo primordial de hacer prevención, pero desde diferentes perspectivas.

Para Reynoso y Seligson (2005) la prevención es fundamental, ya que actualmente existe evidencia epidemiológica que permite identificar condiciones de riesgo ante las cuales es factible establecer programas preventivos. La OMS (1998, apud Vignolo et al., 2011) define prevención como "Medidas destinadas no solamente a prevenir la aparición de la enfermedad, tales como la reducción de factores de riesgo, sino también a detener su avance y atenuar sus consecuencias una vez establecidas" (p. 12).

De acuerdo con Vignolo et al. (2011), la prevención debe comprender el proceso de la enfermedad y sus múltiples componentes para lograr incidir en ésta y diseñar sus acciones partiendo del nivel en que se pretende realizar la intervención, ya sea para intentar evitarla, para detectarla oportunamente o para minimizar sus secuelas.

Dichos niveles de prevención, desde los que se puede intervenir, han sido retomados de los propuestos por la psicología social y se han clasificado de la siguiente forma (Martínez \& García, 2012; Santacreu, Marquéz \& Rubio, 1997; Vingolo et al., 2011).

- Prevención primaria. Parte de la idea de que educar es prevenir; su objetivo es evitar la enfermedad identificando los factores causales para incidir en ellos antes de que se presente el problema; la intervención se produce con la intención de evitarlo.

- Prevención secundaria. Intenta detectar y aplicar tratamientos a las enfermedades en sus primeros estadios. Está dirigida al diagnóstico oportuno y enfocada a reducir al mínimo una alteración con base en la detección temprana y el tratamiento adecuado, esenciales para el control de una enfermedad o para superarla. La intervención preventiva de nivel secundario es ideal cuando aún el daño al organismo no está tan avanzado y se puede detener o controlar.

- Prevención terciaria. Tiene lugar cuando ya se ha diagnosticado la enfermedad, pero empieza a manifestarse e intenta evitar su avance, así como sus complicaciones. Se busca reducir las consecuencias de una alteración o enfermedad. Podría definirse como una acción de tratamiento o rehabilitación después de haber experimentado un problema de salud que ya está presente; puede empeorar y se previenen estados más avanzados de la enfermedad. Este tipo prevención pretende trabajar con las consecuencias que un problema puede ocasionar y evitar que se agrave.

- Prevención cuaternaria. Se ha denominado así a las acciones dirigidas a evitar procedimientos y medicación innecesarios o excesivos; se enfoca en el empoderamiento del paciente y sus familiares respecto a su derecho a decidir respecto al tratamiento ante su enfermedad; también en este nivel se ubican las acciones del sistema sanitario dirigidas a evaluar sus protocolos de atención con pacientes terminales o en proceso de muerte inminente, y el suministro de medicamentos con graves efectos secundarios. Aunque no existe consenso en cuanto a la necesidad de considerar este nivel de prevención, en años recientes se ha manifestado la preocupación de muchos profesionales en cuanto a los efectos negativos de la intervención médica en la que se ha priorizado la realización de procedimientos invasivos y el suministro de medicamentos ante problemas de salud que podrían tratarse de otras formas y que tienen efectos secundarios que impactan en la calidad de vida de la persona (Gervás, 2006).

Para clarificar los primeros tres niveles de prevención, en la tabla 1 se muestran acciones específicas desde las perspectivas descritas, prevención de la enfermedad y promoción de la salud, que pueden usarse en cada uno de los niveles, pero se dirigen a diferente población. Como se observa en la tabla, la perspectiva de promoción de la salud se utiliza cuando lo que se pretende es propiciar el desarrollo de la persona o la comunidad, para con ello mejorar su calidad de vida, tanto en el caso de que ya haya 
enfermado como cuando se encuentra sano. El enfoque de la prevención de la enfermedad se utilizará cuando lo que se desea es modificar un comportamiento que ya se ha descrito como no saludable o de riesgo para la salud.

\section{Tabla 1.}

Intervención en los tres niveles de prevención desde las perspectivas de la promoción de la salud y la prevención de la enfermedad.

\begin{tabular}{|c|c|c|}
\hline & $\begin{array}{c}\text { Promoción DE LA } \\
\text { SALUd }\end{array}$ & $\begin{array}{c}\text { Prevención de LA } \\
\text { enfermedad }\end{array}$ \\
\hline $\begin{array}{c}\text { Perspectiva/ } \\
\text { Nivel }\end{array}$ & $\begin{array}{l}\text { Su objetivo es } \\
\text { fomentar hábitos de } \\
\text { salud a través de: } \\
\text { - La reflexión } \\
\text { respecto a las } \\
\text { creencias. } \\
\text { - Proporcionar } \\
\text { información. } \\
\text { - Fomento de } \\
\text { habilidades } \\
\text { específicas. }\end{array}$ & $\begin{array}{l}\text { Su objetivo es } \\
\text { modificar hábitos no } \\
\text { saludables y eliminar } \\
\text { comportamientos de } \\
\text { riesgo. }\end{array}$ \\
\hline
\end{tabular}

Población general que no presenta un riesgo específico

Ejemplo:

- Entrenamiento en

habilidades asertivas, manejo emocional

o sexualidad

responsable dirigido a adolescentes.

Prevención PRIMARIA

Prevención SECUNDARIA
- Informar respecto

a las consecuencias

individuales,

familiares y físicas de

la adicción al alcohol.

- Campaña

informativa acerca de

habilidades de crianza

de niños y niñas

respecto al manejo

de sus hábitos

alimenticios.

Población en situación de riesgo o vulnerabilidad

- Taller sobre uso de condón para prevenir $\mathrm{VIH}$, dirigido a adolescentes.

Ejemplo:

- Taller o intervención individual o familiar dirigidos a modificar las creencias que

Ejemplo:

- Entrenamiento en prácticas de sexo seguro a parejas de personas infectadas con VIH.

\begin{tabular}{|c|c|c|}
\hline \multirow[b]{2}{*}{$\begin{array}{l}\text { Perspectiva/ } \\
\text { Nivel }\end{array}$} & $\begin{array}{c}\text { Promoción DE LA } \\
\text { SALUD }\end{array}$ & $\begin{array}{l}\text { Prevención de LA } \\
\text { enfermedad }\end{array}$ \\
\hline & $\begin{array}{l}\text { Su objetivo es } \\
\text { fomentar hábitos de } \\
\text { salud a través de: } \\
\text { - La reflexión } \\
\text { respecto a las } \\
\text { creencias. } \\
\text { - Proporcionar } \\
\text { información. } \\
\text { - Fomento de } \\
\text { habilidades } \\
\text { específicas. }\end{array}$ & $\begin{array}{l}\text { Su objetivo es } \\
\text { modificar hábitos no } \\
\text { saludables y eliminar } \\
\text { comportamientos de } \\
\text { riesgo. }\end{array}$ \\
\hline \multirow[b]{2}{*}{$\begin{array}{l}\text { PreVención } \\
\text { TERCIARIA }\end{array}$} & \multicolumn{2}{|c|}{ Población con un diagnóstico de enfermedad } \\
\hline & $\begin{array}{l}\text { Ejemplo: } \\
\text { - Fomento de } \\
\text { la comunicación } \\
\text { asertiva, } \\
\text { entrenamiento del } \\
\text { manejo de emociones } \\
\text { de la persona enferma } \\
\text { respecto a su familia. }\end{array}$ & $\begin{array}{l}\text { Ejemplo: } \\
\text { - Taller o intervención } \\
\text { individual o familiar } \\
\text { acerca de técnicas de } \\
\text { manejo de ansiedad } \\
\text { o biofeedback } \\
\text { con pacientes } \\
\text { hipertensos. }\end{array}$ \\
\hline
\end{tabular}

\section{¿Cómo SE hace UNA INTERVENCIÓN DESDE LA Psicología de la Salud?}

De acuerdo con García, Piqueras, Rivero, Ramos y Oblitas (2008), Morales (1997) y Stone (1998), el profesional de la psicología de la salud inicia su intervención realizando una evaluación que consiste en la recopilación de la información necesaria que le permita comprender los factores psicológicos involucrados en el problema en que pretende incidir. Para efectuar la evaluación puede utilizar diversas herramientas, entre las que se encuentran algunas escalas validadas de acuerdo con tipo de enfermedad o problema de salud —entrevistas, observaciones directas, registros psicofisiológicos y bioquímicos-, que finalmente se conforman como punto de partida para elaborar un diagnóstico; además, puede utilizar información epidemiológica que le permita comprender la prevalencia de enfermedades, características de la población, etcétera.

A partir de los resultados de la evaluación (análisis e interpretación de resultados), se realiza un proceso de análisis de las características del problema, se efectúa un diagnóstico y se diseña la intervención. Tanto el diagnóstico como la intervención deben partir de los postulados específicos del modelo de salud que se haya elegido, así como las variables en que incidirá. Sin embargo, las herramientas específicas provienen de cualquier modelo teórico de la Psicología, así que puede hacerse una intervención con técnicas de modificación de conducta, grupos de reflexión y/o psicoeducación, entre otros. 
Los modelos a los que se hace referencia han sido construidos desde diferentes teorías intentando explicar, predecir e intervenir ante los aspectos psicológicos vinculados con el proceso de salud-enfermedad; cada uno ofrece diferentes explicaciones y postula las variables en las que es necesario incidir para prevenir enfermedades (Enríquez, Sánchez \& Robles, 2011). Aunque se han desarrollado muchos, a continuación se mencionan algunos de ellos, así como sus variables.

- Modelo de creencias en salud, creado por Hackbaum, Kegels, Leventhal y Rostenstock en 1950, considera que los comportamientos relacionados con la salud son el resultado de las creencias y valoraciones internas que hacemos las personas, por lo que, para prevenir enfermedades, los programas deben apuntar hacia cuatro variables (que son la susceptibilidad, los beneficios, las barreras y la severidad) que una persona percibe respecto a comportamientos saludables y la posibilidad de enfermar (Cabrera, Tascón \& Lucumí, 2001).

- Modelo de autoeficacia, creado por Bandura a mediados de los noventa, plantea que la capacidad percibida por la persona respecto a su posibilidad de ejecutar exitosamente un comportamiento preventivo (autoeficacia percibida) es la variable en que es necesario incidir en los programas de prevención, ya que este aspecto se ha observado como un importante predictor del comportamiento (Bandura, 1977).

- Modelo transteórico. En 1970 Prochaska creó un programa de tratamiento para personas con adicciones utilizando principios de diversas teorías; en la década de los noventa consolidó su teoría planteando que el cambio conductual relacionado con hábitos no saludables o que ponen en riesgo la salud, es un proceso en etapas; que las personas tienen diferentes niveles de motivación y de intención respecto al cambio, por lo que para optimizar la intervención es necesario identificar en qué etapa se encuentra la persona para enfocar las intervenciones en lo que necesita para pasar a la siguiente teniendo en cuenta además, como variables, la tentación, la autoeficacia y algunas variables psicosociales como intermediarias del cambio y los procesos experienciales (Prochaska, DiClemente \& Norcross, 1994) Este modelo no es explicativo respecto a las variables que afectan el comportamiento, como los dos anteriores, sino que se centra en el cambio conductual (Cabrera, 2000).

- Teoría de acción razonada y teoría de la conducta planeada. En 1975 Fishbein y Azjen desarrollaron una teoría psicológica que intentaba explicar que el comportamiento humano está determinado por la intención de ejecutarla. Ésta depende de la actitud individual hacia ese comportamiento y está mediada por la percepción de lo que piensan los otros, así como por la motivación para satisfacer esas expectativas, variable que fue nombrada como norma subjetiva. A mediados de los ochenta Azjen replanteó la teoría, a la que denominó de la conducta planeada, afirmando que además de las variables propuestas en la teoría de acción razonada era necesario contemplar otra que es el control conductual percibido, entendido como lo que la persona cree que es capaz de hacer para cuidarse a sí mismo y, de ese modo, prevenir (Azjen, 2011). Aunque estas dos teorías surgieron inicialmente como una explicación de los aspectos que determinan el cambio de conducta, las variables que proponen se han usado como guía en acciones de prevención ante adicciones y salud sexual.

- Modelo de salud biológica propuesto por Emilio Ribes a finales de los ochenta es un modelo explicativo-investigativo basado en los principios teóricos del interconductismo; plantea que el grado de enfermedad que puede desarrollar una persona depende de qué tan agresiva sea ésta a nivel biológico y de su grado de vulnerabilidad, que es el resultado de múltiples factores propios de la interacción del individuo —entendido como sujeto bio-psico-social- con su ambiente (Piña, 2008). En este modelo se afirma que un comportamiento preventivo será eficaz si existen competencias efectivas en la comprensión y evaluación del riesgo, así como condiciones suficientes para lograrlo en términos de sus propias habilidades y el tipo de ambiente en que desenvuelve. De modo que un programa efectivo, de acuerdo con este modelo, debe contemplar dicha interacción individuo-ambiente (Bayés \& Ribes, 1989).

- Modelo de información, motivación y habilidades conductuales propuesto por Fisher y Fisher en 1992, es un modelo de cambio conductual que afirma se pueden desarrollar conductas preventivas cuando: a) se tiene información suficiente y relevante; b) existe motivación para hacerlo a partir de las creencias personales, la norma subjetiva, la autoeficacia y la intención, y c) se aprenden habilidades específicas para modificar la condición de riesgo (Fisher \& Fisher, 2000).

- Modelo integral desarrollado por Fishbein a principios de este siglo; de acuerdo con Enríquez et al. (2011), retoma elementos de algunos de los modelos mencionados, planteando que la intención de cambio está influida por las habilidades conductuales del 
sujeto y por los límites ambientales que se entienden como las características del sujeto influidas por variables que el autor denominó distales, como edad, lugar de residencia, nivel socioeconómico, aspectos culturales, estereotipos, personalidad, manejo de emociones, autoeficacia y su exposición a intervenciones (programas de prevención, información).

Tabla 2.

Acciones y competencias requeridas del profesional de la Psicología de la Salud.

\begin{tabular}{|c|c|c|}
\hline Acciones & Objetivos & Competencias \\
\hline Diagnóstico & $\begin{array}{l}\text { Observación, } \\
\text { evaluación y } \\
\text { comprensión de } \\
\text { los elementos } \\
\text { psicológicos } \\
\text { y del entorno } \\
\text { involucrados en un } \\
\text { problema de salud. }\end{array}$ & $\begin{array}{l}\text { - Conocimientos de } \\
\text { Psicología general } \\
\text { y su aplicación ante } \\
\text { problemas de salud. } \\
\text { - Comprensión de la } \\
\text { dimensión psicológica } \\
\text { involucrada en la } \\
\text { salud. } \\
\text { - Manejo de los } \\
\text { modelos teóricos } \\
\text { propios de la } \\
\text { Psicología de la Salud. } \\
\text { - Conocimiento de } \\
\text { políticas públicas y } \\
\text { reglamentaciones en } \\
\text { materia de salud. } \\
\text { - Habilidad para } \\
\text { evaluar necesidades } \\
\text { individuales, } \\
\text { familiares o } \\
\text { comunitarias. } \\
\text { - Habilidad para } \\
\text { evaluar resultados } \\
\text { de intervenciones } \\
\text { realizadas ya sea } \\
\text { en programas } \\
\text { preventivos de } \\
\text { nivel primario, } \\
\text { secundarias, terciarias } \\
\text { o cuaternarias. }\end{array}$ \\
\hline
\end{tabular}

Modificar aspectos psicológicos (cognitivos, emocionales $\mathrm{y} / \mathrm{o}$ conductuales) $\mathrm{y} / \mathrm{o}$ del entorno social que interfieren en la adecuada adherencia al tratamiento, el afrontamiento de la enfermedad y el desarrollo de conductas que optimizan la calidad de vida posible.

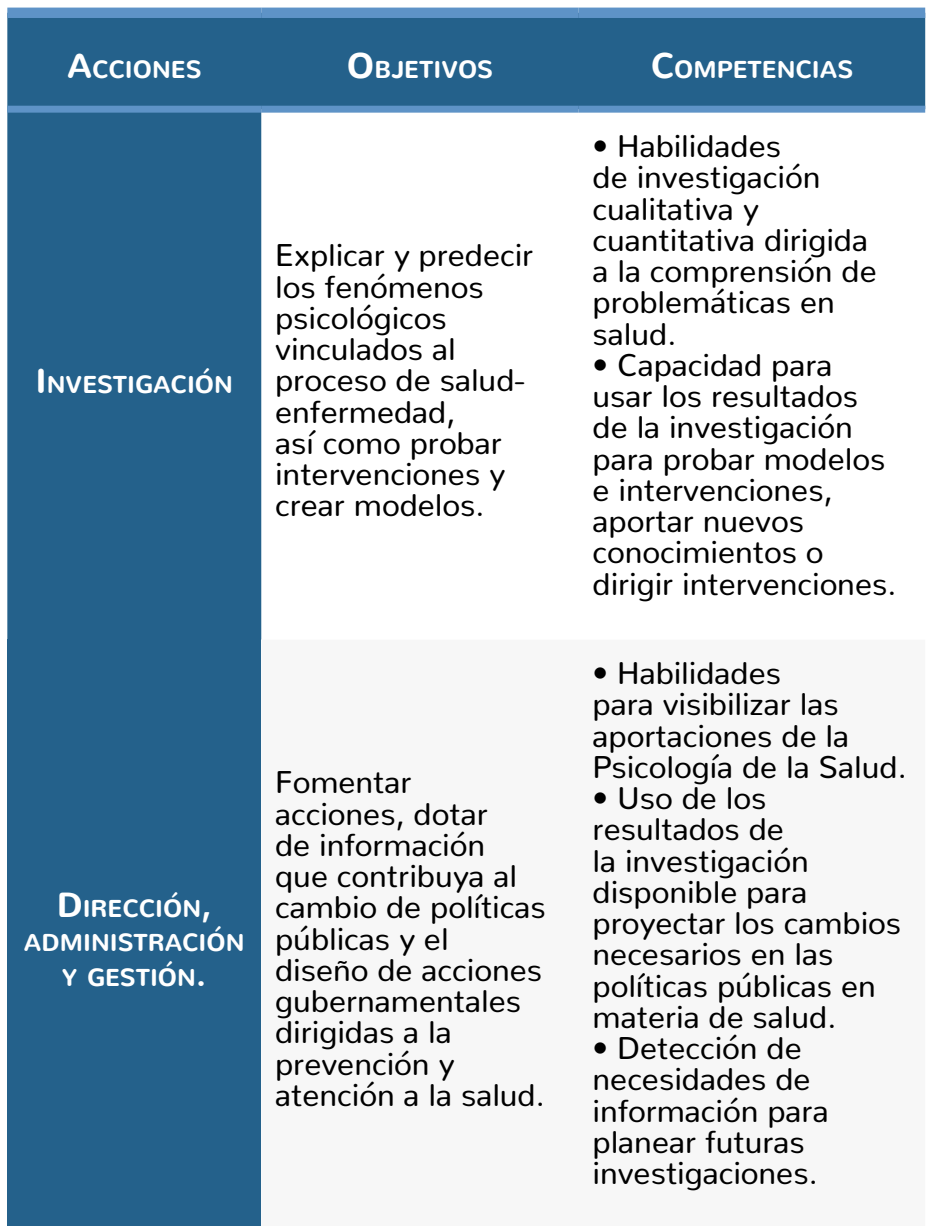

Resumiendo lo que se escribe en este apartado, se tiene que, desde el campo de la psicología de la salud, las intervenciones se refieren a programas de prevención primaria, secundaria o terciaria, de modo que las acciones se diseñan para promover la salud o prevenir la enfermedad con población general, en situación de riesgo o para acompañar procesos de enfermedad dirigidos a la adherencia al tratamiento con población que ya ha desarrollado algún problema de salud; éstos pueden ser individuales, grupales, familiares y comunitarios. En la tabla 2 se muestran los objetivos y competencias requeridas en las acciones que se realizan desde la psicología de la salud de acuerdo con las que señalan Piña et al. (2013).

En cuanto a los lugares para realizar una intervención, podrían ser centros de salud y hospitales, centros geriátricos, unidades de rehabilitación, unidades de dolor crónico, cuidados paliativos y atención a enfermos terminales, centros de voluntariado u organizaciones no gubernamentales, unidades de salud laboral, sector salud público y privado, instituciones de educación pública y privada, comunidades urbanas y rurales. En la práctica privada se estará haciendo una intervención desde 
la psicología de la salud cuando el motivo de consulta se relacione con el aspecto físico de la salud, el cual puede ser mantenerla, evitar una enfermedad o mejorar la calidad de vida (García et al., 2008). Algunos ejemplos de ello podrían ser el manejo de ansiedad que impide la adecuada adherencia a un programa de control de peso, superar alguna adicción, conflictos familiares que interfieren con el adecuado afrontamiento de problemas físicos de salud de alguno de sus integrantes, o la depresión que obstaculiza la toma de decisiones acerca del tratamiento de una enfermedad crónica.

Así que los problemas de salud en los que se puede intervenir son muy diversos; algunos de ellos son: enfermedades crónico-degenerativas, enfermedades infecciosas, trastornos alimentarios, adicciones, estrés, dolor, accidentes. Lo que es importante destacar es que la psicología de la salud está enfocada en lograr mejorar la salud física, bienestar y la calidad de vida que se relaciona con ésta, incidiendo en los factores psicológicos que obstaculizan dicho objetivo.

\section{CAMPo de ACCIÓN del PROFESIONAL EN LA PSI-} COLOGÍA DE LA SALUD

La psicología de la salud es un campo que aún está en desarrollo, y en muchos países, incluyendo México, como se comentaba, no está todavía claramente diferenciada de otras áreas en los programas de formación y en las funciones que desempeña el profesional de la Psicología en las instituciones y programas de salud. Independientemente de si el propio profesional de la psicología de la salud se define como tal o el campo de trabajo donde está inserto lo identifica, es la función que cumple y el objetivo con que lo hace lo que, a final de cuentas, lo coloca en este campo (Morales, 1999; Piña \& Rivera, 2006).

Por otra parte, la intervención desde la psicología de la salud — puede ser de dos tipos, activa o pasivaes siempre de tipo activo, ya que está diseñada para lograr la modificación del comportamiento no saludable, a diferencia de otras ciencias cuyo enfoque es la modificación del entorno para reducir el riesgo, lo cual se ha identificado como de tipo pasivo.

Para clarificar cuáles se consideran intervenciones pasivas y cuáles activas, se mencionará el ejemplo de las políticas públicas que recientemente dirigieron sus esfuerzos hacia la prevención de riesgos relacionados con el tabaquismo (The Association of Faculties of Medicine of Canada, 2012). La legislación ha señalado los espacios que deben ser "libres de humo" y establece una sanción para quien fume o permita fumar en ellos; esta acción protege a quienes no fuman y tiende a modificar directamente el comportamiento del fumador, en términos de no poder fumar en ciertos espacios, pero no está dirigida a incidir en el consumo de tabaco como tal, así que, en tanto esta acción se dirige al cambio del entorno del fumador, se considera de tipo pasivo.

En tanto que una intervención activa puede ir desde proporcionar información hasta la aplicación de una técnica de modificación de conducta, siempre con la intención de lograr un cambio directamente en la población hacia quien está dirigida la intervención.

De manera que los ambientes en que el profesional de la psicología de la salud se puede insertar son muy variados, pero resulta útil contextualizarlos de acuerdo con la siguiente clasificación.

- Ambientes institucionalizados. Actividades que se desprenden de los objetivos de la institución, plan de desarrollo o ejecutar una política institucional; o en la inserción en las actividades que ya realiza la institución. Una institución es un organismo público o privado que ha sido fundado para desempeñar labor cultural, científica, política o social, y cumple con una función de interés público.

- Ambientes no institucionalizados. Proyectos que no provienen de los programas de una institución, sino del interés en trabajar alguna problemática en particular a partir de la evaluación, el diagnóstico o la petición de la institución por haber observado alguna situación específica que es de su interés abordar, pero no cabe en las acciones que realizan en la propia institución porque no es su finalidad. Un ejemplo de ello es el trabajo que se puede realizar en una escuela con los alumnos o el profesor, dirigido a la prevención primaria (como prevención de embarazo en la adolescencia), prevención secundaria (como manejo motivacional del alumnado con sobrepeso para iniciar rutinas de actividad física) o prevención terciaria (como intervención en crisis y canalización de un caso de anorexia).

\section{Diferencias entre psicología de LA SALUd Y OTRAS ÁREAS DE APLICACIÓN}

Como se comentó en apartados anteriores, existe una confusión importante que ha dificultado la definición del campo de estudio de la psicología de la salud y las acciones que desde ella se diseñan para intervenir ante asuntos relacionados con los factores psicológicos que inciden en el proceso de salud-enfermedad. Así que a continuación 
se muestran las diferencias entre la Psicología de la Salud y tres áreas con las que con frecuencia se le confunde.

\section{Psicología de la SALUd VS PSicología Clínica}

Piña (2003) afirma que la psicología de la salud y la psicología clínica comparten el objetivo de facilitar y propiciar el desarrollo saludable de la persona consultante; en la práctica están entrelazadas, y para diferenciarlas es necesario discernir el origen y/o motivo de consulta. Se entenderá como una intervención de la psicología de la salud aquella cuyo origen y/o motivo de consulta se encuentre implicado en el proceso de salud-enfermedad (pérdida, disminución, afectación de la salud física) o en la intención de mejorar algún aspecto de la salud física (modificación de hábitos alimentarios, motivación para realizar actividad física, superar la ansiedad vinculada con la revisión médica).

La psicología clínica, en cambio, se encarga de atender los asuntos en que el motivo de la intervención se relaciona con el ajuste psicosocial o la salud mental, como se le llama desde el sistema sanitario, y puede intervenir con individuos, familias o grupos. Su campo de acción ha sido tradicionalmente enfocado en la atención de personas que ya refieren un problema en sus vidas, sus relaciones o una alteración psicológica usando sus propios modelos teóricos para explicar las causas, las consecuencias y las técnicas de intervención de acuerdo con cada modelo. Sin embargo, la intervención clínica también puede usarse en el nivel de prevención primaria y secundaria, sólo que su enfoque se encuentra en el desarrollo de recursos psicológicos para optimizar la capacidad de las personas respecto a su propia vida, la relación familiar y la interacción con otros (Psychology School Guide, 2016).

De modo que si una persona busca ayuda psicológica para superar los efectos emocionales negativos de una separación de pareja, la intervención se enmarca como psicología clínica; si se atiende a una persona con ansiedad que le impide adherirse al tratamiento prescrito por su médico para controlar su diabetes o su obesidad, se está actuando en el campo de la psicología de la salud, aún cuando esa acción sea realizada en el mismo consultorio y por el mismo profesional.

\section{Psicología de la salud vs medicina conduc-} TUAL

El campo de la medicina conductual aborda el trabajo conjunto, integral y complementario hacia la atención de pacientes con problemas crónicos, entre otros, a través de diferentes modelos de intervención, que implican bá- sicamente entrenar a la persona enferma para aprender a vivir en mejores condiciones, evitar deterioro psicológico y conductual para mejorar su calidad de vida.

Florez (2006) plantea que la medicina conductual concentra las aportaciones de diferentes ciencias conductuales y las disciplinas biomédicas para brindar atención integral a la salud, de manera que utiliza diversas técnicas como el biofeedback, registros fisiológicos y otros derivados de la investigación médica aplicada, se apoya en el modelo cognitivo conductual para realizar sus intervenciones. La medicina conductual se desprende de la psicología de la salud pero está enfocada en la prevención terciaria y cuaternaria que fundamentalmente aborda pacientes con enfermedades graves o en fase terminal para lograr adherencia terapéutica, mejor manejo emocional y cognitivo respecto a su enfermedad, el tratamiento y/o el afrontamiento de la muerte, tanto por parte del propio paciente como de su familia (UNAM, 2013).

\section{Psicología de la salud vs psicología comu- NITARIA Y PSICOLOGÍA SOCIAL}

La psicología comunitaria surge en 1965 debido al empeño en desarrollar programas de salud mental dirigidos a la comunidad como beneficiaria, apuntando hacia la prevención primaria y surgiendo como una alternativa a la clínica tradicional donde se concebía que ante una problemática es necesario hacer una intervención, ubicando la relación entre el profesional y las personas como una atención individualizada, en un consultorio. Este modo de ver la salud mental había impedido el desarrollo de estrategias de prevención efectivas y dejaba de lado el entorno de los individuos como agente que influye en los problemas psicológicos, ya que los atribuía sólo a procesos intrapsíquicos.

Los objetivos de esta área son reducir la incidencia y prevalencia de trastornos y alteraciones mentales mediante la prevención y el desarrollo de nuevas formas de tratamiento, así como la promoción del desarrollo sano y la salud mental tanto del individuo como de la comunidad (Gómez del Campo, 2011).

Así que la psicología comunitaria proviene de la psicología clínica, y por tanto no es psicología de la salud a menos que el objetivo de la intervención en una comunidad esté enfocado en los factores psicológicos que afectan la salud física. La comunidad es un contexto en el que la psicología de la salud puede intervenir, pero no es psicología comunitaria.

La psicología social, por otra parte, como una de las grandes ramas de la Psicología, se interesa en el modo en que se influyen mutuamente el individuo y su entorno. 
Así que, usando el conocimiento que aporta la psicología social, se puede buscar comprensión en el proceso de salud-enfermedad en términos del funcionamiento sistémico entre las personas y los fenómenos sociales en lo que respecta, por ejemplo, a la comprensión acerca de la salud, la enfermedad, la influencia cultural en la creencias y prácticas en torno a la salud, por mencionar algunos.

\section{ConCLusiones}

En la descripción que se hace a lo largo de este trabajo queda claro que, aun cuando la psicología de la salud es una disciplina relativamente nueva, ha logrado definir su objeto de estudio, el enfoque de sus intervenciones y los elementos que delimitan su quehacer profesional, así como la intervención que puede realizar en este ámbito, enfocando su actuación en los factores psicológicos involucrados en el proceso de salud-enfermedad.

Sin embargo, el profesional de la psicología que se desempeña en esta área aún tiene retos enormes, ya que la población y las políticas públicas que rigen el sistema de salud no identifican todavía lo que puede aportar para prevenir la enfermedad, promover la salud y mejorar la calidad de vida de las personas y las comunidades. Probablemente esto sea el resultado de la falta de claridad, del propio profesional, respecto al campo específico en que deben circunscribirse sus acciones y el tipo de herramientas que puede usar, que son propiamente psicológicas y que se fundamentan en el conocimiento específico de esta área.

Lo que es importante destacar es que la psicología de la salud es una disciplina destinada a coadyuvar con otras áreas, sin cuyo conocimiento pierde sentido y dirección; sus acciones no sustituyen el papel del médico, del nutriólogo, de la enfermera dedicada a la prevención, sino que aportan elementos teóricos y metodológicos que provienen de la psicología.

De modo que el psicólogo de la salud, por ejemplo, no dará una conferencia acerca del Plato del Buen Comer ni hará sugerencias en torno a la dieta de un paciente, sino más bien realizará acciones dirigidas hacia los factores psicológicos que facilitan el cambio de hábitos alimenticios y se vinculará con otros profesionales para abordar conjuntamente las necesidades específicas detectadas en ese paciente (Piña \& Rivera, 2006).

Así que es posible que la dificultad para definirse como profesional de la psicología de la salud provenga de la falta de claridad acerca de lo que le corresponde aportar, cómo y para qué, aspectos que se vinculan directamente con los retos respecto al actuar del profesional de la psicología de la salud, de los que se hablaba en otro apartado de este documento.
La falta de definición del quehacer de la psicología de la salud comienza en la escasa formación académica y de especialización en esta área, así como de difusión en torno a los resultados de la investigación y el desarrollo teórico metodológico que se ha generado de ella. Ciertamente algunas instituciones educativas en este país han incluido en sus programas materias y formaciones más amplias (áreas de especialización o de posgrado) en psicología de la salud, por lo que se esperaría que en algunos años el profesional de esta área se identifique claramente como tal y sus aportaciones sean, a su vez, identificables por parte de otros. Por lo pronto es necesario que quienes ya se encuentran actuando en este campo logren congruencia entre la práctica y la teoría, que se utilicen y promuevan las herramientas metodológicas que se han desarrollado, que se documenten adecuadamente y se compartan las intervenciones que realizan; en resumen, que se profesionalice y se sustente científicamente el quehacer de la psicología de la salud.

\section{Referencias}

Arco, J. L., \& Fernández, C. A. (Mayo, 2002). Porque los programas de prevención no previenen. International Journal of Clinical and Health Psychology, 2(2), 209-226. Recuperado de http://www.redalyc.org/articulo.oa?id=33720201

Ajzen, I. (September, 2011). The theory of planned behavior: Reactions and reflections. Psychology and Health, 26(9), 1113-1127. Recuperado de https://www.researchgate. net/publication/51653805_The_theory_of_planned. behaviour Reactions and reflections

Bandura, A. (1977). Self-efficacy: toward a unifying theory of behavioral change. Psychological review, 84(2), 191-215.

Bayés, R. \& Ribes, I. E. (1989). Un modelo psicológico de prevención de enfermedad: su aplicación al caso del SIDA. Papeles del psicólogo, 41. Recuperado de http:// www.papelesdelpsicologo.es/resumen?pii=427

Cabrera, A. G. (2000). El modelo transteórico del comportamiento en salud. Revista Facultad Nacional de Salud Pública,18(2),129-138. Recuperado de http://www. redalyc.org/pdf/120/12018210.pdf

Cabrera, A. G., Tascón, G. J., \& Lucumí, C. D. (Enero-Junio, 2001). Creencias en salud: historia, constructos y aportes al modelo. Revista Facultad Nacional de Salud Pública, 19 (1), 91-101. Recuperado de http://www.redalyc.org/ articulo.oa?id=12019107

Enríquez, N. D., Sánchez, M. R., \& Robles, M. S. (2011). Teorías y modelos psicológicos sobre el estudio de la salud sexual. México: UNAM.

Fisher, J. D., \& Fisher, W. A. (2000). Theoretical Approaches to Individual-Level Change in HIV Risk Behavior. In: Peterson J. L., DiClemente R. J. (eds.). Handbook of HIV Prevention. Aids Prevention and Mental Health. Springer, Boston.

Florez, A. L. (Junio, 2006). La psicología de la salud en Colombia. Univ. Psychol. Bogotá, 5(3), 681-693. Recuperado de 
http://www.scielo.org.co/pdf/rups/v5n3/v5n3a20.pdf

García, L. L., Piqueras, J. A., Rivero, R., Ramos, V., \& Oblitas, G. L. (Enero-Junio, 2008). Panorama de la psicología clínica y de la salud. CES Psicología, 1(1), pp. 70-93. Recuperado de http://www.redalyc.org/articulo.oa?id=423539527008

Gervás, J. (2006). Moderación en la actividad médica preventiva y curativa. Cuatro ejemplos de necesidad de prevención cuaternaria en España. Gaceta Sanitaria, 20 (1),127-134.

Gómez del Campo, F. (2011). Psicología de la Comunidad. México: Plaza y Valdés.

Gómez, M. (2007). La psicología de la salud en un hospital de cuarto nivel de complejidad. Psychologia. Avances de la disciplina, 1(2), 159- 179. Recuperado de http://www. redalyc.org/articulo.oa?ld=297224996003

Grau, J. A., \& Hernández, E. (Enero, 2005). Psicología de la salud: Fundamentos y aplicaciones. México: Universidad de Guadalajara.

Juárez, F. (2011). El concepto de salud: Una explicación sobre su unicidad, multiplicidad y los modelos de salud. International Journal of Psychological Research, 4(1), 70-79.

Labiano, M. (2010). Introducción a la psicología de la salud. En L. Oblitas (ed.), Psicología de la salud y Calidad de vida (pp. 3-21). México: Cengage Learning.

Martínez, J. \& García, M. (2012). Epidemiología y salud pública en Promoción de la salud. España: Paraninfo.

Morales, F. (1999). Introducción a la psicología de la salud. Buenos Aires: Paidós Iberica.

Oblitas, L. A. (2008). El estado del arte de la psicología de la salud. Revista de Psicología,26(2), 219-254. Recuperado de http://pepsic.bvsalud.org/pdf/rp/v26n2/v26n2a02.pdf

Piña, L.J. (Marzo, 2003). Psicología clínica y psicología de la salud: En defensa de la psicología de la salud. Suma Psicológica, 10 (1), 67-80.

Piña , L. J. (Diciembre, 2008). Variaciones sobre el modelo psicológico de salud biológica de Ribes: justificación y desarrollo. Universitas Psychologica, 7(1), 19-32. Recuperado de_http://www.scielo.org.co/pdf/rups/v7n1/ v7n1a03.pdf

Piña, L. J., \& Rivera, B. (2006). Psicología de la salud: algunas reflexiones críticas sobre su qué y su para qué. Universitas Psychologica, 5 (3), 669-680.

Piña , L. J., Sánchez, B. C., García, C. I., Ybarra, J. L. \& García, C. H. (Junio, 2013). Psicología y salud en México: Algunas reflexiones basadas en el sentido común y la experiencia. Diversitas: Perspectivas en Psicología, 9(2), 347-360. Recuperado de http://www.redalyc.org/articulo. oa?id $=67932397008$

Prochaska, J. O., DiClemente, C., \& Norcross, J. C. (1994). Cómo cambia la gente. Aplicaciones en los comportamientos adictivos. RET, Revista de Toxicomanías, 1. 3-14.

Psychology School Guide (2016). What is the Difference Between Health Psychology and Clinical Psychology? Recuperado de http://www.psychologyschoolguide. net/guides/difference-between-health-psychology-andclinical-psychology/

Reynoso, L., \& Seligson, I. (2005). Psicología Clínica y de la Salud. México: Manual Moderno.

Robles, S., Solano, R., Díaz, R., Moreno, D., Frías, B., Rodríguez, M., \& Barroso, R. (2012). Efectos de un programa de prevención de problemas de salud sexual sobre variables psicosociales y conductuales en adolescentes sin experiencia sexual. Revista Electrónica de Psicología Iztacala, 15(3), 1129-1155.

Santacreu, J., Marquéz, M., \& Rubio, V. (1997). La prevención en el marco de la Psicología de la Salud. Psicología y Salud. 10, 81-92. Recuperado de https://www.uam.es/personal pdi/psicologia/victor/SALUD/Bibliog/prevencion.PDF

Secretaría de Salud (2015). Norma Oficial Mexicana nom025-ssa2-2014, para la prestación de servicios de salud en unidades de atención integral hospitalaria médicopsiquiátrica. Diario Oficial de la Federación, 4 de septiembre.

Stone, G. C. (1988). Psicología de la Salud: Una definición amplia. Revista latinoamericana de psicología, 20(1), 15-26.

The Association of Faculties of Medicine of Canada (2012). The stages of prevention. Recuperado de http://phprimer. afmc.ca/Part1-TheoryThinkingAboutHealthChapter4Ba sicConceptsInPreventionSurveillanceAndHealthPromoti on/Thestagesofprevention

Universidad Nacional Autónoma de México (2013). Programa de Maestría y Doctorado en Psicología. Medicina Conductual. Recuperado de http://psicologia.posgrado. unam.mx/medicina-conductual-iztacala/

Universidad Nacional Autónoma de México (2012). Coordinación de Universidad abierta y Educación a distancia (SUAyED). Licenciatura en psicología modalidad a distancia. Recuperado de http://suayed.unam.mx/oferta/fichas distancia/lic psicologia distancia.html

Vignolo, J., Vacarezza, M., Álvarez, C., \& Sosa, A. (2011). Niveles de atención, de prevención y atención primaria de la salud. Archivos de Medicina Interna, 33(1), 11-14. Recuperado de http://www.scielo.edu.uy/pdf/ami/v33n1/v33n1a03. pdf 


\section{Meta-Análisis del Artículo}


Revista Digital Internacional de Psicología y Ciencia Social |Vol. 3 | Núm. 2 | Juilio-Diciembre 2017| ISSN 2448-8119 e-ISSN $2448-8119$

\section{Dimensión Cuantitativa}

\section{Perfil de Evaluación entre pares}
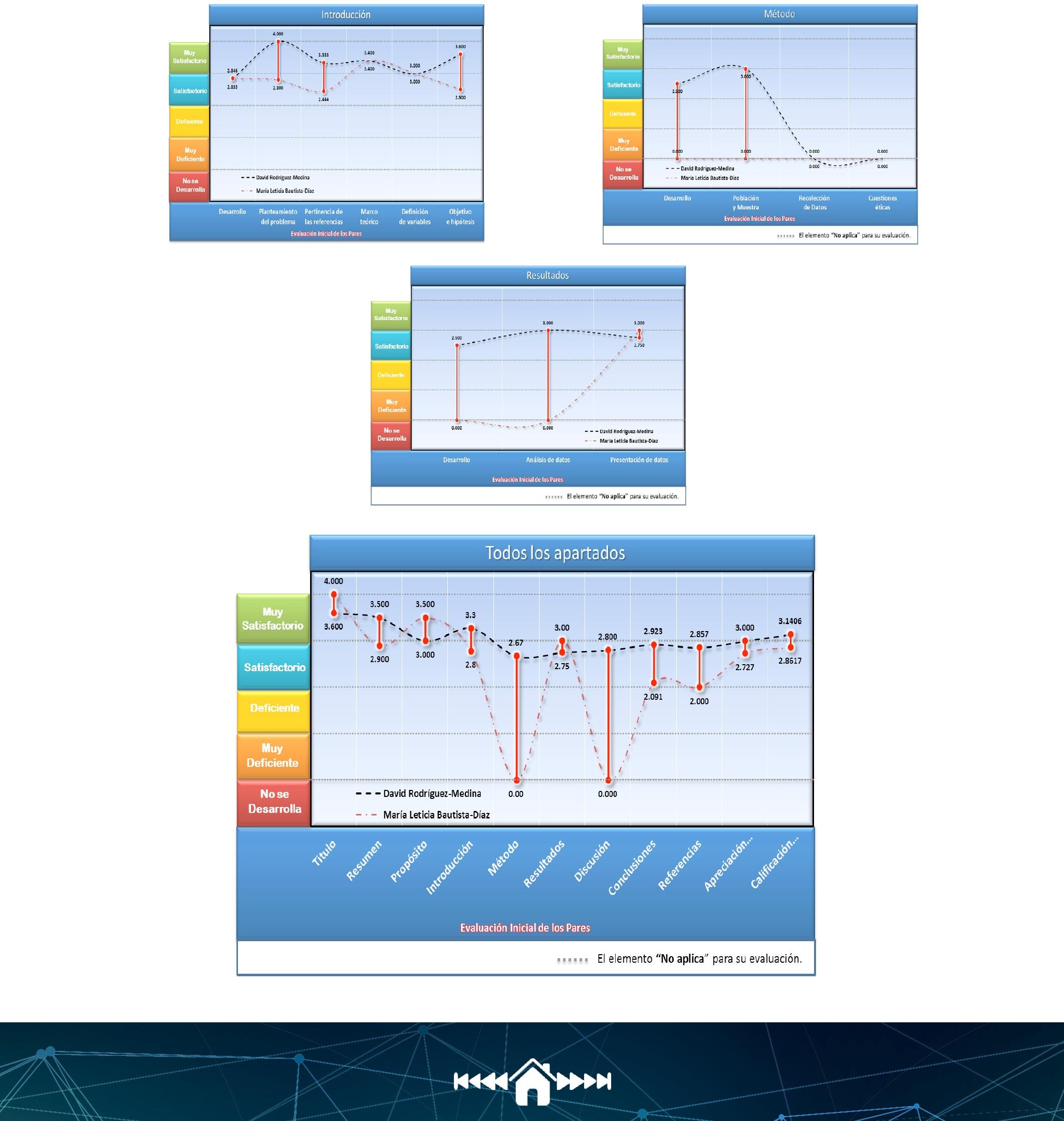


\section{Índice de Concordancia}

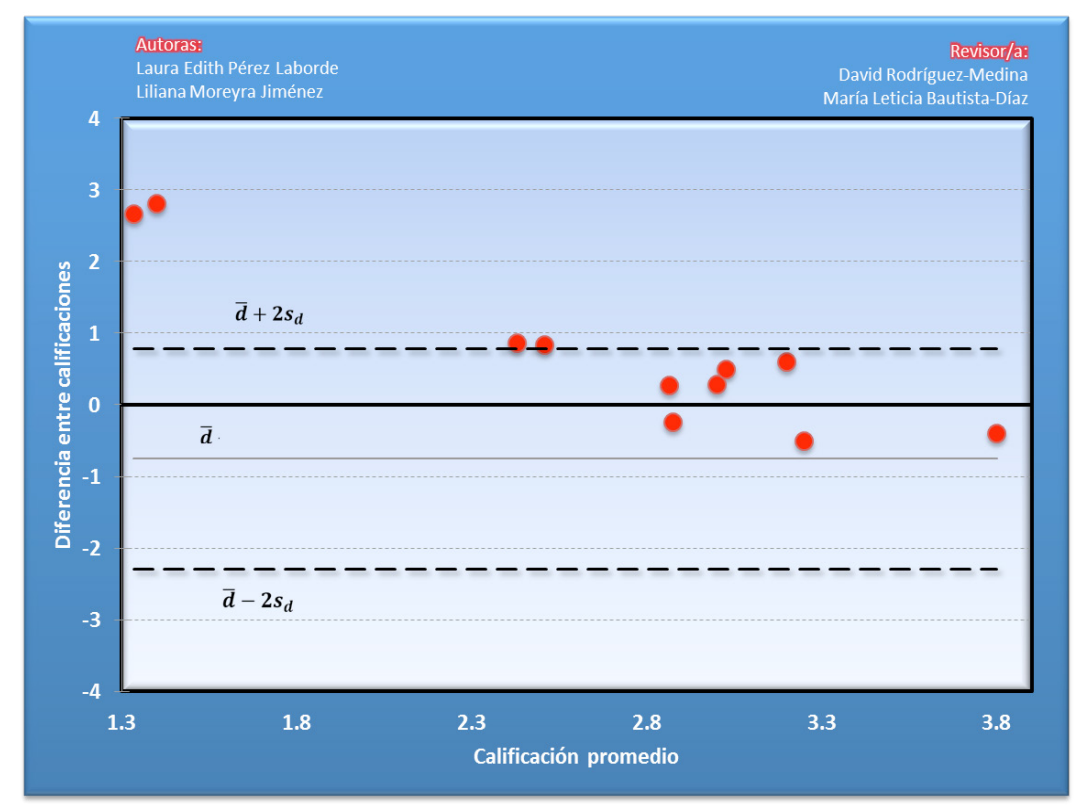

Índice de Acuerdo
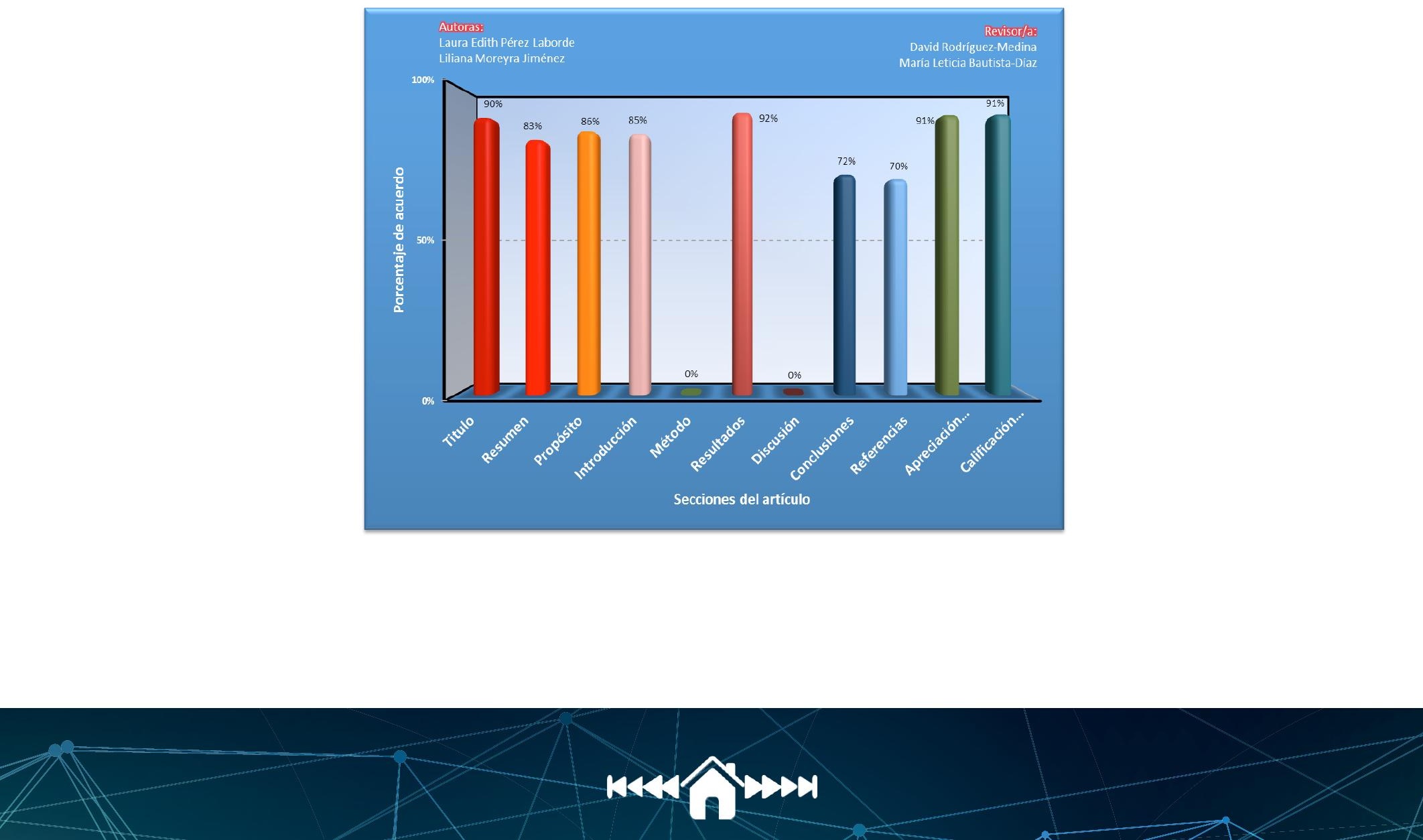
Dimensión Cualitativa

\begin{tabular}{|c|c|}
\hline Revisor 1 & Revisor 2 \\
\hline David Rodríguez-Medina & María Leticia Bautista-Díaz \\
\hline \multicolumn{2}{|c|}{ Título/Autoría } \\
\hline $\begin{array}{l}\text { Sería útil considerar que el título haga alución a los mo- } \\
\text { delos que revisaron, es decir, "EL QUEHACER DE LA } \\
\text { PSICOLOGIA DE LA SALUD: DEFINICIONES, OB- } \\
\text { JETIVOS DESDE LA PERSPECTIVA...” }\end{array}$ & El título es adecuado. \\
\hline \multicolumn{2}{|c|}{ Resumen } \\
\hline $\begin{array}{l}\text { El contenido del resumen es adecuado. Únicamente } \\
\text { deben construirse oraciones más breves, pues el lector } \\
\text { debe hacer un esfuerzo por mantener la información } \\
\text { después de } 3 \text { líneas. }\end{array}$ & $\begin{array}{l}\text { Se refiere que “...en la práctica aún no se encuentra cla- } \\
\text { ramente diferenciada de otras áreas de la psicología, pro- } \\
\text { vocando confusión en quienes buscan intervenir desde } \\
\text { este campo y dificultad en los demás profesionales para } \\
\text { comprender lo que se puede aportar” Lo anterior es un } \\
\text { tanto aventurado decirlo porque no hay sustento que lo } \\
\text { fundamente, quizá las autoras podrían dar un ejemplo de } \\
\text { ello. Se puede enunciar una breve conclusión. }\end{array}$ \\
\hline \multicolumn{2}{|c|}{ Próposito del Estudio } \\
\hline $\begin{array}{l}\text { Revisar y constratar aportaciones internacionales (in- } \\
\text { clyuendo revisiones lationamericanas) con literatura } \\
\text { nacional del tema. }\end{array}$ & Se sugiere "El objetivo del presente trabajo fue..." \\
\hline \multicolumn{2}{|c|}{ Introducción } \\
\hline $\begin{array}{l}\text { Falta constrartar literatura, por ejemplo: el modelo psi- } \\
\text { cosocial con alguno de los modelos biopsicosociales en } \\
\text { materia de salud que clarifique objetivos de la Psicolo- } \\
\text { gía de la salud bajo nuestro contexto Universitario. }\end{array}$ & $\begin{array}{l}\text { Se sugiere incluir otras fuentes para fortalecer las afirma- } \\
\text { ciones ya que, se trata de un de artículo teórico es necesa- } \\
\text { rio ampliar el número de fuentes consultadas, asimismo } \\
\text { se sugiere incluir fuente primarias. En el archivo del ma- } \\
\text { nuscrito, se sugieren diversos cambios o modificaciones, } \\
\text { así como propuestas de redacción. }\end{array}$ \\
\hline \multicolumn{2}{|c|}{ Método } \\
\hline $\begin{array}{l}\text { Sería apropiado mencionar el universo de estudio y su re- } \\
\text { lación temporal con los avances de acuerdo a cada autor/ } \\
\text { modelo revisado. Un diagrama de flujo o bien, una di- } \\
\text { mensión temporal. }\end{array}$ & No aplica. \\
\hline
\end{tabular}




\begin{tabular}{|l|l|}
\hline \multicolumn{1}{|c|}{ Revisor 1 } & \multicolumn{1}{|c|}{ Resultados } \\
\hline $\begin{array}{l}\text { La tabla de niveles de prevención es apropiada de acuerdo } \\
\text { a lo revisado en la literatura. Valdría la pena hacer una si- } \\
\text { milar con los modelos que revisaron sobre los orígenes de } \\
\text { la Psicología de la Salud. }\end{array}$ & No aplica. \\
\hline $\begin{array}{l}|c| \\
\text { Discusión }\end{array}$ \\
\hline $\begin{array}{l}\text { Falta emitir un argumento de las intervenciones en Mé- } \\
\text { xico en Psicología de la Salud en México, que contribu- } \\
\text { ya a los avances de ésta especialidad. }\end{array}$ & No aplica. \\
\hline \multicolumn{2}{|c|}{ Conclusiones } \\
\hline $\begin{array}{l}\text { Faltaría plantear no sólo la utilidad de la Psicología de } \\
\text { la Salud en el contexto nacional, sino una estrategia que } \\
\text { pudiera evaluar sus efectos en sus dimensiones de es- } \\
\text { tudio. Es decir, el lector debe tener claro cómo evaluar } \\
\text { su intervención de acuedo a los intereses del estudio } \\
\text { (clínica, estadística y socialmente). }\end{array}$ & $\begin{array}{l}\text { Se sugiere concluir con la aportación el estudio, ya que se } \\
\text { refiere la falta de claridad del papel del psicólogo de la sa- } \\
\text { lud. La propuesta a partir del estudio es muy valiosa para } \\
\text { el psicólogo de la salud. }\end{array}$ \\
\hline \begin{tabular}{l} 
Sin comenarios. \\
\hline \multicolumn{1}{|c|}{ Referencias } \\
\hline
\end{tabular} & $\begin{array}{l}\text { Se sugiere ampliar el número de referencias, tanto clásicas, } \\
\text { primarias y secundarias para fortalecer las afirmaciones. } \\
\text { No aparecen los autores de los modelos de salud (Hack- } \\
\text { baum (1950), Prochaska (1970) y Fishben. Se sugiere in- } \\
\text { cluirlas. En el archivo del manuscrito se indican una serie } \\
\text { de detalles por corregir en las referencias. }\end{array}$ \\
\hline
\end{tabular}




\section{Sección}

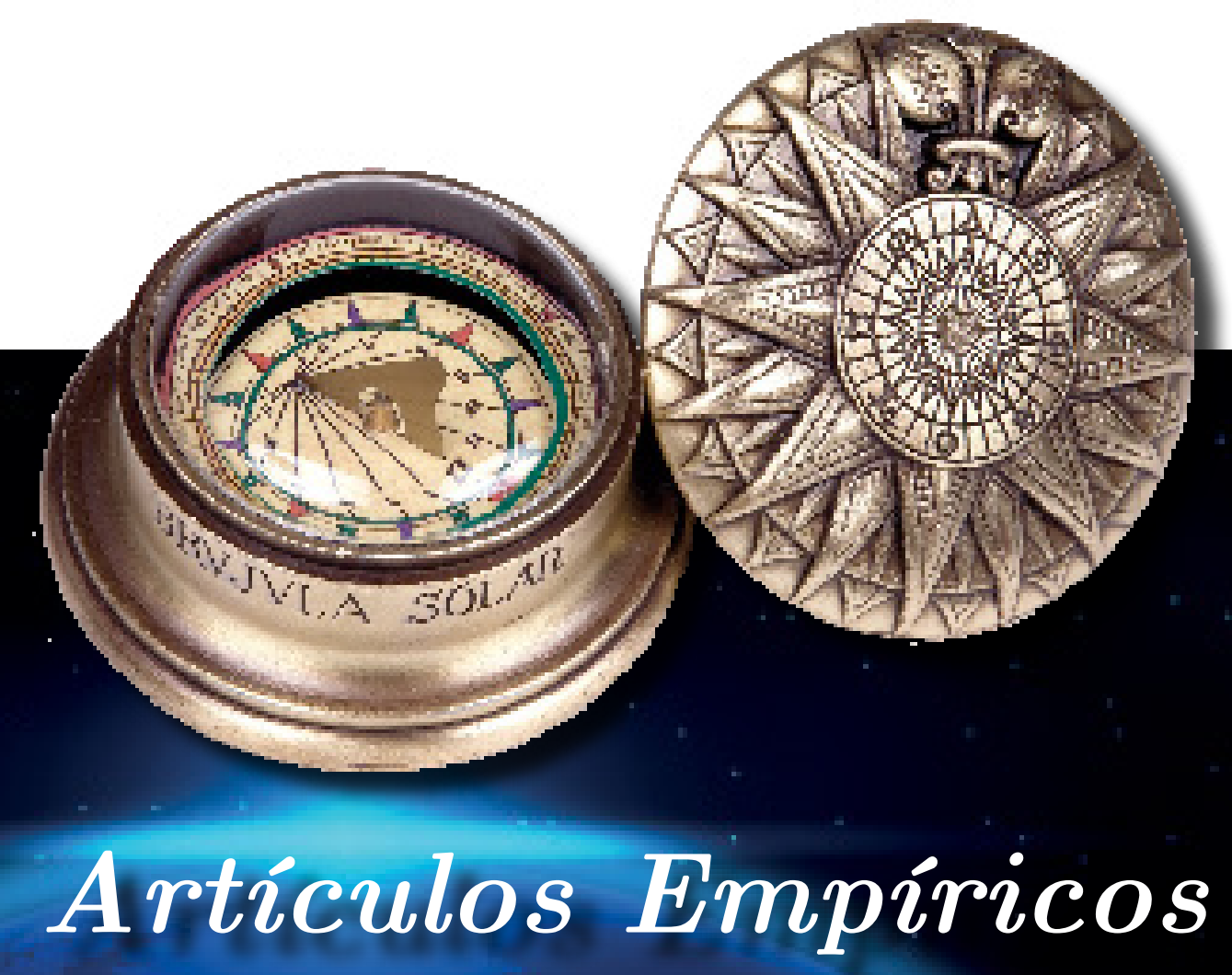




\title{
PERCEPCIÓN DE LOS ESTUdIANTES DE LICENCIATURA RESPECTO A LOS CONOCIMIENTOS ÉTICOS ADQUIRIDOS EN LA CARRERA DE PSICOLOGÍA
}

\author{
Norma Coffin-Cabrera, Sara Guadalupe Hernández-Andrade y Lourdes Jiménez-Rentería \\ FES Iztacala, UNAM \\ México
}

\begin{abstract}
RESUMEN
Se estudió la percepción de adquisición de conocimientos éticos durante la formación educativa de los alumnos de pregrado de la carrera de Psicología, en relación con las variables sexo, turno y semestre. La hipótesis fue que los alumnos de quinto semestre reportarán tener un mayor conocimiento de contenidos éticos. Los objetivos fueron la creación de un cuestionario, conocer sus definiciones de "ética profesional" y "dilema ético", saber si se consideran preparados para tratar con pacientes y conocer su opinión acerca de lo que consideran "ético" en sus profesores. Se realizó un análisis de varianza (ANOVA) para comparar las variables (sexo, turno, semestre), encontrándose que la variable sexo influye en la percepción de adquisición de contenidos éticos $(F(13)=0.34<$ 0.05 ), es decir, las mujeres se perciben mejor preparadas para realizar sus prácticas profesionales porque sus profesores les han enseñado lo suficiente, mientras que los hombres perciben revisar en más asignaturas contenidos éticos.
\end{abstract}

Palabras Clave:

percepción, conocimiento ético, estudiantes universitarios, Psicología.

\section{PERCEPTION OF UNDERGRADUATE STUDENTS REGARDING THE ETHICAL KNOWLEDGE ACQUIRED IN THE PSYCHOLOGY DEGREE}

\begin{abstract}
The goals of this study carried out with College students of Psychology career, currently enrolled in the first and fifth semesters, were focused on their perception about ethical knowledge acquired in their education training, as well as comparing if variables such as semester, sex or shift influenced that perception. This approach makes possible to preview the possible trend of students' traffic across the new approved curriculum, since it already includes ethical contents. Based on the assumption that students of fifth semester must report a greater acquisition of knowledge of ethical contents, one of the objectives of this study was the creation of a questionnaire which allowed knowing this perception of ethical knowledge acquired among participants, as well as knowing their own definitions to "professional ethics" and "ethical dilemma", to know whether or not they perceive themselves enough ethically prepared to deal with patients, and finally to know their opinions about what they consider "ethical" in their teachers. When comparing the results among the variables sex, shift and semester, an (ANOVA analysis was done to compare these variables, finding that gender variable is related to perception of acquiring ethical contents $(F(13)=0.34<0.05)$, meaning that women las perceive being more prepared to carry out their practices with patients, since their teachers have taught them these ethical principles. Thus, it seems that gender variable influences the perception of the acquisition of ethical knowledge, and similarity was found in the students' responses of what they consider "ethical" in a teacher.
\end{abstract}

Keywords:

perception, ethical knowledge, college students, Psychology.

Bitácora del Artículo:

| Recibido: 1 de Agosto de 2017 | Aceptado: 1 Septiembre de 2017 | Publicado en línea: Julio-Diciembre de 2017 | 


\title{
PERCEPCIÓN DE LOS ESTUdiANTES DE LICENCIATURA RESPECTO A LOS CONOCIMIENTOS ÉTICOS ADQUIRIDOS EN LA CARRERA DE PSICOLOGÍA
}

\author{
Norma Coffin-Cabrera, Sara Guadalupe Hernández-Andrade y Lourdes Jiménez-Rentería \\ FES Iztacala, UNAM \\ México
}

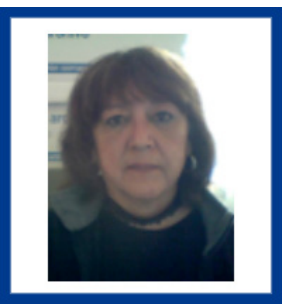

Norma Coffin-Cabrera

FES Iztacala, UNAM

Correo: coffin@unam.mx

La doctora Norma Coffin Cabrera es psicóloga egresada de la Facultad de Psicología de la UNAM. Catedrática e investigadora en la UNAM. Actualmente es profesora titular "C", en la FESI de la UNAM. Es coordinadora de la Subcomisión de Ética de la carrera de Psicología.

Ver más...

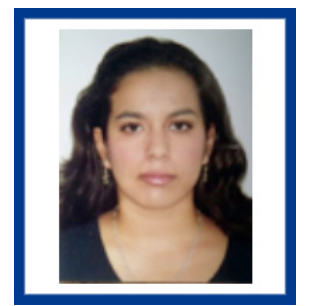

Sara Guadalupe Hernández Andrade FES Iztacala, UNAM

Correo: saragha9@gmail.com

La psicóloga Sara Guadalupe Hernández Andrade, es pasante de la carrera de Psicología de la FES Iztacala de la UNAM de la generación 2013-2016.

Ver más...

\section{CONTRIBUCIÓN DE LAS AUTORAS}

Norma Coffin-Cabrera concibió, desarrolló y coordinó el proyecto, a su vez, sesoró el análisis cuantitativo | Sara Guadalupe Hernández-Andrade realizo el marco teórico, el análisis de datos y redactó los resultados cuanti-cualitativos, elaboró tablas y figuras | Lourdes Jiménez-Rentería coordinó el análisis cualitativo y elaboró la base de datos cualitativa.

\section{AgRADECIMIENTOS}

Las autoras agradecen a la UNAM y a la FES Iztacala por permitir la realización de este estudio. Asimismo, se agradece a la Subcomisión de Ética de la Carrera de Psicología por su asesoría para el presente trabajo. | La autora Sara Hernández Andrade rinde este agradecimiento: "A mi familia,mis amigos y mi compañero de vuelos infinitos".

\section{DATOS DE Filiación DE LAS AUtORES}

Facultad de Estudios Superiores Iztacala, UNAM.

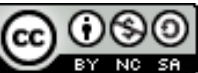

Copyright: ( 2017 Coffin-Cabrera, N., Hernández-Andrade, S.G., \& Jiménez-Rentería, L.

Este es un artículo de acceso abierto distribuido bajo los términos de la licencia Creative Commons Reconocimiento-NoComercial -Compartirlgual 4.0 Internacional, por lo que su contenido gráfico y escrito se puede compartir, copiar y redistribuir total o parcialmente sin necesidad de permiso expreso de sus autoras con la única condición de que no se puede usar con fines directamente comerciales y los términos legales de cualquier trabajo derivado deben ser los mismos que se expresan en la presente declaración. La única condición es que se cite la fuente con referencia a la Revista Digital Internacional de Psicología y Ciencia Social y a sus autoras. 


\section{TABLA DE CONTENIDO}

INTRODUCCIÓN

Objetivos, 26

MÉTODO

Variables, 27

Obtención de la muestra, 27

Instrumento, 27

Diseño

Procedimiento, 28

Consideraciones éticas, 28

Análisis estadísticos, 28

REsultados

Análisis cuantitativo, 28

Análisis cualitativo, 29

Discusión

CONCLUSIONES

REFERENCIAS

Anexos

Anexo 1, 35

Anexo 2, 36

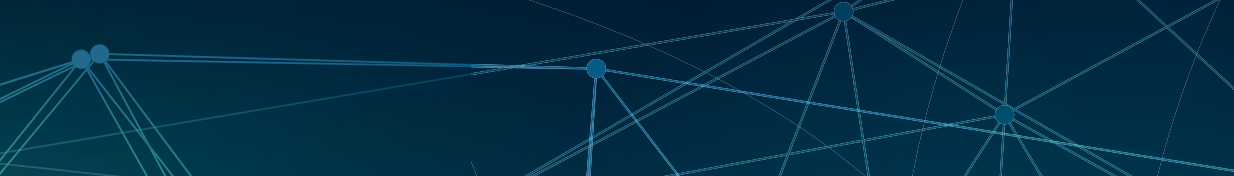




\section{INTRODUCCIÓN}

\section{A} I pensar en una ética de las profesiones, debemos primero tener claro qué es la ética o cuál es su función en la vida de los seres humanos. De acuerdo con Bolívar (2005), la ética puede explicarnos el comportamiento visto desde un enfoque universal, por lo que el comportamiento puede analizarse desde una experiencia moral humana y así decidir qué conductas pueden ser justificables, tomando en cuenta el conjunto de principios morales.

La ética profesional se puede remontar a las ciencias biológicas y de la salud, ya que, durante la Segunda Guerra Mundial, se cometieron muchísimas crueldades que violaban la dignidad de las personas cuando se realizaban experimentos con ellos, por lo que se crea el código de Nuremberg en 1947 en Alemania; es así que el primer código ético se relaciona con la ética de la investigación científica (Simón-Lorda \& Barrio, 2000, citado en Hirsch, 2011).

De aquí se desprende entonces que la ética de las profesiones, según Peña, (2010, citado en Díaz-Barriga, 2016) es una disciplina normativa orientada a analizar y promover la validez moral de los actos que realizan los profesionales en relación con los seres humanos con quienes interactúan, estableciendo los principios que guíen sus actuaciones y la intencionalidad con que se realizan, tomando como referentes los derechos humanos, el respeto a la diversidad y la justicia. Sin embargo, esto no queda solamente como un acuerdo, sino que se estipula en los códigos de ética, los cuales tienen como base los principios de los derechos humanos, tales como la dignidad, la igualdad, el respeto mutuo y la autodeterminación, entre otros (França-Tarragó, 1999).

No basta con decir que se necesita llegar a un acuerdo para establecer lo ético de lo que no lo es, sino que cada profesionista se compromete a desarrollar esta competencia, mejor denominada como "competencia ética", que de forma general también podemos denominar "competencia profesional", como la pericia o aptitud para ejercer una profesión (Nussbaum, 2005), lo cual quiere decir que la persona va desarrollando o construyendo a lo largo de su formación profesional.

Esta competencia incluye el conjunto de conocimientos, modos de actuar y actitudes que buscan sobre todo el bien de los ciudadanos a los que se les pretende brindar un servicio (Bolívar, 2005). Hirsch (2011) menciona que la ética profesional permite "la realización del bien social y la justicia", y que además se relaciona fuertemente con los proyectos de vida de cada ser humano. Las autora considera que son tres los valores importantes dentro de la ética profesional: autonomía, responsabilidad y competencia profesional; y tres los principios fundamentales de la ética profesional: beneficencia, autonomía y justicia.

Ahora bien, ¿cómo se pueden desarrollar estas competencias éticas?; una buena opción es la institución universitaria como la encargada de que esto sea posible; por ejemplo, en el Espacio Europeo de Educación Superior se sigue un modelo propuesto por el denominado Proyecto Tuning, el cual incluye una serie de competencias que se deben desarrollar. Dentro de las competencias interpersonales se incluye un "compromiso ético", que se refiere principalmente a la profesionalidad y compromiso con que deben contar los futuros profesionales para dar un buen servicio a la ciudadanía; es decir, que englobe los valores sociales que se mencionaron anteriormente para preservar la dignidad de todos los seres humanos.

Por tanto, uno de los quehaceres fundamentales en el que debe enfocarse la educación universitaria es el brindar las herramientas a los estudiantes para que desarrollen un pensamiento crítico, el respeto a la diversidad y la capacidad de tomar decisiones con justicia, entre otros. De modo que no se puede reducir el "profesionalismo" a las competencias técnicas y cognitivas, sino también a las competencias éticas que garanticen confianza a las personas que solicitan servicio.

El caso de la formación profesional en México, específicamente en el caso de la psicología, y de acuerdo con lo mencionado por Urbino (1992, citado en Colín y Camarena, 2012), el psicólogo se conceptualiza como un profesionista universitario cuyo objeto de estudio es el comportamiento humano individual y social, que a partir de la investigación de los procesos cognoscitivos-afectivos y de su interacción con el entorno, es un promotor del desarrollo humano que debe ser consciente de sus responsabilidades éticas para consigo mismo y la sociedad, siendo su función genérica la de intervenir como experto del comportamiento en la promoción del cambio individual y social desde una perspectiva interdisciplinaria. Sin embargo, antes de llegar a esta definición se puede retomar el caso de la Universidad Nacional Autónoma de México (UNAM), al ser considerada una de las mejores universidades de Latinoamérica. Empero, la UNAM, a partir de 1977, se mantuvo con el octavo plan de estudios hasta su posterior modificación en 1998 (Colín \& Camarena, 2012). Anteriormente algunos investigadores como Lizárraga (1986, citado en Colín y Camarena, 2012) encontraron deficiencias en el plan de estudios, por ejemplo, que era de carácter más informativo que formativo, ya que sólo se centraba en la adquisición 
de conocimientos y no de la misma manera en el desarrollo de un criterio o estimulación para analizar y resolver problemas, pensamiento autónomo y autorreflexivo, formación de estrategias de estudio, ánimo de innovación e investigación (Colín y Camarena, 2012).

Estos autores refieren que mientras transcurría la primera década de los noventa, la doctora Sandra Castañeda integró un grupo de psicólogos con representantes de las diferentes instituciones formadoras en la profesión de psicología en la República Mexicana - ya que ella era la encargada del desarrollo de indicadores para la certificación de la profesión-. Juntos definieron un modelo que incluía el desarrollo de siete competencias: conceptual, técnica, adaptativa, metodológica, contextual, ética e integrativa. Ante esto, algunas facultades desarrollaron su currículo de acuerdo con estas competencias. Los autores sostienen que en el caso de la Facultad de Estudios Superiores Iztacala (FESI) se tomaron como base competencias generales basadas en las funciones profesionales del psicólogo: evaluación, diagnóstico, intervención, prevención, planeación e investigación. Es hasta 2016 cuando la FESI decide hacer nuevos cambios al plan curricular, entre los que destacan la adopción de contenidos éticos en algunas materias, como Introducción a ámbitos profesionales I y II, Taller de integración universitaria II, Tradiciones y aplicaciones en psicología I, Dimensión social en psicología I y II, Estrategias metodológicas III, Taller de formación profesional II y Social teórica I (véase referencias).

Para especificar la enseñanza de contenidos éticos Pasmanik y Winkler (2009) mencionan la importancia de la enseñanza de la ética en los primeros años de la carrera, ya que es una clave para la identificación con la profesión, además de la interiorización de los principios éticos y el desarrollo de la autonomía moral, es decir, la capacidad de identificar los problemas que de alguna forma no están previstos en los códigos vigentes. Al respecto, Aguirre-Tobón y Díaz-Barriga (2004, citado en Barriga, 2016: 46) mencionan la relevancia de:

Introducir en el currículo y la enseñanza de la ética, diversidad de enfoques que enfatizan el pensamiento crítico, la reflexión, el análisis empático de situaciones reales y la emoción moral como componentes clave, los diferentes enfoques educativos, el análisis de dilemas ético-morales, la discusión de casos reales (en este punto llama la atención como coincide Bolívar [2005], al mencionar que esta estrategia es interesante para iniciar la reflexión y el desarrollo moral tanto de dilemas éticos como de situaciones controvertidas socialmente, Identificación de comportamientos no éticos en el ámbito de la investigación), la práctica y la docencia de la profesión, la revisión crítica de literatura propia del campo disciplinar desde una perspectiva ética, el uso de estrategias de role-playing, simulación de situaciones de conflictos éticos en la profesión, la narración de incidentes críticos con implicaciones éticas que la persona ha vivido o testificado, la lectura comprensiva y crítica de algunos autores clásicos y contemporáneos que discuten el tema de la moral, y la ética o los códigos de conducta profesionales.

Sobre todo, las autoras destacan la importancia de recurrir a enfoques de una "ética aplicada", refiriendo que en este tipo de experiencias educativas es importante que los estudiantes universitarios puedan identificar la problemática subyacente y las partes o perspectivas en conflicto, y argumentar en torno a las implicaciones éticas con base en evidencias y marcos normativos, tomando como referente los principios básicos del ejercicio de una profesión: máximo beneficio, evitación del daño, justicia y competencia.

De la misma forma coinciden Pérez y Cabezas (2007, citado en Guitart, 2007), pues mencionan que la mejor forma de enseñar contenidos éticos es justamente la combinación de la teoría con la práctica, es decir, tener bases filosóficas y epistemológicas de la ética (Maliandi, 2002, citado en Guitart, 2007), junto con el análisis de casos reales, planteamientos de problemas y simulación de un Comité de Ética (cabe mencionar que dentro de la FESI existe una Comisión de Ética y una Subcomisión de Ética de la carrera de Psicología).

Bolívar (2005) menciona la importancia de incluir: a) conocimientos especializados, b) habilidades técnicas de actuación y c) marco de conducta en la actuación profesional. No obstante, Hortal (1995, citado en Hirsch, 2003) menciona que la introducción de materias y contenidos éticos en los planes de estudio no es suficiente ni resuelve el hecho de que los alumnos adquieran una formación profesional, pues se necesita que se incentive en ellos el uso de un criterio racional y crítico, que tomen conciencia de la importancia que es prestar servicios y bienes a la sociedad, así como las obligaciones y compromiso que implica, puesto que durante el ejercicio de la profesión surgen conflictos y dilemas éticos a los que se tendrán que enfrentar con ayuda de las herramientas que adquirieron durante su estancia en la universidad.

Respecto a los dilemas éticos, hay que tomar en cuenta que éstos pueden surgir en cualquier momento y es deber del profesional tener la capacidad para saber cómo enfrentar la situación y tomar decisiones; sin embargo, primero es necesario definir qué es un dilema ético. Del Río (2007) lo define como cuando entran en colisión dos deberes de obligado cumplimiento o, dicho de otra manera, cuando la única forma de cumplir con una obligación sea infringiendo otra, mientras que Louise Terry (2007, citado en Hirsch, 
2011) considera que las diversas obligaciones de los profesionales pueden entrar en conflicto, y con ello pueden surgir los dilemas, los cuales pueden producirse cuando hay dos o más posibles explicaciones de una misma situación.

Al respecto, Guitart (2007) realizó una investigación en donde se les impartió un seminario acerca de la ética profesional del psicólogo. Se les preguntaba a los estudiantes lo que ellos creían que era un dilema ético, antes y después del seminario. Se asignó el valor de cero para las definiciones incorrectas y el valor de 1 para la definición "dos o más principios éticos o normativos contradictorios que suponen una dificultad en la toma de decisiones". Se realizó una prueba T para muestras relacionadas y se encontró que los estudiantes realizaron mejores definiciones después de realizar el programa formativo, aunque hubo $14 \%$ de los estudiantes que seguían definiendo ambigua o incorrectamente el concepto. Esto quiere decir que faltaría introducir la revisión de contenidos éticos para su análisis, así como la preparación de los alumnos cuando se enfrenten a estas situaciones en su ejercicio profesional.

En otra investigación en Bogotá, realizada por González, Gómez, Espinosa, Cárdenas, Garzón, Montoya, Núñez, Solano y Tarquino (2007), diseñaron un instrumento que evaluó el nivel de desarrollo de cinco competencias éticas, las cuales se definieron como discernimiento ético, recto obrar, responsabilidad social, respeto por la dignidad humana y sentido moral. Dichas categorías se construyeron a partir de la implementación de estrategias como grupo focal, construcción de dilemas morales y entrevista semiestructurada, éstas con la finalidad de obtener más información acerca del proceso de reflexión ético que llevan a cabo los entrevistados para responder al dilema. Se aplicó el instrumento a 100 estudiantes de cinco facultades de Psicología de Bogotá. Se compararon estudiantes de primero y último año, y los parámetros de calificación fueron: deficiente, aceptable, satisfactorio y sobresaliente. Se encontró que $80 \%$ de los estudiantes evaluados se encuentra en un nivel de desarrollo "deficiente" y "aceptable" de las competencias, y $20 \%$ está en un nivel "satisfactorio"; en este último se tomó en cuenta sólo a los estudiantes del último año; además se encontró que las mujeres del último año presentaron un mayor desarrollo de las competencias evaluadas.

Para hablar de ética profesional dentro de un plan de estudios en la Universidad, es necesario pensar en los docentes que se van a dar a la tarea de impartir estos conocimientos y de incentivar el desarrollo de competencias éticas en sus alumnos, ya que el ejercicio de la docencia exige dominar el conocimiento y competen- cias que han de ejercer en la institución (además de actualización continua). Al respecto, García García (2010) menciona que en diversos informes se han encontrado características de un buen profesor: compromiso con la profesión, afectividad con los alumnos, conocimiento de la materia que enseña, empleo de técnicas didácticas adecuadas, trabajo colaborativo en grupo de profesores, pensamiento reflexivo y crítico, y motivación por la calidad, entre otros. Además menciona que el objetivo primordial de la educación es el desarrollo en los alumnos de habilidades cognitivas, afectivas, morales y sociales. El compromiso del profesor reside en su amor por su trabajo, su vocación y la conciencia de que es el propio alumno el que va a desarrollar su formación.

Al respecto, Valladares y Lazo (2011) realizaron una investigación en Lima con el objetivo de conocer cómo percibe el docente su ética profesional y si hay una relación significativa con su desempeño laboral. Para ello utilizaron el Inventario de Comportamiento Ético Docente de Ana Hirsch (2005), y el Inventario de Desempeño Laboral de Manuel Torres (s/a, citado en Valladares y Lazo, 2011). El instrumento fue aplicado a 304 docentes de nueve instituciones educativas. Se encontró que existe una correlación significativa entre la percepción de ética profesional y el desempeño docente. Por lo tanto, la formación y capacitación de los docentes es parte importante al momento de ejercer su función dentro del aula, ya que se necesita una preparación ética, técnica y académica.

Con base en esto, las preguntas de investigación en este estudio fueron:

- ¿Los alumnos perciben que aprenden contenidos éticos durante su Licenciatura en Psicología?

- ¿Qué es lo que los alumnos definen como "ética profesional"?

- ¿Los maestros son percibidos como éticos o no éticos?

- ¿Qué es lo que los alumnos definen como "ético" en un profesor?

\section{Objetivos}

Objetivo general: Comparar la percepción de los estudiantes de Psicología de 1o. y 5o. semestres respecto al aprendizaje de ética profesional que han adquirido en su formación académica al momento de la aplicación del cuestionario.

\section{Objetivos específicos}

1. Elaborar un cuestionario para conocer la percepción de los alumnos respecto a la adquisición de conocimientos éticos (anexo). 
2. Conocer si el semestre, sexo y/o el turno son variables que pueden afectar la percepción de los alumnos respecto al conocimiento ético adquirido.

3. Comparar la opinión de los alumnos de 1o. y 5o. semestres respecto a lo que consideran ético en un profesor.

4. Comparar las respuestas de los alumnos de 1 o. y 5o. semestres respecto a la definición de "dilema ético" y "ética profesional".

5. Comparar la percepción de adquisición de conocimientos éticos de los alumnos de 1 o. y 5o. semestres para iniciar su práctica con pacientes.

\section{MÉTodo}

La Hipótesis Nula del estudio fue que no habría diferencias significativas respecto a las variables semestre, sexo y turno en la percepción de los alumnos sobre los conocimientos éticos adquiridos, y su percepción en cuanto a la ética de los profesores.

La Hipótesis Alterna fue que habría diferencias significativas respecto a las variable semestre, sexo y turno en la percepción de los alumnos acerca de los conocimientos éticos adquiridos y su percepción en cuanto a la ética de los profesores.

\section{Variables}

Las variables de interés fueron: semestre (1o. y 5o.), considerando que en el primer semestre los alumnos de Licenciatura no han obtenido conocimientos de principios éticos en la Psicología, y en 5o. semestre, ya que en este grado asisten a impartir prácticas con paciente y es importante tener idea de los conocimientos éticos con que cuentan, como el uso del consentimiento informado.

En cuanto a la variable de interés sexo, se pretendió saber si las percepciones acerca de los conocimientos éticos adquiridos variaron de acuerdo con el género (masculino, femenino). Y la variable de estudio turno (matutino o vespertino) fue considerada, ya que en la población vespertina generalmente los estudiantes de pregrado trabajan y podrían percibir el contar con la adquisición de conocimientos éticos.

Estas variables se correlacionaron con la variable adquisición de conocimientos éticos, la cual puede definirse de acuerdo con Aguirre-Tobón y Díaz-Barriga (2004), así como Díaz-Barriga, Pérez-Rendon y Lara Gutiérrez (2016), quienes mencionan la relevancia de

Introducir en el currículo y la enseñanza de la ética, diversidad de enfoques en enfatizan el pensamiento crítico, la reflexión, el análisis empático de situaciones reales y la emoción moral como componentes clave, los diferentes enfoques educativos, el análisis de dilemas ético-morales, la discusión de casos reales (en este punto Ilama la atención como coincide Bolívar [2005], al mencionar que esta estrategia es interesante para iniciar la reflexión y el desarrollo moral tanto de dilemas éticos como de situaciones controvertidas socialmente, identificación de comportamientos no éticos en el ámbito de la investigación), la práctica y la docencia de la profesión, la revisión crítica de literatura propia del campo disciplinar desde una perspectiva ética, el uso de estrategias de role-playing, simulación de situaciones de conflictos éticos en la profesión, la narración de incidentes críticos con implicaciones éticas que la persona ha vivido o testificado, la lectura comprensiva y crítica de algunos autores clásicos y contemporáneos que discuten el tema de la moral, y la ética o los códigos de conducta profesionales (Díaz Barriga, 2004: 46).

\section{Obtención de la muestra}

La muestra fue no-probabilística por conveniencia. Se escogió un día de la semana y un horario en que se pudieran elegir grupos de 1o. y 5o. semestres del turno matutino y vespertino de la carrera de Psicología en la FESI. A continuación se pedía permiso al profesor en turno para la aplicación de los cuestionarios. Este procedimiento se repitió hasta conseguir una muestra total de 193 estudiantes.

\section{Participantes}

La muestra estuvo conformada por 193 participantes, alumnos de la carrera de Psicología (134 mujeres y 59 hombres), pertenecientes a los semestres 1o. $(\mathrm{N}=97 ; 63$ del sexo femenino y 34 del sexo masculino) y 5o. ( $\mathrm{N}=96$; 71 del sexo femenino y 25 del sexo masculino). Las unidades de análisis fueron los grupos: cuatro grupos de primer semestre (siendo uno del turno matutino) y cinco grupos de quinto semestre (siendo tres del turno vespertino).

\section{Instrumento}

Se creó un cuestionario con un total de 11 preguntas (anexo 1 ), de las cuales cinco presentan cuatro indicadores de respuesta (ninguna clase, pocas clases, algunas clases y mayoría de clases), cuatro preguntas son dicotómicas (sí, no) y tres preguntas son abiertas, con un alfa de Chronbach moderado de 0.682 (respecto a las preguntas con cuatro opciones de respuesta) y de $\partial=0.648$ para todo el cuestionario.

Para su construcción, se basó en la teoría y algunas investigaciones antes mencionadas (Guitart, 2007; García García, 2010, y Hirsch, 2011); además se sometió a revisión por parte del Comité de Ética de la FESI. Al 
principio fueron 12 preguntas, pero después de algunas revisiones se decidió eliminar una pregunta del cuestionario y algunas modificaciones de redacción en otras preguntas; como resultado se obtuvo un cuestionario de 11 preguntas (anexo 1). Por tanto, en el cuestionario se preguntó a los alumnos si percibían que se enseñaba análisis de dilemas éticos-morales, comportamientos no éticos en algún ámbito de aplicación de la psicología, juegos de roles para ejemplificar dilemas éticos y revisión crítica de la literatura contemporánea sobre ética (anexo 1, preguntas 3, 4, 5, 6 y 7). Adicional a esto, las preguntas 1 y 2 fueron dicotómicas (sí, no) y con opción a dar su respuesta de manera abierta, mientras que las preguntas 10 y 11 fueron preguntas totalmente abiertas (anexo).

\section{Diseño}

El diseño de esta investigación fue no experimental transversal cuanti-cualitativo, de tipo descriptivo ex post-facto.

\section{Procedimiento}

A los participantes se les proporcionó un consentimiento informado grupal (véase el apartado "Consideraciones éticas"). Se les indicó leer las instrucciones y subrayar la respuesta que más se adecuara a lo que estaban revisando en las asignaturas o, dado el caso, escribir su opinión; asimismo se les recordó que no era una evaluación académica, sino que la información proporcionada sería para fines de investigación. Se hizo énfasis en la importancia de su colaboración y veracidad de las respuestas. El tiempo para contestarlo fue libre.

\section{Consideraciones éticas}

A los participantes se les proporcionó un consentimiento informado grupal, contenido en el cuestionario, el cual explicaba el objetivo del estudio, solicitando su colaboración voluntaria y anónima, y asegurando guardar la confidencialidad. Se les informó que los datos se registrarían en una base de datos con contraseña, a la cual sólo la asesora y la investigadora tendrían acceso. Dicha base sería destruida después de cinco años. Los datos se utilizarían en publicaciones y eventos de divulgación salvaguardando su identidad. Los participantes podrían suspender la respuesta al cuestionario en cualquier momento, y retirarse del estudio sin ninguna consecuencia. Se les proporcionó el correo de la investigadora responsable para futuras dudas. El presente estudio se deriva de un proyecto madre, el cual cuenta con el VoBo de la Comisión de Ética de la FES Iztacala, UNAM (anexo ).

\section{Análisis estadísticos}

El presente estudio es cuanti-cualitativo. El análisis cuantitativo analizó los datos obtenidos del cuestionario (SPSS, 20.0), utilizando una metodología estadística. El análisis cualitativo analizará las preguntas formuladas de manera abierta, con el objetivo de considerar todas las categorías de respuestas, obteniendo un análisis más fino de las percepciones reportadas.

Una vez resueltos los cuestionarios, se capturaron los ítems en una base de datos en SPSS (20.0) y se realizaron análisis estadísticos descriptivos de la muestra y comparaciones entre grupos mediante ANOVA (semestre, turno y sexo) y $t$ de Student. En cuanto al análisis cualitativo, las respuestas dadas por los estudiantes se vaciaron a una base de datos en Excel y se procedió a la ordenación por categorías para poder comparar las respuestas y opiniones de los alumnos.

\section{Resultados}

\section{Análisis cuantitativo}

En principio se realizaron varias pruebas t de Student para muestras independientes, comparando el total de la muestra con las variables sexo, turno y semestre con la percepción de la adquisición de contenidos éticos reportados, contenidos en las preguntas de opción múltiple del cuestionario (anexo 1, preguntas 3, 4, 5, 6 y 7), para observar si existían diferencias significativas.

En cuanto a la variable sexo, al comparar hombres y mujeres se obtuvo una $\mathrm{t}(113.319)=0.411 ; p>0.05$, por lo que no existen diferencias significativas entre los sexos. Respecto a la variable semestre, al comparar a los alumnos de 10. y 5o. semestres, el resultado fue de $\mathrm{t}$ (187.758) $=-0.287 ; p>0.05$, por lo que tampoco hay diferencias significativas entre semestres. Por último, respecto a la variable turno (matutino y vespertino), el resultado fue de $\mathrm{t}(163.557)=0.779 ; \mathrm{p}>0.05$, por lo que tampoco hay diferencias significativas entre los turnos.

Adicional a esto se realizó un análisis de varianza (ANOVA) para comparar las mismas variables, encontrándose que la variable sexo influye en la percepción de adquisición de contenidos éticos $F(13)=0.34<0.05$.

Respecto a algunas preguntas del cuestionario (1, $2,8,9$ y 10), se realizaron frecuencias y sus respectivos porcentajes, en relación con las variables semestre, turno y sexo, ya que son interesantes algunos datos encontrados que se presentan a continuación.

En cuanto a la variable sexo, en la figura 1 se puede observar que en la pregunta 1 ("¿Sabes qué es la ética profesional?") la mayoría de las mujeres y los hombres 
se concentran en la respuesta con el indicador "No". Lo mismo sucede para las variables turno y semestre.

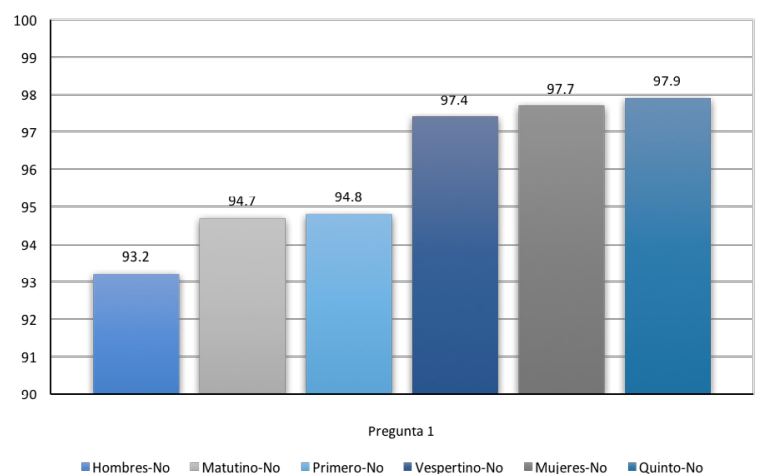

Figura 1.

¿Sabes qué es la "ética profesional"? (Porcentaje)

En la figura 2, respecto a la pregunta 2 ("¿Sabes qué es un dilema ético"?), la mayoría reportan "No" como respuesta principal para las tres variables (sexo, turno y semestre).

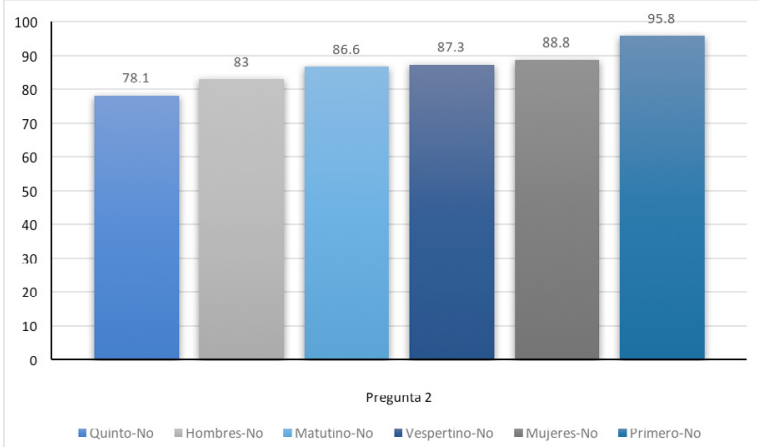

Figura 2.

¿Sabes qué es un "dilema ético"? (Porcentaje)

Referente a la pregunta 8 ( $¿$ Has revisado de manera crítica literatura clásica y/o contemporánea donde aborden la ética, o códigos de conducta profesionales?"), respecto a la variable sexo, mujeres y hombres se inclinan a responder "Pocas clases" (48.5 y $47.4 \%$ ). De igual forma en la variable turno, matutino (54.6\%) y vespertino $(44 \%)$. Y en torno a la variable $1 \mathrm{er}$. semestre $(47.4 \%)$ y 5 o. semestre (48.9\%) (figura 3$)$.

En la pregunta $9(" i$ Te sientes preparado para llevar a cabo tu práctica con un paciente en la CUSI, respecto a la ética profesional que debes tener?"), se observa en la figura 4 que las mujeres se inclinan a la respuesta " $\mathrm{Si}^{\prime \prime}$ (53.7\%) mientras que los hombres se inclinan a "No" (59.3\%); respecto a la variable turno, la mayoría reporta que "Si" en el matutino $(53.3 \%)$ y "No" en el vespertino (52.54\%). En cuanto a la variable semestre, el 1o. reporta en su mayoría que "Sí" (68\%), mientras que el 5o. que "No" (68.7\%) (figura 4).

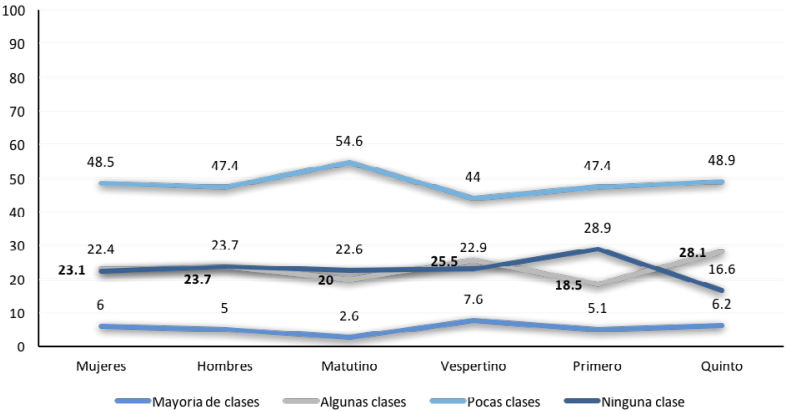

Figura 3.

¿Has revisado de manera crítica literatura clásica y/o contemporánea donde aborden la ética, o códigos de conducta profesionales? (Porcentaje)

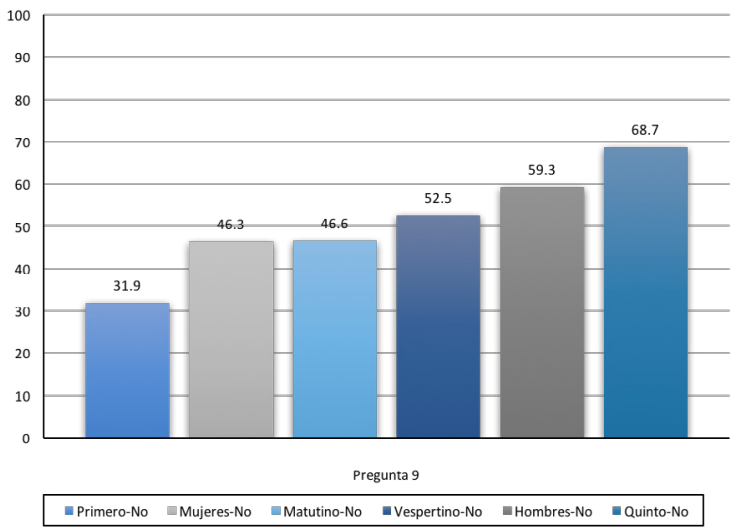

Figura 4.

¿Te sientes preparado para llevar realizar tu práctica con un paciente en la CUSI, respecto a la ética profesional que debes tener? (Porcentaje)

De igual manera en la pregunta $10\left({ }^{\prime}\right.$ Crees que tus profesores te han enseñado lo suficiente respecto a la ética profesional en psicología?"), las mujeres responden "Sí" (56\%) mientras que los hombres responden "No" (57.6\%). En cuanto a la variable turno, tanto el matutino y como el vespertino se inclinan por "Sí", al igual que en la variable semestre, tanto 10. como 5o. (figura 5). Se puede interpretar entonces que las mujeres, el turno matutino y el 1er. semestre se consideran mejor preparados para realizar su práctica profesional en la Clínica Universitaria de Salud Integral (CUSI), porque sus profesores les han enseñado lo suficiente. 


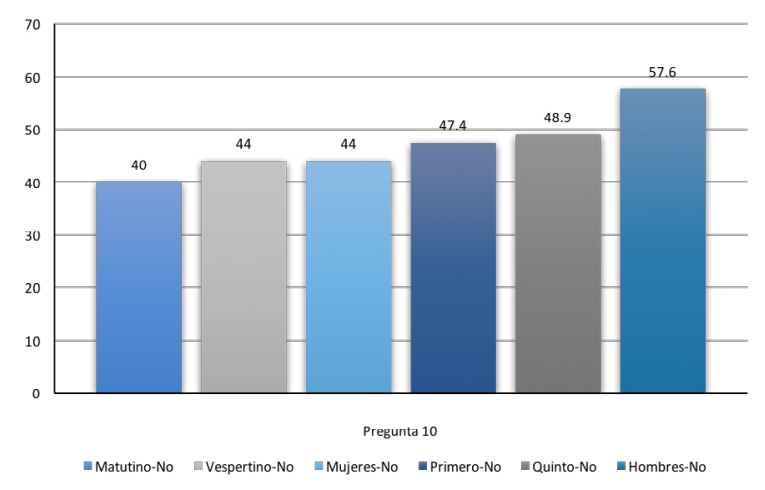

Figura 5.

¿Crees que tus profesores te han enseñado lo suficiente respecto a la ética profesional en Psicología.

\section{Análisis cualitativo}

En cuanto a los análisis cualitativos, se encontró que en la pregunta 1 ("¿Sabes qué es la ética profesional?"), los alumnos tenían opción de subrayar "Sí" o "NO", además de escribir la definición que ellos consideraran correcta.

Referente a los alumnos de 1 er. semestre, $94.8 \%$ respondieron que "Sí" sabían y sólo $5.1 \%$ que "No" sabían que es la ética profesional; de $94.8 \%$ que respondieron que "Sí", sólo 49.5\% de los alumnos escribió la definición correctamente retomando la definición de Hirsch (2011), mientras que el resto respondió de forma incorrecta o no hubo respuesta. Por ejemplo, para las respuestas que se consideraron correctas: "normas morales, reglas, valores", "código que debe seguir un profesionista en su carrera", "lo que debes hacer para preservar la integridad del cliente", y para las que se consideraron incorrectas o incompletas: "no revelar información del paciente", "respetar al paciente". Se puede decir que la mitad de los alumnos sabe qué es la ética profesional.

Ahora, respecto a los alumnos de 50 . semestre sucede de forma similar; $97.9 \%$ responden "Sí" y solo $2 \%$ responden que "No" saben qué es la ética profesional; de los alumnos que contestaron "Sí" sólo 48.9\% indican la definición correcta, mientras que el resto responde de forma incorrecta o no lo hace. Por ejemplo, para las respuestas que se tomaron como correctas: "problemática en la cual no se tiene clara la manera de actuar, aunque se sepa qué es lo correcto", "cuando tienes que decidir entre dos cosas moralmente vistas como bueno o malo", "en un problema no sabes cuál sería la mejor manera para solucionarlo"; y para las respuestas que se consideraron incorrectas o incompletas: "problemática que involucra los valores o moral de la persona", "conflicto entre lo moral y lo correcto", "decisión entre romper o no el código ético". De igual manera, la mitad de los alumnos sabe qué es la ética profesional.

En tanto, en la pregunta 2 " ¿Sabes qué es un 'dilema ético?' ") a los alumnos de 1er. semestre les fue difícil establecer las respuestas correctas, aun teniendo las definiciones de Del Río (2007), ya que de forma general los alumnos respondían que se trataba de tomar una decisión y que involucraba un problema con el bienestar del paciente; sin embargo no se ajustaban exactamente a la definición dada por los teóricos, y en algún punto las respuestas tanto de 1o. como de 5o. semestre eran parecidas.

El 95.9\% respondió que "Sí" sabía, y de este porcentaje sólo $38.14 \%$ respondió que un dilema ético es: "una problemática que se presenta en el ejercicio de tu profesión en la que no sabes qué decidir", es decir, no es la respuesta esperada, pero tampoco es del todo errada. Mientras que $61.85 \%$ respondió que "es un conflicto que involucra los valores o la moral de la persona, en la que no sabes qué es lo correcto, o en la que se pone en juego tu ética o la violación del código ético", entre estos alumnos se incluyen los que no dieron respuesta.

Mientras que en los alumnos de 50 . semestre $78.1 \%$ dijo que "Sí" sabe qué es un dilema ético, de este porcentaje sólo $33.3 \%$ refiere de forma más acercada a la propuesta de Del Río (2007) y Louis Terry (2007, citado en Hirsch, 2011), ellos mencionan que "es un conflicto que surge en el ejercicio profesional, en el que no sabes qué decisión tomar, pues cualquiera de las dos tiene repercusiones positivas y negativas"; sin embargo, aún faltaba mencionar que "es una contraposición entre dos lineamientos del código". El 66.6\% que se consideraron respuestas incorrectas eran parecidas a las de los alumnos de 1er. semestre: "un conflicto en el que se ponen en juego tus valores, tu ética como profesionista, en el que se tiene que romper el código ético".

Por lo tanto, se puede afirmar que ambos semestres tienen una idea general de lo que es un dilema ético, pero aún sus respuestas se quedan incompletas si nos apegamos a las definiciones encontradas en la teoría.

En la pregunta 9 (" $i$ Te sientes preparado para llevar a cabo tu práctica con un paciente de la CUSI, respecto a la ética profesional que debes tener?"), es interesante porque los alumnos de 1 er. semestre, $68 \%$ responden que "Sí" se sienten preparados y de 5o. (68.7\%) responden que "No". En el caso de que su respuesta fuera "No", en otra pregunta se les solicitaba "En caso de que tu respuesta haya sido ' $\mathrm{No}^{\prime}$, ¿qué te gustaría ver en tus clases para sentirte preparado para tratar a un paciente?"; para ordenar sus respuestas se crearon categorías (tabla 1). 
Tabla 1.

Categorías de respuesta de los alumnos respecto a la pregunta 9.

$\begin{array}{ccc} & & \\ \text { Categorías } & 1 \text { ER. } & 50 . \\ & \text { SEMestre } & \text { SEMEstre }\end{array}$

Los profesores enseñan bien, pero yo

no entiendo.

1

Más práctica (ejemplos reales-

cotidianos, role-playing, casos

clínicos, experiencias del profesor,

intervención, actitud y trato al

paciente).

Más teoría (literatura, cursos,

conferencias, código ético, dilemas

éticos, metodología).

$17 \quad 5$

Aún nos falta mucho por aprender/

Depende de mí si me siento capaz.

32

Referente al paciente, sus derechos,

entrevista a la familia, su reacción.

Sin respuesta.

13

72

Alumnos que responden no sentirse preparados.

66

30

Llama la atención que en ambos semestres la categoría más alta fue "Más práctica" con un índice de 56 y $56.6 \%$ para primer y 50 . semestre (tomando en cuenta sólo los alumnos que mencionaron "No" sentirse preparados). Además esto se relaciona con los resultados obtenidos en los análisis por género, turno y semestre, que respondían en la pregunta 7 ("Pocas clases"), es decir, que no realizan juego de roles (role-playing) para ejemplificar situaciones que impliquen un dilema ético.

Ahora, en cuanto a la pregunta $10\left({ }^{\prime} i\right.$ Crees que tus profesores te han enseñado lo suficiente respecto a la ética profesional en psicología?)., ambos semestres responden "Sí"; los de 1o. con 52.5\% y los de 5o. con $51 \%$, aunque podría decirse que en ambos semestres la mitad refiere "Sí" y la otra mitad "No".

En cuanto a las preguntas 11 ("¿Para ti, qué características son importantes para considerar a un profesor 'ético profesional'?") y 12 "¿Para ti, qué características son importantes para considerar a un profesor como 'no ético profesional'?"), se retomaron las categorías propuestas por Hirsch (2011) para ordenar las respuestas en cuanto a lo que consideran "un profesor ético", mientras que se retomaron las categorías propuestas por Martínez Navarro (2010) para ordenar lo que consideran como "un profesor no ético". Es importante mencionar que surgieron algunas subcategorías que no estaban consideradas, por lo que se añadieron a las categorías que se consideraron correspondientes; todo el procedimiento se realizó entre dos investigadores para una mayor confiabilidad (tabla 2).

Tabla 2.

Categorías de respuesta para las preguntas 11 y 12 .

\begin{tabular}{|c|c|c|c|c|c|c|}
\hline & Ético & 10. & 50. & No ÉTıco & 10. & 50 \\
\hline \multirow{10}{*}{ Éticas } & $\begin{array}{l}\text { Actuar con la } \\
\text { idea de prestar el } \\
\text { mejor servicio a } \\
\text { la sociedad. }\end{array}$ & 1 & 0 & Egoísta. & 6 & 8 \\
\hline & $\begin{array}{l}\text { Actuar con } \\
\text { sujeción a } \\
\text { principios } \\
\text { morales y valores } \\
\text { profesionales. }\end{array}$ & 35 & 15 & Subjetivo. & 13 & 8 \\
\hline & $\begin{array}{l}\text { Ética profesional } \\
\text { y personal. }\end{array}$ & 34 & 55 & $\begin{array}{l}\text { Sin ética } \\
\text { profesional. }\end{array}$ & 35 & \\
\hline & Honestidad. & 15 & 3 & Deshonesto. & 13 & 8 \\
\hline & Respeto. & 30 & 28 & Irrespetuoso. & 34 & 23 \\
\hline & & & & Irresponsable. & 15 & 17 \\
\hline & Responsabilidad. & 12 & & Soborno. & 3 & 4 \\
\hline & & & & Acoso. & 1 & 2 \\
\hline & \multirow{2}{*}{ Total } & 12 & 11 & \multirow{2}{*}{ Total } & 12 & 10 \\
\hline & & 7 & 3 & & 0 & 6 \\
\hline \multirow{3}{*}{$\begin{array}{l}\text { Afectivo } \\
\text { emocionales }\end{array}$} & $\begin{array}{l}\text { Capacidad } \\
\text { emocional. }\end{array}$ & 12 & 4 & Paternalismo. & 1 & 0 \\
\hline & $\begin{array}{l}\text { Identificarse con } \\
\text { la profesión. }\end{array}$ & 1 & 4 & $\begin{array}{l}\text { Familiarización } \\
\text { en exceso. }\end{array}$ & 8 & 6 \\
\hline & Total & 13 & 8 & Total & 9 & 6 \\
\hline
\end{tabular}

Conocimiento, formación, preparación y competencia profesional.

Competencias técnicas.

Cognitivas y técnicas

$$
\text { nicas. }
$$

$$
13 \quad 3 \quad \begin{aligned}
& \text { Poca o nula } \\
& \text { formación } \\
& \text { profesional. }
\end{aligned}
$$


profesor ético como no ético en ambos semestres; se puede suponer como una posible explicación es que el sólo hecho de escuchar "ética" es indicio de que las respuestas van a estar dirigidas a la coherencia con esa palabra; sin embargo, en las subcategorías resalta "Ética profesional y personal" como la más alta en cuanto a frecuencia para 10. y 5o. semestres. Para tener un panorama más amplio, en esta subcategoría se englobaron respuestas de los alumnos como: "se rige por el código ético, tiene valores, es congruente, no se involucra con los pacientes ni alumnos, respeta la confidencialidad". Sin embargo, llama la atención que en ambos rubros de ético y no ético de ambos semestres sobresalen también subcategorías como:

- "Actuar con sujeción a principios morales y valores profesionales" (se incluyeron dentro de "ético": objetivo al calificar, igualitario, justo, no se deja sobornar).

- "Honestidad" (se incluyeron como "no ético": deshonesto = corrupto, no sigue sus propias reglas, es "barco").

- "Respeto" (se incluyeron como "no ético": irrespetuoso = discrimina, es altanero, intolerante, autoritario, grosero).

- "Responsabilidad" (se incluyeron dentro de "ético": puntual, comprometido, disciplinado).

Se puede decir que existe una correspondencia entre lo que consideran ético y no ético, por lo que puede explicarse a lo que los mismos alumnos viven día con día con sus profesores, es decir, no es un ideal de lo que esperan de sus profesores, sino que es posible que sea su realidad de la que esperan un cambio.

En seguida, en la categoría "Competencias afectivo emocionales", en cuanto a profesores éticos sobresalen las subcategorías "Capacidad emocional", en donde se incluyeron respuestas como "empático, comprensivo, amable, paciente, tolerante" ${ }^{\prime \prime}$ mientras que en profesores no éticos sobresale "familiarización en exceso", es decir, "involucra sus sentimientos con la clase, tiene una relación sentimental con los alumnos". Respecto a las "Competencias cognitivas y técnicas", en cuanto a profesores éticos destaca la subcategoría "Conocimiento, formación, preparación y competencia profesional" para los de $1 \mathrm{er}$. semestre, y "Competencias técnicas" para los de 5o.; en esta última se consideraron "buen docente, apoya a sus alumnos para que realmente aprendan, tiene control de grupo/situaciones".

Para finalizar, es posible concluir que tanto los alumnos de 1o. y 5o. semestres coinciden acerca de lo que consideran "ético" y "no ético" de sus profesores; además es necesario tener en cuenta que sus respuestas son el vivo ejemplo de lo que acontecen día a día en sus clases, por lo que no se pueden ignorar su respuestas aunque no se ajusten a las definiciones de los teóricos, sino que es una oportunidad para detectar qué está sucediendo en la escuela y cómo se pueden proponer soluciones.

\section{Discusión}

En primer lugar, se puede afirmar que se cumplió con los objetivos planteados en la presente investigación, pues fue posible conocer la percepción de los estudiantes de psicología de 1o. y 5o. semestres respecto al aprendizaje de la ética profesional que han construido en su formación de Licenciatura, además de comparar los resultados por sexo, turno y semestre, en donde se observó que la variable sexo influye en dicha percepción, aceptando la hipótesis alterna.

Sin embargo, se debe reconocer que el instrumento tiene una validez moderada, lo cual puede explicarse por la poca cantidad de ítems que se incluyeron y que además éstos son de varios tipos de respuesta, por lo que se sugeriría realizar otro instrumento que incluya por lo menos el mismo número de ítems para cada tipo de respuesta o seleccionar sólo un tipo de respuesta; no obstante, el instrumento fue de utilidad para conocer la opinión sin restricciones de los estudiantes.

En general, los análisis por sexo, turno y semestre muestran que los alumnos perciben que en "pocas clases" revisan contenidos éticos. Recordemos entonces a Pasmanik y Winkler (2009) cuando mencionan la importancia de enseñar la ética en los primeros años de la carrera, ya que a pesar de que el primer semestre iba a correr con el nuevo cambio de plan curricular, no se observan diferencias considerables respecto al 5o. semestre. Asimismo, retomando a Aguirre-Tobón y Díaz-Barriga (2007) cuando mencionan la relevancia de introducir en el currículo: diversidad de enfoques que enfatizan el pensamiento crítico, el análisis de dilemas ético-morales, análisis de casos reales donde existan dilemas éticos y su posible solución, identificación de comportamientos no éticos en algún ámbito de aplicación de la psicología, realización de juego de roles para ejemplificar situaciones que impliquen un dilema ético y revisión de literatura clásica y/o contemporánea donde se aborde la ética o códigos de conducta profesionales.

Podemos concluir que sería importante realizar otros estudios que permitan en la FES Iztacala, en el caso particular de la carrera de Psicología, conocer si los alumnos perciben que no se transmiten suficientes contenidos éticos en su formación. En esta muestra se aprecia que no perciben esta adquisición de conocimientos. 
Para ejemplificar, es posible rescatar varios datos interesantes de algunas preguntas del cuestionario que se aplicó.

Por ejemplo, en este estudio, en cuanto a género, las mujeres mencionaron considerarse mejor preparadas que los hombres para realizar su práctica profesional en la CUSI, ya que perciben que sus profesores les han enseñado lo suficiente; sin embargo, refieren que son "pocas clases" en las que revisan contenidos éticos. Los hombres, por su parte, perciben que revisan en más asignaturas algunos contenidos éticos; no obstante, ambos sexos refieren no realizar actividades planeadas para ejemplificar dilemas éticos.

En cuanto a la variable turno, cabe rescatar que el turno matutino se considera mejor preparado para efectuar su práctica en la CUSI de la FESI, ya que perciben que sus profesores les han enseñado lo suficiente. Sin embargo, el turno vespertino realiza análisis para identificar comportamientos no éticos en algún ámbito de aplicación de la psicología en más clases.

Y en cuanto a la variable semestre, el 1er. semestre se siente preparado para llevar a cabo su práctica profesional con pacientes porque sus profesores les han enseñado lo suficiente, a diferencia de 50 . semestre, que refiere que aunque sus profesores les han enseñado lo suficiente, no se sienten preparados para su práctica.

Esto llama la atención, ya que se esperaría que los de 5o. semestre tuvieran un conocimiento más amplio respecto a contenidos éticos e intervención psicológica. Es posible afirmar que no se está cumpliendo con lo que menciona Nussbaum (2005) en cuanto a que las competencias éticas y profesionales se van desarrollando a lo largo de la formación profesional de los estudiantes. Por último, ambos semestres coinciden con revisar en "algunas clases" análisis para identificar comportamientos no éticos en algún ámbito de aplicación de la psicología, pero también refieren que no realizan juego de roles para ejemplificar dilemas éticos.

Es interesante que en la pregunta 7 los análisis por sexo, turno y semestre coinciden en que en "Ninguna clase" realizan juego de roles (role-playing) para ejemplificar situaciones que impliquen un dilema ético.

Por otra parte, es interesante que los alumnos de 1 o. y 5o. semestres tengan casi los mismos porcentajes en cuanto a su conocimiento de lo que es la ética profesional y de lo que es un dilema ético, cuando se esperaría que los de 5o. semestre tuvieran un conocimiento mayor.

Por lo tanto, podemos retomar a Hortal (1995, citado en Hirsch, 2003) cuando indica que no es suficiente la introducción de materias y contenidos éticos en los planes de estudio.
En la FESI se implementó un nuevo plan curricular que incluye contenidos éticos, por lo que se espera que haya más claridad en los resultados.

Es necesario, aparte de la preparación académica, crear una cultura ética, es decir, que tengan conciencia de la responsabilidad que implica ser psicólogo y dar un servicio a la sociedad. Para ello es necesario que también los profesores realicen una reflexión acerca de su práctica en la vida cotidiana, pues como menciona García García (2010), en diversos informes se han encontrado características que definen a un buen profesor como: compromiso con la profesión, afectividad con los alumnos, conocimiento de la materia que enseña, empleo de técnicas didácticas adecuadas, trabajo colaborativo en grupo de profesores, pensamiento reflexivo y crítico, y motivación por la calidad, entre otros. Y como se observa en los resultados, los alumnos pueden identificar en sus profesores las conductas éticas y no éticas.

\section{CONCLUSIONES}

A pesar de que el tema de la ética en las profesiones no es algo nuevo, aún existe cierta resistencia para hablar de ello en las asignaturas. Se reconoce la importancia de la enseñanza de contenidos éticos en la universidad, pero todavía no se logra un consenso claro entre las asignaturas o profesores respecto a lo que van a impartir, pues aunque en la literatura se encuentran propuestas para impartir contenidos éticos, en la FESI no se apega a lo encontrado en la literatura, teniendo en cuenta lo que reportaron los alumnos en el cuestionario. Por lo tanto, una futura investigación podría centrarse en conocer los efectos del nuevo currículum que se ha implementado en la FESI, ya que éste se incluye en los objetivos de algunas materias. Un ejemplo es la materia "Taller de formación profesional", en la cual se revisarán la enseñanza y desarrollo de habilidades/principios relacionados con la ética profesional en los diferentes ámbitos de aplicación de la Psicología.

Uno de los objetivos de este estudio fue conocer la opinión de los alumnos respecto a su conocimiento o definición que tienen de "ética profesional", "dilema ético" o "profesor ético", ya que a partir de sus definiciones se tiene un panorama más claro de donde pueden partir los profesores para enseñar contenidos éticos, es decir, que no se dé por hecho que los alumnos vienen, por ejemplo, con este conocimiento desde el nivel medio superior, sino a partir de lo que ellos mismos refieren.

En el caso de las definiciones que dieron de "profesor ético" y "profesor no ético", es interesante que hay respuestas muy diversas, lo cual sirve como un punto de apoyo para que sean los mismos alumnos los que de- 
nuncien cuando observen alguna conducta que perciban como "no ética"; por otro lado, no se considera que las respuestas sean fuera de lugar o de contexto, sino que son los mismos alumnos los que dan su opinión para que el desempeño de los profesores mejore.

Está en manos de todos crear una cultura ética, alzar la voz cuando no estamos de acuerdo en algo, y siempre y cuando sea en pro de la mejora de la universidad, ya que muchas veces los alumnos pueden verse invadidos por el miedo a represalias.

Otra de las aportaciones de este estudio es que los alumnos ya han manifestado qué es lo que necesitan éticamente para sentirse mejor preparados cuando tengan que enfrentar el mundo profesional, y es sobre todo realizar más ejercicios prácticos que los acerquen a la realidad a la que muy pronto se enfrentarán; no sólo bastan los fundamentos teóricos o la enseñanza de las técnicas; los alumnos necesitan prepararse éticamente previo a realizar prácticas con usuarios reales, o en su caso debatiendo con ayuda de los profesores casos imaginarios o realizando role playing, en donde se ejemplifiquen las reacciones o posibles situaciones de los usuarios, y en donde se pongan en juego dilemas éticos; y algo muy importante, cómo se debe resolver un dilema ético, ya que en muchas de las respuestas de los alumnos se mencionaba un "deber moral" o una decisión que implicaba el juicio moral del psicólogo implicado, cuando la realidad es que hay que guiarse por el código ético para resolver la situación, y así, por medio de su formación educativa, se puede ir perfeccionando el trato hacia los usuarios y el refinamiento de sus habilidades para tomar decisiones.

Entonces, es responsabilidad de la institución educativa, que incluye profesores, alumnos, autoridades y comités de Ética, llegar a ese consenso acerca de qué es lo que se va a enseñar respecto a contenidos éticos, y cómo se van a enseñar, tomando en cuenta las necesidades y dificultades de los alumnos, pues somos todos los que conformamos el futuro de la educación, el futuro de un país.

\section{Referencias}

Aguirre- Tobón, M. y Díaz -Barriga, F. (2007). Principios y dilemas éticos reportados por estudiantes de Psicología en el ejercicio de prácticas profesionales. Memorias Congreso COMIE. www.comie.org.mx/congreso/ memoriaelectronica/v09/.../at06/PRE1178941846.pdf

Bolívar, A. (2005). El lugar de la ética profesional en la formación universitaria. Revista mexicana de investigación educativa, 10(24).

Colin, E. \& Camarena, T. (2012) La formación profesional del psicólogo en México: Trayecto de la construcción de su identidad disciplinar. Enseñanza en investigación y psicología. Vol. 17, (1), pp. 151-170.

Del Río, C. (2007). Dilemas éticos relacionados con la confidencialidad. Información Psicológica. No. 90. Pp1227

Díaz-Barriga, F., Pérez-Rendón, M. M., \& Lara Gutiérrez, Y. (2016). Para enseñar ética profesional no basta con una asignatura: los estudiantes de Psicología reportan incidentes críticos en aulas y escenarios reales. Revista iberoamericana de educación superior, 7(18), 42-58.

Esteban Guitart, M. (2007). ¿Conocen los estudiantes de psicología lo que es un dilema ético? Propuesta de un programa de formación en ética profesional. Revista de Enseñanza Universitaria (30), 58-65.

França-Tarragó, O. (1999). Ética para psicólogos: introducción a la psicoética. Desclée de Brower.

García García, E. (2010). Competencias éticas del profesor y calidad de la educación. Revista electrónica interuniversitaria de formación del profesorado, 13(4).

González, M. R., Gómez Villegas, L. S., Espinosa J. C., Cárdenas, D. C., Garzón, Y., Montoya, E. M.,Núñez, E.N. \& Tarquino, J.E. (2007). Evaluación por competencias de la dimensión ética en la formación de psicólogos en Colombia. Diversitas: Perspectivas en psicología, 3(1) pp. 11-24

Guitart, M. E. (2009). La dimensión ética de la práctica profesional: Evaluación de un programa formativo. Revista Diálogo Educacional, 9(26), 91-101.

Hirsch, A. (2011). Dilemas, tensiones y contradicciones en la conducta ética de los profesores. Sinéctica (37), 1-16.

Hirsch, A. (2005). Construcción de una escala de actitudes sobre ética profesional. Revista electrónica de investigación educativa, 7(1), 01-14.

Hirsch Adler, A. (2003). Elementos significativos de la ética profesional. Reencuentro, (38).

Nuevo plan de estudios de la carrera de Psicología. FES Iztacala (2015). http://psicologia.iztacala.unam.mx/Docs-CambioCurricular/TomolPsicologiaFESIztacala27_11_2015.pdf. Recuperado el 17 de noviembre de 2016.

Nuevo plan de estudios de la carrera de Psicología. FES Iztacala (2015). http://psicologia.iztacala.unam.mx/Docs-CambioCurricular/TomolIPsicologiaFESIztacala27_11-2015.pdf. Recuperado el 16 de noviembre de 2017.

Nussbaum, M. (2005). El cultivo de la humanidad: una defensa clásica de la reforma en la educación liberal. Barcelona: Andes Bello.

Pasmanik, D., \& Winkler, M. I. (2009). Buscando orientaciones: pautas para la enseñanza de la ética profesional en psicología en un contexto con impronta postmoderna. Psykhe (Santiago), 18(2), 37-49.

Valladares, M. T., \& Lazo, R. L. (2011). Relaciones entre ética profesional y desempeño laboral en profesores de un distrito del cono norte de Lima. Revista de Investigación en Psicología, 14(1), 79-93. 


\section{Anexos}

\section{Anexo 1}

El presente cuestionario contiene preguntas relacionadas con la Ética que debe prevalecer en tu educación profesional. Tu participación será anónima, voluntaria y confidencial. Al responder las preguntas aceptas que los datos obtenidos sean utilizados para fines de investigación.

\section{Sexo: $F \quad M$}

Instrucciones: Lee las preguntas que se presentan a continuación; en algunas tendrás que subrayar la respuesta que mejor describa tu opinión. En otras preguntas tendrás que escribir tu opinión (puedes usar la parte de atrás de la hoja). Recuerda que esto no es una evaluación y conocer tu opinión ayudará a futuras intervenciones para el desarrollo de una cultura ética en la FESI.

1. ¿Sabes qué es la "ética profesional"?
a)
Sí
b) $\mathrm{No}$

Respuesta:

2. ¿Sabes qué es un "dilema ético"?
a)
Sí
b) $\mathrm{No}$

Respuesta:

3. ¿Has realizado análisis de dilemas ético-morales durante tus clases?
a) En la mayoría de las clases.
b) En algunas clases.
c) En pocas clases.
d) En ninguna clase.

4. ¿Has discutido casos reales en donde exista un dilema ético y la posible decisión final?
a) En la mayoría de las clases.
b) En algunas clases.
c) En pocas clases.
d) En ninguna clase.

5. ¿Has realizado análisis para identificar comportamientos no éticos en algún ámbito de aplicación de la psicología (educativo, clínico, organizacional, investigación)?
a) En la mayoría de las clases.
b) En algunas clases.
c) En pocas clases.
d) En ninguna clase.

6. ¿Has realizado juego de roles (role-playing) para ejemplificar situaciones que impliquen un dilema éti$\mathrm{CO}$ ?
a) En la mayoría de las clases.
b) En algunas clases.
c) En pocas clases.
d) En ninguna clase.

7. ¿Has revisado de manera crítica literatura clásica y/o contemporánea donde aborden la ética, o códigos de conducta profesionales?
a) En la mayoría de las clases.
b) En algunas clases.
c) En pocas clases.
d) En ninguna clase.

8. ¿Te sientes preparado para llevar a cabo tu práctica con un paciente en la CUSI, respecto a la ética profesional que debes tener?
a) Sí
b) $\mathrm{No}$

8.1. En caso de que tu respuesta haya sido "No", ¿qué te gustaría ver en tus clases para sentirte preparado para tratar a un paciente?

Respuesta:

9. ¿Crees que tus profesores te han enseñado lo suficiente respecto a la ética profesional en psicología?
a)
Sí
b) $\mathrm{No}$

10. Para ti, ¿qué características son importantes para considerar a un profesor "ético profesional"?

Respuesta:

11. Para ti, ¿qué características son importantes para considerar a un profesor como "no ético profesional"? Respuesta:

¡Gracias por tu colaboración! 
Anexo 2

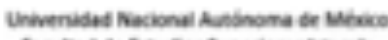

Los Reyes tatacala a 21/09/2016

Oficio: centesvosestej1093

\section{DRA. COFFIN CABRERA NORMA}

Presente;

En atencin a su solichud de avd, por la Comision de tica de esta faculad. para su proyecto denominado La ttica y biobtica en la formación profesional del psieblogo ante el cambio curricular en la FES Ixtacala, que va a vometir a Comwocatoria PAPCA 2016

Esta comision aconst la sigulente cpinion sbonica:

Avalado sin recomendaciones

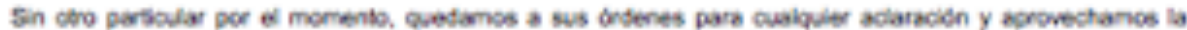
coprturidad para enviale un atento saludo y nuestro respelo acadtmica.
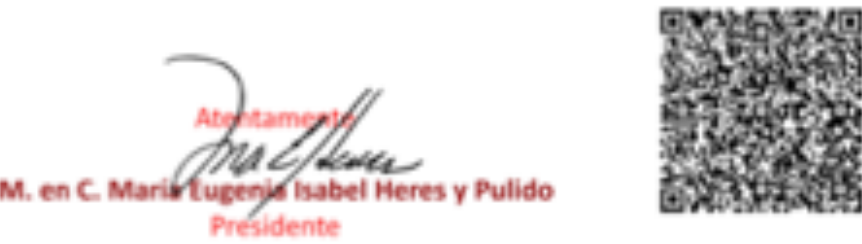


\section{Meta-Análisis del Artículo}




\section{Dimensión Cuantitativa}

\section{Perfil de Evaluación entre pares}
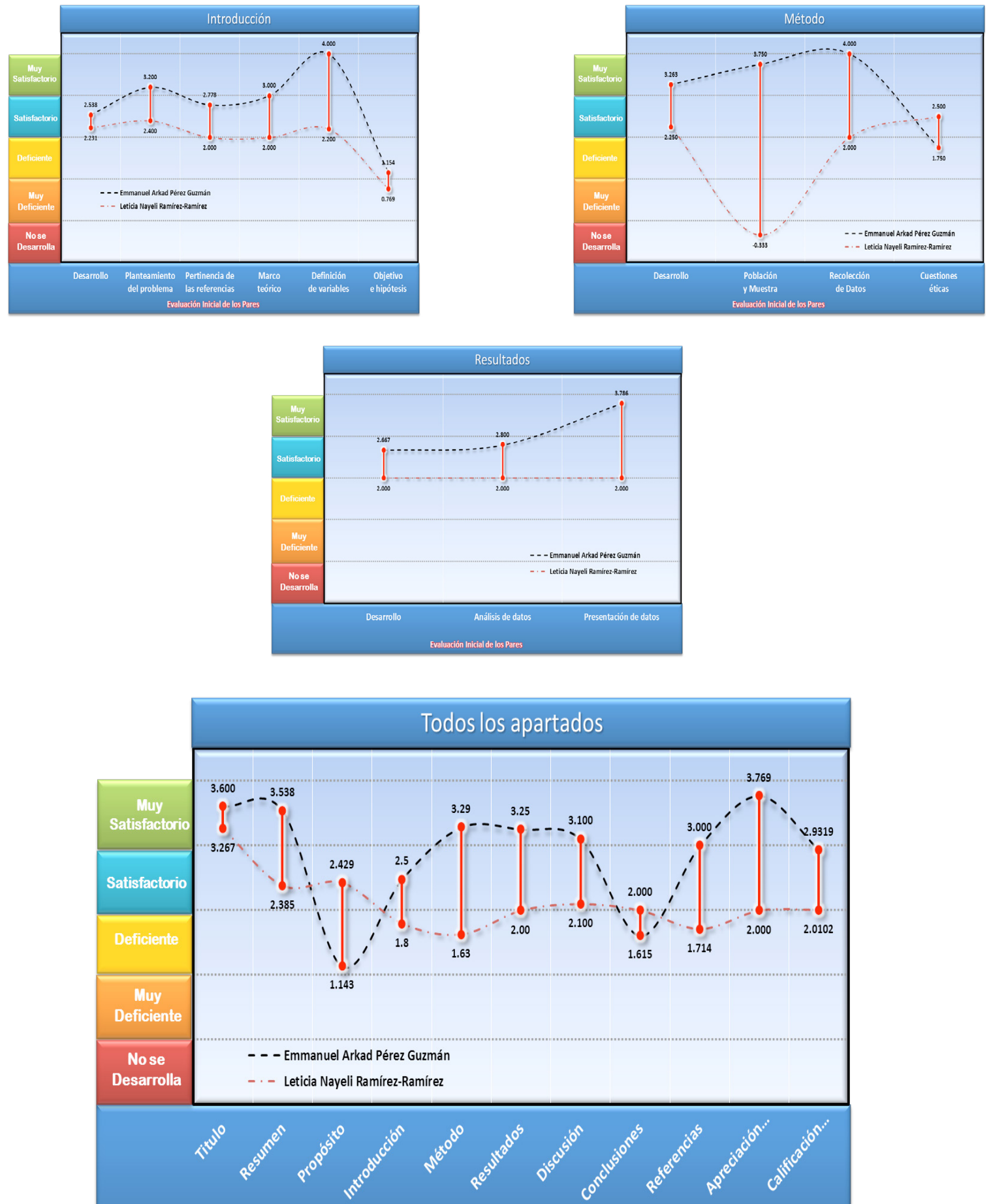


\section{Índice de Concordancia}

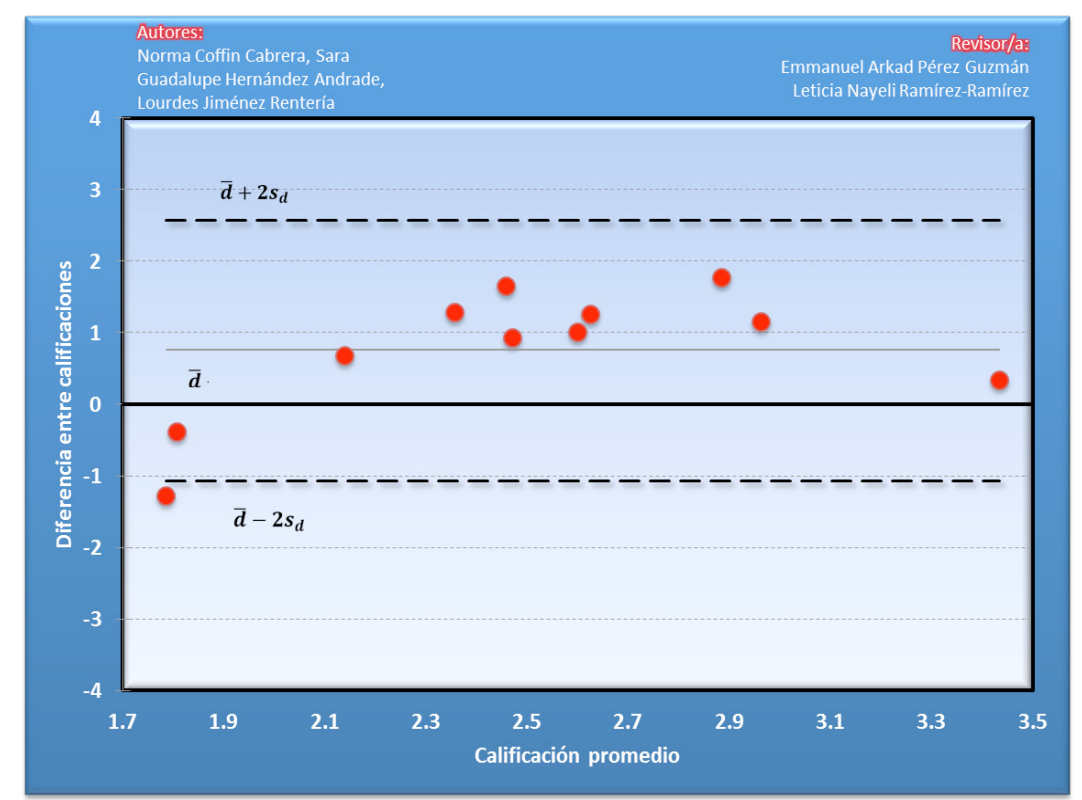

Índice de Acuerdo
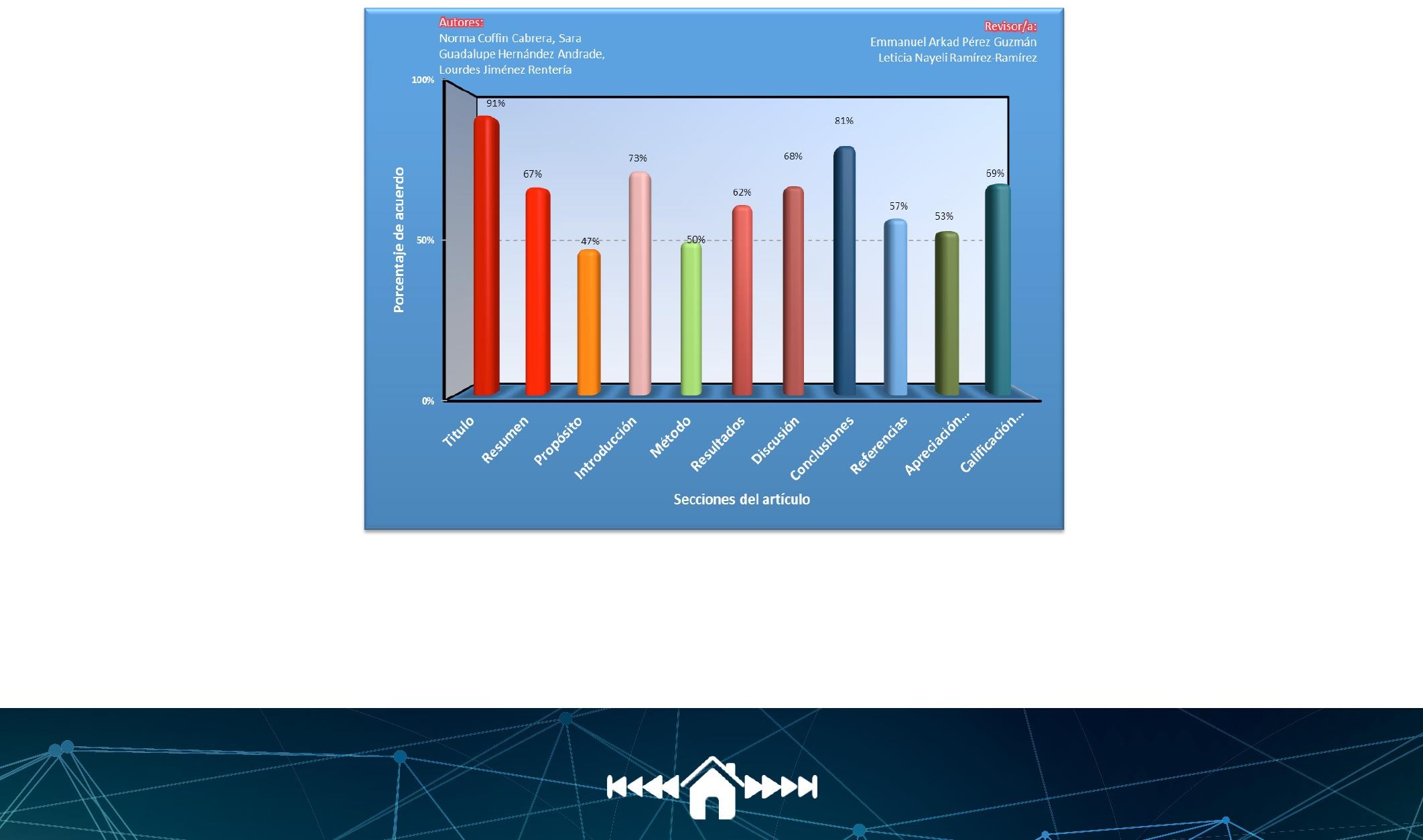


\begin{tabular}{|c|c|}
\hline Revisor 1 & Revisor 2 \\
\hline Emmanuel Arkad Pérez Guzmán & Leticia Nayeli Ramírez-Ramírez \\
\hline
\end{tabular}

En relación al título del artículo, solo haría la observación que no hace referencia a que son estudiantes de pregrado. Entiendo que dados los lineamientos de publicación no pudo ser más preciso el título, sin em-

Necesario especificar el contexto de la investigación y el nivel esducativo de los participantes. bargo, considero que es un aspecto que debe cuidarse.

\section{Resumen}

Faltó agregar resultados con valores numéricos y en las palabras claves considero que seria importante incluir la palabra psicología.

No sigue la metodología sugerida en los estandares de calidad de las revistas (IMRD), necesario desarrollar justificación y relevancia de la investigación en la línea de investigación. No presenta hipótesis, diseño de investigación, ni resultados expresados en términos númericos. Sobrepasa las 150 palabras. Se enuncian menos de 5 palabras clave y la versión en inglés requiere precisiones y revisión de gramática.

\section{Próposito del Estudio}

No se identificaron en el texto las preguntas de investigación y/o hipótesis planteadas por los investigadores y que se derivan de la problemática abordada. Es necesario que se incluyan.
Si bien es un tema vigente en el ámbito educativo, la revisión de literatura es débil; se sugiere usar referencias de las investigaciones más actuales en el tema a nivel nacional e internacional (por lo menos de 5 años atrás). Asimismo, se presenta una gran discrepancia en el uso de conceptos y variables de la investigación, ej.: conocimientos, competencias, aprendizaje. Las variables del estudio no aparecen claramente definidas, tampoco se explica las razones por las que se seleccionó el enfoque cuantitativo para responder a las preguntas de investigación que no aparecen delineadas en el estudio. En la sección de resultados indica bajo el apartado "Análisis cualitativos" sin explicitar los métodos o estrategias de análisis empleadas. Finalmente, en la sección de discusión no se señala el aporte del estudio y cómo abona a lo ya documentado por otros autores en el área de competencias éticas y desarrollo profesional. 


\begin{tabular}{|c|c|}
\hline Revisor 1 & Revisor 2 \\
\hline \multicolumn{2}{|c|}{ Introducción } \\
\hline $\begin{array}{l}\text { 1. Considero que dadas las características del estudio } \\
\text { y las variables que se establecieron, existían elementos } \\
\text { para formular hipótesis. 2. Por otro lado, en el marco } \\
\text { teórico, presentan un dato erroneo. El Código de Nu- } \\
\text { remberg fue promulgado y publicado en el año de 1947, } \\
\text { no en } 1957 \text {. }\end{array}$ & $\begin{array}{l}\text { Definición de variables y conceptos Plantear hipótesis y } \\
\text { preguntas de investigación }\end{array}$ \\
\hline \multicolumn{2}{|c|}{ Método } \\
\hline $\begin{array}{l}\text { 1. Se recomienda incluir en los anexos el instrumento de } \\
\text { recolección de datos que fue utilizado en la investigación. } \\
\text { 2. Esta investigación tendría que haber pasado por la revi- } \\
\text { sión de un comité de ética o bioética de la institución en la } \\
\text { que fue desarrollada. }\end{array}$ & $\begin{array}{l}\text { La sección de método requiere de muchas precisiones no } \\
\text { mencionadas en la investigación. La principal es la cons- } \\
\text { trución y válidez del instrumento empleado, así como el } \\
\text { diseño utilizado y su fundementación (en qué fuentes está } \\
\text { sustentado). Adicional, es necesario presentar una defini- } \\
\text { ción operacional de las variables del estudio y el procedi- } \\
\text { miento de muestreo empleado. }\end{array}$ \\
\hline \multicolumn{2}{|c|}{ Resultados } \\
\hline Sin observaciones. & $\begin{array}{l}\text { La redacción de los datos no permite la ubicación correcta } \\
\text { y ordenada de los hallazgos. Asimismo, falta fundamenta- } \\
\text { ción en las estrategias de análisis seguidas. }\end{array}$ \\
\hline \multicolumn{2}{|c|}{ Discusión } \\
\hline $\begin{array}{l}\text { En un párrafo de la discusión mencionan que, de acuerdo } \\
\text { a X resultado y planteamiento teórico: ...podemos con- } \\
\text { cluir que en la FES Iztacala no se toman en cuenta del } \\
\text { todo estas sugerencias.... No se si los resultado de la inves- } \\
\text { tigación sean lo suficientemente concluyentes para llegar } \\
\text { a el, incluso creo que podría ser falaz (falacia de presupo- } \\
\text { sición). Además de generar una polémica y debate fuera } \\
\text { de los objetivos, métodos y resultados de la investigación. }\end{array}$ & $\begin{array}{l}\text { Necesario comparar con investigaciones recientes. En la } \\
\text { sección de conclusiones se hacen juicios de valor sobre los } \\
\text { hallazgos que no están fundamentados en los resultados re- } \\
\text { portados "Se reconoce la importancia de la enseñanza de } \\
\text { contenidos éticos en la universidad, pero todavía no se logra } \\
\text { un conceso claro entre las asignaturas o profesores respecto } \\
\text { a lo que van a impartir, sino que pareciera que cada quien } \\
\text { asume lo que es importante de enseñar a los alumnos." }\end{array}$ \\
\hline \multicolumn{2}{|c|}{ Conclusiones } \\
\hline $\begin{array}{l}\text { Considero que las conclusiones están poco desarrolladas } \\
\text { en relación a los datos obtenidos en el estudio. Creo que } \\
\text { se podrían proponer, aunque de manera somera algunas } \\
\text { propuesta para atender esta problemática y/o futuras in- } \\
\text { vestigaciones para darle continuidad a la investigación. }\end{array}$ & $\begin{array}{l}\text { No se proponen investigaciones futuras y se encuentran } \\
\text { opiniones no fundamentadas de los datos. }\end{array}$ \\
\hline \multicolumn{2}{|c|}{ Referencias } \\
\hline $\begin{array}{l}\text { Casi todas las referencias tienen más de } 5 \text { años de haber } \\
\text { sido publicadas. Seria necesario realizar una búsqueda } \\
\text { más detallada o identificar si la problemática que abor- } \\
\text { da la investigación se ha trasladado o ha evolucionado } \\
\text { a un campo conocimiento emergente. }\end{array}$ & $\begin{array}{l}\text { Las referencias en su mayoría están desactualizadas y pre- } \\
\text { sentan errores en el formato APA, sexta edición. }\end{array}$ \\
\hline
\end{tabular}




\section{Historia del Proceso}

\section{EDITORIAL}


http://dx.doi.org/10.22402/j.rdipycs.unam.3.2.2017.134.179-195

\title{
HUMOR, VIOLENCIA Y ÁMBITO UNIVERSITARIO
}

\author{
Irene Aguado-Herrera y María Teresa Pantoja-Palmeros \\ FES Iztacala, UNAM \\ México
}

\section{RESUMEN}

El presente artículo tiene como objetivo analizar el humor y la risa como estrategias subjetivas que permiten elaborar y trasformar las violencias presentes en el proceso de formación. La investigación se realizó a partir de un dispositivo grupal denominado "Taller de Investigación Implicación: Violencia y Ámbito Universitario”, dirigido a alumnos y egresados de la carrera de Psicología de la Universidad Nacional Autónoma de México, FES Iztacala.

Palabras Clave:

Violencia(s), humor, grupo y ámbito universitario

\section{HUMOR, VIOLENCE AND UNIVERSITY ENVIRONMENT}

\section{ABSTRACT}

This article analyses the role of humor and laughter strategies that can contribute to apprehend and transform forms of violence that take place during higher education. The study was conducting using a group device called: "analyses and engagement workshop: violence and higher education". All participants in these seminars were students and alumni from the psychology program at the Iztacala campus of the National Autonomous University of Mexico.

\section{Keywords:}

violence, humor, group, higher education 


\author{
HUMOR, VIOLENCIA Y ÁMBITO UNIVERSITARIO
}

\author{
Irene Aguado-Herrera y María Teresa Pantoja-Palmeros \\ FES Iztacala, UNAM \\ México
}

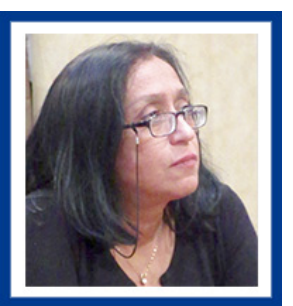

Irene Aguado-Herrera

FES Iztacala, UNAM

Correo: ireneag@unam.mx

Doctora en Educación por la UPN, Especialidad: Práctica psicoanalítica posicionamiento ético ante el dolor, Colegio de Saberes, Formación en Sociología Clínica con Vincent de Gaulejac París VII Laboratorio de Cambio Social. Profesor Titular A T.C. UNAM FES Iztacala Carrera de psicología.

Ver más...

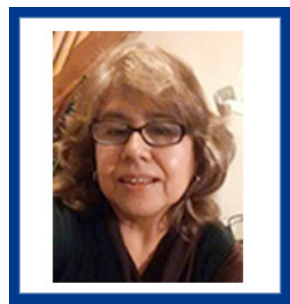

María Teresa Pantoja-Palmeros

FES Iztacala, UNAM

Correo: mtpantjo@unam.mx

Actualmente cursa el Doctorado en Saberes sobre Subjetividad y Violencia en el Colegio de Saberes. Profesora Asociado "B" Tiempo Completo en el Área de Psicología Social Teórica de la Facultad de Estudios Superiores Iztacala de la UNAM.

Ver más...

\title{
CONTRIBUCIÓN DE LAS AUTORAS
}

Se atribuye a amabas autoras por igualdad la autoría de la presente investigación

\section{AgRADECIMIENTOS}

Esta publicación fue posible gracias al apoyo del proyecto PAPCA "Subjetividad y Procesos Educativos" (FESI-DIPPAPCA-2016-22). FES Iztacala, Universidad Nacional Autónoma de México. Responsable doctor José Refugio Velasco García; corresponsable doctora Irene Aguado Herrera.

\section{Datos de Filiación de las Autoras}

Facultad de Estudios Superiores Iztacala, UNAM.

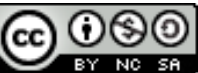

Copyright: (c) 2017 Aguado-Herrera, I., Pantoja-Palmeros, M.T.

Este es un artículo de acceso abierto distribuido bajo los términos de la licencia Creative Commons Reconocimiento-NoComercial -Compartirlgual 4.0 Internacional, por lo que su contenido gráfico y escrito se puede compartir, copiar y redistribuir total o parcialmente sin necesidad de permiso expreso de sus autoras con la única condición de que no se puede usar con fines directamente comerciales y los términos legales de cualquier trabajo derivado deben ser los mismos que se expresan en la presente declaración. La única condición es que se cite la fuente con referencia a la Revista Digital Internacional de Psicología y Ciencia Social y a sus autoras. 


\section{TABLA DE CONTENIDO}

INTRODUCCIÓN

VIOLENCIA, SUS INTERPRETACIONES Y EL HUMOR

MetodologíA

Objetivo de la investigación, 26

Objetivo de intervención, 26

Consideraciones metodológicas sobre el dispositivo, 26

RESULTADOS

Los sentidos generados en las dramatizaciones y el humor, 27

Representaciones, 27

DISCUSIÓN Y CONCLUSIONES 


\section{INTRODUCCIÓN}

$\mathrm{E}$ n el presente texto expondremos una línea de análisis que hemos trabajado como parte del proyecto de investigación que realizamos en relación con los procesos subjetivos presentes y articulados en la educación, particularmente en el ámbito universitario. El responsable de este proyecto es el doctor José Refugio Velasco García y la corresponsable es la doctora Irene Aguado Herrera.

La premisa de que partimos es que todo proceso educativo es posible y se sostiene en los procesos subjetivos que en él se articulan, tensan, complementan y contradicen. Entre estos procesos subjetivos, adquieren un papel relevante los que remiten y hacen patente el orden de lo inconsciente de los sujetos involucrados en la institución, en el proceso y en la tarea educativa. Sujetos que son a la vez agentes y objetos de los procesos de subjetivación y de desubjetivación.

En los diferentes dispositivos grupales que se han diseñado e implementado como parte de la investigación, uno de los aspectos que se ha hecho presente de manera reiterada es el referente a la presencia de actos de violencia en el ámbito universitario y en el proceso de formación específicamente; también se ha trabajado y analizado el humor como método o estrategia subjetiva que permite la elaboración y resignificación de la violencia. Por tal razón el objetivo en este trabajo es mostrar los aspectos del humor y la risa que se produjeron en un espacio confeccionado específicamente para explorar la violencia en la institución universitaria.

\section{VIOLENCIA, SUS INTERPRETACIONES Y EL HUMOR}

En la universidad como en cualquier espacio social se despliegan, se abordan y desbordan, problemáticas contemporáneas que causan un malestar en el sujeto. En el espacio universitario el fenómeno de la violencia se manifiesta de muchas formas y ha sido abordado desde muchos puntos de vista, dando lugar a distintas interpretaciones en torno a ese fenómeno humano y sólo nos estamos refiriendo a interpretaciones de orden teórico y metodológico, donde el pensamiento académico parece aclarar los motivos y consecuencias de la violencia.

También se dan interpretaciones espontáneas de quienes están vinculados con sus emblemas, sus sistemas de organización administrativa, sus jerarquías de poder y sus finalidades explícitas e implícitas. Muchas de dichas interpretaciones tienen la intención de esclarecer el devenir de la violencia; simplemente se producen en las relaciones sociales cotidianas, dentro de las geografías específicas que habitamos. Emergen de manera espontánea y su destino es incierto, se olvidan con mucha rapidez, no trascienden en el tiempo, pero en ocasiones dejan huella indeleble en la memoria de los grupos que le dan vida a la institución.

La violencia ha sido analizada desde una gran diversidad de discursos y en diferentes ámbitos, situaciones y espacios, por lo que no se tiene un concepto unívoco y general de violencia. Por esta razón, cada autor e investigador tiene el reto de delimitar conceptualmente su punto de partida y hacerlo explícito. En nuestro caso partimos de los conceptos freudianos de pulsión y de pulsión de muerte, articulándolas a los fenómenos inconscientes. Retomamos lo planteado por Freud (1920) para proponer a la violencia como una manifestación de la pulsión de muerte, sin que con ello pretendamos agotar lo que respecto a este rasgo humano se pueda decir.

En este sentido, Gerber (2006: 191) señala que "[...] la violencia se encuentra en el núcleo mismo de lo humano", ya que el carácter violento de la pulsión tiene su origen en el propio acto violento que constituye al hombre desviándole del orden natural, y con ello instituyendo el orden social, en el cual se dará lugar a la constante tensión entre orden y caos, vida y muerte, creación y destrucción.

De las múltiples funciones y materialidades de la violencia, aquí nos enfocaremos sólo a la manifestación que

[...] encuentra su fundamento en la negación del otro, rompe toda posibilidad de juego entre los sujetos involucrados, hace del sujeto un objeto, objeto de exterminio, de placer, de uso o abuso. Lo desaparece como sujeto al imponer su fuerza, más que debilitar la capacidad de resistir, la quiebra, la anula, la cercena; la libertad es abolida, el reconocimiento del otro es borrado [...] la otredad se vuelve objeto a destruir, a exterminar, o bien a abusar (García, 2005: 118).

Desde el psicoanálisis la posibilidad que se abre ante la violencia:

[...] es la de transformar ese goce, destructivo y mortífero en su esencia, en acto creador, hacer del lenguaje que trae consigo la vida y condena a la muerte, el espacio donde siempre sea posible que una palabra diferente ponga un límite siempre provisional al empuje arrollador de eso que no dejará de cuestionarlo, parte maldita, pulsión de muerte, goce, que deben ser reconocidos en su importancia y su valor para mantenernos vivos en el deseo (Gerber, 2007: 209).

Como se indicó, la violencia es inherente al sujeto y se expresa permanentemente, por lo que irrumpe 
en toda institución, y la educativa no es la excepción. La institución educativa hija y heredera del proyecto de la modernidad tiene entre sus propósitos fundamentales la homogenización, el control y la disciplina de los miembros de la sociedad, para lo cual es necesaria la existencia de un juego, de un entramado de poder. Sin embargo, como señala Anzaldúa (2016: 77-78):

también tienen lugar en el seno de la institución educativa y entre todos los agentes que en ella se encuentran, expresiones de violencia de manera aceptada, naturalizada, normalizada e incluso institucionalizada, que no sólo son un ejercicio del poder, sino un abuso tendiente a la intimidación, la humillación, la domesticación o el sometimiento, logrando un acostumbramiento de prácticas y pautas de conducta, controles, estigmas, violencias institucionales verbales o escritas, que son aceptadas sin mayor reflexión.

Respecto al humor, encontramos que Freud (1981: 2998) señala que "lo grandioso reside a todas luces en el triunfo del narcisismo, en la victoriosa confirmación de la invulnerabilidad del yo. El yo rehúsa dejarse ofender y precipitar al sufrimiento por los influjos de la realidad; se empecina en que no pueden afectarlo los traumas del mundo exterior; más aún: demuestra que sólo le representan motivos de placer".

Se puede afirmar que el humor es rebelde; lo curioso es que Freud (1981: 2998) dice que esta rebeldía comparte con el síntoma "procesos regresivos y reaccionarios", escamoteando el sufrimiento del yo. Nuestro autor sitúa el humor al lado de la neurosis, la embriaguez, el retraimiento y la propia locura: "El humor debe a esta vinculación una dignidad que le falta del todo, por ejemplo, al chiste, pues este sirve tan sólo al beneficio placentero, o bien pone esta ganancia al servicio de la agresión".

No profundizaremos por ahora en las diferencias que establece Freud entre el chiste y el humor; sólo nos concentramos en esta dignidad o superioridad que adquiere el yo ante los sufrimientos de la vida y que resalta el fundador del psicoanálisis. El humor es, pues, una forma de enfrentar con valor esos sufrimientos, de demostrar al mundo y a sí mismo que todavía se puede encontrar algo de placer en un mundo trágico. El yo minimiza así ese sufrimiento con las armas del humor, jugando con el lenguaje y generando un estado afectivo. El humor parece indicarnos: "¡Mira, ahí tienes ese mundo que te parecía tan peligroso. No es más que un juego de niños, bueno apenas para tomarlo en broma!" (Freud, 1981: 3000).

Lo interesante aquí es que en el juego del humor está involucrado el lenguaje, la risa que muestra un estado afectivo placentero, al tiempo que el superyó expresa su fas amable, de tal manera que surge una voz que se torna protectora y solidaria con el yo. Creemos que esta combinación de elementos lleva a Freud en este texto a decir que, si en el humor el superyó habla cariñosamente, entonces "tenemos muchísimo que aprender acerca de la esencia del superyó" (Freud, 1981: 3000).

No podemos olvidar que en varios momentos de su obra, Freud aborda el carácter obsceno y feroz del superyó, lo cual contrasta con la manera en que en el texto sobre el humor reivindica el rostro amable de esa instancia del aparato psíquico. Por ejemplo, en La disección de la personalidad psíquica, se describe a un superyó que se da a la tarea de mantener la autoridad parental, representando no sólo las normas y leyes a las que debe apegarse un sujeto dentro de la cultura, sino que también reúne costumbres y hábitos familiares, populares, raciales, incorporando subrogados parentales como los maestros, personajes ejemplares o ideales admirados por la sociedad. En ese texto se llega a decir que aunque la educación de los padres haya sido benigna, la estructura superyoica desarrolla por sí misma funciones feroces, punitivas, sancionando al yo y haciéndole pagar por cosas que fueron ya castigadas en el pasado. Es en el texto sobre el humor, una de las pocas ocasiones en que Freud asigna al superyó un carácter amable, protector y benevolente y ubica al humor como un Don, una estrategia, un recurso para que el yo enfrente y transforme la violencia.

Freud mismo ofrece una prueba de ello cuando, hacia el año 1938, en Viena, después de haber pasado por situaciones terribles, ya que su hija había estado en manos de la Gestapo, su casa había sido revisada por los nazis y él se había sometido a 23 operaciones en la mandíbula a causa del cáncer; al recibir a su viejo amigo vienés Walter Schmideberg en su casa de Londres lo saludó con un "¡heil Hitler!", como si consintiera por fin en pronunciar, a través de ese chiste lúgubre, el nombre infame del destructor de su obra" (Roudinesco, 2016: 442).

Con este marco de referencia en nuestra investigación, uno de los soportes metodológicos empleado ha sido el psicodrama, donde el humor y la risa como expresiones subjetivas han desempeñado un papel importante en un espacio confeccionado específicamente para explorar la violencia en la institución universitaria. El psicodrama es una estrategia de investigación e intervención que, aunque tiene su origen en el campo teatral, se ha implementado en diferentes escenarios, con diversos objetivos y desde diferentes discursos teóricos. El psicodrama orientado psicoanalíticamente, según Basquin, Duboisson, Samuel-Lajeunese y Testemale-Monod (1977) y Safouan, (1979), permite actualizar en el aquí y el ahora una situación que se vive como coagulada, reificada, Cosificada. Al darle vida, al movilizarla, los involucrados incluyen sus cuerpos, su palabra, sus emociones y otra 
temporalidad. En la puesta en escena se interpreta, y por lo tanto se modifica, la representación de lo acontecido, a lo que se remite o alude. Tenemos así algo que no es repetición sino posibilidad de reubicarse, de generar nuevos sentidos de esa escena anterior, dando lugar a una nueva escena en la que se intenta, se ensaya la posibilidad de reelaborar vínculos humanos conflictivos; estas nuevas producciones de sentido encaminan hacia una posición subjetiva diferente, a una rectificación donde el sujeto se constituye en actor de la historia, de su historia. Ya que el fin y el objetivo de la acción psicodramática, como señala Massota (1979: 12), son "reinscribir al sujeto en su historia, o bien, es lo mismo, en inscribir las condiciones de esa historia en el sujeto".

El trabajo grupal genera las condiciones para que lo evocado que se pone en acto, en un aquí y ahora, "en un hacer como si", dé lugar a que en los participantes se produzca la reviviscencia, con la intención de que se generen re-significaciones producidas grupalmente. Asimismo, al poner a jugar el cuerpo para encarnar personajes reales o ficticios, tenemos la posibilidad de enfrentar a protagonistas de carne y hueso, lo cual nos puede permitir percibir los efectos de la repetición, así como la posibilidad de crear nuevas interpretaciones, descubrir estrategias y recursos subjetivos; tanto para los que escenifican el acontecimiento a que se hace referencia, como para aque

éllos que son espectadores de la dramatización. Como se puede apreciar, lo singular y lo grupal son dos dimensiones que se movilizan en este tipo de trabajo que permite y requiere la participación creadora y activa del humorista o los humoristas. Creación humorística que modifica no a la situación o acontecimiento vivenciado y representado, sino a los que ponen en juego el humor, su humor. De ahí que Lieberman (2005: 126) señale, respecto al humor, que "es una medicina para lo incurable, a la vez inútil y eficaz".

\section{Metodología}

\section{Objetivo de la investigación}

Analizar los actos de violencia que tienen lugar y de los que somos sujetos y objeto en el ámbito universitario (FES-Iztacala/Psicología) en el proceso de formación.

\section{Objetivo de intervención}

Que los participantes puedan producir un cambio de posición subjetiva acerca de la violencia presente en las instituciones educativas, que permita otras modalidades de convivencia.

\section{Consideraciones metodológicas sobre el dispositivo}

Una de las estrategias para avanzar en la dirección señalada es haber implementado en cuatro ocasiones un dispositivo grupal con el método clínico denominado "Taller de Investigación Implicación. Violencia y Ámbito Universitario", dirigido a alumnos y egresados de la carrera de Psicología. La convocatoria se ha realizado a través del Programa de Superación Académica de Iztacala, y los grupos se han conformado por un promedio de 10 participantes. Cada taller constó de cinco sesiones, de tres horas de duración cada una, y son coordinados por un equipo de tres psicoanalistas.

El procedimiento que se ha seguido incluye los soportes metodológicos ${ }^{1}$ que se enuncian a continuación de manera general, entre los cuales se encuentra el de la dramatización, el cual se describe detalladamente, toda vez que el análisis que realizamos se centra en lo trabajado con este soporte.

\section{Familiarización.}

1.1. Presentación (nombre y condición escolar).

1.2. Presentación, análisis y firma del consentimiento informado por parte de los participantes del taller.

1.3. Escribir una palabra o idea acerca de la violencia.

1.4. Escribir una palabra o idea sobre sus expectativas del taller.

2. Técnica de caldeamiento grupal.

3. Resurgencia al inicio de cada sesión.

4. Elaboración de un dibujo en el que representen alguna situación que consideren como violenta en el ámbito universitario y su proceso de formación. Narrativa del dibujo por cada uno de los autores.

5. Escritura de un texto de manera individual y anónima de cada uno de los participantes acerca de una situación de violencia que hayan vivido en el ámbito universitario y su proceso de formación, y que no han podido hablarla con alguien y, por tanto, les genera malestar.

6. Dramatización de una escena en la que representen alguna situación que consideren como violenta en el ámbito universitario y su proceso de formación, que haya sido plasmada en el dibujo realizado en el soporte 4 . El procedimiento que se sigue en este soporte metodológico es el siguiente.

6.1. El día anterior se les invita a que lleven utilería y el equipo coordinador también proporciona material (sombreros, gorras, mascadas, bigotes, etcétera). 6.2. Los participantes se dividen en dos equipos.

1 Acerca de la fundamentación y justificación de los soportes metodológicos empleados, véase Aguado (2016). 
6.3. Cada equipo elige de entre las escenas dibujadas por los integrantes del equipo la que quieren representar, y se asignan los roles.

6.4. Cada equipo hace la representación que eligió y, al término de la representación, todos pueden participar comentando acerca de lo que sintieron o pensaron.

6.5. A partir de lo elaborado se vuele a re-escenificar, incluyendo los cambios que deseen. Se puede modificar: la conformación del equipo, cambiar los roles y el contenido de la escena.

6.6. Al término de la representación, todos pueden participar comentando acerca de lo que sintieron o pensaron.

7. Cierre y devolución.

\section{Resultados}

\section{Los sentidos generados en las dramatizaciones y el humor}

A lo largo del trabajo con los diferentes soportes se identificó una amplia gama de acciones violentas en las que los participantes se reconocieron como sujetos y objeto de las mismas. También se localizó una variedad de situaciones y agentes de violencia, señalando como una constante las que se ejercen por parte del profesorado, desde las más sutiles (descalificaciones, falta de respeto) hasta acoso y abuso sexual, por lo que este fue un contenido frecuente en las dramatizaciones.

De las dramatizaciones que se realizaron en los diferentes talleres analizaremos sólo aquéllas en que se recurrió al humor como estrategia subjetiva privilegiada al momento de plantearse la re-escenificación. El humor se tornó un medio que abría la posibilidad de enfrentar la ansiedad, la ira, el temor, la vulnerabilidad, mostrando el grado de implicación de los participantes, al mismo tiempo que se tomaba distancia de lo acontecido promoviendo un cambio de posición desde la cual se recuperaban ellos como sujetos, descolocando al otro del lugar de poder desde el cual ejerció el acto violento.

Es importante destacar que la dramatización permite la inclusión de otros recursos tanto intrasubjetivos como intersubjetivos (grupales), lo que propicia la emergencia del humor; sin embargo, ésta por sí misma no garantiza que se disponga de aquél como estrategia o método, ya que dependerá tanto de los recursos subjetivos de los participantes como de las características de la grupalidad, lo que confirma lo señalado por Freud en el sentido de que el humor es un Don raro y precioso.

\section{Representaciones}

\section{El maestro nacionalista}

La escena elegida para ser representada fue la que una de las participantes recordó que cuando estuvo en la preparatoria y uno de sus compañeros llevaba puesta a una de las clases una chamarra con la bandera de Estados Unidos. El maestro, iracundo, le dijo que se quitara la chamarra porque era indignante que estuviera ese símbolo en un espacio de educación aquí en México; el chico se resistió a quitársela, por lo que el maestro lo obligó a retirarse del salón.

Para la dramatización los participantes del taller trajeron utilería y acordaron escenificar esa situación. Traían una bandera de México, otra de Estados Unidos muy pequeña, una del equipo de futbol de la UNAM, sombrero, bigotes, lentes muy grandes sin micas, pelucas y sacos. Se pusieron de acuerdo y formaron un escenario donde simulaban un salón de clase. Uno de ellos se vistió de maestro (portaba bigote, sombrero, saco y la bandera de México puesta como delantal) y comenzó a hablar con un tono norteño. Una integrante asumió el papel de alumna, tomó la banderita de Estados Unidos y se la puso en su suéter. El maestro muy indignado regañó a la alumna y le dijo que si no se quitaba esa chamarra con la bandera de Estados Unidos mejor se saliera del salón. Pero la estudiante le dijo que tenía frío, además que no ofendía a nadie. Sus compañeros la empezaron a defender y comenzó la discusión. En ese momento quien actuaba de profesor, simulando sacó a patadas a la alumna, y se generalizó la risa, sobre todo cuando el que más serio se mostraba era él, con su tono de norteño y con todo ese disfraz tan hábilmente caracterizado. Surgió la risa porque los asistentes tuvieron la habilidad de representar las experiencias vividas anteriormente de manera graciosa y divertida.

\section{La maestra iracunda}

Otra escena representada fue planteada en los siguientes términos. Al grupo del que forma parte Adriana $^{2}$, en una de las prácticas que realizan como parte de su formación, les correspondió organizar un evento en la explanada de la escuela, en el cual se realizaron diferentes actividades dirigidas tanto a la población interna de la escuela como a la comunidad aledaña. El día previsto Adriana llegó a la explanada con el material de apoyo para la actividad con un retraso de algunos minutos; al verla la maestra de la práctica le gritó que se apurara y cuando estuvo cerca,

2 El nombre de la participante se ha cambio a efecto de conservar el anonimato. 
enfrente de sus compañeros le reclamó su impuntualidad, gritándole muy agresivamente, utilizando además adjetivos negativos para referirse a ella, a sus ademanes y a su desempeño académico. Ante esta situación, Adriana sólo lloró y una de sus compañeras y amiga intervino para consolarla y entonces también ella fue objeto de regaños y malos tratos por parte de la maestra.

La primera vez que se habló de esta situación aparecieron sentimientos de ansiedad, enojo y desconcierto, además hubo lágrimas. De esta manera se hizo patente la imposibilidad de manejar una situación en la que hubo abuso por parte de alguien con poder y autoridad. La persona directamente afectada recordó la situación y dijo que después de eso permanentemente aparecía el deseo de abandonar la escuela. Otros tres compañeros participantes del taller, y que también habían presenciado esa situación y recordaban junto con ella, mostraron evidentes estados de frustración, enojo y tristeza.

Al pasar a la dramatización, encontramos dos tiempos diferenciados. En el primero de ellos la escena se representó tal y como la recordaban; en el segundo tiempo, que llamaremos "reescenificación", se dio un giro importante, ya que se introdujeron elementos de burla y ridiculización, enfatizando las características físicas y el comportamiento de la maestra, lo cual les permitió poder actuar atribuyéndose la posibilidad de enfrentar la violencia cuestionando tanto la forma como el contenido del acto violento. Poder introducir el humor, y con él reírse de la situación, les permitió no sólo desdramatizar, sino mirar también desde otro ángulo el lugar donde el otro se ubicó al ser violento, mostrando cómo se descolocó de un lugar de autoridad legítima al ponerse fuera de control y congruencia, haciendo patente cómo, ante la falta de argumentos, aparece la descalificación. Esto, que no fue posible de realizar en el momento en que sucedió la violencia, se hizo evidente al recrear y resignificar lo acontecido. La vivencia de humillación y desvalorización se pudo transformar en posibilidad de elaboración y reivindicación de quienes sufrieron la agresión, lo cual les permitió incluso pensar no sólo su lugar como agredidos, sino el lugar del otro que, atrapado por la violencia, hace evidente sus propias imposibilidades. Con esto lograron descolocarse del lugar de objeto de violencia (humillación y descalificación) y recuperarse como sujetos con derechos y responsabilidades.

\section{DisCUSIÓN Y CONCLUSIONES}

Los peores momentos se pueden tornar divertidos. En las dos viñetas expuestas se ilustra cómo en un dispositivo para explorar la violencia, en la dramatización, los participantes pusieron en acto sus recursos subjetivos singulares y grupales para, de manera lúdica, traer al presente experiencias que en el pasado los hicieron sufrir. En el juego y con el juego se reescribe la historia y el sujeto mismo. En este sentido Morales (1997: 168) dice:

En el juego, el niño no sólo intenta anudar historias sino que eso le produce alegría. ¿Por qué una niña ríe cuando juega? Porque está creando un texto nuevo a partir de otros textos. Jugar es descubrir las bondades del lenguaje; es inventar nuevas historias; es asistir a la posibilidad humana de crear nuevos latidos, y eso es maravillosamente placentero.

El juego del niño es muy serio, pero no es solemne. A la seriedad gozosa del niño, a esa risa y concentración ante el invento espontáneo, la humanidad respondió con rito y solemnidad. La religión hizo del juego, rito; y de la seriedad de lo allí jugado, solemnidad. [...] Los dioses griegos jugaban y se reían; el dios monoteísta es serio y solemne.

Así, el sujeto le imprime pulsión de vida a lo quebrantado, se dignifica al manejar el mundo de los objetos materiales y de los sentimientos, juega con ellos, los cambia de lugar; también pone en juego su cuerpo. El humor entonces aparece como una posibilidad de no dejarse someter por el otro, y que si ese sometimiento ocurrió en el pasado, podemos suspender ese sometimiento para que no se vuelva un eterno retorno.

Las dramatizaciones permitieron jugar con las situaciones violentas y ocasionar risa; aquí también se crearon otros textos y otros estados de ánimo. La recreación se volvió creación ante lo doloroso; al malestar del pasado se le puso un sombrero y un bigote, se le ridiculizó al tiempo que surgía la carcajada.

En esta experiencia, la violencia se reconoció en diferentes ámbitos de nuestra vida cotidiana y específicamente dentro del ámbito universitario se vislumbraron algunas de sus diversas manifestaciones: como violencia enmascarada en donde los golpes físicos no están presentes. Así, pudimos situar a la violencia, de acuerdo con Zizek (2009), quien señala que la violencia tiene diversos rostros donde podemos encontrar desde actos criminales, de terror, disturbios civiles y conflictos mundiales. Todos estos como actos muy visibles. 
Pero hay una violencia encarnada en el lenguaje. Bordieu (1999) sitúa esta forma de expresión como una violencia simbólica, como esa forma de someter y dominar al otro por medio del poder, e incluso la generosidad, lo cual puede producir un sentimiento de deuda y responsabilidad que son difíciles de pagar; específicamente hablamos de los Dones y su otorgamiento.

La ansiedad, el miedo, la vergüenza, la violencia y la agresión se expresaron en el trabajo grupal, permitiendo transformarlas en productividad y en creatividad. Primero se produjeron palabras habladas, escritas, relacionadas con el odio y venganza hacia quienes ubican como agentes de la violencia. Recordar y elaborar en la intimidad del grupo las historias de acoso, de abuso, vividas como dolorosas dio lugar a un nivel de simbolización que no podemos despreciar, pasando del cuerpo mudo a la palabra hablada, a la escritura y a la puesta en acto de un hacer como sí.

Al reflexionar acerca de la representación uno de los participantes comentó: "los peores momentos también se pueden tornar divertidos". Nosotros señalamos: no sólo Hollywood puede crear argumentos y escenas divertidas, también ustedes lo hicieron. Se rieron de la agresión, de la violencia, se mostraron violentos con la violencia por medio del humor y la risa; parece que ahora la derrotaron. Así se demuestra que el recurso del humor no sólo ofrece al yo la cara benevolente del superyó, sino que además abre la posibilidad de una salida, una solución exitosa, en este caso ante la violencia, consistente en rectificar no la realidad o el acontecimiento, sino la posición del sujeto que la desafía, se rebela reconstituyéndose como sujeto con dignidad y accede al placer.

Diseñar un dispositivo grupal partiendo del psicoanálisis ha permitido la posibilidad de sostener dos procesos fundamentales: investigar e intervenir. En relación con la investigación fue posible reconocer y dar cuenta de cómo en los procesos subjetivos que se dan en la práctica educativa está presente la pulsión de muerte en las expresiones de violencia de diversa índole, desde las sutiles hasta las más evidentes, generando efectos tanto en el propio proceso educativo como en los sujetos que lo sostienen. Respecto a la intervención al permitir que los participantes pusieran en palabras o en actos los acontecimientos violentos rememorados, se generó una representación psíquica y una resignificación que permitió reconocer, develar, desenmascarar las acciones violentas en las que cotidianamente se ven involucrados, abriéndose con ello la posibilidad de poner en juego los recursos subjetivos con que cuentan, o incluso darse otros, específicamente el humor, para enfrentar la violencia y con ello trasformar sus efectos de mal-estar y sufrimiento en posibilidad de cambio y creación. En los dos casos que se representaron fue desenmascarado el efecto desubjetivisante de la violencia al ubicarlos ante el otro como simple objeto, y con ello se dio la posibilidad de cuestionar la verticalidad y la posición de dominio y sumisión en algunos tipos de vínculo maestro-alumno, e incluso imaginar y poner en acto formas distintas de ubicarse y afrontar, tanto de manera singular como colectiva, a la violencia.

En lo expuesto encuentra justificación y razón de ser la implementación de este tipo de dispositivos en tanto espacios suficientemente subjetivizados y operativos para que esa violencia inherente a toda institución, que no se reduce a la violencia legítima y regulada, y que circula permanentemente en la institución educativa, pueda ser objeto de elaboración, resignificación y transformación en algo más creativo y menos destructivo, siendo el humor un recurso psíquico que pudo desplegarse en este sentido.

Entonces, cabe señalar que la implicación es un proceso esencial para realizar y sostener este tipo de dispositivos, ya que la subjetividad de todos los involucrados, tanto los integrantes del grupo como del equipo de coordinación, constituye tanto el material objeto de análisis como el propio trabajo de análisis. Así, los participantes al implicarse, al sentirse concernidos pudieron no sólo hablar de los acontecimientos violentos vivenciados por ellos, sino también al escucharse y escuchar al otro movilizaron sus recuerdos, sus vivencias, sus afectos, sus cuerpos. También se involucraron en los procesos intersubjetivos propios de toda grupalidad, al re-conocerse en el dicho y sentir de los otros: dando lugar a expresiones como "a mí también me ha pasado", "yo también sentí", "eso me recordó", "yo lo avalo" o "me permite evocar".

En las dos viñetas presentadas se hizo patente su implicación en más de una forma: al traer y compartir con el grupo recuerdos íntimos y dolorosos, al encontrar eco en el resto de los integrantes del grupo y haciéndolo suyo para poder grupalmente asumir el reto de re-presentar lo narrado, darle vida y con ello plasticidad al alterar acciones, sensaciones, diálogos, e incluso geografías; se dio una posibilidad creativa, emotiva, dándole sentidos inéditos e inimaginables. Entre ellos, por qué no, la risa como posibilidad de derrotar la pulsión de muerte, provisoriamente, sí, abriendo paso a Eros, a la creación, a la sublimación, con la carga de violencia que también ahí se juega. 


\section{Referencias}

Aguado, I. (2016). Taller elaborativo vivencial: dispositivo de formación, en I. Aguado y J. Velasco (coords.). Escenarios educativos, subjetividad y psicoanálisis. México: Navarra.

Anzaldúa, R., Grajeda, B. (2016). Institucionalización de la violencia, en C. Carrillo, Las violencias en los entornos escolares. Guadalajara: CUSEA-Universidad de Guadalajara.

Basquin, Duboisson, Samuel-Lajeunese y Testemale-Monod (1977). El psicodrama. Un acercamiento psicoanalítico. México: Siglo XXI.

Bourdieu, P. (1999). Meditaciones pascalianas. Argentina: Anagrama.

Freud, S. (1990/1930). El malestar en la cultura. Obras Completas. Tomo XXI, Argentina: Amorrortu.

Freud, S. (1990/1920). Más allá del principio del placer. Obras Completas. Tomo XVIII. Argentina: Amorrortu.

Freud, S. (1981/1927). El Humor. Obras Completas. Tomo III. Madrid: Biblioteca Nueva.
García, M. I. (2005). Poder, violencia y palabra, en Revista Tramas, núm. 25, México: UAM-Xochimilco, pp. 113-128.

Gerber, D. (2007). Violencia, erotismo y pasión, en Marco Jiménez. Subversión de la violencia. México: Juan Pablos/ UNAM, FES-Acatlán.

Gerber, D. (2006). El psicoanálisis en el malestar en la cultura. Argentina: Lazos.

Lieberman, M. (2005). Entre la angustia y la risa. México: UAMXochimilco.

Massota, O. (1979). "Prólogo", en M. Safouan, Reflexiones sobre el psicodrama. Buenos Aires: Argonauta.

Morales, H. (1997). Sujeto y escritura. Lacan el psicoanálisis y la modernidad. Guadalajara: Ediciones de la Noche.

Roudinesco, E. (2016). Freud en su tiempo y en el nuestro. México: Debate.

Safouan, M. (1979). Reflexiones sobre el psicodrama. Buenos Aires: Argonauta.

Zizek, S. (2009). Seis reflexiones marginales. Barcelona: Paidós.

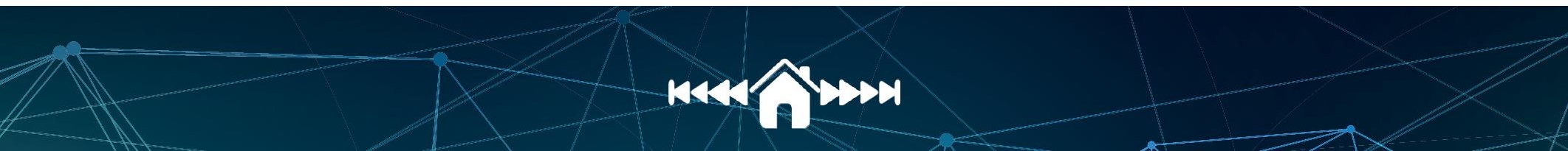




\section{Meta-Análisis del Artículo}


Revista Digital Internacional de Psicología y Ciencia Social | Vol. 3 | Núm. 2 | Juilio-Diciembre 2017| ISSN 2448-8119 e-ISSN $2448-8119$

\section{Dimensión Cuantitativa}

\section{Perfil de Evaluación entre pares}
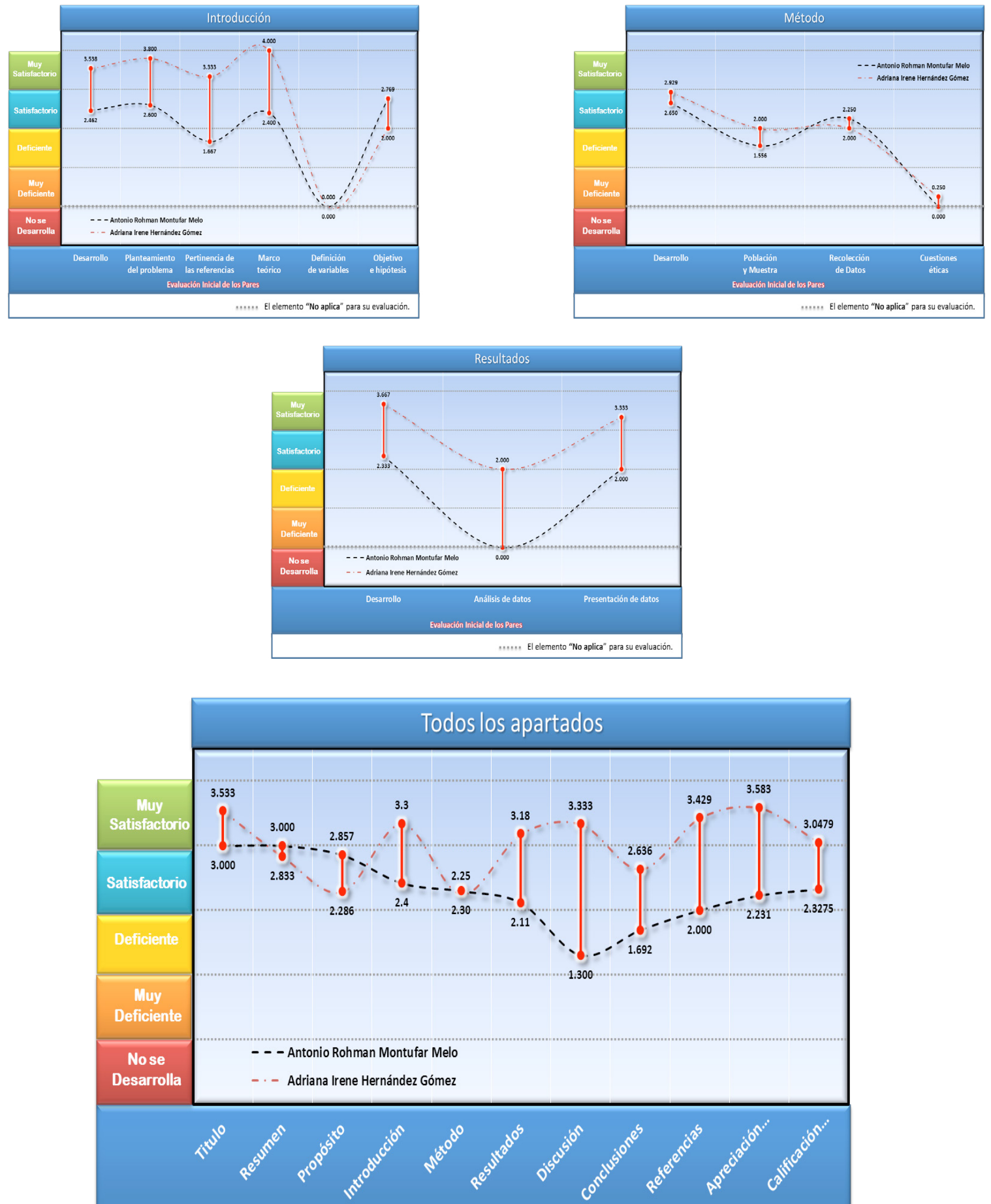


\section{Índice de Concordancia}

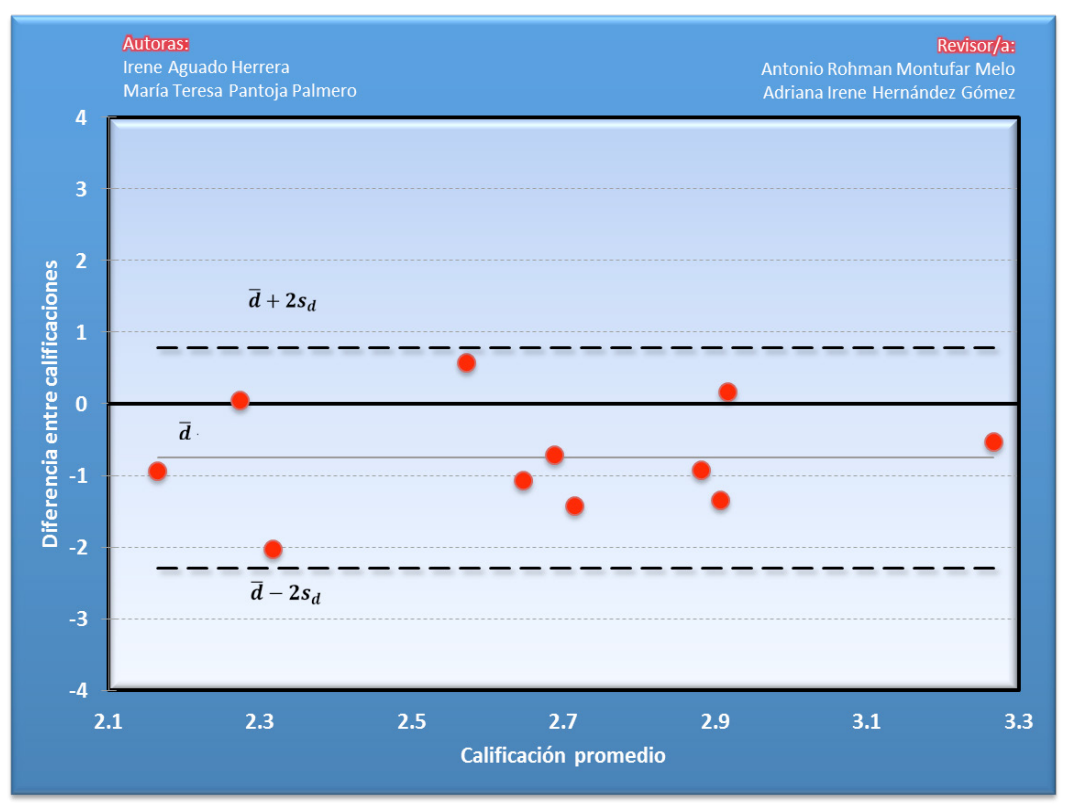

Índice de Acuerdo
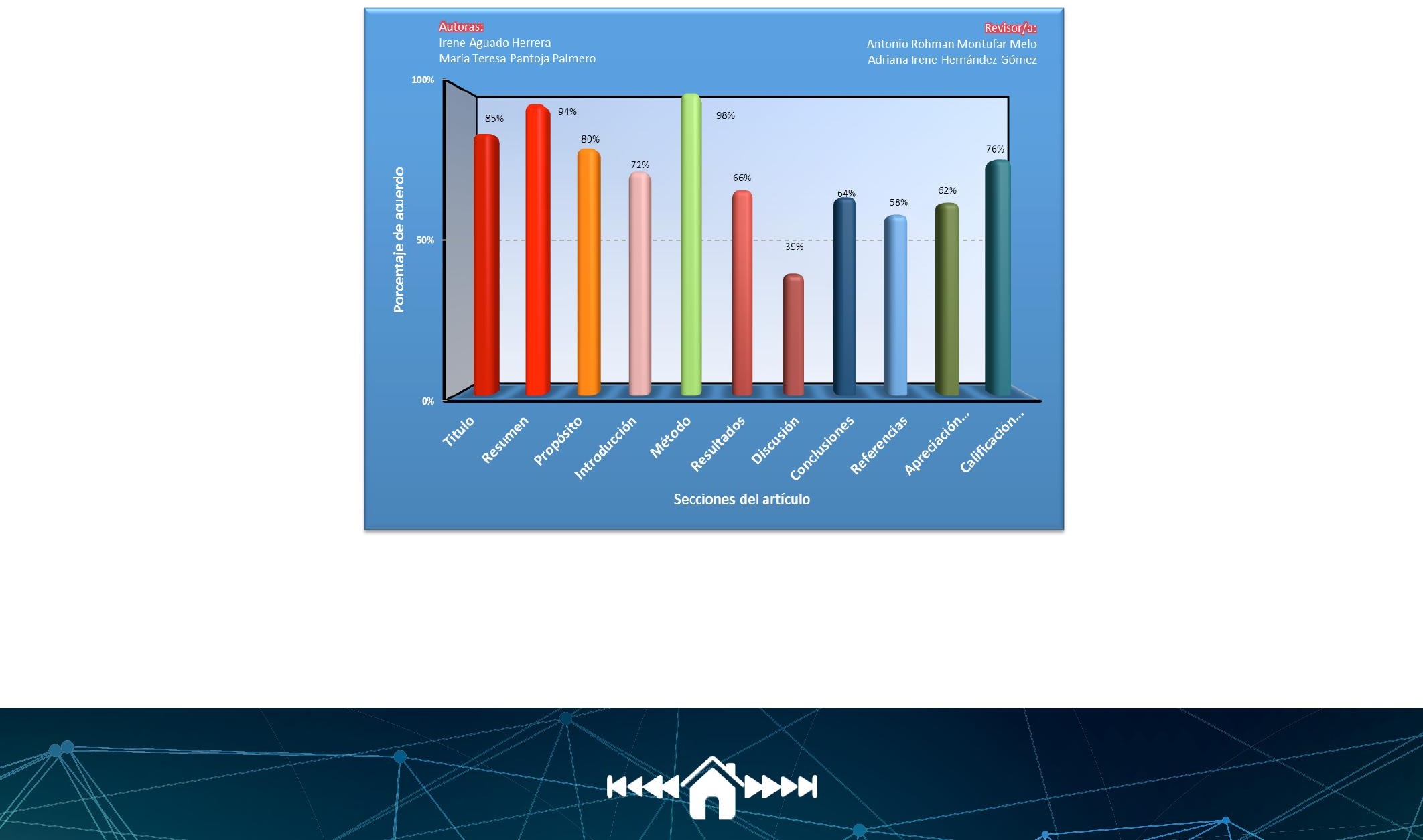


\begin{tabular}{|c|c|}
\hline Revisor 1 & Revisor 2 \\
\hline Antonio Rohman Montufar Melo & Adriana Irene Hernández Gómez \\
\hline \multicolumn{2}{|c|}{ Título/Autoría } \\
\hline $\begin{array}{l}\text { En cuanto al título no hay inconveniente, salvo que no explica } \\
\text { del todo la cuestión referida a los grupos de trabajo, que es rele- } \\
\text { vante en la parte empírica de la investigación. }\end{array}$ & $\begin{array}{l}\text { El título es comprensible y sencillo; sin embargo, es tan abierto a la } \\
\text { interpretación, que es necesario leer el objetivo para saber de qué tra- } \\
\text { ta el artículo. Se sugiere especificar un poco más. Faltaría también } \\
\text { incluir el correo electrónico de las autoras. }\end{array}$ \\
\hline
\end{tabular}

\section{Resumen}

El resumen adolece de ciertas carencias en cuanto a referir los resultados obtenidos; tampoco incluye una idea del planteamiento teórico que respalda todo el trabajo.

\section{Próposito del Estudio}

El propósito queda claro, no hay inconveniente con él.
Se sugiere, para el resumen, complementar la metodología y agregar una breve descripción de lo encontrado, junto con las conclusiones. Adicional a esto, haría falta que las palabras clave reflejen la población con la que se trabajó, así como la visión teórica con la que se trabaja (psicoanálisis).

A lo largo del trabajo, se describen 4 objetivos diferentes. El primero de ellos: "mostrar los aspectos del humor y la risa que se produjeron en un espacio confeccionado específicamente para explorar la violencia en la institución universitaria", es el que corresponde con los resultados y las conclusiones. Sin embargo, los restantes 3 objetivos que se presentan no corresponden. Haría falta, para mejor comprensión del lector, diferenciar o dejar muy claro los objetivos del Proyecto de Investigación "Subjetividad y Procesos Educativos", de los objetivos que tuvo el taller de investigación-implicación que se realizó con los alumnos, para centrarse sobre el humor, objetivo de este artículo. Aún cuando haya otros elementos importantes encontrados en el taller, el centro del artículo debe mostrarse siempre con la cuestión del humor.

\section{Introducción}

El principal problema de esta sección es que el marco teórico está constituido más bien por referencias a autores de muchos años atrás. la información, en su gran mayoría, no se halla actualizada. Las aportaciones de Freu y Anzieu, entre otros, son por demás valiosas, pero deberían ser mayormente acompañadas por otras de fabricación actual. Además, como se verá más adelante, muchas de esas citas no hallan eco en el tratamiento, y por tanto no se ven reflejadas en las conclusiones. Hay, por tanto, una distancia considerable entre el marco teórico y la aproximación empírica.
Se hace una buena revisión teórica del tema; sin embargo, se sugiere incluir, si las hay, algunas investigaciones similares en el tema, así como mostrar de manera mucho más clara las formas en que se presenta la violencia en la formación universitaria. Por último, se sugiere enriquecer con ideas propias de las autoras, las citas textuales que son utilizadas a lo largo de la introducción, analizando y contextualizando el contenido de éstas. 


\begin{tabular}{|c|c|}
\hline Revisor 1 & Revisor 2 \\
\hline \multicolumn{2}{|c|}{ Método } \\
\hline $\begin{array}{l}\text { No hay mayor inconveniente con esta sección, sólo el forma- } \\
\text { to de redacción, y la carencia de una explicación profunda } \\
\text { del por que de las técnicas utilizadas, ya que no hay un fun- } \\
\text { damento teórico que las sustente. }\end{array}$ & $\begin{array}{l}\text { La cuestión del humor, analizada en este artículo, se desprende } \\
\text { de lo encontrado a lo largo del taller en el que participaron los es- } \\
\text { tudiantes. Es decir, a partir de las observaciones de lo ocurrido, se } \\
\text { retoman estos momentos de humor para su análisis. Esto implica } \\
\text { que, de alguna manera, el análisis que se realiza corresponde a } \\
\text { una metodología de corte cualitativo. Se sugiere, para que el ar- } \\
\text { tículo cumpla satisfactoriamente con los criterios metodológicos } \\
\text { aquí considerados, describir de manera muy precisa lo realizado } \\
\text { en el taller, pero especificando participantes, materiales, lugar en } \\
\text { el que se lleva a cabo, técnica de recopilación de la información y } \\
\text { categorías de análisis; todos estos elementos, necesarios para dar } \\
\text { cuenta de una investigación de corte cualitativo. Adicional a esto, } \\
\text { como se suele hacer en investigación de corte cualitativo y sobre } \\
\text { todo cuando se trata de investigación-implicación, es importante } \\
\text { aclarar sobre la confidencialidad de lo trabajado con el grupo, as } \\
\text { como aquello que se le devuelve al terminar el taller. }\end{array}$ \\
\hline \multicolumn{2}{|c|}{ Resultados } \\
\hline $\begin{array}{l}\text { Como se comentaba anteriormente, la relación entre lo de- } \\
\text { sarrollado en el parco teórico y los resultados (de los que } \\
\text { derivarán las conclusiones) es pobre, por lo que debe traba- } \\
\text { jarse esta parte. }\end{array}$ & $\begin{array}{l}\text { Es importante mencionar que muchos de los elementos que se } \\
\text { evelúan en esta sección de resultados no aplican para una in- } \\
\text { vestigación de corte cualitativo, adicional a esto, la problemática } \\
\text { descrita anteriormente en cuanto a los múltiples objetivos que } \\
\text { aparecen en el artículo, hace que la evaluación sea menor en esta } \\
\text { sección tomando en cuenta la cuestión de los resultados. Hacien- } \\
\text { do las adecuaciones respecto a los objetivos, esto se soluciona- } \\
\text { ría de inmediato. Por último, la descripción de los resultados se } \\
\text { muestra muy somera. Aun cuando se describen dos experiencias } \\
\text { de violencia representadas por los estudiantes dentro del taller } \\
\text { pareciera que pueden aprovecharse muchos más elementos de } \\
\text { las mismas; sobre todo pensando que el marco teórico de este } \\
\text { artículo es el psicoanálisis, el uso y análisis de fragmentos de lo } \\
\text { dicho y expresado (además de las risas) podrían posibilitar un } \\
\text { análisis mucho más rico para efectos del objetivo. }\end{array}$ \\
\hline \multicolumn{2}{|c|}{ Discusión } \\
\hline $\begin{array}{l}\text { Ésta es quizá la sección más débil del estudio, ya que la pro- } \\
\text { yección de lo tratado en el marco teórico no se despliega } \\
\text { correctamente aquí, por lo que la lógica del estudio parece } \\
\text { endeble. }\end{array}$ & $\begin{array}{l}\text { Se agrupan en el artículo, tanto Discusión como Conclusio- } \\
\text { nes, y si bien esto no es un error, sí se presentan demasiado } \\
\text { someras. Al igual que se comentó anteriormente, el análisis } \\
\text { de los dichos, chistes, palabras, risas, en fin, fragmentos de } \\
\text { lo ocurrido (dicho) en las representaciones descritas, puede } \\
\text { aportar muchos más elementos de análisis que los que aqui } \\
\text { se incluyen. }\end{array}$ \\
\hline
\end{tabular}




\begin{tabular}{|l|l|}
\hline \multicolumn{2}{|c|}{ Revisor 1 Conclusiones } \\
\hline \multicolumn{2}{|c|}{ Revisor 2 } \\
\hline $\begin{array}{l}\text { Los comentarios de esta sección van dirigidos a las mismas } \\
\text { adolescencias ya versadas anteriormente. }\end{array}$ & $\begin{array}{l}\text { Para este apartado, repito mi comentario anterior: Se agrupan } \\
\text { en el artículo, tanto Discusión como Conclusiones, y si bien } \\
\text { esto no es un error, sí se presentan demasiado someras. Al igual } \\
\text { que se comentó anteriormente, el análisis de los dichos, chistes, } \\
\text { palabras, risas, en fin, fragmentos de lo ocurrido (dicho) en las } \\
\text { representaciones descritas, puede aportar muchos más elemen- } \\
\text { tos de análisis que los que aquí se incluyen. }\end{array}$ \\
\hline \multicolumn{1}{|c|}{ Referencias } \\
\hline $\begin{array}{l}\text { Deberían acompañarse las referencias clásicas con otras más } \\
\text { actuales (lo cual ya se había acotado). También debe respe- } \\
\text { tarse el formato APA, lo cual no se hace a lo largo dela artí- } \\
\text { culo, y la lista de referencias no es la excepción. }\end{array}$ & $\begin{array}{l}\text { Los autores clásicos como Freud, Massota y Bourdieu incluso, } \\
\text { por supuesto no necesitan estar "actualizados", el resto de las } \\
\text { referencias bibliográficas son adecuadas al tema y varias de ellas } \\
\text { de autores contemporáneos. Sin embargo, podría ser un muy } \\
\text { buen aporte revisar algunas otras contribuciones psicoanalíti- } \\
\text { cas al tema del humor y la violencia. }\end{array}$ \\
\hline
\end{tabular}




\section{Historia del Proceso}

\section{EDITORIAL}


http://dx.doi.org/10.22402/j.rdipycs.unam.3.2.2017.135.196-211

\title{
Efectos del Taller de Estrategias de Aprendizaje en el desempeño de ALUMNOS DE PSICOLOGÍA
}

\author{
José Gonzalo Amador-Salinas, Virginia González-Rivera, Alejandra Reyes-García, Alejandro \\ González-Villeda, Pablo Balderrama-Camacho, Alberto Prado-Martínez \\ Centro Interdisciplinario de Ciencias de la Salud, Unidad Santo Tomás, IPN. \\ México
}

\begin{abstract}
RESUMEN
En el presente trabajo, se llevó a cabo una intervención en alumnos de primer ingreso a de licenciatura en psicología del Centro Interdisciplinario de Ciencias de la Salud, Unidad Santo Tomás del Instituto Politécnico Nacional, por medio del taller "estrategias de aprendizaje", con el propósito de observar su efecto en el desempeño académico. Los resultados muestran que la evaluación realizada por medio del cuestionario EDAOM en la pre prueba y post prueba, arroja diferencias estadísticamente significativas, por lo que se cree que los asistentes mejoraron en el conocimiento, uso y aplicación de las estrategias de aprendizaje revisadas en el taller, también se comparó el promedio de calificaciones antes y después del taller, obteniendo igualmente diferencias estadísticamente significativas. Se concluye que el taller fue eficaz, pero se requiere mejorar las prácticas docentes y dar un mayor y mejor seguimiento a los alumnos en su trayectoria escolar.
\end{abstract}

Palabras Clave:

Estrategias de aprendizaje, taller, EDAOM, rendimiento académico, alumnos de nivel superior.

\section{EFFECTS OF THE WORKSHOP ON LEARNING STRATEGIES IN THE PERFORMANCE OF PSYCHOLOGY STUDENTS}

\begin{abstract}
The students of first semester of psychology degree at Centro Interdisciplinario de Ciencias de la Salud, Unidad Santo Tomás, of the Instituto Politécnico Nacional, through the workshop "learning strategies", in order to observe its effect on academic performance. The results show that the evaluation performed trough the EDAOM questionnaire in the pretest and posttest there are statistically significant differences. It is believed that students improve knowedge and they use the application of learning strategies reviewed in the workshop. We also compared the average scores before and after the workshop, also obtaining statistically significant differences. It is concluded that the workshop was effective, but that it is necessary to improve teaching practices and give a greater and better follow up to the students in their school career.
\end{abstract}

Keywords:

learning strategies, workshop, EDAOM, academic performance, upper level students.

Bitácora del Artículo:

| Recibido: 1 de Agosto de 2017 | Aceptado: 1 Septiembre de 2017 | Publicado en línea: Julio-Diciembre de 2017 | 


\title{
Efectos del Taller de Estrategias de Aprendizaje en el DESEMPEÑO DE ALUMNOS DE PSICOLOGÍA
}

\author{
José Gonzalo Amador-Salinas, Virginia González-Rivera, Alejandra Reyes-García, Alejandro \\ González-Villeda, Pablo Balderrama-Camacho, Alberto Prado-Martínez \\ Centro Interdisciplinario de Ciencias de la Salud, Unidad Santo Tomás, IPN.
}

México

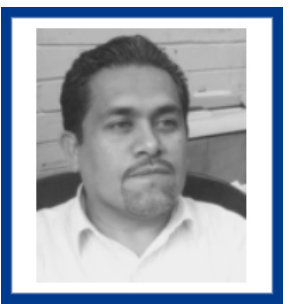

José Gonzalo Amador-Salinas

Unidad Santo Tomás, IPN

Correo: g-zama@hotmail.com

José Gonzalo Amador Salinas: Egresado de la FESI; trabajó como psicólogo en el DIF Xalostoc de 1997 al 2002; actualmente se desempeña como profesor de tiempo completo, titular B, en el Centro Interdisciplinario de Ciencias de la Salud Unidad Santo Tomás (IPN).

Ver más...

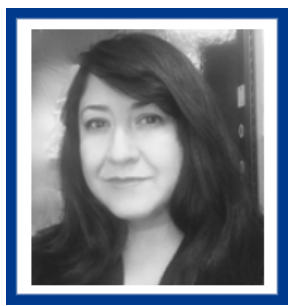

Virginia González-Rivera Unidad Santo Tomás, IPN Correo: vicky_gori@live.com

Licenciada en psicología por la FES Iztacala (UNAM), actualmente se desempeña como profesora Titular $C$ del Instituto Politécnico Nacional, en el Centro Interdisciplinario de Ciencias de la Salud Unidad Santo Tomas.

Ver más...

\section{CONTRIBUCIÓN DE LOS AUTORES}

José Gonzalo Amador-Salinas propuso el proyecto, lo coordinó, elaboró y registró el taller, integró la información, redactó el informe final, revisó la base de datos e integró el análisis estadístico, elaboró la discusión y las conclusiones. | Virginia González-Rivera elaboró e impartió el taller, propuso la metodología, propuso y revisó el análisis estadístico, revisó el manuscrito final, elaboró la discusión y las conclusiones. I Alejandra Reyes-García revisó el manuscrito, redactó el resumen y su versión en inglés, participó en la integración del marco teórico. | Alejandro González-Villeda revisó el manuscrito final, hizo correcciones de estilo y redacción, participó en la búsqueda de información, revisó la aplicación y calificación de los instrumentos. ! Pablo Balderrama-Camacho aplicó y calificó los instrumentos, y capturó información en la base de datos. ! Alberto Prado-Martínez participó en la búsqueda de información, procesamiento de la información, revisó el manuscrito y elaboró las referencias bibliográfícas.

\section{AgRADECIMIENTOS}

Este trabajo se realizó con el apoyo del Programa de Fortalecimiento de Grupos de Investigación, de la Dirección de Investigación y Posgrado del IPN, número de registro del proyecto: 20162129.

\section{Datos de Filiación de los Autores}

\author{
Centro Interdisciplinario de Ciencias de la Salud, Unidad Santo Tomás, IPN.
}

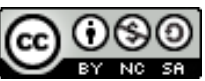

Copyright: ( 2017 Amador-Salinas, J. G., González-Rivera, V., Reyes-García, A., González-Villeda, A., Balderrama-Camacho, P., \& Prado-Martínez, A. Este es un artículo de acceso abierto distribuido bajo los términos de la licencia Creative Commons Reconocimiento-NoComercial -Compartirlgual 4.0 Internacional, por lo que su contenido gráfico y escrito se puede compartir, copiar y redistribuir total o parcialmente sin necesidad de permiso expreso de sus autoras con la única condición de que no se puede usar con fines directamente comerciales y los términos legales de cualquier trabajo derivado deben ser los mismos que se expresan en la presente declaración. La única condición es que se cite la fuente con referencia a la Revista Digital Internacional de Psicología y Ciencia Social y a sus autoras. 


\section{TABLA DE CONTENIDO}

INTRODUCCIÓN

MÉTOdO

Participantes, 26

Materiales, 26

Procedimiento

Mediciones, 27

Análisis estadísticos, 27

Resultados

Discusión

CONCLUSIONES 


\section{INTRODUCCIÓN}

Tegún la Organización para la Cooperación y el Desarrollo Económico (OCDE), 16\% de los adultos mexicanos entre los 25 y 64 años de edad tienen estudios de educación superior; por lo tanto, se estima que $25 \%$ de los jóvenes en México se gradúen de licenciatura o técnico superior universitario y obtengan un título en algún momento de su vida (Moraes, 2016).

Por otro lado, la Secretaría de Educación Pública (SEP) afirma que en México asisten a la educación superior un total de 3,648,945, de los cuales 2,579,289 asisten en la educación pública y 1,069,656 estudiaron en la educación privada, existiendo un índice de graduación de $23 \%$, y un abandono escolar de $6.7 \%$ (SEP, 2016).

De esta manera, en el Instituto Politécnico Nacional (IPN) se dice que la matrícula del ciclo escolar 2016-2017 fue de 104,409 estudiantes en el sistema escolarizado, y en particular los de nuevo inicio para la modalidad escolarizada fueron 18,146 (SGE, 2016). Respecto a los alumnos inscritos en el Centro Interdisciplinario de Ciencias de la Salud, Unidad Santo Tomás (CICS-UST) del IPN, la licenciatura en Psicología tiene un total de 1,192 alumnos inscritos, de los cuales 552 corresponden al turno matutino y 640 al vespertino; los alumnos de primer ingreso fueron 109 en el turno matutino y 220 en el vespertino; en total 329, con un porcentaje de reprobación total de $15.77 \%$ y un abandono de $2.52 \%$ (SGE IPN, 2016).

Estos alumnos de nuevo ingreso a la licenciatura de Psicología deben adaptarse a los requerimientos del modelo educativo por competencias, al plan de estudios 2010 y a las prácticas de enseñanza propias del cuerpo docente de la licenciatura, por lo que requieren de estrategias de aprendizaje que los capacite en su vida académica. Por este motivo, el propósito de este trabajo fue evaluar las estrategias de aprendizaje con que cuentan los alumnos de primer ingreso a la licenciatura en Psicología, para establecer un taller de capacitación centrado en sus necesidades y medir sus efectos en el rendimiento académico. Esta investigación parte de la hipótesis de que, al dotar de habilidades y estrategias a partir de un taller, los participantes mejorarán en el uso de las estrategias de aprendizaje y mostrarán un mejor rendimiento académico.

De esta manera, algunos investigadores han Ilamado la atención para atender las necesidades de capacitación en estrategias de aprendizaje; por ejemplo, León, Risco \& Alarcón (2014) han planteado que la mitad de los alumnos de licenciatura utilizan métodos de aprendizaje como las estrategias elaboración y ensayo (resúmenes, toma de apuntes, subrayado, repetición de las ideas principales en voz alta), pero que muestran problemas con las estrategias de organización (no todos usan los organizadores de conocimientos) y las estrategias metacognitivas de planeación (repaso de temas, elaboración de horarios, establecimiento de objetivos y búsqueda de recursos).

Esto es importante porque se ha comprobado que la planificación y la autorregulación son determinantes en el desempeño académico; de esta manera, De la Fuente, Pichardo, Justicia \& Berbén (2008) analizaron la relación entre enfoques de aprendizaje, autorregulación y rendimiento en estudiantes universitarios de tres universidades públicas europeas; en el estudio participaron 579 estudiantes. En sus resultados se aprecia que un aprendizaje más profundo va acompañado de mayor planificación y de un comportamiento y estrategias más autorreguladoras; mencionan que hay una relación negativa entre el enfoque superficial y la autorregulación del aprendizaje, considerando además que los alumnos en esta situación se encuentran menos satisfechos con el aprendizaje logrado.

También Gargallo (2006) realizó un estudio para comprobar si existe relación entre el uso de estrategias de aprendizaje de los alumnos y su rendimiento académico, ya sea en menor o mayor proporción; participaron 545 estudiantes elegidos aleatoriamente del primero y segundo ciclos escolares. Sus resultados indican que los alumnos de los primeros grados de estudios no disponen de suficientes estrategias de conocimiento de fuentes de búsqueda de información ni de transferencia, y que en su mayoría usan estrategias de motivación extrínseca; determinó que hay evolución positiva en el uso de estrategias conforme los alumnos tienen mejor rendimiento; por el contrario, los alumnos de bajo rendimiento no disponen de estrategias de control ni de habilidades de interacción social, ni de transferencias; al mismo tiempo, su motivación es extrínseca y no disponen de estrategias relacionadas a la autoeficacia y con las expectativas positivas. Además, Cano y Justicia (1993, citado en González, Castañeda \& Maytorena, 2000) afirman que los alumnos de alto rendimiento utilizan estrategias de procesamiento profundo, memoria de hechos y alta motivación de logro, y los de bajo rendimiento se caracterizan por utilizar procesamiento elaborativo, motivación extrínseca y miedo al fracaso.

A su vez Lorenzo \& Herrera (2009) analizaron las estrategias de aprendizaje que utilizan los alumnos de la titulación de maestría; participaron 165 estudiantes; sus resultados indican que la mayoría de los alumnos dijeron estudiar en su recámara; también encontraron que los alumnos no muestran estrategias metacognitivas de 
planificación del aprendizaje adecuadas. Finalmente, los alumnos participantes reportaron que nunca realizan el examen sin leer previamente todas sus preguntas; sin embargo, después del examen no siempre recuerdan lo estudiado, consecuencia, quizá, del uso de un enfoque superficial del aprendizaje (Biggs, 2001, citado en Lorenzo \& Herrera, 2009) o de que las estrategias y metodologías docentes que implementa el profesorado no fomenta el aprendizaje autónomo, colaborativo y crítico del alumnado sino, por el contrario, un aprendizaje mecánico y más cercano a lo memorístico.

También Camarero, Martín \& Herrero (2000) realizaron un estudio para indagar respecto a las influencias de factores socioacadémicos (tipo de estudios, curso y rendimiento académico) en los estilos y estrategias de aprendizaje de los estudiantes universitarios. La muestra estuvo conformada por 447 alumnos seleccionados de manera aleatoria de cursos iniciales y finales; sus resultados muestran que los alumnos de humanidades usan más estrategias de aprendizaje, emplean significativamente más las estrategias de los procesos atencionales (subrayados) y las estrategias de repetición (repasos), en contraste con los alumnos de otras disciplinas. Concluyen que los alumnos de menor rendimiento académico reflejan una mayor tendencia a actuar por intuición, les cuesta más esfuerzo el trabajo metódico y minucioso, y pensar en recompensas a mediano o largo plazos, disfrutando más del momento presente.

Por otra parte, Valle et al. (2008) realizaron un estudio para identificar posibles perfiles de aprendizaje autorregulado en una muestra de estudiantes universitarios; sus resultados indican que para la autorregulación las variables cognitivas (estrategias de elaboración y organización) tienen una importancia mayor que la motivación; concluyen que existe una relación positiva estadísticamente significativa entre la autorregulación del aprendizaje y el rendimiento académico. Sin embargo, según Covington (1984, citado en Navarro, 2003) si se contempla la motivación de los estudiantes, se podrían describir tres tipos de ellos: los orientados al dominio (sujetos que tienen éxito escolar, presentan alta motivación de logro y muestran confianza en sí mismos), los que aceptan el fracaso (sujetos que presentan una imagen propia deteriorada y desesperanza aprendida) y los que evitan el fracaso (carecen de aptitud y autoestima, y ponen poco esfuerzo en su desempeño).

Además, Valle, Cabanach, Rodríguez, Núñez \& González (2006) mencionan que la orientación al aprendizaje mantiene relaciones positivas con el uso de estrategias, tanto cognitivas como metacognitivas.
Por lo mencionado: que la mitad de alumnos tienen problemas con las estrategias de organización o planeación (León, Risco \& Alarcón, 2014; Cano y Justicia, 1993, citado en González, Castañeda \& Maytorena, 2000), además de que para mejor aprendizaje es necesario la planificación (De la Fuente, Pichardo, Justicia \& Berbén, 2008), y que los alumnos de primer ingreso no usan suficientes estrategias (Gargallo, 2006; Cano y Justicia, 1993, citado en González, Castañeda \& Maytorena, 2000), acompañado de la afirmación de que hay indicios de que los alumnos no usan estrategias metacognitivas de planeación (Lorenzo \& Herrera, 2009; Amador et al., 2015), ya que los alumnos de menor rendimiento planean menos (Camarero, Martín \& Herrero, 2000) y que para mejorar el rendimiento académico es necesario que los alumnos usen más la autorregulación (Valle, Cabanach, Rodríguez, Núñez \& González, 2006). Se ha propuesto que existan acciones encaminadas a mejorar el conocimiento y uso de las estrategias de aprendizaje; por ejemplo, Santibáñez \& Sabando (2016) realizaron un estudio para establecer la relación entre las estrategias de aprendizaje y características socioeducativas en estudiantes universitarios de primer semestre; participaron en el estudio 168 estudiantes de primer semestre;en los resultados se aprecia que los estudiantes que puntuaron bajo deberían ser objeto de orientación y apoyo psicopedagógico. Concluyen que la mayoría de las acciones remediales aparecen tardíamente, cuando ya los estudiantes tienen muy avanzado el semestre. Proponen que el diagnóstico de las estrategias de aprendizaje en el inicio de los ciclos escolares puede proporcionar valiosa información para el desarrollo de orientaciones institucionales más efectivas. Un dato interesante es que Cano y Justicia (1993, citado en González, Castañeda \& Maytorena, 2000) afirman que, en las instituciones educativas mexicanas, aún no es una actividad curricular cotidiana el modelamiento de las habilidades del pensamiento, y mucho menos la evaluación de resultados de aprendizaje, desde un enfoque cognoscitivo.

Finalmente Martín (2003) y Pozo (1990; citado en Núñez, González, Solano \& Rosário, 2006) indican que es necesario capacitar para el aprendizaje autónomo y permanente, ya que en la actualidad muchos estudiantes que alcanzan estudios superiores no se encuentran adecuadamente preparados para lo que se requiere de ellos en la Universidad, al no ser capaces de autorregular su propio proceso de aprendizaje (Allgood, Risko, Álvarez y Fairbanks, 2000; citado en Núñez, González, Solano \& Rosário, 2006), y en consecuencia se cree que esta falta de estrategias y procesos de autorregulación para enfrentarse al aprendizaje es el factor principal del 
fracaso universitario (Tuckman, 2003, citado en Núñez, González, Solano \& Rosário, 2006; Teresita, 2010).

Ante este panorama, algunos investigadores han diseñado intervenciones con la finalidad de capacitar a los alumnos en estrategias de organización y metacognitivas; por ejemplo Solano, et al. (2007) realizaron un estudio para observar si un programa de intervención mejoraría las competencias en autorregulación de estudiantes de nuevo ingreso; para ello utilizaron un diseño experimental; el grupo experimental tuvo acceso a un programa de seis sesiones (una por semana), en las cuales, después establecer los objetivos del programa y la reflexión necesaria, practicaron los aprendizajes estratégicos. Los resultados indican que existieron diferencias estadísticamente significativas en el grupo experimental comparando la evaluación previa y la posterior, y no se observan diferencias estadísticas en el grupo control en las mediciones previa y posterior.

También González \& Maytorena (2004) propusieron un programa de formación para las habilidades y estrategias de aprendizaje, al cual denominaron "Taller de aprender a aprender", con el objetivo de que los estudiantes de bachillerato y universitarios tuvieran contacto con las estrategias sistemáticas de aprendizaje. El taller contó con material de autoaprendizaje y se desarrolló en sesiones de grupo de 15 a 20 estudiantes con dos instructores que dirigieron las sesiones con un formato de taller centrado en la tarea, en el que se dio la dscusión dirigida, la retroalimentación y actividades de refuerzo. Estos autores reportan un incremento de las calificaciones de los alumnos por su participación en el taller.

De esta manera, para tener éxito en la capacitación a los alumnos, es necesario mencionar el modelo de Zimmerman (1998, citado en Núñez, González, Solano \& Rosário, 2006) respecto a que los cursos deben promover los seis siguientes aspectos: 1) el establecimiento de objetivos; 2) la planificación estratégica; 3) la percepción de autoeficacia; 4) el interés intrínseco en la tarea; 5) el control volitivo, y 6) la autorreflexión.

Finalmente reiteramos el objetivo de este trabajo, que fue evaluar las estrategias de aprendizaje con que cuentan los alumnos de primer ingreso a la licenciatura de Psicología, para establecer si con un taller de capacitación centrado en sus necesidades se pueden observar diferencias en el rendimiento académico. $Y$ nuestra hipótesis es: al dotar de habilidades y estrategias de aprendizaje a partir de un taller, los participantes mejorarán en el uso de estas estrategias de aprendizaje y mostrarán un mejor rendimiento académico.

\section{Método}

\section{Participantes}

Participaron en el estudio 37 alumnos de primer ingreso a la licenciatura en Psicología del CICS-UST, del IPN, generación 2017-2021, con edades de entre los 18 y 20 años de edad; todos eran parte del grupo de nuevo ingreso a la licenciatura, del turno matutino.

\section{Materiales}

Computadoras con programa Excel de Office Windows, presentaciones en el programa PowerPoint, hojas bond, plumones, lecturas de las diferentes materias.

\section{Procedimiento}

El presente estudio se enfoca en la investigación cuantitativa, con un diseño preexperimental con preprueba y postprueba, y un muestreo por conveniencia. Para evaluar sus estrategias de aprendizaje, se aplicó el EDAOM a un grupo de nuevo ingreso a la licenciatura en Psicología en la sala de cómputo; previamente se había instalado la versión del cuestionario en Excel en las computadoras; los alumnos fueron conducidos al lugar de la aplicación y se les pidió que leyeran las instrucciones y que externaran las posibles dudas. Se les explicó que la información personal sería resguardada y que sólo se tomarían los datos numéricos de manera grupal para el análisis estadístico; también se les mencionó que los resultados de su cuestionario sólo serían analizados de manera personal (entre el instructor y el participante) con fines meramente académicos. Después de aclarar las dudas, se pidió a los participantes que respondieran el cuestionario y se les recordó que durante la aplicación podrían solicitar asesoría por las posibles dudas.

Una vez aplicado el cuestionario, se obtuvieron los perfiles y con base en esta información se diseñó el taller de acuerdo con las siguientes directrices planteadas por Boekaerts \& Corno (2005, citado en Teresita, 2010):

- Propiciar espacios en que las estrategias utilizadas puedan describirse en forma verbal; por ejemplo, durante el desarrollo de una actividad grupal.

- Aprovechar la experiencia y el conocimiento que el profesor tiene de cómo, cuándo y por qué utilizar determinadas estrategias mediante el modelado.

- Usar el portafolio de evidencias, que permite realizar el seguimiento y la evaluación de los trabajos y del desempeño académico de cada alumno con el objetivo de brindar orientaciones concretas. 
- El impulso de actividades grupales en las que se priorice el aprendizaje colaborativo.

También se buscó lograr las recomendaciones del Espacio Europeo de Enseñanza Superior (2010) respecto a que los alumnos necesitan desarrollar competencias genéricas básicas para su adecuado desempeño académico, como son: 1) capacidad de análisis y síntesis; 2) capacidad de organización y planificación; 3) capacidad de gestión de la información; 4) obtener información de forma efectiva; 5) razonamiento crítico, y 6) capacidad para pensar de forma creativa y desarrollar nuevas ideas y conceptos.

De esta manera, el objetivo del taller fue que los alumnos participantes conocieran y usaran de manera apropiada las diferentes técnicas y estrategias de aprendizaje, por medio de la retroalimentación, recomendaciones acerca de sus productos, de la reflexión del tipo de aprendizaje logrado con el uso de las estrategias revisadas, la planificación de sus actividades de aprendizaje y el modelamiento. Para lograr lo mencionado, se eligió impartir el taller por medio de la estrategia de proyecto, con el objetivo de que los participantes pudieran planear, implementar y evaluar la aplicación de las estrategias de aprendizaje en su realidad académica; el proyecto que se evaluó fue un portafolio de evidencias que contenía las diferentes técnicas de aprendizaje revisadas en el taller. El instructor presentó conceptualmente cada tema y fomentó prácticas que permitieron a los participantes integrar la información con las herramientas usadas (Pimienta, 2012), propició la discusión constructiva y la reflexión grupal, dio retroalimentación correspondiente al desempeño individual, dando seguimiento a los resultados del cuestionario EDAOM; finalmente, el taller tuvo una duración total de seis sesiones de cinco horas. Con lo anterior se consideró que el taller estuviera orientado al desarrollo y no sólo a la reducción de déficits (Núñez, González, Solano \& Rosário, 2006) y a enseñar la autorregulación con actividades de aprendizaje que promovieran, a través del modelado, acciones del estudiante para autorregular su proceso de aprendizaje (Paris y Paris, 2001, citado en Álvarez, 2009). En este trabajo se entiende el aprendizaje autorregulado como "un proceso activo en el cual los estudiantes establecen los objetivos que guían su aprendizaje intentando monitorizar, regular y controlar su cognición, motivación y comportamiento con la intención de alcanzarlos" (Rosário, 2004: 37; citado en Núñez, González, Solano \& Rosário, 2006); por planificación estratégica: la selección - por parte del alumno- de un abanico de estrategias de aprendizaje o de métodos que les permite alcanzar los objetivos diseñados (Zimmerman y Martí-
nez-Pons, 1992, citado en Núñez, González, Solano \& Rosário, 2006), y por estrategias de aprendizaje, como una secuencia de actividades, operaciones o planes dirigidos a la consecución de metas de aprendizaje y que tienen un carácter consciente e intencional en el que se implican procesos de toma de decisiones por el estudiante ajustadas al objetivo que pretende alcanzar (Rodríguez \& García-Merás, 2005). Finalmente, el rendimiento académico será entendido como el promedio de calificaciones del semestre.

\section{Mediciones}

La variable independiente fue el taller impartido a los alumnos participantes, el cual se registró en la Dirección de Educación Superior del IPN.

Las variables dependientes fueron dos:

1. Las estrategias de aprendizaje usadas por los alumnos que fueron medidas por el cuestionario de Estrategias de Aprendizaje y Orientación Motivacional (EDAOM, instrumento que tiene una validez de 0.67, además obtiene 0.89 de validez concurrente en tareas académicas diversas, presenta una consistencia interna de 0.94 alfa de Cronbach). El cuestionario arroja una calificación general numérica, que se puede clasificar en los siguientes perfiles:

- Suficiente, de 100 a 76 (se interpreta que no hay riesgo para el estudiante).

- Regular, de 75 a 56 (sugiere reforzar las estrategias deaprendizaje u orientaciones motivacionales del estudiante, correspondientes a la subescala en cuestión; no representa aún una falla crítica).

- Insuficiente, de 55 a 0 (indica necesidad crítica de entrenar en estrategias de aprendizaje u orientaciones motivacionales del estudiante; se considera una falla significativa).

2. El rendimiento escolar (el promedio de calificaciones obtenidos en las unidades de aprendizaje) obtenido de su historial académico.

\section{Análisis estadísticos}

El análisis estadístico propuesto fue analizar las calificaciones generales obtenidas en el cuestionario EDAOM y en el promedio de calificaciones obtenido en sus respectivas unidades de aprendizaje (materias o asignaturas) por medio de la prueba de los signos; de esta manera se obtuvo un balance respecto a si las calificaciones (EDAOM y su promedio académico) incrementaron, decrementaron o permanecieron iguales. También se analizaron las medias de las calificaciones generales del EDAOM con la prueba t de Student para grupos relacionados, haciendo el mismo análisis para los promedios 
académicos de los participantes obtenidos en sus unidades de aprendizaje antes y después del taller.

\section{Resultados}

En la evaluación previa al taller con el cuestionario EDAOM, en referencia a los perfiles se obtuvo: 1 participante en el perfil suficiente, 27 participantes en el perfil de regulares y 9 participantes en el perfil de insuficientes. Posterior al taller se observó: 7 participantes en el perfil de suficiente, 26 participantes en el perfil de regulares y 4 participantes en el perfil de insuficientes (Figura 1).

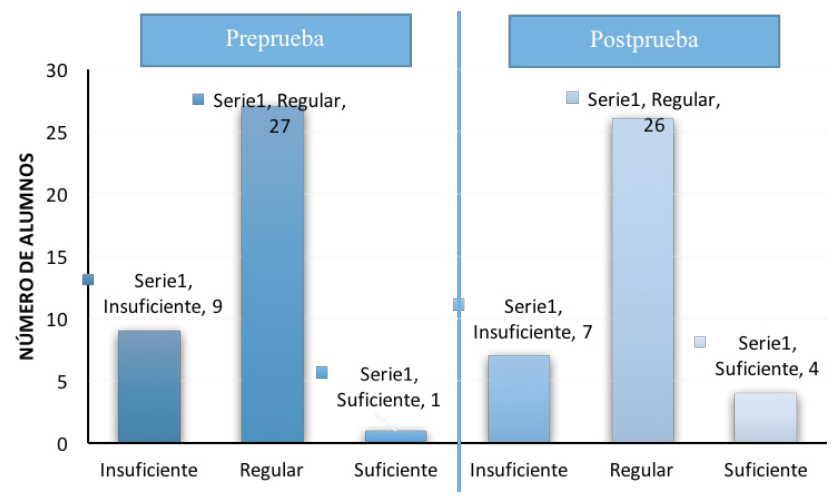

Figura 1.

Se observa, según el perfil obtenido en el cuestionario EDAOM, un aumentó en el perfil de suficiente, y disminuyó el perfil de insuficiente.

Respecto a los cambios identificados en el perfil del cuestionario EDAOM: 22 alumnos permanecieron sin cambio de perfil ( 2 en insuficiente, 19 en regular y 1 en suficiente), 6 pasaron de regular a suficiente, 7 pasaron de insuficiente a regular y 2 pasaron de regular a insuficiente (figura 2).

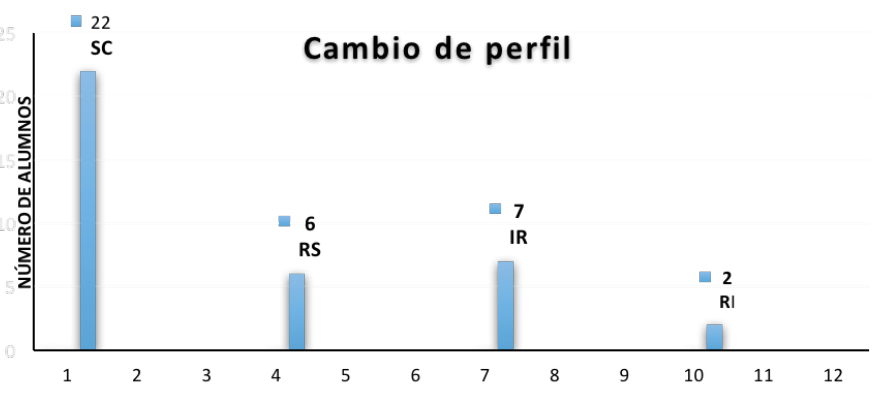

Figura 2.

Cambios de perfil en la puntuación general del EDAOM (SC, sin cambio; $R S$, de regular a suficiente; $I R$, de insuficiente a regular, y $R I$, de regular a insuficiente).
Para saber si los cambios en las calificaciones obtenidas por los participantes en el cuestionario EDAOM es relevante, se aplicó la prueba de los signos, obteniendo que hubo 9 diferencias negativas (es decir, 9 participantes bajaron su calificación general en el EDAOM), mientras que existieron 28 diferencias positivas (28 participantes subieron sus puntuaciones); se obtuvo un valor $p=0.003$, por lo que se acepta la hipótesis de trabajo en donde se afirma que al dotar de habilidades y estrategias de aprendizaje a partir de un taller, los participantes mejorarán en el uso de estas mismas y mostrarán un mayor rendimiento académico.

De la misma manera, para conocer la tendencia de las calificaciones obtenidas en sus respetivas unidades de aprendizaje, se aplicó la prueba de los signos, obteniendo 9 diferencias negativas (es decir, 9 participantes bajaron su calificación), mientras que existieron 27 diferencias positivas (27 participantes subieron sus calificaciones) y 1 empate (se mantuvo la misma calificación); se obtuvo un valor $p=0.005$, por lo que se acepta la hipótesis de trabajo.

Por otro lado, la media de calificaciones en el cuestionario EDAOM en la preprueba fue de 61.266, y en la postprueba fue de 67.6645 (figura 3). Mientras que las medias de las calificaciones en las unidades de aprendizaje fueron, en la preprueba, de 8.2062, y en la postprueba de 9.1092 (figura 4).

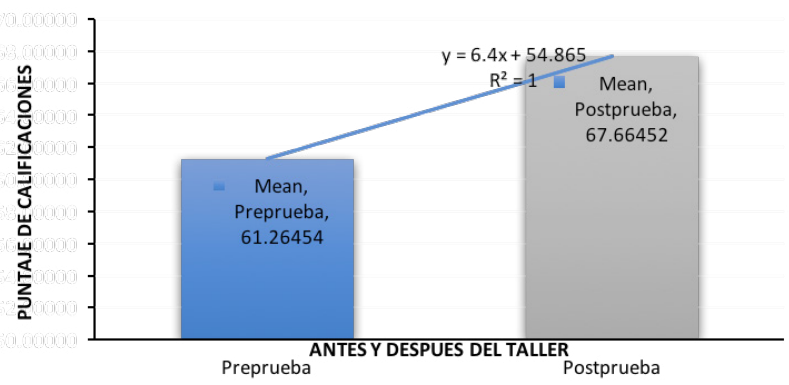

Figura 3.

Promedio de la calificación general obtenido en el EDAOM, antes y después del taller.

Para comprobar si las diferencias en los promedios de la puntuación general del EDAOM eran estadísticamente significativas, se aplicó la prueba t de Student para grupos relacionados, obteniendo un valor de $(\mathrm{t}=-4.355$, $\mathrm{gl}=36$ y $\mathrm{p}=0.001)$ y una correlación de $(\mathrm{r}=0.566$ y $\mathrm{p}$ $=0.001$ ), por lo que se acepta la hipótesis de trabajo.

De la misma manera, para comprobar si las diferencias en los promedios de calificaciones en la preprueba y la postprueba eran estadísticamente significativas, se aplicó la prueba t de Student para grupos relacionados, obteniendo un valor de $(\mathrm{t}=-5.436, \mathrm{gl}=36$ y $\mathrm{p}=0.001)$, por lo que se acepta la hipótesis de trabajo. 


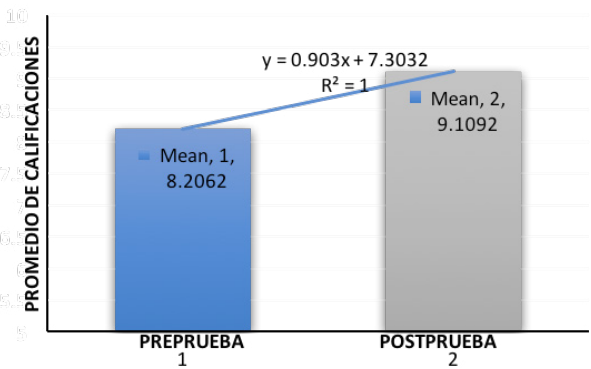

Figura 4.

Comparación del promedio de calificaciones antes y después del taller.

\section{Discusión}

De acuerdo con nuestros resultados hay una coincidencia con lo mencionado por Solano et al. (2007), ya que, al igual que ellos, se encontraron diferencias estadísticamente significativas al comparar las puntuaciones de la preprueba y la postprueba, tanto en los resultado del cuestionario EDAOM como en el promedio de las calificaciones (González \& Maytorena, 2004); también se coincide con Gargallo (2006) y Valle et al. (2008) en que hay relación positiva en el uso de estrategias conforme los alumnos tienen mejor rendimiento, ya que, como se pudo observar, el promedio de calificaciones de los participantes se modificó con tendencia ascendente después del taller, además de que varios lograron cambiar de perfil, en su mayoría mejorando sus habilidades. Sin embargo, la mejora del promedio de calificaciones puede ser debida a otras variables; se recomienda que en otros trabajos se tenga un grupo control con el cual se pueda comparar el desarrollo de esta variable.

De igual manera, se coincide con Santibáñez \& Sabando (2016) en que un diagnóstico de las estrategias de aprendizaje en el inicio de los ciclos escolares puede proporcionar valiosa información para el desarrollo de orientaciones institucionales más efectivas; en este trabajo se obtuvo información importante para el diseño del taller, ya que se pudo dar seguimiento individual a las necesidades de los alumnos, junto con la retroalimentación grupal y las recomendaciones acerca de los productos que presentaban.

Como mencionan Wang \& Wu (2008, citado en Rodríguez et al., 2010), la retroalimentación que reciben los alumnos respecto a su trabajo favorece el proceso de autorregulación del aprendizaje en términos de autoeficacia. En este trabajo observamos que al dar seguimiento y proporcionar retroalimentación los participantes mejoraban la elaboración de sus productos, una actitud de mayor compromiso y motivación, lo que ha sido com- probado también por Tuckman (2002 y 2003, citado en Rodríguez et al., 2010), en particular lo referente a la afirmación de que el aprendizaje estratégico y autorregulado mejora el desempeño (González \& Maytorena, 2004).

También se pudo corroborar lo dicho por Allgood, Risko, Álvarez y Fairbanks (2000, citado en Núñez, González, Solano \& Rosário, 2006) acerca de que muchos estudiantes que alcanzan estudios superiores no se encuentran adecuadamente preparados para lo que se requiere de ellos en la Universidad y que no son capaces de autorregular su propio proceso de aprendizaje, sobre todo en lo referente a la panificación del estudio, la elaboración de esquemas, etcétera (Amador et al., 2015).

Contrario a lo que recomiendan algunas investigaciones (proyecto STAR, citado en Mattew, 2013; Poy, 2014; Hernández, 2015; González \& Maytorena, 2004) con relación a que grupos más pequeños reciben mayor calidad de retroalimentación y mayor seguimiento de sus productos; el grupo que manejamos en esta investigación constaba de un número muy significativo de integrantes, por lo que nuestros resultados podrían ser afectados por esta variable.

\section{CONCLUSIONES}

Se comprobó que una intervención mediante un taller con el diagnóstico adecuado y con seguimiento, retroalimentación grupal e individual (entre instructor y asistente) resulta efectiva en la mejora de las diferentes estrategias de aprendizaje y en el incremento del rendimiento académico; cabe mencionar que dicho taller debe estar orientado a la tarea y debe motivar a los estudiantes en su dominio de las herramientas de aprendizaje. Por lo que, de acuerdo con los resultados obtenidos, comprobamos que existen diferencias significativas en el rendimiento escolar despúes de la impartición de un taller de estrategias de aprendizaje; asimismo hubo una mejora significativa en el manejo de estas estrategias.

Se recomienda que los profesores de la carrera soliciten a los alumnos de nuevo ingreso productos de manera homologada, con el objetivo de que dichas estrategias sean practicadas y evaluadas de manera constante. También se propone un seguimiento de manera longitudinal a los participantes en el taller, con la finalidad de monitorear su desempeño a lo largo de sus estudios y compararlos con otros estudiantes que no han tomado el taller. No obstante, se propone la creación del taIler de manera virtual, para que sea más práctico en su aplicación y sean más ágiles tanto la retroalimentación como el seguimiento de los participantes.

Las variables que no se pudieron controlar son: que para algunos participantes no era la licenciatura que ha- 
bían elegido, por lo que estaban en proceso de cambio de carrera, lo que pudo haber generado falta de interés y motivación en el curso. Otra variable es el número de alumnos participantes, porque grupos más pequeños podrían haber recibido mayor calidad de retroalimentación y mayor seguimiento de sus productos. Finalmente se recomienda que en otros trabajos se manejen grupos pequeños, así como un grupo control con el cual se puedan obtener resultados más certeros.

\section{Referencias}

Álvarez, V. I. (2009). Evaluar para contribuir a la autorregulación del aprendizaje. Electronic Journal of Research in Educational Psichology, 3(7), 1007-1030.

Amador, S. A., González, R. V., Balderrama, C. J., Cerecedo, V. P., López, O. J., Rivera, P. I., \& Suárez, G. B. (2015). Rendimiento escolar en alumnos de nivel superior del IPN. Revista Digital Internacional de Psicología y Ciencia Social, 1(1), 90-101.

Camarero, S. F., Martín, d. B., \& Herrero, D. J. (2000). Estilos y estrategias de aprendizaje en estudiantes universitarios. 59(1-2), 615-622.

De la Fuente, A. J., Pichardo, M. C., Justicia, F., \& Berbén, A. (2008). Enfoques de aprendizaje, autorregulación y rendimiento en tres universidades europeas. Psicothema, 20(4), 705-711.

Espacio Europeo de Enseñanza Superior. (2010). Declaración de Bolonia. Disponible en: http://www2.uned.es/facpoli/ documentos de trabajo c politica/DECLARACIONES/ DECLARACION\%20BOLONIA.pdf

Gargallo, L. B. (2006). Estrategias de aprendizaje, rendimiento y otras variables relevantes en estudios universitarios. Revista de psicología general aplicada, 59(1-2), 109-130.

González, L. D., \& Maytorena, N. M. (2004). Desarrollo de habilidades y estrategias. En F. S. Castañeda, Educación, aprendizaje y cognición. Teoría en la Práctica. Ciudad de México: Manual Moderno, pp. 423-430.

González, L. D., Castañeda, F. S., \& Maytorena, N. M. (2000). Estilos de aprendizaje y aprovechamiento en ingresantes universitarios. Revista de Psicología de la PUCP, 18(2), 199-225.

Hernández, L. (2015). México, líder de la OCDE en salones atiborrados. Excelsior. 27 de Noviembre.

León, U. A., Risco, d. V., \& Alarcón, S. C. (2014). Estrategias de aprendizaje en educación superior en un modelo curricular por competencias. Revista de Educación Superior, 43(4), 123-144.

Lorenzo, Q. O., \& Herrera, T. L. (2009). Estrategias de aprendizaje en estudiantes universitarios. Un aporte a la construcción del Espacio Europeo de Educación Superior. Educación y educadores, 12(3), 75-98.

Mattew, C. (2013). Tamaño de la clase y resultado en los estudiantes: investigación e implicaciones políticas. Tamaño de la clase y resultado en los estudiantes: investigación e implicaciones polítcas. Ciudad de México:
Instituto Nacional de Evalación Educativa, pp. 1-17.

Moraes, C. d. (2016). Nota País. Disponible en: https://www. oecd.org/education/skills-beyond-school/EAG2016Mexico.pdf [Consultado: 14 de febrero de 2017].

Navarro, R. E. (2003). El rendimiento académico: concepto, investigación y desarrollo. Revista Electrónica Iberoamericana sobre Calidad, Eficacia y Cambio en Educación, 1(2), 1-15.

Núñez, J. C., González, P. J., Solano, P., \& Rosário, P. (2006). El aprendizaje autorregulado como medio y meta de la educación. Papeles del Psicólogo, 139-146.

Pimienta, P. J. (2012). Estrategias de enseñanza-aprendizaje. Docencia universitaria basada en competencias. Ciudad de México: Pearson.

Poy, S. L. (2014). La proporción de alumnos por maestro en México, de las más altas de la OCDE. La Jornada. 14 de septiembre.

Rodríguez, R. M., \& García-Merás, E. (2005). Las estrategias de aprendizaje y sus particularidades en lenguas extranjeras. Revista Iberoamericana de Educación, 1-10.

Rodríguez, S., Valle, A., Rosário, P., Núñez,J. C., Cerezo, R., \& Bernardo, A. B. (2010). New media for the promotion of self-regulated learning in higher education. Psicothema, 306-315.

Santibáñez, B. M., \& Sabando, G. Á. (2016). Estudio preliminar sobre estrategias de aprendizaje en estudiantes universitarios de primer semestre. Axioma (15), 86-95. Pontificia Universidad Católica del Ecuador, Sede Santo Domingo.

SEP (2016). Principales cifras del sistema educativo nacional 2016-2017. Disponible en: http://www.planeacion.sep. gob.mx/Doc/estadistica_e_indicadores/principales cifras/principales cifras 20152016 bolsillo.pdf [Consultado: 14 de febrero de 2017].

SGE (2016). Tarjeta Estadística Ejecutiva. Ciudad de México: IPN. Disponible en: http://www.ipn.mx/ofertaeducativa/ Documents/Estadistica-Basica-2016.pdf

SGE IPN (2016). Estadistica básica. Ciudad de México: IPN. Disponible en: http://www.gestionestrategica.ipn.mx/ Evaluacion/Documents/Estadistica/EBASICA 2016-1 V2.pdf [Consultado: 14 de febrero de 2017].

Solano, P., Núñez, J. C., González-Pienda, J., Valle, A., Rosário, P., \& Mourão, R. (2007). Eficacia de un programa instruccional para la mejora de procesos y estrategias de aprendizaje en la enseñanza superior. Psicothema, 19(3), 422-427.

Teresita, D. F. (2010). El aprendizaje autorregulado y su orientación por parte del docente universitario. Congreso Iberoamericano de educación, metas 2021. Buenos Aires, Argentina: Congreso Iberoamericado de Educación, pp. 1-16.

Valle, A., Cabanach, R. G., Rodríguez, S., Núñez, J. C., \& González, P. J. (2006). Metas académicas, estrategias cognitivas y estrategias de autorregulación del estudio. Psicothema, 18, 165-170.

Valle, A., Núñez, J. C., Cabanach, R. G., González, P. J., Rodríguez, S., Rosário, P., Muñoz, C. M. (2008). Perfiles de autorregulación y rendimiento académico. Psicothema, 20(4), 724-731. 


\section{Meta-Análisis del Artículo}


Revista Digital Internacional de Psicología y Ciencia Social | Vol. 3 | Núm. 2 | Juilio-Diciembre 2017| ISSN 2448-8119 e-ISSN $2448-8119$

\section{Dimensión Cuantitativa}

\section{Perfil de Evaluación entre pares}
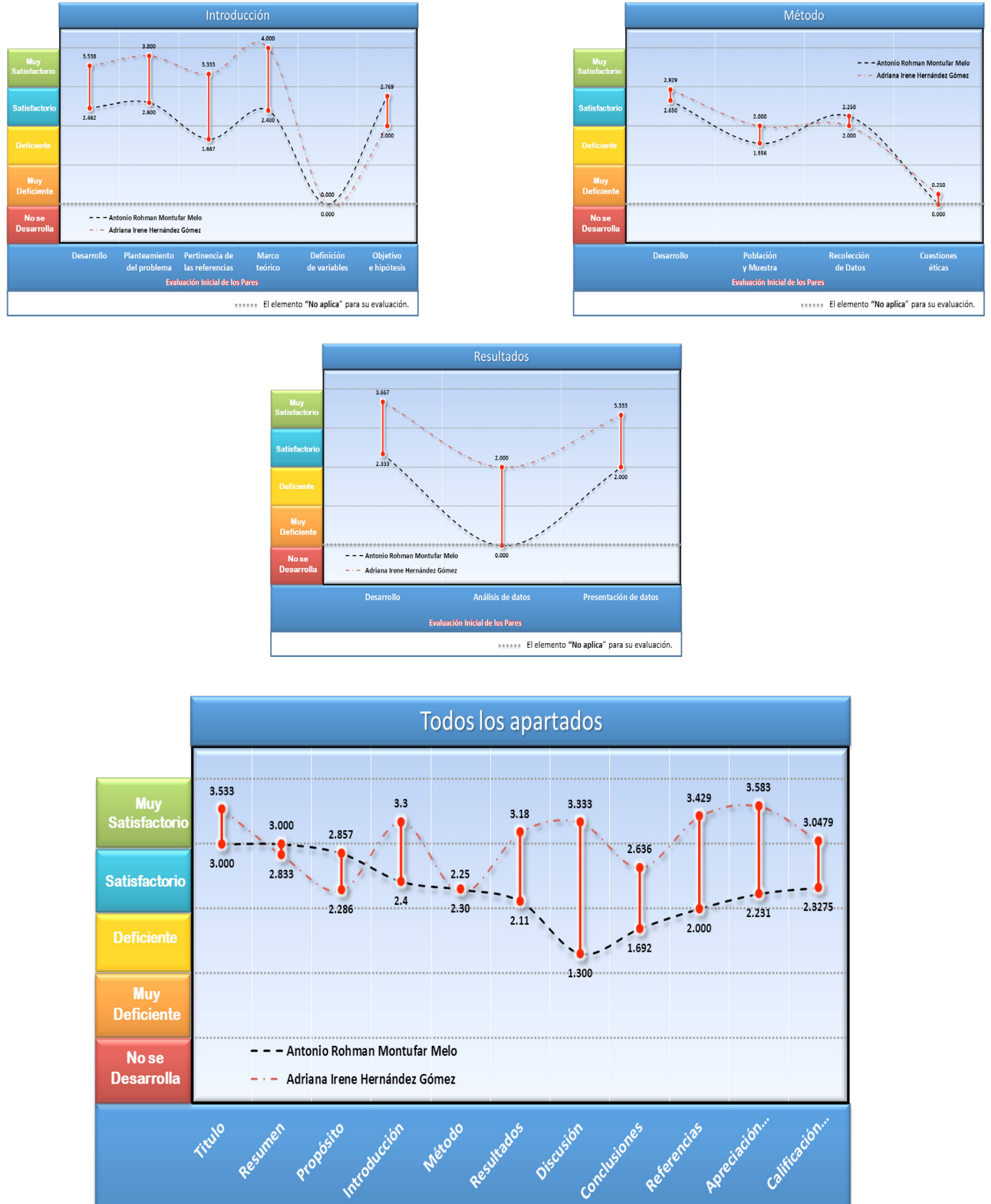


\section{Índice de Concordancia}

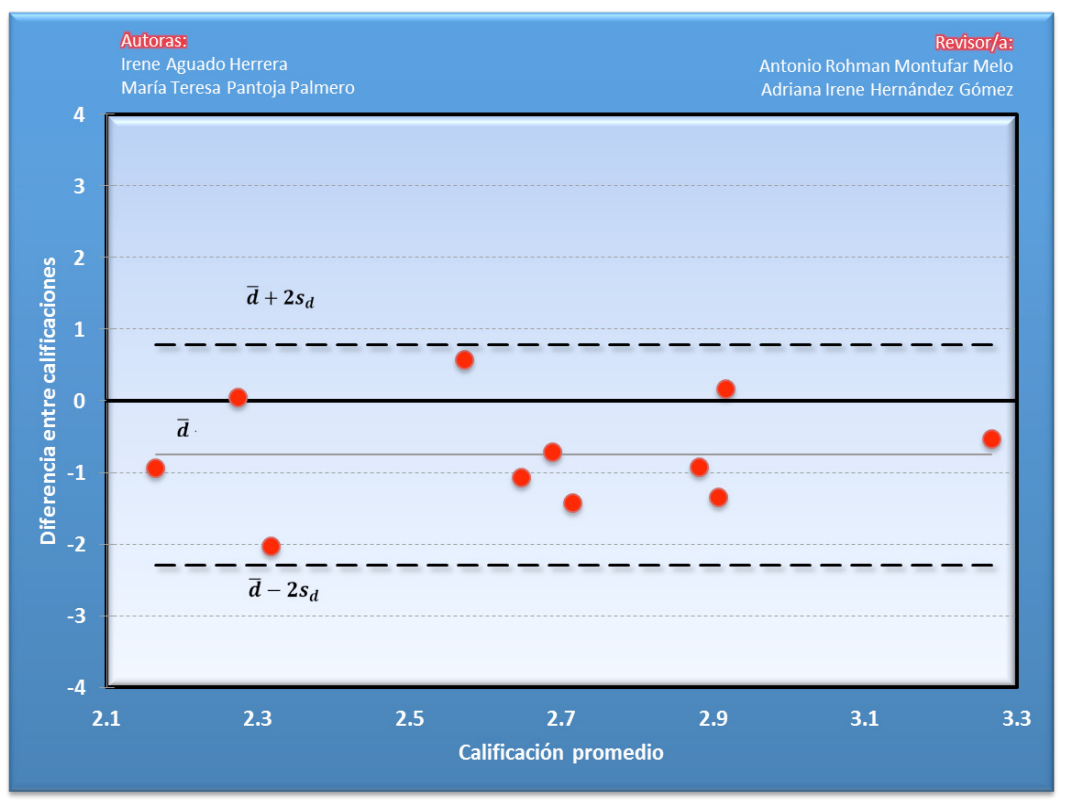

Índice de Acuerdo
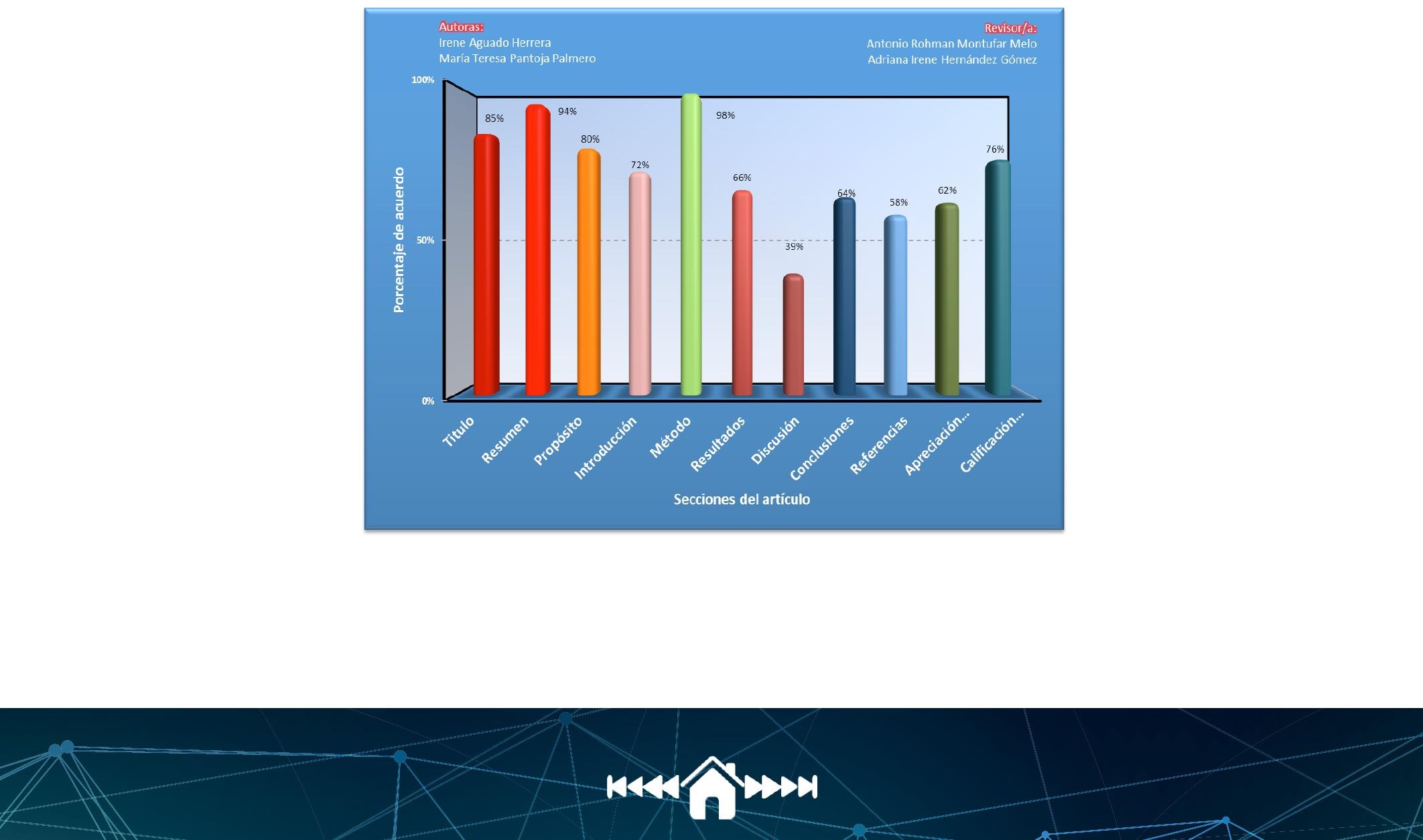


\begin{tabular}{|c|c|}
\hline Revisor 1 & Revisor 2 \\
\hline \multicolumn{2}{|c|}{ Método } \\
\hline $\begin{array}{l}\text { No se estructura de manera clara el método. Se hace men- } \\
\text { ción de un instrumento del cual se desconoce su proceden- } \\
\text { cia, constitución y objetivo de evaluación. El consentimien- } \\
\text { to informado parece ser expuesto solo de manera verbal } \\
\text { pero no se es lo suficiente claro en cómo y que sepresentó } \\
\text { a los participantes. Se dividió en grupos a la población sin } \\
\text { justificar el porqué, no se menciona como fue la interven- } \\
\text { ción de manera precisa y las condiciones para la misma. }\end{array}$ & Ninguna sugerencia. \\
\hline \multicolumn{2}{|c|}{ Resultados } \\
\hline $\begin{array}{l}\text { Se presentan resultados contradictorios a los esperados y } \\
\text { estos no son explicados. Se realizó un corrector análisis } \\
\text { estadístico sin embargo la interpretación se queda en va- } \\
\text { lores de significancia y no en sus implicaciones. }\end{array}$ & $\begin{array}{l}\text { Se sugiere revisar la presentación de las figuras de acuerdo } \\
\text { al estilo APA 3era. Edición. }\end{array}$ \\
\hline \multicolumn{2}{|c|}{ Discusión } \\
\hline $\begin{array}{l}\text { La comparación de los resultados con otros autores es } \\
\text { limitada a resaltar congruencias con investigaciones } \\
\text { pasadas, se puede ofrecer un análisis más completo de } \\
\text { los resultados. Se establecen afirmaciones que no son } \\
\text { sustentables con los resultados obtenidos. }\end{array}$ & $\begin{array}{l}\text { La sección se encuentra bien elaborada, no se tienen su- } \\
\text { gerencias. }\end{array}$ \\
\hline \multicolumn{2}{|c|}{ Conclusiones } \\
\hline $\begin{array}{l}\text { Se presenta una conclusión muy pobre en cuanto a lo } \\
\text { desarrollado en las otras sección, esto puede ser debido } \\
\text { a la inclusión de elementos de la conclusión en la dis- } \\
\text { cusión. }\end{array}$ & $\begin{array}{l}\text { Se sugiere describir las dificultades de la investigación y } \\
\text { como se pueden resolver así como proponer investigacio- } \\
\text { nes futuras. }\end{array}$ \\
\hline \multicolumn{2}{|c|}{ Referencias } \\
\hline $\begin{array}{l}\text { Es necesario homologar el estilo de las referencias, así } \\
\text { como el de las citas, para lo que se sugiere apegarse al } \\
\text { manual de estilos de publicación de la APA. }\end{array}$ & $\begin{array}{l}\text { Se sugiere revisar las referencias para identificar que cum- } \\
\text { plan los lineamientos estilo APA, así también que coinci- } \\
\text { dan citas y referencias. }\end{array}$ \\
\hline
\end{tabular}


http://dx.doi.org/10.22402/j.rdipycs.unam.3.2.2017.142.212-225

\title{
APOYO PSICOLÓGICO A LA FAMILIA: EFECTO EN LA ESTRUCTURA FAMILIAR DE PACIENTES CON HEMOFILIA
}

\author{
Maricela Osorio-Guzmán y Silvina Graña \\ FES Iztacala, UNAM \\ México
}

\begin{abstract}
RESUMEN
El diagnóstico de hemofilia impacta en la familia rompiendo la homeostasis de la misma. Los objetivos del estudio fueron: analizar la estructura familiar de una muestra de padres que tienen un hijo con hemofilia y describir la estructura familiar de las personas que asisten a terapia psicológica y que son apoyados por el programa "Padres Acompañantes". Participaron 39 madres y padres de pacientes pediátricos con hemofilia de diferente tipo y grado clínico, quienes respondieron el cuestionario FACES III. En los índices de cohesión se encontró que $89 \%$ de las familias presentan una estructura semirrelacionada; respecto a la adaptación, $86 \%$ presentó una estructura rígida. Se evidenciaron diferencias en el nivel de adaptación, dependiendo si la familia asiste o no a tratamiento psicológico. De lo anterior se deriva que la estructura familiar se modifica con la irrupción del diagnóstico de hemofilia y genera vulnerabilidad psicológica en este grupo primario; se concluye que el trabajo psicológico promueve un reequilibro saludable, fomentando una mejor calidad de vida a nivel familiar.
\end{abstract}

\section{Palabras Clave:}

hemofilia, familia, cohesión, adaptabilidad, tratamiento psicoterapéutico

\section{PSYCHOLOGICAL SUPPORT TO THE FAMILY: EFFECT ON THE FAMILY STRUCTURE OF PATIENTS WITH HEMOPHILIA}

\begin{abstract}
Hemophilia diagnosis impacts heavily on the family disrupting its homeostasis. The objective of this study is to analyze the family structure in a sample of parents whose child suffers from hemophilia, and to compare the family structure of people attending psychotherapy sessions who are supported by the 'Accompanying Parents' program. Thirty-nine mothers and fathers of pediatric patients with hemophilia of different type and severity participated in the study and answered the FACES III questionnaire. In the cohesion indexes it was found out that 89 per cent of the families present a semi-related structure; concerning their adaptability, whereas 86 per cent show a rigid one. Adaptation level differences were evinced depending on whether or not families undergo psychological treatment. The sudden diagnosis of hemophilia generates psychological vulnerability in the family group. Psychological therapy promotes a healthy restructuring that fosters better familial quality of life.
\end{abstract}

Keywords:

hemophilia, Family, Cohesion, Adaptability, Psychotherapy treatment

Bitácora del Artículo:

| Recibido: 1 de Agosto de 2017 | Aceptado: 1 Septiembre de 2017 | Publicado en línea: Julio-Diciembre de 2017 | 


\title{
APOYO PSICOLÓGICO A LA FAMILIA: EFECTO EN LA ESTRUCTURA FAMILIAR DE PACIENTES CON HEMOFILIA
}

\author{
Maricela Osorio-Guzmán y Silvina Graña Vitale \\ FES Iztacala, UNAM \\ México
}

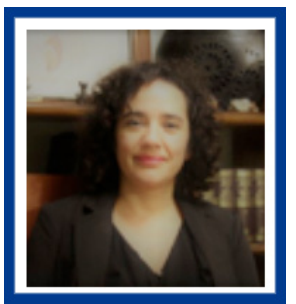

Maricela Osorio-Guzmán

FES Iztacala, UNAM

Correo: mosorio@unam.mx

Profesora titular "C" de tiempo completo de la carrera de Psicología, UNAM, FESI. Doctorado en Ciencias Psicológicas y Pedagógicas, Área: Psicología de la Salud y Prevención del Riesgo Individual y Social por la Universidad de los Estudios de Nápoles Federico II en Italia.

Ver más..

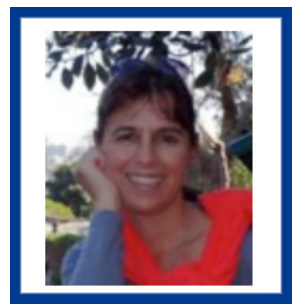

Silvina Graña Vitale FES Iztacala, UNAM Correo: silvinagrana@yahoo.com

Psicóloga clínica. Trabaja en la Fundación de la Hemofilia de la Argentina, con niños, adolescentes y familia. Coordina talleres y encuentros en todo el país. Miembro del Comité Psicosocial de la Federación Mundial de Hemofilia (FMH). Miembro del Comité Multidisciplinario de la FMH para el Congreso Mundial 2018.

Ver más...

\section{CONTRIBUCIÓN DE LAS AUTORAS}

Maricela Osorio-Guzmán concibió la idea, elaboración marco teórico, método, análisis y redacción de datos, conclusiones y referencias. I Silvina Graña estuvo a cargo de la aplicación de los instrumentos, colaboración en el MT, elaboración resumen, abstract y colaboración en la elaboración de conclusiones.

\section{AgRADECIMIENTOS}

Las autoras agradecen a la World Federation of Hemophilia la beca CIEHEMO otorgada para la realización de Capacitación Especializada en el Centro "Dr. Alfredo Pavlovsky" de la Fundación de la Hemofilia e Instituto de Investigaciones Hematológicas "Dr. Mariano R. Castex" (IIHEMA) de la Academia Nacional de Medicina, Buenos Aires, Argentina. A su vez se agradece a la Dra. Daniela Neme, Directora Médica de la Institución, por el apoyo para la realización de esta investigación con la que día a día renovamos el deseo de trabajar en forma muldisciplinaria. Al grupo de Padres Acompañantes, por su generosidad y dedicación.

\section{Datos de FiLiación de las Autoras}

Facultad de Estudios Superiores Iztacala, UNAM. | Fundación de la Hemofilia de la Argentina.

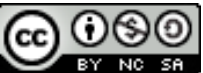

Copyright: (c) 2017 Osorio-Guzmán, M., \& Graña, S.

Este es un artículo de acceso abierto distribuido bajo los términos de la licencia Creative Commons Reconocimiento-NoComercial-Compartirlgual 4.0 Internacional, por lo que su contenido gráfico y escrito se puede compartir, copiar y redistribuir total o parcialmente sin necesidad de permiso expreso de sus autoras con la única condición de que no se puede usar con fines directamente comerciales y los términos legales de cualquier trabajo derivado deben ser los mismos que se expresan en la presente declaración. La única condición es que se cite la fuente con referencia a la Revista Digital Internacional de Psicología y Ciencia Social y a sus autoras. 


\section{TABLA DE CONTENIDO}

INTRODUCCIÓN

MÉTOdo

Participantes, 25

Materiales, 25

Procedimiento, 25

Análisis estadísticos, 25

RESULTADOS

Características demográficas de la muestra, 26

Estructura familiar, correlaciones y diferencias, 26

CONCLUSIONES 


\section{INTRODUCCIÓN}

\section{Trean} a hemofilia es una enfermedad en la sangre que se caracteriza por la deficiencia de uno de los factores de coagulación (Pruthi, 2005). Es una enfermedad congénita; se dice que la transmisión está relacionada con el sexo, ya que el gen responsable se encuentra en el cromosoma $X$; en general las mujeres son portadoras de la enfermedad y los varones son los afectados. Las personas con bajos niveles de factor VIII presentan hemofilia $\mathrm{A}(\mathrm{HA})$, y las que presentan bajos niveles de factor IX, hemofilia B (HB). Ambos tipos de hemofilia son clínicamente iguales, y pueden ser leves, moderados o severos de acuerdo con el nivel de factor circulante. El tratamiento consiste en la aplicación por vía endovenosa del factor deficitario. La incidencia de la hemofilia en la población mundial se estima en 1 de cada 10,000 varones nacidos vivos. La hemofilia se distribuye de manera uniforme en la población, y la Federación Mundial de Hemofilia (FMH) estima que a nivel mundial hay 400,000 personas con esta coagulopatía. Específicamente en la Argentina, hay casi 3,000 casos registrados (Consenso de Médicos Especialistas en Hemofilia de la República Argentina, 2015).

El momento del diagnóstico en un niño con una enfermedad crónica como la hemofilia, es vivido por la mayoría de las familias como una situación traumática, registrándose la aparición de altos niveles de estrés y sufrimiento psicológico. Esto se debe en parte al cambio de la rutina general y a la pérdida de control de la situación familiar por los padres, así como a la incertidumbre derivada de la enfermedad misma (Arranz, Costa, Bayés, Cancio, Magallón y Fernández, 2000; Goldstein, Golan, Kenet y Martinowitz, 2000; Kelley, 2006; Graña y Rodríguez, 2000; Osorio, 2016).

Esta situación produce una crisis dentro del núcleo familiar, rompiendo el equilibrio con que la familia se manejaba hasta ese momento. Esta pérdida de la homeostasis se manifiesta en múltiples niveles como en el ámbito laboral, la relación de pareja, la relación entre hermanos, en el área psicoemocional, etcétera, y diferentes trabajos internacionales dan cuenta de ello (Balcells y Ribalta, 2000; O'Mahony, 2002; Herrick, Nussbaum, Holtzman y Wissow, 2004; Hashim, 2008; Benoit de García, 2008; Goldstein, 2008; Graña, 2010).

Desde el ámbito de la psicología, es relevante realizar entrevistas con los padres para orientarlos y dar seguimiento a sus procesos de afrontamiento ante este nuevo reto. Ade- más, es importante que el espacio se amplíe a toda la familia, incluyendo a los niños con hemofilia, a los hermanos sin la patología, a los maestros y a las personas significativas para este grupo primario (Spilsbury, 2004; Graña, 2014).

En la Fundación de la Hemofilia en Buenos Aires, el consultorio de psicología implementó el programa "Padres Acompañantes", en el cual varios matrimonios, madres y/o padres con niños con hemofilia severa fueron convocados y entrenados por la psicóloga para conformar un grupo de voluntarios; dicho programa oferta un espacio de encuentro con "Padres Nuevos" (diagnóstico reciente de sus hijos) y/o en situaciones de crisis. Los integrantes, por haber ya tenido experiencia con la enfermedad, pueden compartir sus vivencias para mostrar otra manera de relacionarse y convivir con la hemofilia de los hijos y en su familia, es decir, los padres acompañantes funcionan como un otro semejante, como un modelo posible de identificación (Graña, 2010). Además, siguiendo los conceptos de Winnicott (1979), este grupo se ubica en un lugar tercero, funcionando como sostén.

Los objetivos del programa consisten en crear una red de soporte social, familiar e institucional, colaborar en el proceso de aceptación del diagnóstico y en el restablecimiento de la homeostasis familiar, considerando a la hemofilia como una situación más de la vida cotidiana (Graña, 2010).

Por su parte, el abordaje psicológico consiste en realizar entrevistas a las familias de reciente diagnóstico, abordando el impacto de la enfermedad crónica en la familia. Se recibe al grupo familiar primario y, de acuerdo con cada caso, se implementa una serie de sesiones de orientación y seguimiento (Graña, 2010, 2014). De ser necesario, se propone un espacio de psicoterapia que puede ser — como ya se mencionó- familiar, de pareja, a los hermanos sin la patología, a los niños con hemofilia, e incluso a la familia extendida o cuidadores. En este marco también se ofrece la posibilidad de participar en el programa "Padres Acompañantes", teniendo una familia/madre/padre acompañante.

Mientras que en el caso de los adultos la vía privilegiada del trabajo terapéutico es por medio de la palabra, con los niños el trabajo se realiza sobre todo mediante el dibujo y el juego. De acuerdo con Winnicott (1982), lo universal en el niño es el juego; esta actividad es una experiencia creativa, facilitadora de un crecimiento saludable y posibilita las relaciones de grupo. Es principalmente por medio del juego que el niño descubre el mundo, establece relaciones con los otros, haciendo posible la socialización. Asimismo, el juego es el vehículo por el cual los niños expresan sus emociones, ansiedades y preocupaciones. Además, el juego simbólico es la vía regia por la cual los niños elaboran conflictos y situaciones traumáticas. 
La función del psicólogo no es la de mero observador del juego del niño, sino que tiene un rol activo en el mismo, fomentando e interviniendo activamente cuando éste se ve interrumpido o inhibido, para que pueda ser retomado. Además, puede él mismo ser un objeto durante su desarrollo o un personaje en el juego que despliega el infante (Graña, 2010).

Por otra parte, en el área académica y profesional, uno de los modelo que ha tenido una gran difusión y credibilidad en los últimos años es el Modelo Circumplejo de Sistemas Familiares y Maritales (Olson, 2000; Olson, Russell y Sprenkle, 1989; Olson, Sprenkle y Russell, 1979); dicho modelo ha tenido consenso entre los investigadores respecto a la relevancia de dos dimensiones que se consideran críticas para entender y tratar familias que se encuentran bajo niveles altos de estrés, las cuales son la cohesión y la adaptabilidad. Olson, Portner y Lavee (1985) definen cohesión familiar como "el grado de unión emocional (o apego) percibido por los miembros de la familia; mientras que la adaptabilidad (o flexibilidad) está referida al grado en que la familia es capaz de cambiar su estructura de poder, sus roles y reglas en respuesta al estrés (Schmidt, 2001: 31).

Olson, Portner y Lavee (1985, apud Schmidt, 2003), consideran que la cohesión y la adaptabilidad están curvilíneamente relacionadas con la salud familiar, y que las familias que funcionan moderadamente a lo largo de las dimensiones de cohesión y adaptabilidad se conducen de manera más saludable y tienen mayor probabilidad de un afrontamiento eficaz frente a las demandas ambientales, comparadas con familias localizadas en los extremos.

También Schmidt, Barreyro y Maglio (2009) mencionan que el grado de cohesión y flexibilidad que presenta cada familia constituye un indicador del tipo de funcionamiento que predomina en el sistema: extremo, de rango medio o balanceado. Los sistemas maritales o familiares balanceados tienden a ser más funcionales y facilitadores del funcionamiento, siendo más problemáticos los extremos.

De lo expuesto se desprenden los objetivos del presente trabajo, los cuales fueron analizar la estructura familiar de una muestra de padres que tienen un hijo con hemofilia y describir la estructura familiar de las personas que asisten a terapia psicológica y que son apoyados por el programa "Padres Acompañantes".

\section{MÉtodo}

\section{Participantes}

Participaron 39 padres y madres de pacientes pediátricos con hemofilia de diferente tipo y grado clínico, los cuales cumplieron con los siguientes criterios de inclusión: ser padre o madre de por lo menos un niño con hemofilia, saber leer y escribir, y aceptar participar en la investigación. A todos los participantes se les explicó en qué consistía su participación y todos firmaron el consentimiento informado. El proyecto general del cual se desprende esta investigación fue revisado y aprobado por el Comité de Bioética de la Carrera de Psicología de la Facultad de Estudios Superiores Iztacala.

Criterios de exclusión: padres que no supieran leer y escribir o que se rehusaron a participar en la investigación.

El tipo de muestreo utilizado fue intencional o de conveniencia: se caracteriza porque el investigador selecciona directa e intencionadamente los individuos de la población, ya que tienen las características que él desea estudiar; además, las muestras son seleccionadas porque son accesibles para el investigador (Shaughnessy, Zechmeister y Zechmeister, 2007).

\section{Materiales}

Se aplicó un cuestionario diseñado ad hoc para obtener datos demográficos y del padecimiento (éste incluía preguntas como escolaridad, tipo de hemofilia, grado clínico, número eventos hemorrágicos, tipo de tratamiento, número de hospitalizaciones y antecedentes familiares, entre otras); y el FACES III (FamilyAdaptability and CohesionEvaluationScales) en español (Ponce, Gómez, Irigoyen, Terán, Landgrave, Hernández et al., 1999; Ponce et al., 2002), el cual contiene 20 ítems (10 para evaluar cohesión familiar y 10 para adaptabilidad familiar), cuya escala de respuesta es tipo Likert. Los ítems están distribuidos en forma alterna, los reactivos nones evalúan cohesión familiar y los pares adaptabilidad. Los valores van de 1 a 5 (nunca, 1 ; casi nunca, 2; algunas veces, 3; casi siempre, 4, y siempre, 5). El cuestionario tiene una confiabilidad de $\square=0.69$.

\section{Procedimiento}

Se elaboró un cuestionario para obtener datos demográficos e información acerca del padecimiento; se seleccionó el instrumento FACES III; los instrumentos se aplicaron en el consultorio de psicología de la Fundación de la Hemofilia en Buenos Aires, en las fechas y horarios en que pacientes y familiares asistieron al servicio de hematología para los controles semanales/mensuales, o a consulta psicológica. El tiempo aproximado en cada aplicación fue de 15 minutos.

\section{Análisis estadísticos}

Se realizó un análisis descriptivo de las variables sociodemográficas de la muestra; se calcularon y describieron los puntajes de cada una de las escalas que componen el instrumento; se compararon las medias obtenidas en cada área, 
por medio de la t de Student, considerando las variables tipo de hemofilia, severidad, tratamiento psicológico, acompañamiento de padres, etcétera, y se obtuvieron las correlaciones por medio de la prueba $r$ de Pearson entre las diferentes variables y las áreas del cuestionario. Para apoyar el análisis de datos se utilizó el programa estadístico SPSS 22.

\section{Resultados}

\section{Características demográficas de la muestra}

Participaron 39 padres y madres de pacientes pediátricos con hemofilia (33\% hombres y $67 \%$ mujeres), cuya media de edad fue de 38.84 (desviación típica [DT] = 9.76) y las edades fluctuaron de 17 a 64 años. De esta muestra, 14\% pertenece al grupo de padres acompañantes, y $60 \%$ asiste regularmente a atención psicológica. Respecto a su escolaridad, 28\% tiene educación terciaria y $25 \%$ es universitario.

La edad promedio de los pacientes fue de 7.02 años (DT $=4.17$ ); el tipo de hemofilia que padecían los niños era $91 \%$ hemofilia A y el restante $9 \%$ hemofilia B. Respecto al grado clínico, $7 \%$ fue leve, $4 \%$ moderado y $89 \%$ severo. La media de edad del diagnóstico fue de 8 meses (DT $=6.3$ ) y los datos variaron de 0 a 24 meses. Todos los pacientes son tratados con factor, $91 \%$ está en profilaxis y el restante $9 \%$ en tratamiento a demanda. El $67 \%$ no ha tenido ninguna hospitalización, la media es igual a 1.26 hospitalizaciones al semestre (DT $=2.15)$ y $28 \%$ ha tenido uno o dos eventos hemorrágicos en un año (sangrado de tobillo, codo o rodilla). El 36\% tiene un hermano, 18\% dos hermanos, y el rango es de 1 a 4 hermanos. El 51\% de los pacientes con hemofilia $(\mathrm{PCH})$ tienen antecedentes familiares, siendo abuelos y primos los más comunes.

\section{Estructura familiar, correlaciones y diferencias}

Respecto a los promedios de los índices obtenidos en la prueba Faces III aplicada, es interesante observar la variabilidad de los datos mínimos y máximos en las escalas de cohesión - la cual, como ya se dijo, es el grado de unión emocional (o apego) percibido por los miembros de la familia - y adaptabilidad - la que hace referencia al grado en que la familia es capaz de cambiar su estructura de poder, sus roles y reglas en respuesta al estrés- $(\mathrm{DE}=5.7$ y 5.2, respectivamente) (tabla 1$)$.

Tabla 1.

Índices de dispersión de las áreas del Faces III.

\begin{tabular}{cccccc} 
Área & Media & $\begin{array}{c}\text { Desviación } \\
\text { típica }\end{array}$ & Moda & $\begin{array}{c}\text { Puntaje } \\
\text { Mínimo }\end{array}$ & $\begin{array}{c}\text { Puntaje } \\
\text { MÁximo }\end{array}$ \\
\hline Cohesión & 40.35 & 5.71 & 43 & 14 & 49
\end{tabular}

\begin{tabular}{lccccc}
\multicolumn{1}{c}{ Área } & Media & $\begin{array}{c}\text { Desviación } \\
\text { típıcA }\end{array}$ & Moda & $\begin{array}{c}\text { Puntaje } \\
\text { Mínimo }\end{array}$ & $\begin{array}{c}\text { Puntaje } \\
\text { MÁxımo }\end{array}$ \\
\hline Adaptabilidad & 26.93 & 5.28 & 27 & 17 & 42 \\
Tipo familia & 33.64 & 4.16 & 32 & 18 & 44
\end{tabular}

En cuanto a los tipos de estructura familiar, respecto a la cohesión $11 \%$ resultó no relacionada, mientras que $89 \%$ fue semirrelacionada; acerca de la adaptabilidad, $86 \%$ se clasificó como rígida y sólo 14\% fue estructurada (tabla 2).

Tabla 2.

Porcentaje de los diferentes tipos de estructura familiar encontrados en la muestra.

\begin{tabular}{cccccc} 
TIPO DE COHESIÓN & \multicolumn{2}{c}{ TIPO DE } & TiPO DE FAMILIA \\
\hline $\begin{array}{c}\text { No } \\
\text { relacionada }\end{array}$ & $\begin{array}{c}\text { Semi- } \\
\text { relacionada }\end{array}$ & Rígida & Estructurada & Extrema & $\begin{array}{c}\text { Rango } \\
\text { medio }\end{array}$ \\
$11 \%$ & $89 \%$ & $86 \%$ & $14 \%$ & $58 \%$ & $42 \%$
\end{tabular}

En el análisis de las correlaciones se identificó una asociación leve negativa significativa entre el nivel de cohesión y la escolaridad del paciente $(r=-0.27$; $p<0.05)$, lo que indica que el grado de unión emocional (o apego) percibido por los miembros de la familia es mayor cuando los pacientes tienen menos escolaridad; se encontró también una asociación moderada entre el nivel de adaptabilidad y las complicaciones $(r=-0.4 ; p<0.01)$, lo que indica que habrá menos posibilidades de adaptación familiar si se presenta un mayor número de complicaciones (hemorragias, artropatías, etcétera).

Tabla 3.

Correlación entre las principales variables sociodemográficas y las diferentes áreas del FACES III.

\begin{tabular}{|c|c|c|c|c|c|c|c|c|c|c|c|}
\hline & 1 & 2 & 3 & 4 & 5 & 6 & 7 & 8 & 9 & 10 & 11 \\
\hline $\begin{array}{l}\text { 1. Edad del } \\
\text { paciente }\end{array}$ & 1 & & & & & & & & & & \\
\hline 2. Severidad & 0.23 & 1 & & & & & & & & & \\
\hline $\begin{array}{l}\text { 3. Tipo de } \\
\text { tratamiento }\end{array}$ & 0.13 & $-0.37^{* *}$ & 1 & & & & & & & & \\
\hline $\begin{array}{l}4 . \\
\text { Hospitalizaciones }\end{array}$ & -0.14 & -0.25 & -0.017 & 1 & & & & & & & \\
\hline 5. Complicaciones & -0.07 & 0.04 & -0.04 & $0.48^{* *}$ & 1 & & & & & & \\
\hline $\begin{array}{l}\text { 6. Escolaridad del } \\
\text { paciente }\end{array}$ & $0.66^{* *}$ & 0.17 & 0.04 & 0.02 & 0.16 & 1 & & & & & \\
\hline 7. Edad del padre & $0.48^{*+}$ & 0.14 & 0.07 & -0.02 & -0.03 & $0.52^{* *}$ & 1 & & & & \\
\hline $\begin{array}{l}\text { 8. Escolaridad del } \\
\text { padre }\end{array}$ & 0.09 & $-0.34^{* *}$ & $0.35^{* *}$ & 0.09 & 0.05 & 0.14 & -0.07 & 1 & & & \\
\hline $\begin{array}{l}\text { 9. Nivel de } \\
\text { cohesión }\end{array}$ & -0.14 & -0.11 & 0.10 & -0.07 & -0.09 & $-0.27^{*}$ & -0.14 & -0.12 & 1 & & \\
\hline $\begin{array}{l}\text { 10. Nivel de } \\
\text { adaptabilidad }\end{array}$ & -0.09 & 0.13 & 0.02 & -0.07 & $0.4^{* *}$ & -0.01 & -0.08 & -0.20 & 0.14 & 1 & \\
\hline $\begin{array}{l}\text { 11. Tipos de } \\
\text { familia }\end{array}$ & 0.11 & 0.02 & 0.17 & 0.23 & 0.19 & 0.07 & 0.05 & -0.12 & $0.29^{*}$ & $0.5^{* *}$ & 1 \\
\hline \multicolumn{12}{|c|}{${ }^{*} \mathrm{p}<0.05 ;{ }^{* *} \mathrm{p}<0.01$. } \\
\hline
\end{tabular}


Por último se pueden observar dos correlaciones positivas entre los niveles de cohesión $(r=0.29 ; p<0.05)$ y los niveles de adaptabilidad $(r=0.5 ; p<0.01)$ con los tipos de familias, lo que indica la influencia de cada uno de estos constructos en la estructuración y funcionamiento familiar (tabla 3).

Para analizar si existían diferencias en la estructura familiar de acuerdo con algunas variables se aplicó la t de Student, obteniendo dos datos interesantes de comentar: el primero se refiere a que se encontraron diferencias significativas en los niveles de cohesión y de adaptabilidad entre la hemofilia A (HA) y la hemofilia B (HB) (tabla 4).

Tabla 4.

Diferencias entre la $H A$ y la $H B$.

\begin{tabular}{lccc}
\multicolumn{1}{c}{ Categoría } & T & $\begin{array}{c}\text { Grados de } \\
\text { LiBERTAD }\end{array}$ & $\begin{array}{c}\text { Nivel DE } \\
\text { SignificANCIA }\end{array}$ \\
\hline $\begin{array}{l}\text { Nivel de cohesión } \\
\text { Nivel de }\end{array}$ & -2.57 & 37 & 0.03 \\
$\begin{array}{l}\text { adaptación } \\
\text { Tipo de familia }\end{array}$ & -3.04 & 37 & 0.004 \\
\end{tabular}

El segundo dato - y el más relevante para este estudiofueron diferencias en el nivel de adaptación, dependiendo si la familia asiste o no a tratamiento psicológico (tabla 5).

\section{Tabla 5.}

Diferencias entre asistir o no a tratamiento psicológico.

\begin{tabular}{lccc}
\multicolumn{1}{c}{ Categoría } & T & $\begin{array}{c}\text { Grados de } \\
\text { Libertad }\end{array}$ & $\begin{array}{c}\text { Nivel DE } \\
\text { SIGNIFICANCIA }\end{array}$ \\
\hline $\begin{array}{l}\text { Nivel de cohesión } \\
\text { Nivel de }\end{array}$ & 1.24 & 37 & 0.21 \\
$\begin{array}{l}\text { adaptación } \\
\text { Tipo de familia }\end{array}$ & 1.21 & 37 & 0.03 \\
& 0.17 & 37 & 0.86
\end{tabular}

Finalmente, al comparar las diversas variables con la condición padres acompañantes no existieron diferencias significativas en ningún índice.

\section{CONCLUSIONES}

Efectuar estudios para analizar la estructura familiar de personas que viven un proceso de salud/enfermedad brinda elementos para observar los cambios que se producen al interior de estos grupos primarios y obtener herramientas para programar actividades de apoyo que les permitan superar y/o adaptarse mejor a dicha condición (Osorio y Graña, 2016).

En el presente estudio fue posible observar cómo familias que tienen un miembro diagnosticado con hemofi- lia y presentan variables sociodemográficas más o menos homogéneas (tratamiento adecuado, acceso a la Fundación y todos sus servicios médicos, atención psicológica etcétera), tienen estructuras familiares distintas, lo cual se refleja en la amplitud de sus respuestas en el cuestionario aplicado. Lo anterior fue reportado también por Kelley (2006) en un estudio que realizó con familias de varios países de Latinoamérica, donde encontró diferencias no sólo de un estado a otro, sino incluso a nivel local.

Al calcular los índices y clasificar a las familias de los participantes se obtuvo que respecto a la cohesión, la mayoría es del tipo semirrelacionada (o separada), lo que implica en cierto grado que sus integrantes son capaces de ser independientes $y$, al mismo tiempo, pueden estar relacionados con sus familias (Olson, Russell y Sprenkle, 1989; Schmidt, 2001). En cuanto al constructo de adaptabilidad -la cual se refiere al grado en que la familia es capaz de cambiar su estructura de poder, sus roles y reglas en respuesta al estrés-se encontró que un porcentaje alto de las familias se clasifican como rígidas, lo que implica un estilo familiar autocrático, en donde la capacidad de cambio es limitada. Ambas características - con pequeñas variantes - fueron encontradas en un estudio precedente, con familias mexicanas de pacientes con hemofilia (Osorio y Graña, 2016).

Respecto a las asociaciones encontradas se evidenció un mayor nivel de apego percibido por los miembros de la familia cuando los pacientes tienen menos escolaridad; esto puede indicar que (debido a la edad) los más jóvenes aún no hayan iniciado su instrucción o que los pacientes (debido al padecimiento) pasen mayor tiempo en casa y esto fomente dicha cohesión; lo anterior puede no ser necesariamente adecuado para el desarrollo integral del paciente (Osorio, 2016).

Asimismo se encontró una asociación moderada entre el nivel de adaptabilidad y las complicaciones, lo que indica que habrá menos posibilidades de adaptación familiar si se presenta un mayor número de complicaciones (hemorragias, artropatías, etcétera), debido a que el grupo familiar tendrá que modificar constantemente sus actividades y rutina para acompañar al paciente al hospital o para brindarle la atención necesaria en casa, datos que coinciden con lo indicado por Arranz, Costa, Bayés, Cancio, Magallón y Fernández (2000).

También se analizó el programa "Padres Acompañantes", variable en la cual no se obtuvieron datos estadísticamente significativos; sin embargo, en la práctica u observación directa se muestra un impacto cualitativo que trae aparejada una mejora en el bienestar general de las familias acompañadas, siendo reportado por otros autores en eventos académicos y de divulgación (Graña y Rodríguez, 
2000; Graña, 2010, 2014). Esta situación impulsa a apoyar y a difundir con mayor ímpetu el programa, ya que se tiene la convicción de su utilidad clínica.

Uno de los datos más sobresalientes es haber encontrado diferencias en las estructuras familiares de pacientes con $\mathrm{HA}$ y $\mathrm{HB}$, de lo que se desprende que el tipo de organización familiar se ve afectada de manera desigual, aunque médicamente las manifestaciones clínicas son iguales en ambas hemofilias.

Otro resultado interesante es la diferencia significativa que existe en la adaptabilidad de la familia, dependiendo de si asisten o no a terapia psicológica, ya que el dato muestra la importancia de asistir a este servicio, que enseña y otorga herramientas que facilitan la adaptación a la condición de la familia para afrontar la enfermedad crónica.

No obstante a lo anterior, como punto de reflexión las autoras se plantean la necesidad de investigar si las familias que no asisten a terapia son — por sí mismasmenos adaptadas, y eso determina que no acudan a consulta psicológica; además de agregar al análisis variables como tiempo de trayecto a la Fundación y días/ horarios del servicio. Asimismo, para futuras investigaciones se pretende efectuar entrevistas que complementen la información recabada con los instrumentos.

Con base en estos resultados, se proyectarán diversos programas que difundan la importancia de asistir al servicio psicológico y facilitar a las familias que no estén asistiendo al servicio, información acerca de la relevancia de este tipo de apoyo. Se seguirá fomentando — como ya se mencionó- el programa "Padres Acompañantes" para que tenga un impacto mayor en la población de la Fundación.

\section{REFERENCIAS}

Arranz, P., Costa, M., Bayés, R., Cancio, H., Magallón, M. \& Fernández, F. (2000). El apoyo emocional en hemofilia. Madrid: Industrias Gráficas Sprint.

Balcells, M. \& Ribalta, T. (2000). Psychological examinations for the early detection of madurative dysfunctions in hemophiliac children: preliminary results. Haemophilia, 6 (suppl. 4): 413.

Benoit de García, H. (2008). Sharing a hard life: how hemophilia affects the family. A Mother's perspective. Haemophilia, 14 (suppl. 2): 129.

Consenso de Médicos Especialistas en Hemofilia de la República Argentina (2015). Guía para el manejo de la Hemofilia Congénita. Argentina: Fundación de la Hemofilia.

Goldstein, G. (2008). Siblings interaction in families with hemophilia. Haemophilia, 14 (suppl. 2): 129.

Goldstein, G., Golan, G., Kenet, G. \& Martinowitz, U. (2000). From the beginning: Group therapy with parents of babies with hemophilia. Haemophilia, 6 (suppl. 4): 417.

Graña, S. \& Rodríguez, O. M. (2000). Experience with
Accompanying Parents. Haemophilia, 6 (suppl. 4): 418.

Graña, S. (2010). Initial diagnosis: strategies to promote acceptance. Haemophilia, 16 (suppl. 4): 128.

Graña, S. (2014). Growing up with Hemophilia: Children's Perspective. Haemophilia, 20 (suppl. 3): 158.

Hashim, A. (2008). Sharing a hard life: how hemophilia affects the family. A Father's perspective, Haemophilia, 14 (suppl. 2): 129.

Herrick, E., Nussbaum, R., Holtzman, N.A. \& Wissow, L. (2004). Asking Fathers: a study of psychosocial adaptation. Haemophilia, 10 (5): 582-589.

Kelley, L. (2006). Criando un niño con hemofilia en América Latina. USA: Baxter Bioscience.

O'Mahony, B. (2002). What we must do to improve hemophilia care around the world. HemAware, 7 (2). 46-51.

Olson, D. H. (2000). Circumplex model of Marital and Family Systems, Journal of Family Therapy, 22: 144-167.

Olson, D. H., Portner, J. \& Lavee, Y. (1985). Manual de la Escala de Cohesión y Adaptabilidad Familiar (FACES III Manual). Minneapolis: Life Innovation.

Olson, D. H., Russell, C. \& Sprenkle, D. H. (1989). Circumplex Model of Marital and Family Systems II: Empirical studies and clinical intervention. Advances in Family Intervention, Assessment and Theory, 1: 129-176.

Olson, D. H., Sprenkle, D. H. \& Russell, C. S. (1979). Circumplex model of marital and family systems, I: Cohesion and adaptability dimensions, family types, and clinical applications. Family Process, 18: 3-28.

Osorio G. M. (2016). Repercusiones biopsicosociales en los padres que tienen un hijo con hemofilia. Revista de Investigación en Psicología, 19 (2): 111-121.

Osorio, G. M, y Graña, S. (2016). Descripción de la estructura familiar de pacientes con hemofilia. Comparación ArgentinaMéxico. Revista Costarricense de Psicología, 35 (1), 1-15.

Ponce, R. E., Gómez, C. F., Terán, T. M., Irigoyen, C. A. \& Landgrave, I. S. (2002). Validez de constructo del cuestionario FACES III en español (México). Aten Primaria, 30 (10): 624-630.

Ponce, R. E., Gómez, C. F., Irigoyen, C. A., Terán, T. M., Landgrave, I. S., Hernández, G. A. et al. (1999). Análisis de la confiabilidad de FACES III (versión en español). Aten Primaria, 23: 479-84.

Pruthi, R. K. (2005). Hemophilia: a practical approach to genetic testing. Mayo Clin Proc, 80, 1485-99.

Schmidt, V. (2001). Recursos para el afrontamiento de eventos vitales estresantes en familias de drogodependientes. RIDEP, 11 (1): 75-92.

Schmidt, V. (2003). Estrés en familias de drogodependientes. Tesis doctoral. Buenos Aires: Facultad de Psicología, U. B. A.

Schmidt, V. Barreyro, J. P. \& Maglio, A. L. (2009). Escala de evaluación del funcionamiento familiar FACES III: ¿Modelo de dos o tres factores? Escritos de Psicología, 3 (2): 30-36.

Shaughnessy, J. J., Zechmeister, E. B., \& Zechmeister, J. S.(2007). Métodos de investigación en psicología. México: Mc Graw Hill.

Spilsbury, M. (2004). Models for psychosocial services in the developed and developing world. Haemophilia, 10 (suppl. 4). 25-29.

Winnicott, D. (1979). Objetos y fenómenos transicionales: estudio de la primera posesión "no yo". En: Escritos de pediatría y psicoanálisis: 1931/1956. Barcelona: Laia.

Winnicott, D. (1982). Realidad y juego. Buenos Aires: Gedisa. 


\section{Meta-Análisis del Artículo}


Revista Digital Internacional de Psicología y Ciencia Social | Vol. 3 | Núm. 2 | Juilio-Diciembre 2017| ISSN 2448-8119 e-ISSN $2448-8119$

\section{Dimensión Cuantitativa}

\section{Perfil de Evaluación entre pares}
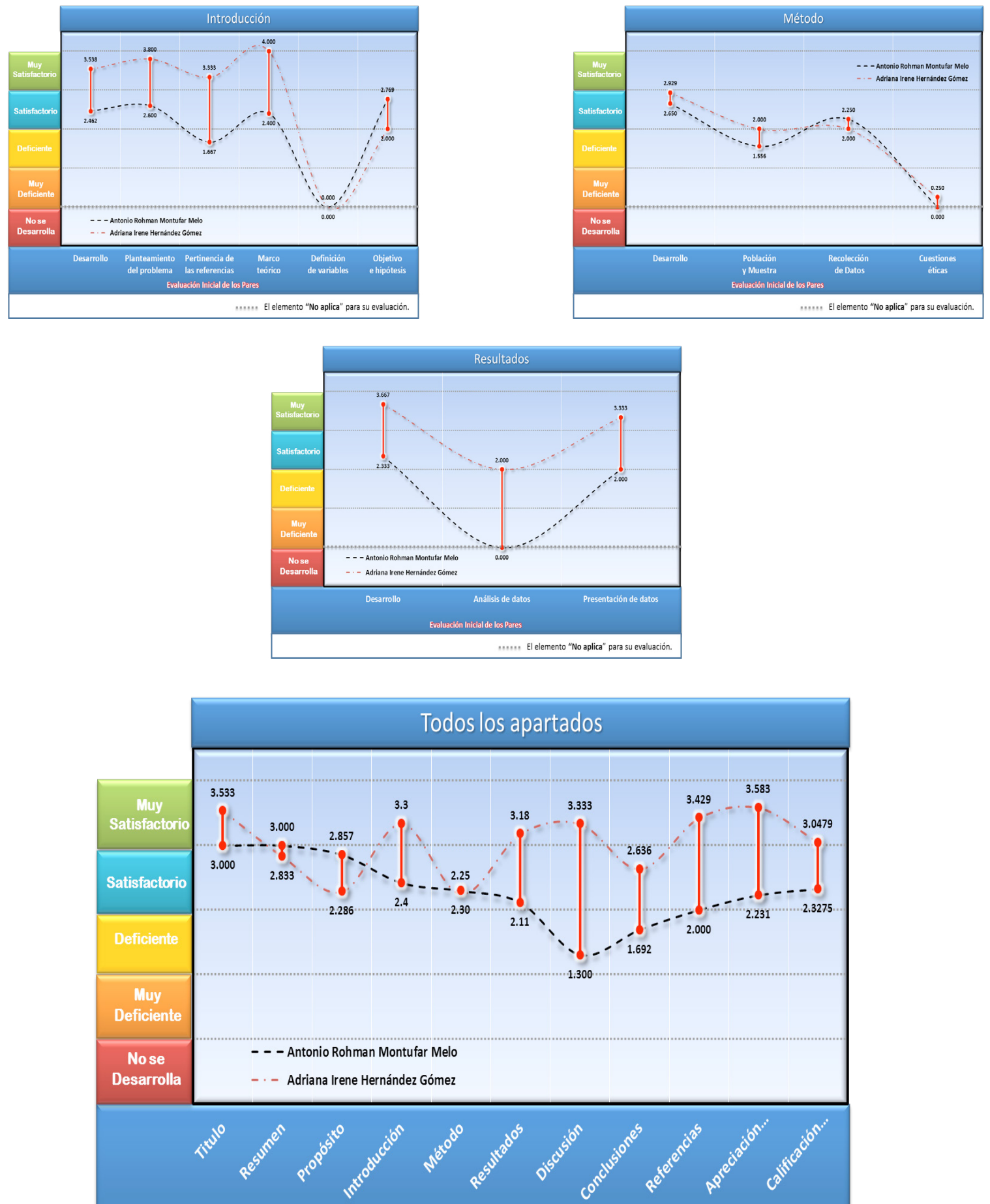


\section{Índice de Concordancia}

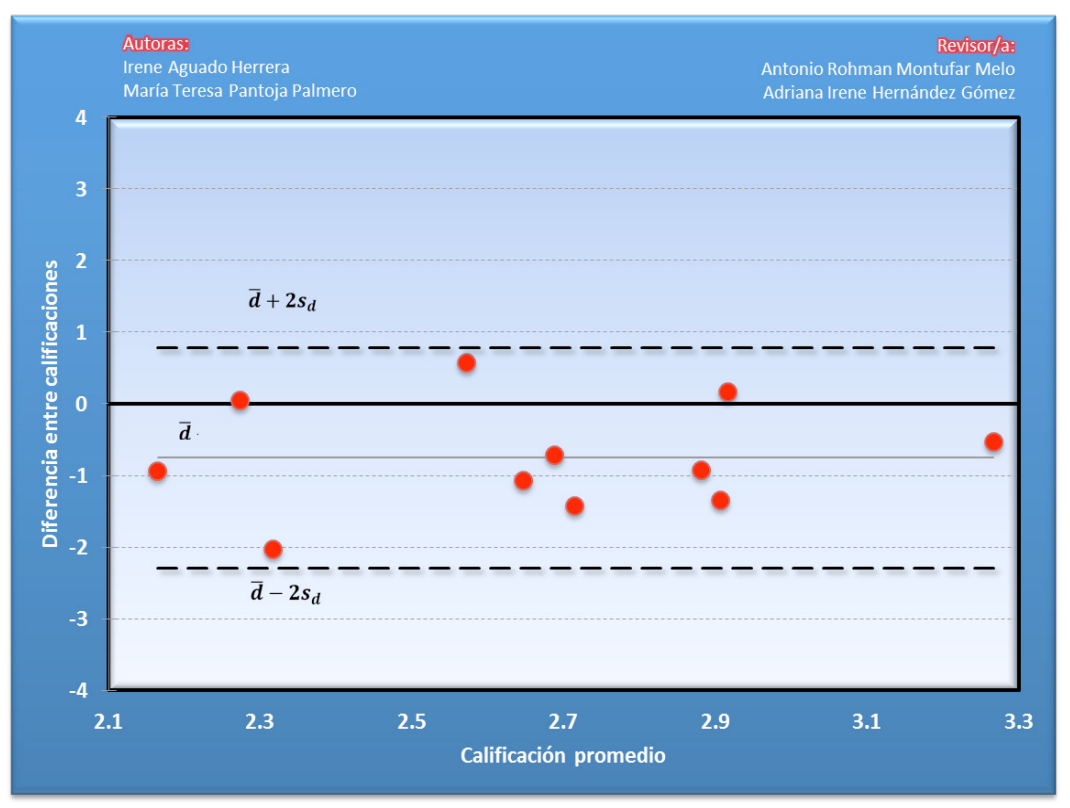

Índice de Acuerdo
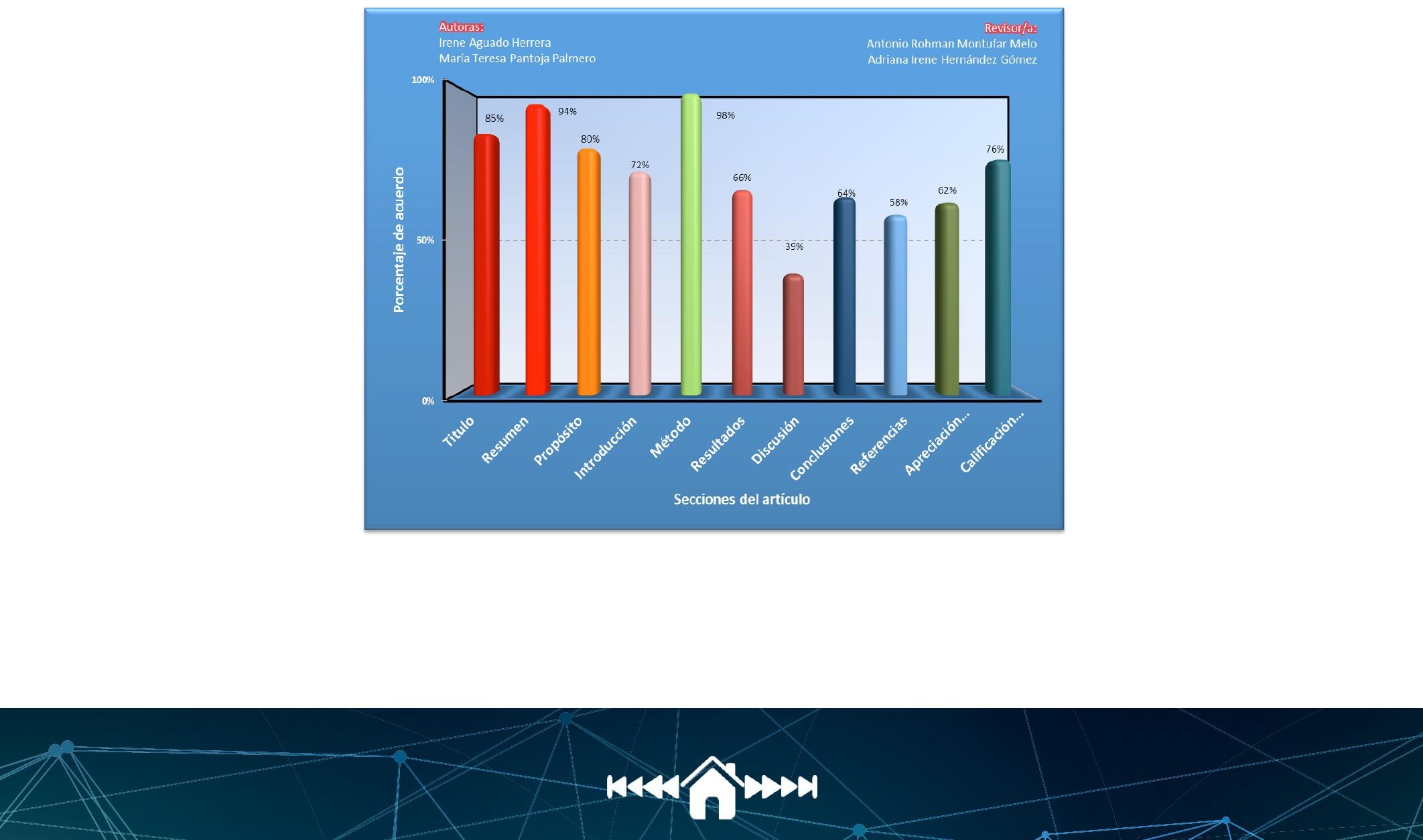


\begin{tabular}{|c|c|}
\hline Revisor 1 & Revisor 2 \\
\hline \multicolumn{2}{|c|}{ Resultados } \\
\hline $\begin{array}{l}\text { Para facilitar la lectura, conviene presentar previamen- } \\
\text { te la descripción de las categorías Cohesión y Adaptabi- } \\
\text { lidad en el apartado metodológico; lo mismo vale para } \\
\text { los tipos de estructura familiar: relacionada, semi-re- } \\
\text { lacionada y tipo de familia. Se sugiere aclarar por qué } \\
\text { los autores tomaron la decisión de usar el estadígrafo r } \\
\text { de correlación, ya que al ser una muestra tan pequeña } \\
\text { se pierde la fuerza estadística; quizá sea mejor utilizar } \\
\text { la ji-cuadrada en cada instrumento. Se fuerza la signi- } \\
\text { ficancia estadística usando un coeficiente que no sería } \\
\text { conveniente aplicar ya que la muestra es muy chica. }\end{array}$ & No hay comentarios. \\
\hline \multicolumn{2}{|c|}{ Discusión } \\
\hline $\begin{array}{l}\text { Antes de las conclusiones, sería muy apreciable que los } \\
\text { autores agregasen un apartado de DISCUSION en el } \\
\text { que comparan sus resultados con otros autores que han } \\
\text { trabajado en el mismo tema, haciendo la salvedad de la } \\
\text { limitación de por el tipo de muestreo y por el tamaño } \\
\text { de la muestra. }\end{array}$ & $\begin{array}{l}\text { Quiza analizar estudios en nuestro pais y las caracteristicas de las } \\
\text { familias mexicana, aportarian nuevas vertientes en su trabajo. }\end{array}$ \\
\hline \multicolumn{2}{|c|}{ Conclusiones } \\
\hline $\begin{array}{l}\text { Se sugiere tener cautela con la aseveración "la diferen- } \\
\text { cia significativa que existe en la adaptabilidad de la fa- } \\
\text { milia dependiendo de si asisten o no a terapia psicoló- } \\
\text { gica" teniendo en cuenta los estadígrafos utilizados. }\end{array}$ & $\begin{array}{l}\text { Me parece que seria muy interesante proponer mas inves- } \\
\text { tigaciones con familias con otras enfermedades cronicas, } \\
\text { de otros paises, comparando mas variables, etc. Les falta- } \\
\text { ria agregar un poco mas de estas ideas. }\end{array}$ \\
\hline \multicolumn{2}{|c|}{ Referencias } \\
\hline $\begin{array}{l}\text { Revisar el Manual de Estilo de la American Psychologi- } \\
\text { cal Association (APA) para referenciar adecuadamente } \\
\text { las fuentes consultadas. }\end{array}$ & $\begin{array}{l}\text { Aunque mucha informacion tiene entre } 10 \text { y } 15 \text { años de } \\
\text { antiguedad, o incluso mas, son necesarias de retomar y no } \\
\text { creo que demerite el escrito. }\end{array}$ \\
\hline
\end{tabular}




\section{Sección}

\section{Innovación y Desarrollo Tecnológico}


http://dx.doi.org/10.22402/j.rdipycs.unam.3.2.2017.140.227-241

\title{
LA EVALUACIÓN PSICOFISIOLÓGICA CON IMAGEN TÉRMICA INFRARROJA EN LOS PROCESOS PSICOLÓGICOS
}

\author{
David Alberto Rodriguez-Medina y Benjamín Domínguez-Trejo \\ Facultad de Psicología, UNAM \\ México
}

\begin{abstract}
RESUMEN
La evaluación psicofisiológica tradicional utiliza instrumentos de medición que, si bien no son invasivos (no dañan tejido celular), pueden resultar obstrusivos, es decir, interferir con alguna conducta o implante médico en un participante de estudio. Recientemente se han desarrollado tecnologías no invasivas ni obstruyentes para evaluar la actividad autonómica. Una de estas herramientas es la imagen térmica infrarroja, útil para el monitoreo clínico y registro psicofisiológico que detecta los cambios de temperatura asociados a procesos cognitivos, afectivos y/o conductuales. El presente artículo de innovación tecnológica presenta los usos, la naturaleza, el funcionamiento y la utilidad en la aplicación de distintos protocolos de evaluación psicofisiológica afectiva en diversos grupos como participantes sanos, mujeres sobrevivientes de cáncer de mama y pacientes con dolor crónico. Se promueve el uso de la imagen infrarroja térmica para la evaluación de distintos procesos psicológicos, como la conducta facial (voluntaria e involuntaria), la medición de estrés cognitivo y social. Se sugiere como un biomarcador para valorar los alcances de las intervenciones psicológicas en el campo de la salud, interacciones sociales, cognición y emoción.
\end{abstract}

Palabras Clave:

imagen infrarroja térmica, expresión facial, actividad simpática

\section{PSYCHOPHYSIOLOGICAL EVALUATION WITH INFRARED THERMAL IMAGING IN PSYCHOLOGICAL PROCESSES}

\begin{abstract}
The traditional psychophysiological assessment uses measurement instruments that, while not invasive (they do not damage cellular tissues) may be obstructive, that is, interfere with some Behavior or medical implant in a study participant. Recently non-invasive or obstructive technologies have been developed to evaluate the autonomic activity. One of these tools is infrared thermal imaging, useful for clinical monitoring and psychophysiological recording that detects temperature changes associated with cognitive, affective and/or behavioral processes. The present article of technological innovation presents the uses, nature, functioning, and utility in the application of different protocols of affective psychophysiological evaluation in groups diverse of healthy subjects, women survivors of breast cancer and patients with chronic pain. The use of the thermal infrared image is promoted for the evaluation of different psychological processes, such as facial behavior (voluntary and involuntary), measurement of cognitive and social stress. It is suggested as a biomarker to assess the scope of psychological interventions in the field of health, social interactions, cognition and emotion.
\end{abstract}

Keywords:

thermal infrared image, facial expression, sympathetic activity

Bitácora del Artículo:

| Recibido: 1 de Agosto de 2017 | Aceptado: 1 Septiembre de 2017 | Publicado en línea: Julio-Diciembre de 2017 | 


\title{
LA EVALUACIÓN PSICOFISIOLÓGICA CON IMAGEN TÉRMICA INFRARROJA EN LOS PROCESOS PSICOLÓGICOS
}

\author{
David Alberto Rodriguez-Medina y Benjamín Domínguez-Trejo \\ Facultad de Psicología, UNAM \\ México
}

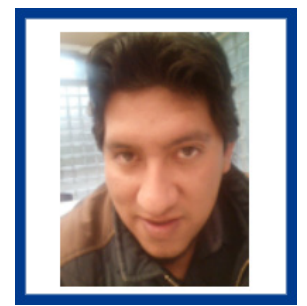

David Alberto Rodriguez-Medina Facultad de psicología, UNAM

Correo: psic.d.rodriguez@comunidad. unam.mx

Estudiante del programa de Doctorado en Psicología y Salud, Facultad de Psicología, UNAM. Diplomado en Psicofísiología Aplicada a la Psicología Clínica, INPRFM. Asesor clínico del servicio de Psicología del H. Ignacio Zaragoza, ISSSTE.

Ver más...

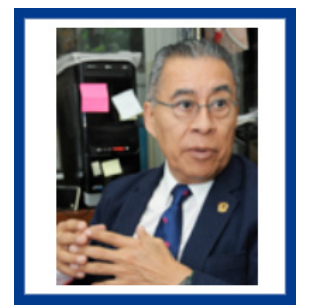

Benjamín Domínguez-Trejo Facultad de Psicología, UNAM Correo: benjamín@unam.mx

Doctor en Psicología, Profesor Investigador de Tiempo Completo, nivel C, Facultad de Psicología. Investigador nivel I del Sistema Nacional de Investigadores. PRIDE nivel D. Ha escrito decenas de artículos nacionales e internacionales de investigación clínica, así como artículos de divulgación científica.

Ver más...

\section{Contribución de los Autores}

David Alberto Rodriguez-Medina desarrolló el proyecto de investigación y la redacción de artículo. | Benjamín Domínguez-Trejo participó como tutor del proyecto de investigación.

\section{AgRADECIMIENTOS}

Los autores agredecen a la Psic. Gabriela Jael Pérez García, Dr. Luis Alberto Morales Hernández, Mtro. Irving Cruz Albarrán, Dr. Juan Primo Rangel, (UAQ); Dra. Patricia Cortés Esteban (ISSSTE - CMN 20 de Noviembre), Dra. Patricia Zamudio Silva (ISSSTE Zaragoza); Dra. Beatríz Goméz (UAM-I); y Dr. Germán Palafox Palafox (UNAM). Grupo de investigación Mente - Cuerpo de la Facultad de Psicología, UNAM: Gerardo Leija, Li Erandi, Ricardo Márquez, Omar Chavarría, Sandra Vergara, Sara Pluma, Mariana Ortíz, Carolina Carreño, Erik Mateos y Esael Pineda. | Proyecto elaborado con el financiamiento del proyecto académico: PAPIIT, Clave IN304515. Biomarcadores (autonómicos e inmunológicos) como indicadores del componente emocional en el Dolor Crónico.

\section{Datos de Filiación de los Autores}

División de Investigación y Estudios de Posgrado, Facultad de Psicología, UNAM

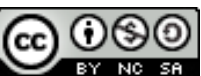

Copyright: @ 2017 Rodriguez-Medina, D. A.,, \& Domínguez-Trejo, B.

Este es un artículo de acceso abierto distribuido bajo los términos de la licencia Creative Commons Reconocimiento-NoComercial -Compartirlgual 4.0 Internacional, por lo que su contenido gráfico y escrito se puede compartir, copiar y redistribuir total o parcialmente sin necesidad de permiso expreso de sus autoras con la única condición de que no se puede usar con fines directamente comerciales y los términos legales de cualquier trabajo derivado deben ser los mismos que se expresan en la presente declaración. La única condición es que se cite la fuente con referencia a la Revista Digital Internacional de Psicología y Ciencia Social y a sus autoras. 


\section{TABLA DE CONTENIDO}

NATURALEZA DE LA INNOVACIÓN

Medición de la temperatura periférica, 232

CARACTERÍSTICAS DE LA INNOVACIÓN

Evaluación psicofisiológica térmica con diferentes cámaras, 232

Cualidades y condiciones generales de registro de infrarrojo térmico, 233

RANGO DE APLICACIÓN DE LA INNOVACIÓN

Protocolos de evaluación psicofisiológica con infrarrojo térmico, 233

Investigación psicofisiológica con imagen térmica infrarrojo térmico en México, 233

FUNCIONAMIENTO DE LA INNOVACIÓN

Evaluación categórica del termograma con imagen infrarroja térmica, 234

Evaluación intervalar del termograma con imagen infrarroja térmica, 234

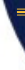




\section{INTRODUCCIÓN}

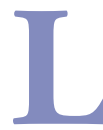

a regulación de la temperatura corporal depende de las interacciones entre el sistema nervioso central, en particular, el hipotálamo, y el sistema nervioso periférico. La actividad autonómica térmica ha sido objeto de análisis de diversos estudios de investigación psicofisiológica clínica y básica. Uno de los factores que modifican la temperatura corporal, mediante los termorreceptores de la piel (temperatura periférica), es la conducta (Rustemeyer, Radtke \& Bremerich, 2007). Asimismo, la temperatura periférica se ha utilizado para evaluar procesos afectivos y cognitivos (loannou, Gallese \& Merla, 2014).

Diversos modelos de organización autonómica en emociones han evaluado la dirección de los cambios de temperatura de acuerdo con diferentes paradigmas. En un artículo de revisión, Kreibig (2010) describe los cambios de temperatura en los dedos de las manos asociados a distintas emociones, tanto positivas como negativas. La revisión de loannou et al. (2014) menciona la dirección de los cambios de temperatura en las distintas partes del rostro en cada condición experimental afectiva. De manera general, las situaciones afectivas negativas producen decrementos de temperatura, y los eventos positivos generan un incremento de temperatura.

Estudios más recientes han evaluado los cambios de temperatura periférica en el rostro ante diversas situaciones emocionales experimentales (dolor, estrés, activación sexual, ansiedad, culpa y alegría, entre otros). Diversas investigaciones en humanos (Gómez et al., 2015) y en animales (Ioannou et al., 2014; Kano, Hirata, Deschner, Behringer \& Call, 2016; Kuraoka \& Nakamura, 2011) han reportado cambios de temperatura en distintas áreas del rostro (regiones de interés observables, RIO) en monos Rhesus de acuerdo con situaciones desagradables, particularmente en la nariz. Cuando una situación emocional se percibe negativa, la nariz tiende a enfriarse por un proceso de vasoconstricción de la actividad nerviosa autonómica simpática. De manera opuesta, cuando el sujeto experimenta serenidad se asocia con una predominancia parasimpática, la cual genera un proceso de vasodilatación y con ello un incremento de temperatura nasal (Rodríguez, Domínguez, Cortés, Cruz, Morales \& Leija, 2017).

De acuerdo con Gómez et al. (2015) y Sillero, Fernández, Arnaiz \& Bouzas (2016), los protocolos de evaluación termográfica en humanos dependen de fac- tores ambientales (como la temperatura y humedad de la habitación), factores técnicos (como las propiedades de la cámara térmica, la selección de las RIO, validez y confiabilidad de las mediciones, el protocolo de investigación y tipo de análisis estadístico) y factores individuales (como la edad, el sexo, valores antropométricos, ciclo circadiano, historia médica, tasa metabólica, emociones, terapia clínica y actividad física).

El uso de una cámara de imagen infrarroja térmica ha sido reportado en las revistas más importantes de investigación experimental como Nature; por ejemplo, en la evaluación de la actividad autonómica asociada a estrés (Tyler et al., 2015). El costo de estos equipos de registro de imagen infrarroja térmica oscila, de acuerdo con las características de la imagen térmica (en función de la cantidad de pixeles), entre los 1,200 y los 75,000 dólares estadounidenses. Para la investigación psicológica en México se oferta como una opción atractiva si se realiza interdisciplinariamente con los grupos de investigación que utilizan estos equipos tecnológicos. Uno de ellos es el de Visión Artificial de la Universidad Autónoma de Querétaro (UAQ), campus San Juan de Río, encabezado por el doctor Luis Morales Hernández y el doctorante Irving Cruz Albarrán. Este grupo de investigación maneja diferentes equipos de imagen infrarroja térmica. Los estudios psicológicos que se muestran en el presente artículo son un ejemplo de su colaboración interdisciplinaria.

El presente manuscrito propone la evaluación psicofisiológica con imagen infrarroja térmica aplicada a diversos protocolos de investigación psicológica, como la expresión facial (voluntaria e involuntaria), la respuesta afectiva del paciente con dolor crónico, y la evaluación térmica de estrés cognitivo-afectivo ${ }^{1}$. Se enfatiza el uso de esta herramienta de medición para valorar los cambios psicofisiológicos que subyacen a procesos psicológicos; sin embargo, no es objeto mostrar al lector los resultados cuantitativos de cada una las investigaciones reseñadas sobre los patrones de temperatura encontrados en las distintas poblaciones de estudio (los cuales están sometidos en revistas especializadas en termología y psicofisiología), pero sí el abanico de posibilidades para su aplicación en la investigación psicológica en México.

\footnotetext{
${ }^{1}$ Deacuerdo con cada proyecto de investigación, los autores de esteartículo del Grupo Mente-Cuerpo de la Facultad dePsicología de la UNAM trabajaron en conjuntamente con el grupo de investigación del doctor Morales, de la UAQ; el servicio de Oncología encabezado por la doctora Patricia Cortés Esteban, y la Clínica del Dolor, conel doctor Rafael HernándezSantos, ambos servicios del Centro Médico Nacional 20 de Noviembre, ISSSTE; y el servicio de Psicología, con la doctora Patricia Zamudio Silva, del Hospital Regional Ignacio Zaragoza, ISSSTE. Psicología.
} 


\section{NATURALEZA DE LA INNOVACIÓN}

\section{Medición de la temperatura periférica}

En el campo de registro psicofisiológico existen dos vertientes principales de evaluación: las medidas centrales (que corresponden a la actividad del sistema nervioso central) y las medidas periféricas (utilizadas para la evaluación del sistema nervioso periférico: somático y autonómico). La temperatura periférica se inserta en la actividad autonómica. Se ha utilizado como un indicador del estado de salud de un paciente, el tono afectivo y el balance autonómico. La termografía ha sido correlacionada con la actividad electroencefalográfica y se ha llegado a conclusiones integrales entre los procesos cognitivos y las respuestas autonómicas. Su medición ha evolucionado desde los termómetros de mercurio, cristal termolíquido, termisores electrónicos, hasta la imagen infrarroja térmica.

Los termómetros convencionales se han utilizado en una amplia variedad de problemas psicofisiológicos asociados a la actividad autonómica simpática (como el dolor, el estrés y migrañas, entre otras).

La imagen infrarroja térmica, a diferencias de los equipos de registro térmico, supone tres ventajas técnicas para el registro psicofisiológico: 1) no requiere contacto con la piel del sujeto de estudio, permitiendo evaluar procesos psicológicos cognitivos, afectivos y/o conductuales; 2) el área de evaluación es considerablemente mayor al de los termómetros convencionales que sólo miden un punto en particular; un termograma permite analizar y comparar los cambios de temperatura durante un proceso psicológico (conducta, cognición o emoción) en las RIO de interés para el investigador, así como sus interacciones entre sí; por ejemplo, la relación entre la temperatura de los dedos de las manos y la nariz (figura 1), o la relación inversa entre la temperatura del músculo corrugador y la nariz durante un proceso estrés-relajación (Rodríguez-Medina et al., 2017), y 3) como ventaja adicional de equipo de registro psicofisiológico, la termografía presenta un costo-beneficio de portabilidad y reducción de presupuestos económicos para un grupo de investigación si se comparan con equipos comerciales de biofeedback con sensibilidad y especificidad similar; para abatir el costo, sólo se requiere diseñar, programar y/o adaptar el software de la cámara termográfica para valorar la sensibilidad, de acuerdo con la cantidad de pixeles que posea la imagen térmica.

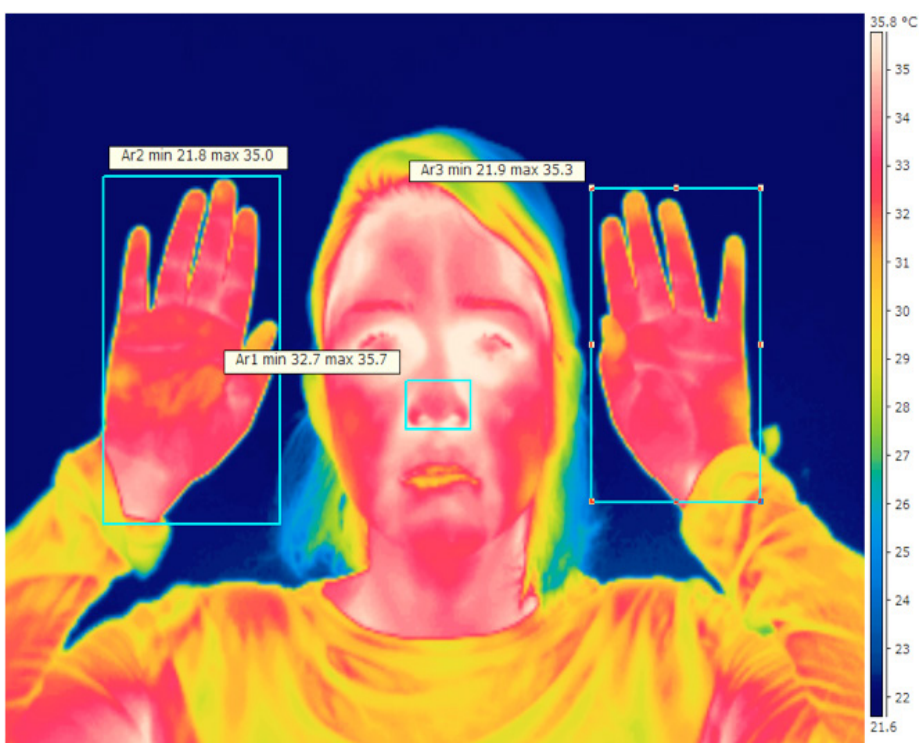

Figura 1.

Diferentes regiones de interés observables (RIO), mano izquierda, mano derecha y nariz.

\section{Características de La INNOVACIÓN}

\section{Evaluación psicofisiológica térmica diferentes cámaras}

Para evaluar la temperatura y sus efectos clínicos o de investigación sobre una RIO existen dos maneras de hacerlo: 1) de forma visual-categórica, mediante el uso de la paleta de colores que se encuentra a un costado de la imagen térmica (cada color corresponde a una temperatura, indicando los valores máximos y mínimos de temperatura de cada termograma) y 2) de manera cuantitativa, donde cada pixel en una imagen térmica representa un valor de temperatura; de acuerdo al nivel de resolución de la cámara, se puede hacer una valoración confiable de la temperatura de una RIO.

Para hacer una valoración clínica rápida, como herramienta de gabinete en cualquier consultorio de hospital, clínica o centro de salud, basta con una cámara con una resolución de $80 \times 160$ pixeles. El costo del equipo aproximado es de 1,200 euros sin el software de sensibilidad para evaluación clínica. Para estudios de investigación conviene utilizar un equipo de mayor resolución, como uno de $320 \times 240$ pixeles, cuyo valor aproximado en el mercado es de 3,600 euros, y también requiere la programación de un software con sensibilidad y especificidad (Figura 2). Sin el software específico adaptado a las variaciones de temperatura del cuerpo humano, las cámaras térmicas tienen una sensibilidad de cambio que oscila entre 0.06 y $0.15^{\circ} \mathrm{C}$. 


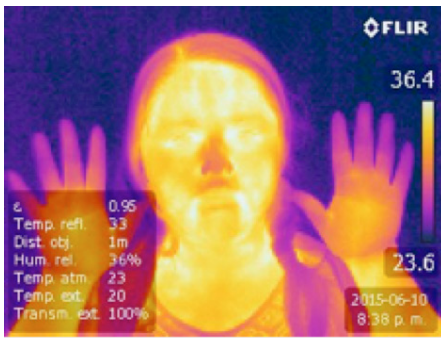

Flir E4

$80 \times 160$ pixeles

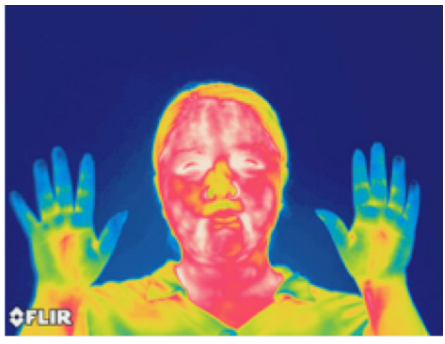

Flir A320

$320 \times 240$ pixeles
Figura 2.

Diferentes cámaras de infrarrojo térmico: Flir A320 y Flir E4.

\section{Cualidades y condiciones generales de registro de infrarrojo térmico}

Para propósitos de evaluación clínica, una resolución de $80 \times 160$ pixeles es suficiente para el monitoreo de una RIO en un paciente. Su utilidad clínica es superior a la de un termómetro electrónico cuya sensibilidad sólo se registra en la superficie de contacto, y es similar a la de equipos de registro psicofisiológico como los de biofeedback de coherencia de la variabilidad de la frecuencia cardiaca. Sin embargo, una de las características de la imagen infrarroja térmica es que no son invasivos ni obstrusivos con la piel del paciente, es decir, no es necesario adherir ningún sensor al cuerpo del sujeto. Esto permite, además, un cuidado del equipo de infrarrojo térmico menor respecto al manejo de la instrumentación de los equipos de registro psicofisiológico convencionales que utilizan cables, optimizando el tiempo de medición tanto para la evaluación con el sujeto como para el guardado de los instrumentos.

Otra cualidad del equipo de imagen infrarroja térmica es su portabilidad, debido a que la cámara se puede transportar con facilidad al lugar de evaluación. Tiene un peso aproximado de $500 \mathrm{~g}$, y se puede colocar en un tripié a una distancia de un metro del sujeto.

Para realizar un registro de infrarrojo térmico es necesario mantener la temperatura constante de $22^{\circ} \mathrm{C}^{+}-2^{\circ} \mathrm{C}$ de la sala de registro; el sujeto no debe haber ingerido estimulantes o depresores entre 6 y 2 horas previas al registro, y 3 horas sin alimentos. Además, es necesario que el sujeto permanezca en reposo cuando menos 10 minutos antes de iniciar el registro de la línea base o medición pretest, con el objetivo de asegurar que los cambios de temperatura se deban a la manipulación del experimentador. Lo que se pretende evaluar son los cambios fásicos de temperatura debidos a los procesos psicológicos que el sujeto experimenta, o las condiciones que interfieren en la actividad autonómica. Para una revisión completa de las condiciones de registro véase Fernández-Cuevas et al. (2015), Gómez et al. (2015) y Sillero et al. (2016).

\section{RANGO DE APLICACIÓN DE LA INNOVACIÓN}

\section{Protocolos de evaluación psicofisiológica con infrarrojo térmico}

Existen numerosas investigaciones del uso de la imagen térmica infrarroja como herramienta de evaluación psicofisiológica de procesos psicológicos, como la carga mental ${ }^{2}$ (Gómez et al., 2015), la supresión de estrés psicofisiológico $^{3}$ (Tyler et al., 2015), la relajación ${ }^{4}$ en un paciente con dolor crónico (Rodríguez-Medina et al., 2017), el estrés agudo ${ }^{5}$ (Herborn et al., 2015), el tono psicofisiológico afectivo $^{6}$ (Cardone \& Merla, 2014), regulación de las emociones interpersonales ${ }^{7}$ (Güney, Sattel, Cardone \& Merla, 2015), las tareas cognitivas (Pinti, Cardone \& Merla, 2015), y la evaluación emocional (en adultos) de la respuesta a infantes (Esposito et al., 2014), entre otros estudios.

\section{Investigación psicofisiológica con imagen térmica infrarrojo térmico en México}

En México los registros de termografía en el campo de la salud sólo se habían restringido a estudios en oncología o medicina interna. A partir de junio de 2015 se han realizado estudios psicofisiológicos pioneros en México con imagenología infrarroja térmica con el propósito de trasladar los estudios de laboratorio al campo de la psicología de la salud. Las líneas de investigación se han centrado en los cambios autonómicos térmicos asociados a la conducta facial (expresión facial emocional voluntaria e involuntaria) en sujetos médicamente sanos, mujeres sobrevivientes cáncer de mama y pacientes con dolor crónico; estrés cognitivo, mediante el paradigma de facilitación emocional; estrés social, con el uso del Trier Social Stress Test.

\footnotetext{
2 Se define como la cantidad de esfuerzo mental en la memoria de trabajo.

${ }^{3}$ Durante una respuesta de estrés se contraen vasos sanguíneos, inhibiendo su flujo y reduciendo la temperatura.

${ }^{4}$ La respuesta de relajación promueve un reflejo parasimpático vasodilatador.

${ }^{5}$ Referido como una respuesta de estrés durante una tarea de laboratorio (física o psicológica).

${ }^{6}$ La temperatura periférica (rostro, manos, pies) en sincronía con otros indicadores de estrés-relajación; por ejemplo, una temperatura elevada con una frecuencia cardiaca o presión arterial normal.

${ }^{7}$ Las relaciones afectivas agradables producen una sensación de "calidez", aumentando la temperatura periférica; caso opuesto si una persona se encuentra en una situación desagradable.
} 
a

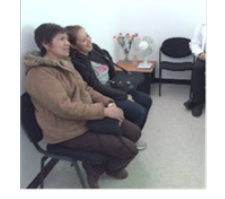

b

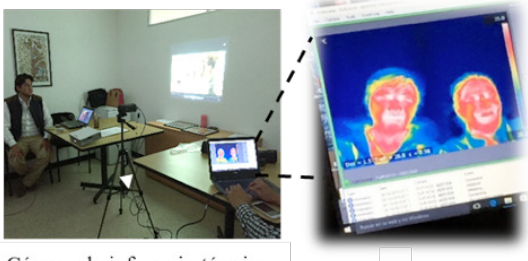

Cámara de infrarrojo térmico

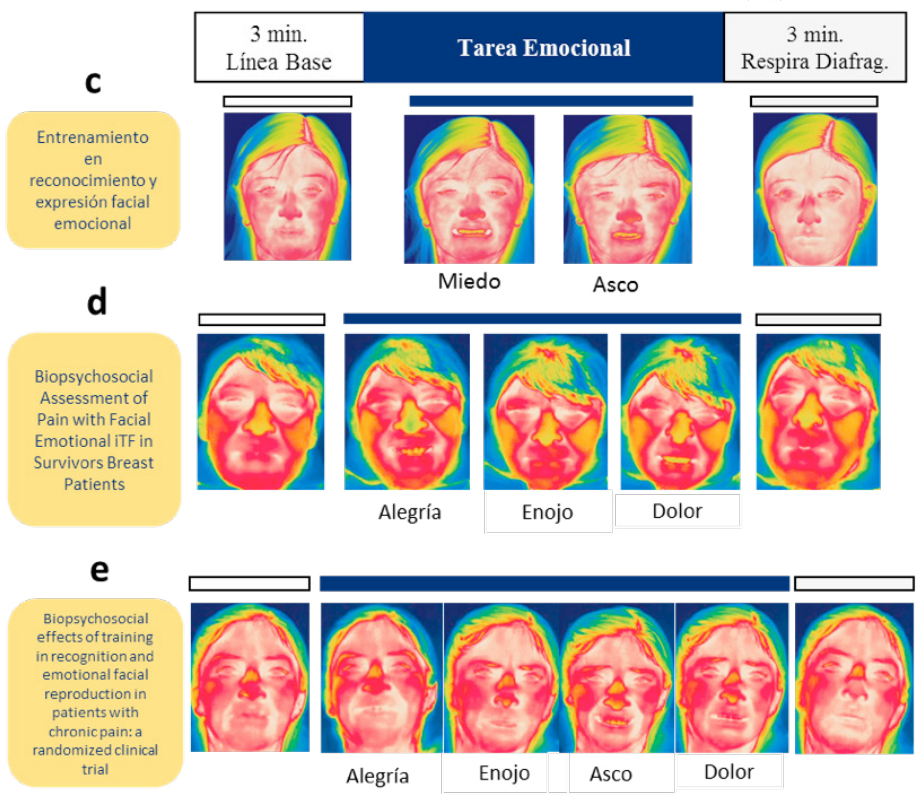

$\mathbf{f}$
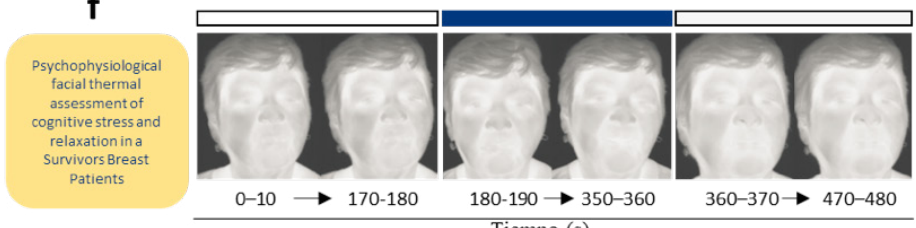

Tiempo (s)

Enfoque experimental. (a) Colocación del sujeto para el registro psicofisiologico. (b) Registro térmico de la actividad autonómica de acuerdo con los paradigmas experimentales. (c) Conducta facial emocional voluntaria en sujetos clínicamente sanos (Rodríguez et al., 2015; datos inéditos). (d) Conducta facial emocional voluntaria en pacientes sobrevivientes de cáncer de mama (Rodríguez et al. 2015; datos inéditos). (e) Conducta facial emocional espontánea (Rodríguez et al., 2016; datos inéditos). (f) Estrés cognitivo (Rodríguez et al., 2017).

\section{Figura 3.}

Protocolos de evaluación psicofisiológica térmica.

En la figura 3 se muestran los protocolos (de manera general) y algunos de los resultados de la actividad autonómica térmica de cada proyecto. Similar a loannou et al. (2014), se han identificado algunos patrones de temperatura en rostro (nariz, frente, barbilla y mejillas) y en manos de acuerdo con el estado afectivo; sin embargo, los cambios autonómicos térmicos están más pronunciados en personas cuya respuesta inflamatoria (actividad inmunológica) es menor respecto a los cambios térmicos observados en participantes con un alto nivel de actividad inflamatoria (pacientes con dolor crónico, estrés crónico).

\section{FunCIONAMIENTO DE LA INNOVACIÓN}

\section{Evaluación categórica del termograma con imagen infrarroja térmica}

De acuerdo con los objetivos del clínico o investigador, puede hacer una lectura visual de los datos de temperatura en las diferentes RIO que desee examinar mediante el uso de la paleta de colores que el termograma provee. Esta evaluación permite el monitoreo en tiempo real de la temperatura de un paciente o un sujeto en condiciones experimentales.

Para realizar un examen más detallado que la inspección, se puede optar por una evaluación categórica por medio de la conversión de cada termograma a un formato de imagen BMP 256, que indica que cada pixel de la imagen térmica se transforma en un rango de 256 colores que distingue el ojo humano. Éstos pueden agruparse en 10 intervalos (convirtiendo la imagen a una escala de grises, se pueden visualizar con claridad) y asignarse valores de acuerdo con el color que representa un nivel de temperatura (figura 4).

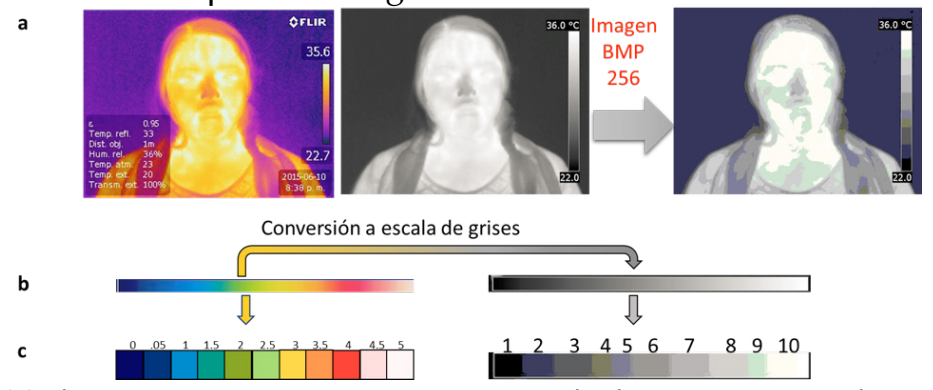

(a) El termograma se convierte en una escala de grises y se guarda en formato BMP 256. (b) La paleta de colores se cambia unidimensionalmente de negro a blanco con los diferentes matices del gris. (c) Una vez guardada la imagen en formato BMP, se agrupan los pixeles y se pueden distinguir visualmente en 10 intervalos, donde se les puede asignar un valor categórico.

Figura 4.

Evaluación categórica. Conversión de un termograma a una imagen de BMP 256.

\section{Evaluación intervalar del termograma con imagen infrarroja térmica}

Para realizar la evaluación intervalar de la imagen térmica es necesario un software adaptado para la medición de la temperatura en el cuerpo humano. En uno de los proyectos del Ingeniería en Mecatrónica (Benítez, Cruz \& Morales, 2016) de la UAQ, se desarrolló un software capaz de registrar la temperatura de un termograma en el orden de cienmilésimas de grados centígrados. Cada termograma se compone de entre 300,000-400,000 pixeles. Cada pixel representa un dato de temperatura. Para tener una idea del número de pixeles de una RIO (por ejemplo, la nariz), contiene entre 1,500 a 1,800 datos de tempera- 
tura por cada termograma. En las figuras 5 y 6 se resume el funcionamiento general del software.
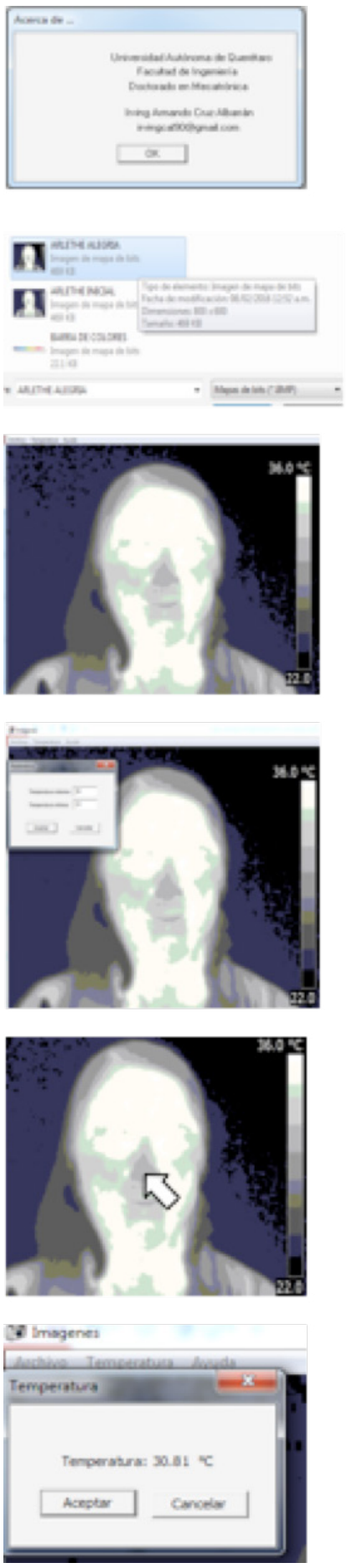

\section{5}

Ir a temperatura para obtener el valor térmico de la RIO.

El software es propiedad intelectual de los Ingenieros Benitez, Cruz \& Morales [2016) de la UAQ.

Selección de la imagen térmica en formato BMP.

\section{2}

Abrir la imagen térmica en formato BMP.

Abrir Parómetros para colocar el rango de temperatura máxima y minima.

\section{4}

Seleccionar punto oárea de la RIO.

\section{Figura 5.}

Pasos para medir la temperatura periférica en una RIO en un punto en particular.

\section{Conclusiones}

La evaluación de los cambios autonómicos asociados a distintas actividades psicológicas se ha documentado en diversas investigaciones (Kreibig, 2010). Los estudios psicológicos exploratorios México que se presentaron siguen esta misma ruta bidireccional entre las bases biológicas de la actividad autonónimica-inmunologica y su utilidad clínica en pacientes con enfermedades crónicas no transmisibles, y evaluar las interacciones entre el sistema nervioso autónomo y la actividad inflamatoria, como en el caso pacientes con dolor crónico oncológico y no oncológico.

La termografía aplicada a la evaluación psicofisiológica de procesos psicológicos (cognitivos, afectivos, conductuales, sociales) constituye una opción viable para la investigación psicológica de economías emergentes 
como la de México. Su rango de aplicación es amplio, y se sugiere su incorporación en diversos contextos como en el campo de la Psicología Clínica y de la Salud, para trastornos afectivos (Herborn et al., 2015) , psicofisiológicos (como el dolor crónico) (Güney et al., 2015; Rodríguez-Medina et al., 2017) y de regulación emocional; en materia de Psicología Social Experimental, para evaluar las interacciones socioafectivas (Esposito et al., 2014); en Psicología Educativa para valorar procesos cognitivos del aprendizaje y su carga afectiva asociada (Pinti et al., 2015); en el terreno de la Psicología Fisiológica, para la evaluación de la influencia de un fármaco o sustancia en temperatura de animales o humanos bajo condiciones experimentales (Tyler et al., 2015).

Debido a su amplia utilidad en la investigación básica, aplicada y clínica, se sugiere continuar explorando las fortalezas de esta herramienta tecnológica $y$, en su caso, documentar las limitaciones en diversos protocolos de evaluación psicológica. Desde esta perspectiva, se propone la colaboración interdisciplinaria en proyectos de investigación clínica (Ingeniería en Mecatrónica, Medicina y Biomedicina, entre otras), mediante el uso de biomarcadores que muestren un nivel de evidencia para la evaluación de procedimientos psicológicos. Dentro de sus limitaciones se encuentra el costo elevado de los equipos importados de infrarrojo térmico. Para suplir esa complicación, actualmente se desarrollan prototipos de cámara infrarroja térmica portátiles con resolución 80 × 120 pixeles y 160 × 240 pixeles gracias a la colaboración interdisciplinaria. Otra limitación importante para el estudio de los cambios autonómicos es la necesidad de que el participante no haya ingerido alimentos o cualquier tipo de estimulante (cafeína, tabaco) entre 24, 12 o 2 horas previas al estudio, de acuerdo con el objetivo del mismo. Este punto destaca en el contexto hospitalario donde la adherencia de los pacientes es fundamental para hacer el registro adecuado. No obstante, por ser una tecnología no invasiva, el paciente no se siente incómodo, haciendo amigable el monitoreo psicofisiológico para él y para el clínico.

\section{Referencias}

Benítez, J., Cruz, I., \& Morales, L. (2016). Sistema de visión artificial para detección de termobiomarcadores. México.

Cardone, D., \& Merla, A. (2014). The thermal dimension of psychophysiological and emotional responses revealed by thermal infrared imaging. 2014 IEEE International Conference On Image Processing (ICIP). http://dx.doi. org/10.1109/icip.2014.7025389

Esposito, G., Nakazawa, J., Ogawa, S., Stival, R., Putnick, D., \& Bornstein, M. (2014). Using infrared thermography to assess emotional responses to infants. Early Child Development and Care, 185(3), 438-447. http://dx.doi.or g/10.1080/03004430.2014.932153

Fernández-Cuevas, I., Bouzas Marins, J., Arnáiz Lastras, J., Gómez Carmona, P., Piñonosa Cano, S., García-Concepción, M., \& Sillero-Quintana, M. (2015). Classification of factors influencing the use of infrared thermography in humans. Infrared Physics \& Technology, 71, 28-55. http://dx.doi. org/10.1016/j.infrared.2015.02.007

Gómez, E., Salazar, E., Domínguez, E., Iborra, O., de la Fuente, J., \& de Córdoba, M. (2015). Neurotermografía y termografía psicosomática (1a. ed.). Granada: Ediciones Fundación Internacional Artecittà.

Güney, Z., Sattel, H., Cardone, D., \& Merla, A. (2015). Assessing embodied interpersonal emotion regulation in somatic symptom disorders: a case study. Frontiers In Psychology, 6(68), 1 - 14. http://dx.doi.org/10.3389/fpsyg.2015.00068

Herborn, K., Graves, J., Jerem, P., Evans, N., Nager, R., McCafferty, D., \& McKeegan, D. (2015). Skin temperature reveals the intensity of acute stress. Physiology \& Behavior, 152, 225 230. http://dx.doi.org/10.1016/j.physbeh.2015.09.032

Ioannou, S., Gallese, V., \& Merla, A. (2014). Thermal infrared imaging in psychophysiology: Potentialities and limits. Psychophysiology, 51(10), 951-963. http://dx.doi. org/10.1111/psyp.12243

Kano, F., Hirata, S., Deschner, T., Behringer, V., \& Call, J. (2016). Nasal temperature drop in response to a playback of conspecific fights in chimpanzees: A thermo-imaging study. Physiology \& behavior, 155, 83-94.

Kreibig, S. (2010). Autonomic nervous system activity in emotion. Biological Psychology, 84(3), 394-421. http:// dx.doi.org/10.1016/j.biopsycho.2010.03.010

Kuraoka, K., \& Nakamura, K. (2011). The use of nasal skin temperature measurements in studying emotion in macaque monkeys. Physiology \& behavior, 102(3), 347-355.

Pinti, P., Cardone, D., \& Merla, A. (2015). Simultaneous fNIRS and thermal infrared imaging during cognitive task reveal autonomic correlates of prefrontal cortex activity. Scientific Reports, 5(1). http://dx.doi.org/10.1038/ srep17471

Rodríguez-Medina, D., Cruz, I., Domínguez, B., Morales, L., Leija, G., \& Cortés, P. (2017). Psychophysiological facial thermal assessment of the relaxation in a patient with osteoarthrosis. Pan American Journal Of Medical Thermology, 3(1), 33-36. http://dx.doi.org/10.18073/23584696/PAJMT.V3N1P33-36

Rustemeyer, J., Radtke, J., \& Bremerich, A. (2007). Thermography and thermoregulation of the face. Head \& Face Medicine, 3(1). http://dx.doi.org/10.1186/1746-160x-3-17

Sillero, M., Fernández, I., Arnaiz, J., \& Bouzas, J. (2016). Protocol for thermographic assessment in humans. Pre-Congress XIII EAT Congress Course on "Medical applications of human thermography (pp. 1-57). Madrid. http://dx.doi. org/10.13140/RG.2.1.1749.2969

Tyler, W., Boasso, A., Mortimore, H., Silva, R., Charlesworth, J., \& Marlin, M. et al. (2015). Transdermal neuromodulation of noradrenergic activity suppresses psychophysiological and biochemical stress responses in humans. Scientific Reports, 5(1).http://dx.doi.org/10.1038/srep13865 


\section{Meta-Análisis del Artículo}




\section{Índice de Concordancia}

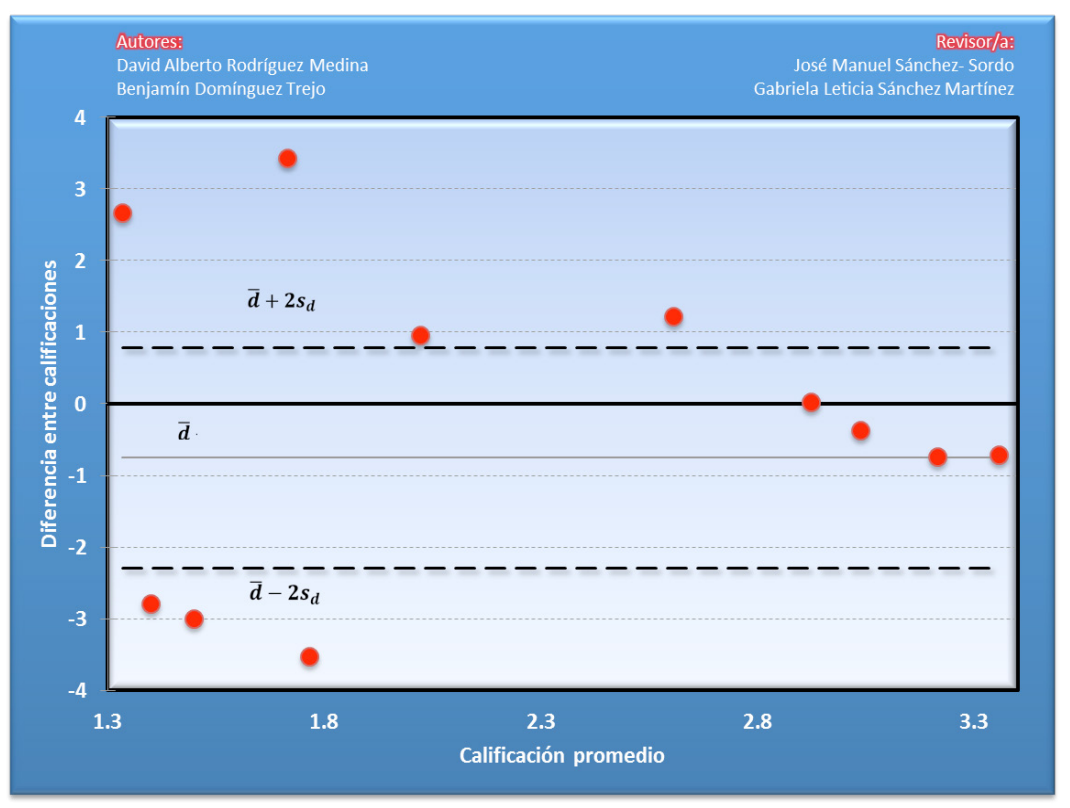

Índice de Acuerdo
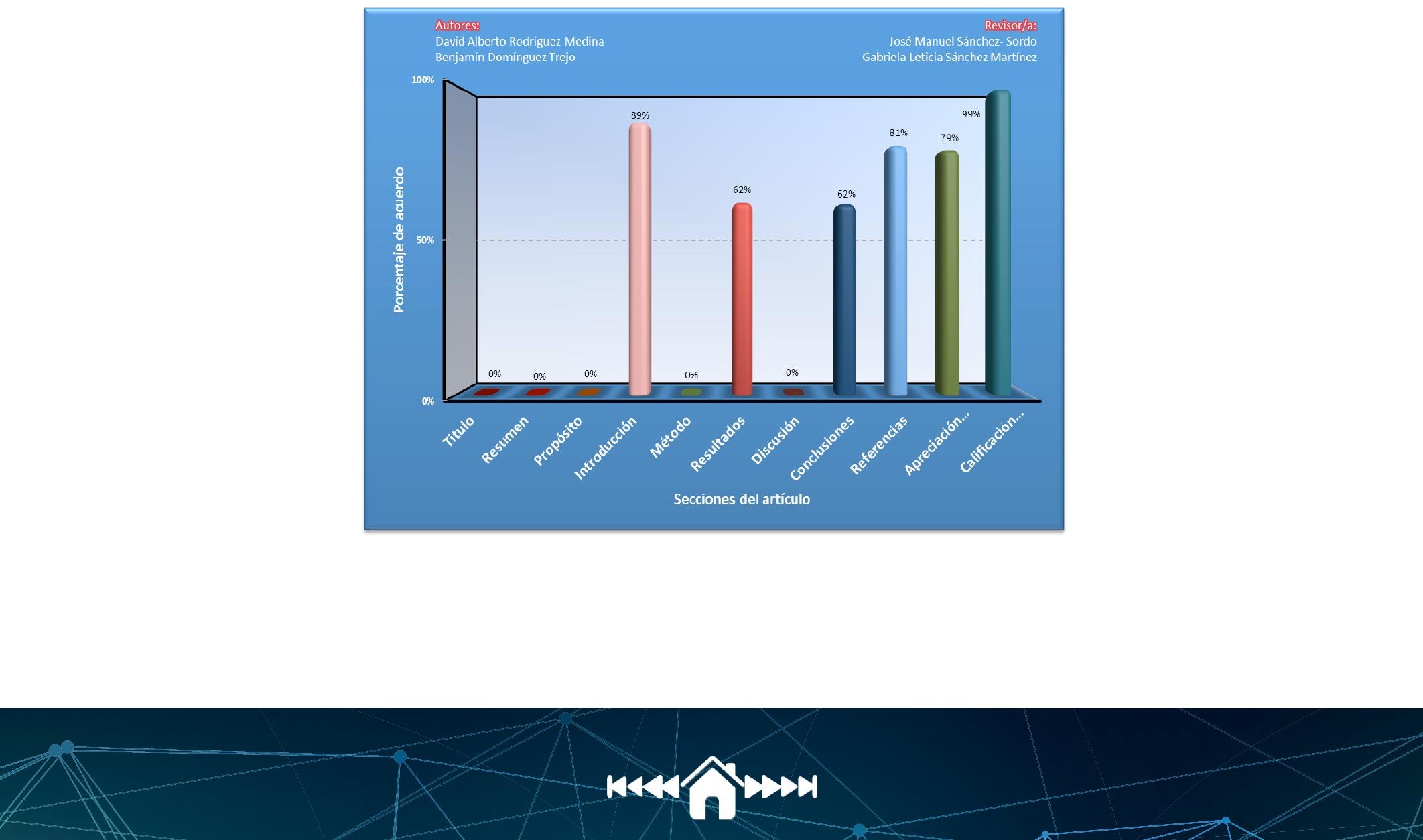


\begin{tabular}{|c|c|}
\hline Revisor 1 & Revisor 2 \\
\hline José Manuel Sánchez-Sordo & Gabriela Leticia Sánchez Martínez \\
\hline \multicolumn{2}{|c|}{ Título/Autoría } \\
\hline & $\begin{array}{l}\text { El título es general, abarca el tema central del trabajo; } \\
\text { pero habría que revisar las palabras clave. En el título } \\
\text { no se menciona al expresión facial ni la actividad sim- } \\
\text { pática. Del mismo modo, faltaría especificar un poco } \\
\text { más sobre la temática del trabajo. Revisar datos de los } \\
\text { autores, p.ej. el correo electrónico del segundo autor. }\end{array}$ \\
\hline \multicolumn{2}{|c|}{ Resumen } \\
\hline & $\begin{array}{l}\text { No hay división en párrafos dentro del resumen. Den- } \\
\text { tro del resumen se habla sobre personas sanas, con cán- } \\
\text { cer de mama y dolor crónico, pero no se hace referencia } \\
\text { a ello de en el título del trabajo; tampoco se mencionan } \\
\text { estrés cognitivo y social. El tlítulo es más general y pa- } \\
\text { rece que aquí se acota la temática, aunque tampoco se } \\
\text { ve reflajado dentro de las palabras clave; sin embargo, } \\
\text { al estar dentro del resumen da la impresión de que son } \\
\text { puntos importantes del trabajo. }\end{array}$ \\
\hline \multicolumn{2}{|c|}{ Próposito del Estudio } \\
\hline & $\begin{array}{l}\text { El documento es de revisión teórica. Se propone el uso } \\
\text { de Imagen infrarroja térmica, sin embargo, no se pro- } \\
\text { fundiza en el tema. Se mencionan algunos estudios de } \\
\text { manera muy general. }\end{array}$ \\
\hline \multicolumn{2}{|c|}{ Introducción } \\
\hline Todo bien. & $\begin{array}{l}\text { El trabajo es de revisión teórica, no presenta como tal } \\
\text { hipótesis ni objetivos. Falta profundizar en la revisión } \\
\text { teórica, menciona varios datos pero falta relacionarlos } \\
\text { con el título, y las palabras clave. Menciona otros te- } \\
\text { mas, que no se mencionan dentro del resumen. }\end{array}$ \\
\hline \multicolumn{2}{|c|}{ Método } \\
\hline Varios apartados no aplican para este tipo de artículo. & No lo hay. Es un documento de revisión teórica. \\
\hline
\end{tabular}




\begin{tabular}{|c|c|}
\hline Revisor 1 & Revisor 2 \\
\hline \multicolumn{2}{|c|}{ Resultados } \\
\hline Presenta imágenes ilustrativas. & $\begin{array}{l}\text { Pese a ser una revisión teórica, faltaría explicar los re- } \\
\text { sultados de las investigaciones que se mencionan en el } \\
\text { marco teórico, más allá de mostrar las imágenes. Sería } \\
\text { importante mencionar si hay patrones térmicos iden- } \\
\text { tificados con base a la expresión emocional, al dolor, } \\
\text { etc. No queda claro el porque mencionar de inicio en } \\
\text { el resumen el dolor crónico y el cáncer de mama; así } \\
\text { como el estrés. Se entiende que hay cambios térmicos } \\
\text { con base a diferentes situaciones; sin embargo, habría } \\
\text { que identificar diferencias o considerar correlaciones } \\
\text { entre p.ej. la emoción y la temperatura registrada; el } \\
\text { dolor y los cambios térmicos, etc. Las imágenes son } \\
\text { ilustrativas, pero p.ej. en el caso de la figura } 3 \text {, se ven } \\
\text { diferentes expresiones emocionales de diferentes gru- } \\
\text { pos; sin embargo, no se menciona más al respecto: si } \\
\text { hay o no diferencias, en dónde radican; si es igual sin } \\
\text { importar la condición de la persona evaluada, etc. }\end{array}$ \\
\hline \multicolumn{2}{|c|}{ Discusión } \\
\hline Debería problematizar más el uso de esta tecnología. & El documento no presenta discusión. \\
\hline \multicolumn{2}{|c|}{ Conclusiones } \\
\hline $\begin{array}{l}\text { Debería de tener más datos empíricos ya que con po- } \\
\text { cos datos proponen el uso de imagen térmica como la } \\
\text { mejor opción sin mencionar sus contras. }\end{array}$ & $\begin{array}{l}\text { Se revisaron varias investigaciones dentro del marco } \\
\text { teórico; sin embargo, no se retoman en las conclu- } \\
\text { siones. Falta concretar los resultados de la revisión } \\
\text { teórica y con base en ello redactar las conclusiones del } \\
\text { trabajo. El tema puede explotarse más. }\end{array}$ \\
\hline \multicolumn{2}{|c|}{ Referencias } \\
\hline Bien. & $\begin{array}{l}\text { Revisar que el formato general cumpla en todas con } \\
\text { los criterios del APA. }\end{array}$ \\
\hline
\end{tabular}


Revista Digital INTERnacional de Psicología y CienCIA SoCIAL, Año 3, Volumen 3, No. 2, julio-diciembre 2017, es una publicación semestral editada por la Universidad Nacional Autónoma de México, Ciudad Universitaria, Delegación Coyoacán, C.P. 04510, Ciudad de México, a través de la Facultad de Estudios Superiores Iztacala, Av. de los Barrios \#1, Colonia Los Reyes Iztacala, Tlalnepantla Estado. de México. C.P. 54090, Tel. (55) 5623-1333, Ext. \#39707, http://cuved.unam.mx/rdipycs/ , rdipycs@gmail.com. Editor Responsable: Arturo Silva Rodríguez. Reserva de Derechos al Uso Exclusivo No. 042016-012514394300-203, ISSN: 2448-8119, ambos otorgados por el Instituto Nacional del Derecho de Autor. Responsable de la última actualización de este número, Laboratorio de Evaluación y Educación Digital de la Universidad Nacional Autónoma de México (UNAM), Facultad de Estudios Superiores Iztacala, Lic. José Manuel Sánchez Sordo, Av. de los Barrios \#1, Colonia Los Reyes Iztacala, Tlalnepantla Estado. de México. C.P. 54090, fecha de última modificación, 08 de Septiembre de 2017.

Las opiniones expresadas por los autores no necesariamente reflejan la postura del editor de la publicación. Se autoriza la reproducción total o parcial de los textos aquí publicados siempre y cuando se cite la fuente completa y la dirección electrónica de la publicación. 